INSTITUTO DE QUÍMICA/ INSTITUTO DE FÍSICA/INSTITUTO DE BIOCIÊNCIAS/FACULDADE DE EDUCAÇÃO

\title{
AS CONCEPÇÕES DE CIÊNCIA DOS LIVROS DIDÁTICOS DE QUÍMICA, DIRIGIDOS AO ENSINO MÉDIO, NO TRATAMENTO DA CINÉTICA QUÍMICA NO PERÍODO DE 1929 A 2004.
}

\section{SIMONE ALVES DE ASSIS MARTORANO}

Orientadora: Profa. Dra. Maria Eunice Ribeiro Marcondes

\begin{abstract}
Dissertação de mestrado apresentada ao Instituto de Física, ao Instituto de Química, ao Instituto de Biociências e a Faculdade de Educação da Universidade de São Paulo, para a obtenção do título de Mestre em Ensino de Ciências.
\end{abstract}

São Paulo 
UNIVERSIDADE DE SÃO PAULO

INSTITUTO DE QUÍMICA/ INSTITUTO DE FÍSICA/INSTITUTO DE BIOCIÊNCIASIFACULDADE DE EDUCAÇÃO

AS CONCEPÇÕES DE CIÊNCIA DOS LIVROS DIDÁTICOS DE QUÍMICA, DIRIGIDOS AO ENSINO MÉDIO, NO TRATAMENTO DA CINÉTICA QUÍMICA NO PERÍODO DE 1929 A 2004.

SIMONE ALVES DE ASSIS MARTORANO

Orientadora: Profa. Dra. Maria Eunice Ribeiro Marcondes

Banca Examinadora:

Profa. Dra. Maria Eunice Ribeiro Marcondes (IQ-USP)

Prof. Dr. Pedro da Cunha Pinto Neto (FE-UNICAMP)

Profa. Dra. Silvia Maria Leite Agostinho (IQ-USP)

São Paulo 
FICHA CATALOGRÁFICA

Preparada pelo Serviço de Biblioteca e Informação do Instituto de Física da Universidade de São Paulo

Martorano, Simone Alves de Assis

As Concepções de ciência dos livros didáticos de química, dirigidos ao ensino médio, no tratamento da cinética química no período de 1929 a 2004 . São Paulo, 2007.

Dissertação (Mestrado) - Universidade de São Paulo. Instituto de Química.

Orientador: Prof. Dra. Maria Eunice Ribeiro Marcondes Área de Concentração: Ensino de Ciências.

Unitermos:1. Livros didáticos; 2. Ensino médio; 3. Cinética química; 4. Filosofia da ciência; 5. História da ciência. 
Para

Fábio, meu marido, Gabriel e Rafael, meus filhos, amor e gratidão pelo apoio incondicional e compreensão ao Congo desta jornada. 


\section{Agradecimentos}

Aos meus pais, Alcides e Darcy, pelo apoio, suporte e carinho necessários, para que eu pudesse completar essa jornada com tranqüilidade.

À minha querida sogra, Maria Júlia, que sempre esteve disposta a me ajudar, sempre com palavras de incentivo.

À professora Maria Eunice, que com sua sabedoria guiou meus passos nesse mestrado, orientando-me a fazer as melhores escolhas durante esse percurso.

A todos meus amigos do GEPEQ, que contribuíram enormemente para o meu aprendizado.

Às minhas queridas amigas, Angella, Marlene, Miriam, Luciane, Gislaine e Nilza, que me incentivaram e ajudaram de diversas maneiras na realização deste trabalho.

Aos meus queridos amigos, Fábio, Alessandro, Anderson e Denilse, do projeto pró-reitoria, que tornaram a quinta-feira um dia muito especial.

Aos meus amigos do programa, Fábio, Eri, João, Rita, e Daniele, por este tempo de convívio, troca de experiências e amizade. 


\section{RESUMO}

O objetivo central deste trabalho foi investigar como a Cinética Química foi sendo apropriada pelos livros didáticos destinados ao Ensino Médio, em um determinado período de tempo (1929-2004), através do estudo do desenvolvimento histórico dos conceitos químicos envolvidos neste tema. Outro objetivo foi o de identificar as concepções sobre ciência veiculadas pelos livros didáticos ao tratarem o tema Cinética Química.

O modelo adotado para a análise dos livros didáticos está baseado na linha de pesquisa desenvolvida por Níaz (2001) e Justi (1997; 1999), que se baseia na história e filosofia da ciência para entender o tratamento dado aos conceitos químicos pelo livro didático. Para isso, foi utilizada a metodologia de Imre Lakatos, da reconstrução racional do conhecimento científico, para analisar a evolução histórica das idéias sobre Cinética Química.

A reconstrução histórica foi feita a partir de pesquisas de historiadores da ciência, artigos de pesquisadores e artigos originais dos cientistas que estiveram envolvidos no estudo da cinética química. Foram propostos quatro Programas de Investigação Científica que representam o conhecimento científico sobre a Cinética Química no período de 1850 até 1935 , ano em que foi proposta a teoria do estado de transição. Tais Programas foram utilizados para evidenciar os níveis de explicação teórica atingidos em vinte livros didáticos.

As concepções de ciência apresentadas pelos livros didáticos foram analisadas sob o ponto de vista de duas perspectivas filosóficas: a empirista/indutivista e a racionalista.

Os livros didáticos até a década de 60 se dedicam a explicar a influência de concentração nas reações químicas, apresentando justificativas em termos 
empíricos e matemáticos, mas não em termos moleculares. A Partir do final dos anos 60 começam a aparecer explicações em termos das teorias de colisão e do estado de transição. As explicações em termos de energia de ativação ou barreira de energia sobre o efeito da temperatura na velocidade das reações também começam a aparecer nos livros a partir do final da década de 60 .

Com relação às concepções de ciência, pôde-se perceber que e a perspectiva filosófica predominante nos livros didáticos é a empirista/indutivista, independentemente da época em que foram editados, o que parece revelar que os autores não levaram em consideração as mudanças de perspectiva que ocorreram durante esse período. 


\begin{abstract}
The main aim of the present study is to investigate how the didactic transposition of knowledge on chemical reactions kinetics happened in high school textbooks published during the period from 1929 to 2004 . This work was carried out by an analysis of the historical development of the chemical concepts related to this subject. Another objective was to identify the concepts about science that are conveyed by textbooks to present the subject of chemical kinetics.

The model adopted for the analysis of the textbooks is based on the research line of Níaz (2001) and Justi (1997; 1999), which is based in the history and philosophy of science to understand the approach adopted by textbooks to present chemical concepts. The method of rational reconstruction of the scientific knowledge, by Imre Lakatos, was used to analyze the historical evolution of the ideas about chemical kinetics.
\end{abstract}

Four scientific investigation programs that represent the scientific knowledge about chemical kinetics from 1850 to 1935 , year when the theory of the transition state was presented, were proposed. These programs were used to highlight the level of theoretical explanation reached in twenty textbooks.

The concepts of science presented by the textbooks were examined in the light of two philosophical perspectives: the empirical/inductive and the rationalist.

The textbooks published until the sixties were dedicated to explain the effect of concentration on chemical reactions in terms of empirical and mathematical grounds, rather than on a molecular basis. From the end of the sixties, explanations based on the collision and transition state theories began to emerge. Moreover, during this 
period the concept of activation energy barrier was applied to explain the effect of temperature on chemical reaction rates.

The philosophical approach to the concepts of science prevailing in textbooks seems to be the empirical/inductive one regardless of the period when these books were edited, revealing that the authors did not consider the changes in perspective that occurred during this period. 


\section{SUMÁRIO}

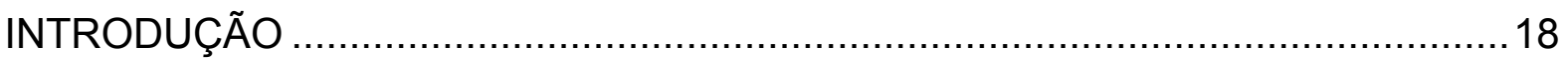

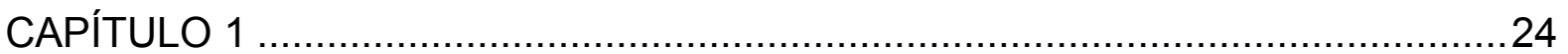

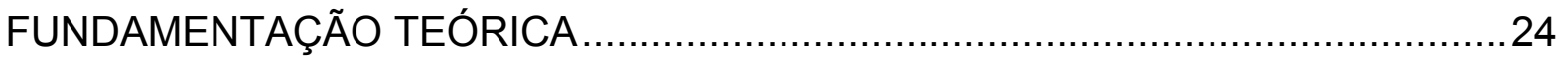

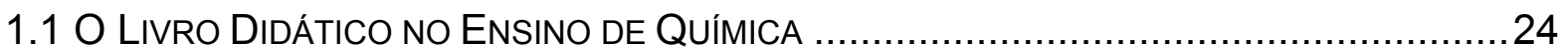

1.2 A HISTÓRIA E A FILOSOFIA DA CIÊNCIA No ENSINO dE QUÍMICA …...........................27

1.3 A HISTÓRIA DA CIÊNCIA E SUA RECONSTRUÇÃo RACIONAL ...................................29

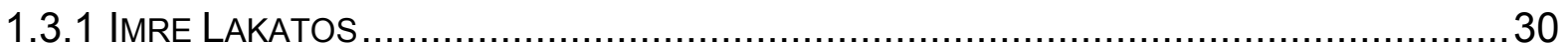

1.4 ESTUDOS FOCALIZANDO A HISTÓRIA E FILOSOFIA DA CIÊNCIA NO ENSINO DE QUÍMICA ..34

CAPÍTULO 2

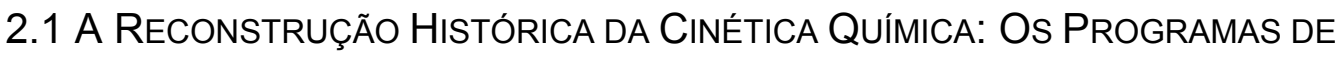

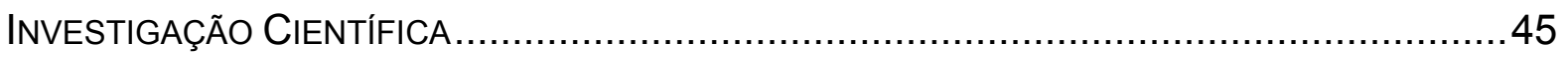

2.1.1 O PERÍODO DE 1850 A 1867: O RECONHECIMENTO DA CINÉTICA QUÍMICA COMO

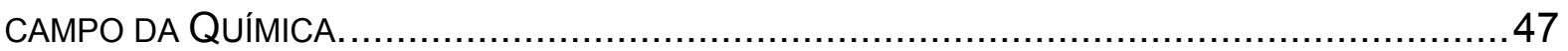

2.1.2 PERÍODO DE 1872 A 1888: O USO DO CONCEITO DE ENERGIA PARA EXPLICAR A VELOCIDADE DE UMA REAÇÃO.

2.1.3 PeRÍOdo DE 1889-1918: As PRIMEIRAS TEORIAS DE COLISÕES ENTRE MOLÉCULAS.60

2.1.4 Período de 1918-1935: A teORIA do Estado de TRANSIÇÃo. 69

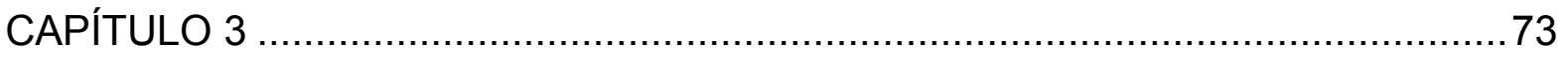

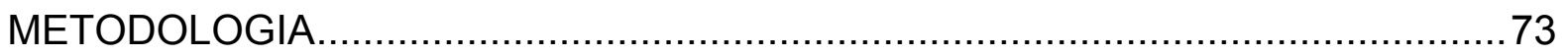

3.1 CRITÉRIOS ADOTADOS NA ESCOLHA DOS LIVROS DIDÁTICOS. ...................................73

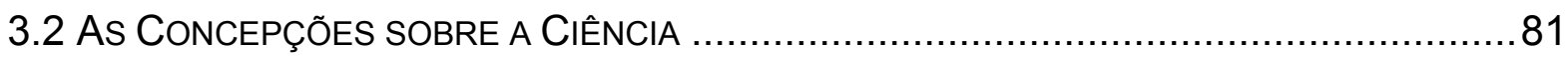

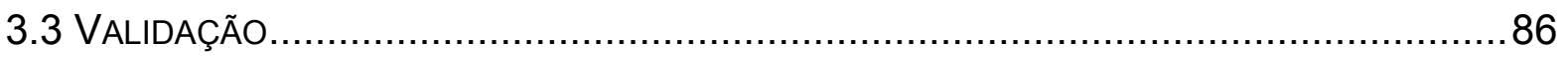


CAPITULO 4

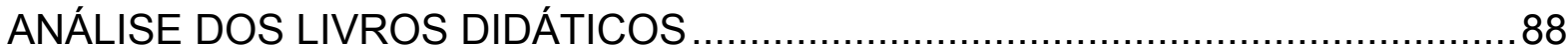

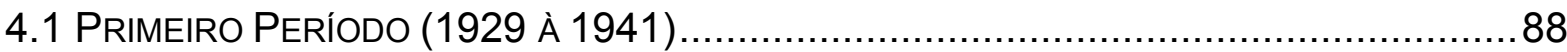

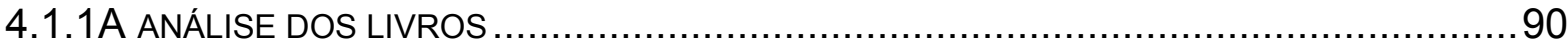

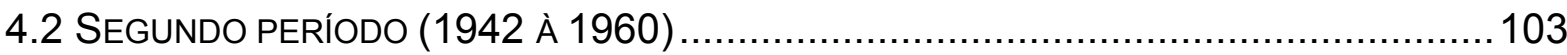

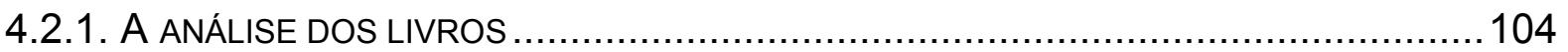

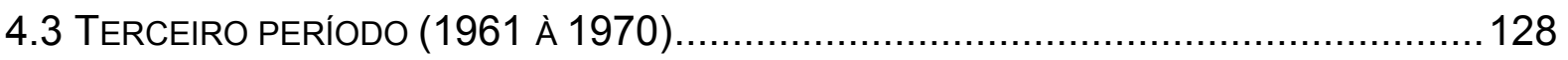

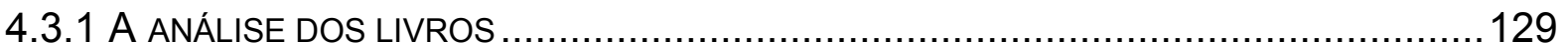

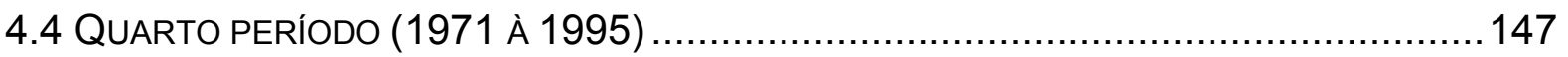

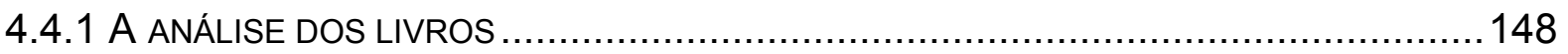

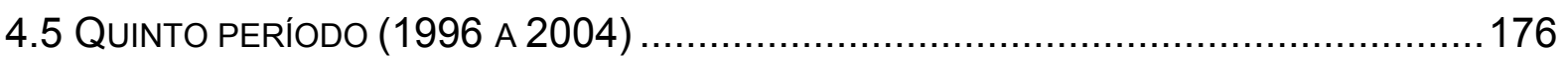

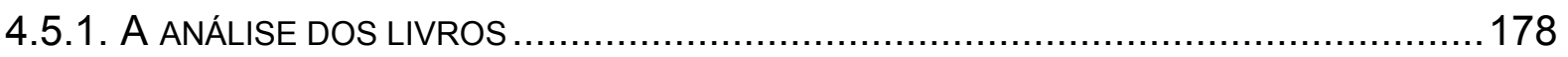

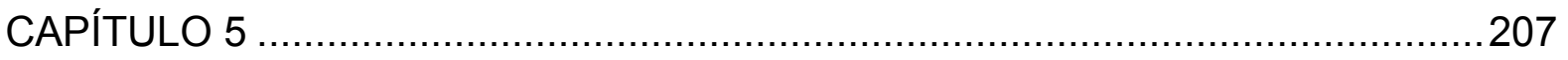

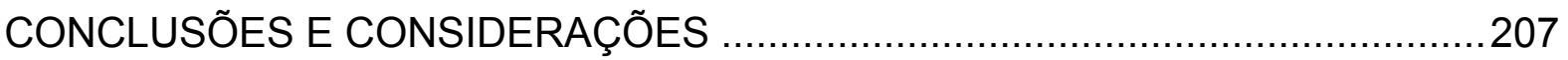

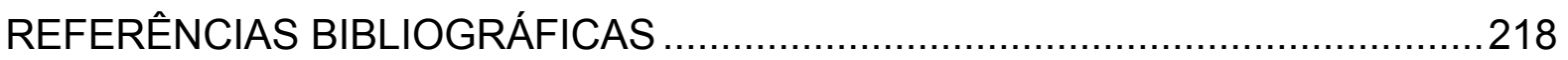

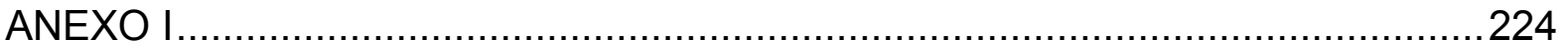




\section{LISTA DE TABELAS}

\section{CAPÍTULO 3:}

Tabela 3.1- Livros didáticos estudados por período e ano de edição.

Tabela 3.2- Livros didáticos de acordo com a reforma educacional referente a cada período de tempo. .75

Tabela 3.3- Caracterização do livro didático de 1946. Nota: PIC-II: Programa de Investigação Científica de Pfaundler e Van’t Hoff (1872-1888); PIC-III: Programa de Investigação Científica de Lewis, Ostwald e Arrhenius (1889-1918). .87

Tabela 3.4- Concepções da ciência apresentadas pelo livro didático de 1946. Nota: E/I=Empirista/Indutivista, R=Racionalista, N= Não identificado. .87

\section{CAPÍTULO 4:}

Tabela 4.1- Caracterização dos livros didáticos do primeiro período (1929-1932). 102

Tabela 4.2- Concepções da ciência apresentadas pelos livros didáticos do primeiro período $(1929-1932)$ 102

Tabela 4.3 -Caracterização dos livros didáticos do segundo período (1942 -960). 127

Tabela 4.4- Concepções de ciência apresentadas pelos livros didáticos segundo período $(1942-1960)$

Tabela 4.5- Caracterização dos livros didáticos do terceiro período (1961-1970)...... 146

Tabela 4.6-Concepções de ciência apresentadas pelos livros didáticos do terceiro período $(1961-1970)$ 
Tabela 4.7- Caracterização dos livros didáticos do quarto período (1971-1995) 175

Tabela 4.8- Concepções de ciência apresentadas pelos livros didáticos do quarto período (1971-1995) 175

Tabela 4.9- Caracterização dos livros didáticos do quinto período (1996-2004). 206

Tabela 4.10- Concepções de ciência apresentadas pelos livros didáticos do quinto período $(1996-2004)$ 206

\section{CAPÍTULO 5:}

Tabela 5.1- Caracterização dos livros didáticos (1929-2004). .216

Tabela 5.2- Concepções de ciência apresentadas pelos livros didáticos (1929-2004)......217 


\section{LISTA DE QUADROS}

\section{CAPÍTULO 2:}

Quadro 2.1- Extrato do "Poggendorf's Annalen der Physik und chemie", The law by the action of acids on cane sugar occurs 48

\section{CAPÍTULO 3:}

Quadro I- Resumo das principais características dos Programas de Investigação Científica. Explicação, em termos microscópicos, da velocidade de uma reação química 78

Quadro II- Resumo das principais características dos Programas de Investigação Científica. Influência da concentração na velocidade de uma reação química. 79

Quadro III- Resumo das principais características dos Programas de Investigação Científica. Influência da temperatura na velocidade da reação química. .80

Quadro IV- Categorias para a identificação da perspectiva filosófica adotada pelos livros didáticos. .85 


\section{LISTA DE FIGURAS}

\section{CAPÍTULO 2:}

Figura 2.1- Capa do livro Lições de Físico Química, "La Dynamique Chimique", de J. H. Van't Hoff editado em Paris no ano de 1898 55

Figura 2.2- esquema da aparelhagem que Van't Hoff (1898)..... .56

Figura 2.3- O gráfico de Ink versus 1/T é uma reta quando a reação segue o comportamento descrito pela equação de Arrhenius (eq.23). 67

\section{CAPÍTULO 4:}

Figura 4.1- Definição da velocidade de uma reação encontrada no livro. (p.364)

Figura 4.2- Apresentação em ordem cronológica, dos estudos realizados sobre o efeito da concentração na velocidade de uma reação. (p.366) 115

Figura 4.3- Enunciado da lei da ação das massas. (p.367). 115

Figura 4.4- Trecho do prefácio do livro. (p.7)

Figura 4.5- Expressão matemática que relaciona a temperatura com a velocidade de uma reação. (p.302). 132

Figura 4.6- O quociente entre o número de mols que reagiram e o intervalo de tempo é chamado de velocidade da reação. (p.130). 135

Figura 4.7- O aumento de colisões por segundo depende da concentração (p.132)..... 137

Figura 4.8- O efeito da temperatura sobre a distribuição das energias cinéticas atômicas. ( $p$. 137) 138 
Figura 4.9- Diagrama da energia potencial. 139

Figura 4.10- Enunciado da Lei de Guldberg-Waage (p.194) 150

Figura 4.11- Curva de Maxwell-Boltzmann (p. 191) 153

Figura 4.12- Formação do complexo ativado.(p.64). 156

Figura 4.13- Efeito da temperatura sobre a distribuição da energia cinética.(p.65)....... 158

Figura 4.14- Relação entre a temperatura e a velocidade de uma reação (p.101). 161

Figura 4.15- Regra de Van' Hoff (p.101). 161

Figura 4.16- Enunciado da Lei de Guldberg-Waage. (p.161). 164

Figura 4.17- Cálculo da ordem de uma reação. (p.178). 164

Figura 4.18- Curvas de distribuição das energias cinéticas das moléculas reagentes em duas temperaturas $T_{1}$ e $T_{2} \cdot(p .153)$ 165

Figura 4.19- Cálculo da velocidade usando-se a regra de Van't Hoff (p. 155)..... 166

Figura 4.20- Diagrama que relaciona a variação de energia durante uma reação química(p.85) 169

Figura 4.21-Influência da concentração na velocidade da reação. (p.84). 170

Figura 4.22- Reapresentação dos choques microscópicos (p.139). 180

Figura 4.23- A ocorrência de uma reação depende da orientação espacial apropriada (demonstrado no lado esquerdo da figura).(p.140). 181

Figura 4.24- Relação entre a concentração e a velocidade, sob a análise da Teoria das colisões (p.148). 182

Figura 4.25- lei da velocidade de uma reação (p.152). 184

Figura 4.26- Relação válida tanto para sistemas homogêneos quanto para os heterogêneos. (p.145). 184 
Figura 4.27- Regra de Van't Hoff. (p.145). 185

Figura 4.28- Relação entre a temperatura e a velocidade de uma reação(p.146)....... 185

Figura 4.29- Relação entre a temperatura e a velocidade de uma reação. (p.147) 186

Figura 4.30- Distribuição de energias cinéticas dos átomos em função da temperatura ( $p$. 70). 191

Figura 4.31- Ilustração de uma colisão efetiva (p.73). 192

Figura 4.32- Possíveis percursos de uma transformação química (p. 72), 192 


\section{INTRODUÇÃO}

Uma das preocupações que tem orientado pesquisas no ensino de ciências é a de encontrar respostas para as questões de como os estudantes de ciência constroem os seus conhecimentos científicos, e quais seriam os fatores que podem influenciar esse processo de construção.

Em estudos realizados em diversos contextos (Campanário e Otero, 2000), aparecem algumas conclusões comuns sobre as concepções dos alunos sobre a natureza do conhecimento científico. Por exemplo, alguns alunos tendem a considerar que o conhecimento está fundamentado principalmente no estudo objetivo de determinados fatos e este conhecimento se aproxima cada vez mais, com o passar do tempo, à verdade absoluta e se articula em torno das leis que existem independentemente dos cientistas que as descobriram. Poucos alunos entendem as reformulações do conhecimento científico como uma das características da ciência.

De acordo com Driver (1996), as concepções dos alunos sobre a ciência e o conhecimento científico podem sofrer influências de diversos fatores, como por exemplo, a influência da mídia, através de conversas com adultos e outros colegas, e a imagem da ciência retratada explicita ou implicitamente nas aulas. Nas aulas de química, as concepções sobre a ciência e o conhecimento científico podem aparecer na forma como o professor organiza e desenvolve as suas aulas, nos métodos de ensino, na forma de transmissão do conhecimento científico das aulas teóricas, nas atividades experimentais e também na escolha do material didático a ser utilizado no ensino. 
Praia e Chachapuz (1994), também, tal como Driver (1996), acreditam que a imagem de ciência que os alunos possuem depende, algumas vezes, do que lhes é proporcionado pelos seus professores em sala de aula, assim eles acham compreensível o crescente interesse da investigação educacional pelo ensino de ciência de um ponto de vista epistemológico. Segundo os autores, há atualmente, evidências claras de que as concepções dos professores acerca da natureza da ciência e do conhecimento científico e do que é o método, influencia a forma de abordar um determinado conteúdo e, portanto a imagem da ciência transmitida ao aluno.

Em relação ao ensino, Cachapuz (1994) diz que uma perspectiva empirista do conhecimento científico pode levar os alunos a acreditarem que se a observação meticulosa for seguida, a aprendizagem de conceitos é algo (inquestionavelmente) adquirido. Daí a ênfase posta no trabalho experimental, com as características referidas acima, bem como na tão divulgada "aprendizagem por descoberta". Como conseqüência direta, os alunos podem não se aperceber do caráter problemático do conhecimento científico.

Pode-se então presumir que algumas das dificuldades que os alunos apresentam em aprender determinados conceitos químicos sejam justificadas pela maneira com que ele aprendeu a ver a ciência, pois muitos destes conceitos não são possíveis de se serem aprendidos pela simples observação de um determinado fenômeno, mas só podem ser compreendidos se o aluno souber construir modelos mentais, o que pode ser difícil ao aluno que possui uma visão empirista da ciência.

Essa visão empírica do conhecimento científico que o aluno apresenta talvez possa ser conseqüência da maneira como os cursos de química são estruturados, ou da forma de apresentação dos conceitos químicos nos livros didáticos. 
Geralmente, é o livro didático que determina a maneira e a seqüência da apresentação de qualquer tema; ele acaba sendo muito mais uma referência do conteúdo a ser ensinado, do que um material de apoio para o professor planejar a sua aula. Como afirma Alice Lopes (1992): "o livro didático não atua como auxiliar do processo de transmissão do conhecimento, mas como modelo padrão, autoridade absoluta, critério último de verdade: parece modelar os professores". Mas, tem-se que levar em conta que ainda o livro didático é o veículo que auxilia o professor no preparo de sua aula seja ele bom ou não.

Também, não é só na apresentação do conteúdo químico que a visão de ciência é manifestada desta maneira, pode-se encontrar uma visão de ciência extremamente empirista, segundo Del Pino (2001), nos experimentos propostos pelos livros didáticos. Nos livros didáticos brasileiros estudados pelo autor, os experimentos propostos não permitem que o aluno construa generalizações a partir dos dados coletados, mas sim, parecem enfocar quase que exclusivamente as capacidades de realização da prática e observação, reforçando, segundo o autor, a imagem da química como "ciência de receita", reforçando assim uma imagem de ciência extremamente empirista.

Pode-se então pensar que o livro didático, como às vezes é o único texto que o aluno tem acesso na hora de estudar certos conceitos científicos, influencia a maneira de pensar deste aluno sobre o que é ciência e como ela se desenvolve.

Propõe-se neste trabalho, investigar como o livro didático apresenta o tema cinética química, em certo período de tempo, para verificar que possíveis concepções sobre a ciência que ele pode transmitir aos alunos. O modelo adotado para a análise dos livros didáticos está baseado na linha de pesquisa desenvolvida por Níaz (2001) e Justi (1997; 1999). Esses autores se baseiam na história da 
ciência para entender o tratamento dado aos conceitos químicos pelo livro didático. Para isso será utilizada a metodologia lakatosiana de reconstrução racional para analisar a evolução das idéias sobre cinética química. Portanto, esse estudo tem como objetivos:

1. Investigar como a cinética química foi sendo apropriada pelos livros didáticos destinados ao Ensino Médio, em um determinado período de tempo (19292004), através do estudo do desenvolvimento histórico dos conceitos químicos envolvidos neste tema.

2. Identificar as concepções sobre ciência veiculadas pelos livros didáticos ao tratarem o tema Cinética Química.

Portanto, neste trabalho a hipótese admitida é a que: "Na abordagem do tema Cinética Química, os livros didáticos dirigidos ao ensino médio, poderão apresentar concepções sobre a natureza da ciência e da construção do conhecimento científico que não são condizentes com a perspectiva filosófica Racionalista, mas sim apresentar concepções fortemente marcadas pela perspectiva empirista/indutivista".

Escolheu-se a cinética química como tema para este trabalho, por considerá-la um conteúdo imprescindível para a formação básica em química do aluno do ensino médio. O conhecimento da cinética química proporciona ao aluno o entendimento da velocidade de uma reação química e dos fatores que a determinam ou a modificam, mas, além disso, leva ao entendimento do mecanismo (ou caminho) de uma reação.

Com respeito à projeção da cinética na vida real e no meio ambiente, segundo Pitombo (1974), existem vários segmentos que ilustram a sua contribuição. Nos processos industriais em distintas direções tais como a obtenção de produtos químicos, medicamentos, as evidências proporcionadas pelos estudos cinéticos, tem 
permitido melhorar rendimentos com o conseqüente abaixamento nos custos. De outro lado, no organismo humano se verifica uma série de processos que seguem um caminho cinético de acordo com um propósito superior: manter as condições ótimas para a preservação da vida. E isto se estende, é claro, a todos os seres vivos.

Outro ponto importante na escolha da cinética é a quase ausência de pesquisas em ensino sobre o tema, com exceção podem-se citar os trabalhos de Justi $(1997,1999)$.

Diante da importância da cinética química nestes vários seguimentos, esse trabalho tem como foco o livro didático de química destinado ao Ensino Médio, no tratamento do tema Cinética Química. Esse estudo possui como viés metodológico à utilização da história e da filosofia da ciência para a criação das categorias que foram utilizadas na análise do livro didático, onde é apresentada uma revisão bibliográfica de estudos que foram desenvolvidos tendo como enfoque o livro didático e a utilização da história e da filosofia da ciência no ensino de química, que orientou a criação das categorias de análise.

Como condição necessária para essa análise é apresentada, no capítulo 2 , uma reconstrução racional dos conteúdos químicos, abordados dentro do tema Cinética Química, usando-se como referencial teórico a perspectiva filosófica de Imre Lakatos.

No capítulo 3, descreve-se a metodologia da pesquisa, como foram estabelecidos os critérios para escolha dos livros didáticos, como foram elaboradas as categorias para a identificação das concepções da ciência presentes nos livros didáticos analisados e como foi feita a validação destas categorias. 
No capítulo 4, são apresentados os dados e a análise dos resultados, e no capítulo 5, as considerações finais e a conclusão. Em anexo, encontram-se informações sobre os livros didáticos que foram analisados neste trabalho, como o título, autores, ano de edição, indicação do capítulo referente à cinética química e número total de páginas deste capítulo. 


\section{CAPÍTULO 1}

\section{FUNDAMENTAÇÃO TEÓRICA}

\subsection{O Livro Didático no Ensino de Química}

Na química, como em qualquer outra disciplina escolar, o livro didático ainda possui um papel importante na dinâmica do ensino. Embora hoje o aluno possa contar com outros recursos para obter informações sobre a ciência, o livro didático continua tendo um importante papel na transmissão de conhecimentos científicos.

O livro didático tem sido o foco de muitas pesquisas em ensino de ciências. Alguns estudos, como os de Lopes (1992), Melo (2002), Schnetzler (1980), Liso (2002), Justi (1997) focalizam a análise do conteúdo químico apresentado no livro didático, outros se focam na imagem de ciência que esses livros podem transmitir aos alunos, como os estudos de Cachapuz (1997), Níaz (1994, 2000, 2001), e Chiappetta (1991). Na maioria desses estudos percebe-se a preocupação dos autores em entender como o conhecimento científico foi transposto para o livro didático.

O processo de adaptação, ou de transformação do conhecimento científico em conhecimento escolar é denominado por Yves Chevallard (Lopes; 1999) de transposição didática. Este tem por objetivo tornar os saberes selecionados efetivamente transmissíveis e assimiláveis, sendo que nesse processo só se considera a influência das ciências de referência, o papel da escola está em fornecer a didática que será encarregada de fazer esta transposição. Neste processo, o que ocorre muitas vezes é que o conteúdo dos livros didáticos acaba aparecendo como 
um saber sem produtor, sem origem, sem lugar, transcendente ao tempo, como se pode verificar pela falta de referências bibliográficas e históricas, ou seja, não aparece no desenvolvimento do conteúdo o processo de construção do conhecimento científico. Nas palavras de Lopes (1999):

"Um elemento do conhecimento científico, quando deslocado das
questões que ele permite resolver e dos conceitos com os quais
constitui uma rede relacional, tem a sua natureza fortemente
modificada. Trata-se de uma despersonificação e de uma
descontemporalização dos conceitos, quando se tornam objetos de
ensino".

Segundo Lopes (1999), o termo transposição didática está associado à idéia de reprodução, movimento de transportar de um lugar para outro sem alterações. Ela defende a sua idéia de adaptação do conhecimento científico, denominando este processo de (re) construção de saberes na instituição escolar de mediação didática: "Mediação didática é o processo de constituição de uma realidade a partir de mediações contraditórias, de relações complexas, não imediatas. Um profundo sentido de dialogia”. Para a autora, nesse processo de mediação didática, o conhecimento científico ao ser adaptado para o ensino médio deveria mostrar a forma complexa do processo de sua construção. Mesmo que se considere o processo de transposição didática mais complexo do que uma simplificação do conhecimento científico que visa atender às necessidades cognitivas dos alunos do ensino médio, sua base esta centrada na ciência de referência.

Já Chervel posicionou-se contra as proposições de Yves Chevallard. Para André Chervel (Pessanha et al, 2004), o processo de transposição didática não é neutro, ou seja, ele não depende apenas das ciências de referência, mas sim sofre influências de outros fatores, como as intervenções de elites intelectuais e do poder político institucional, dentro do ambiente escolar, o que confere à disciplina escolar 
uma relativa autonomia. A disciplina escolar se constituiria pela passagem dos saberes por um filtro específico, social, desta maneira que após algum tempo, poderia guardar poucas relações com o saber de origem (Pessanha et al, 2004). Portanto, para entender as mudanças no ensino a disciplina escolar deveria ser estudada historicamente, contextualizando o papel exercido pela escola em cada momento histórico (Bittencourt;1999).

O conteúdo químico que á apresentado atualmente pelo livro didático, diverge na forma de apresentação e na quantidade de informações dos livros de outras décadas, e também difere na maneira como apresenta algumas características da ciência, o que pode influenciar as idéias e concepções de ciência do leitor em cada época. Para entender essas diferenças, neste trabalho, admitiu-se que o desenvolvimento do tema cinética química no livro didático, através dos anos, pode ter sofrido influências das reformas educacionais dirigidas ao ensino médio. Para entender essas influências, os livros didáticos foram agrupados em cinco períodos que correspondem aos períodos de vigência das reformas educacionais brasileiras.

As reformas educacionais, segundo Villani (et al 2005), visam principalmente adequar o conteúdo a ser ensinado, tendo em vista as conquistas científicas e as mudanças na concepção de ciência e de ensino, bem como promover a democratização do ensino e a formação básica generalista. Portanto, espera-se neste trabalho estabelecer relações entre os possíveis reflexos educacionais no ensino e os livros didáticos escolhidos para análise. 


\subsection{A História e a Filosofia da Ciência no Ensino de Química}

Algumas pesquisas em ensino de ciências, especificamente focadas na história da Química e na filosofia da ciência, visam, a partir de análises, propor abordagens alternativas que contribuem para diminuir as dificuldades que os alunos apresentam na aprendizagem de determinados conceitos químicos. Wandersee e Griffard (2002), defendem que a história da química pode ajudar os educadores desta área a desenvolver, usar e investigar materiais e estratégias para promover o melhor entendimento, por parte dos alunos, dos conceitos químicos. Para eles o principal objetivo da educação em química é ajudar os estudantes a construir um entendimento significativo da natureza e das transformações da matéria. Sendo assim, o conhecimento de onde estas idéias vêm e como elas foram construídas através do tempo poderá ser útil aos estudantes na construção desse entendimento. Os estudantes poderão assim, ter a habilidade de conectar os conhecimentos químicos recentemente aprendidos com os seus conhecimentos anteriores e com o conhecimento histórico coletivo da comunidade química global.

Justi e Gilbert (1999), resumiram em quatro argumentos as vantagens de se utilizar a história e a filosofia da ciência no ensino de ciências. Eles são:

- Ensinar os estudantes sobre a natureza da ciência. O ponto principal deste argumento é que a evolução das metodologias científicas tem sido uma das principais realizações culturais da última metade do século passado e, portanto, deveriam fazer parte da educação dos jovens.

- Habilitar os professores a explorarem algum paralelo entre o desenvolvimento histórico da química, e o desenvolvimento do entendimento da química pelos estudantes. Segundo os autores, não há um acordo geral sobre a existência de uma relação entre mudanças na ciência e no entendimento do conteúdo específico. 
- Desenvolver nos estudantes a habilidade do pensamento crítico;

- Ajudar os professores a superarem problemas práticos na produção de metodologias de trabalho que serão utilizados no processo de ensino em sala de aula.

Segundo Abimbola (1983), quando os currículos de ciência incluem a filosofia da ciência, aparecem questões importantes como as descritas a seguir: Como é estabelecido o conhecimento científico? Como é que eventualmente este conhecimento muda de forma e de significado? Assim, a educação em ciência pode olhar para a filosofia da ciência e usá-la como guia na resolução de problemas relativos ao currículo de ciência.

Segundo Lopes (1999), a história da ciência é capaz de ajudar os alunos a compreenderem mais claramente os conceitos científicos, como também permite questionar a visão que o senso comum tem do conhecimento científico como um conhecimento derivado da experiência e da observação imediata. Além de desconstruir a idéia de ciência como um conhecimento acabado, definitivo, restrito aos cientistas.

Mas, pode-se observar que na maioria dos livros didáticos a história e a filosofia da ciência não são utilizadas no desenvolvimento dos conceitos químicos. De acordo com Níaz (2001), pesquisas em educação em ciências têm reconhecido não somente a importância desses conteúdos, mas também as suas implicações nos livros didáticos. Kuhn, filósofo da ciência, também reconheceu a natureza não histórica da ciência nos livros didáticos:

\footnotetext{
"Os livros didáticos começam por truncar o sentido do cientista na história da disciplina e então tentam prover um substituto para o que eles eliminaram. Caracteristicamente, os livros didáticos de ciência
} 
contêm fragmentos de história, ou no capítulo introdutório, ou mais freqüentemente, em referências espalhadas de grandes heróis do passado" (Kuhn (1970) em Níaz (2001)). (tradução nossa)

Defende-se neste trabalho que os livros didáticos poderiam desenvolver 0 tema, cinética química, utilizando-se a história e filosofia da ciência, explorando assim as principais características do desenvolvimento da ciência que são: o processo de construção das teorias científicas pelos cientistas, o papel da comunidade científica na aceitação ou rejeição destas teorias, e o processo da troca de uma teoria por outra. Por exemplo, ao abordar as dificuldades na aceitação de uma nova teoria, tanto o professor quanto ao aluno que utilizam o livro didático, podem verificar que este processo, às vezes, pode durar longos anos. Se a aceitação de uma nova teoria foi tão difícil para os próprios cientistas, maior atenção deveria ser dada a ela, principalmente por parte do professor ao planejar as suas estratégias de ensino.

\subsection{A História da Ciência e sua Reconstrução Racional}

Segundo Moreno et al (2000), a ciência, como toda atividade humana, é histórica, ou seja, é mutante, não só porque está sujeita à dinâmica do tempo, mas também porque, enquanto transcorre, constrói-se, modifica-se, evolui, amplia-se e desenvolve-se. A história da ciência ocupa-se em estudar essas mudanças, de como se produzem e das conseqüências que geram. Outro ponto apontado por Moreno et al (2000) é o de que a atividade científica pode ser vista como se fosse formada por três níveis distintos. O primeiro nível corresponderia às mudanças teóricas, ou seja, a criação, modificação e substituição de velhas hipóteses por novas, outro nível seria o das mudanças que ocorrem nos procedimentos, ou seja, os métodos que caracterizam o trabalho da ciência e um último nível que seria relativo às mudanças 
institucionais, diz respeito à influência da comunidade científica, no desenvolvimento da ciência.

Neste trabalho, pretende-se estudar principalmente as mudanças das teorias e dos métodos utilizados pela comunidade científica, na sua tentativa de entender a velocidade de uma reação química, para tal, optou-se por realizar uma reconstrução histórica de acordo com as idéias de Imre Lakatos.

As idéias de Lakatos fazem parte de uma nova corrente filosófica denominada nova filosofia da ciência surgida a partir da metade do século XX, como resultado de várias críticas ao positivismo, visão filosófica até então dominante. De acordo com essa nova filosofia, o que o cientista observa e investiga é uma "construção" da realidade que está em acordo com a sua formação, marco teórico e até valores sociais, por tanto não existem observações neutras. O que é mais interessante na nova filosofia da ciência, segundo Níaz (2001), é o foco orientado para explicar a mudança das teorias, sendo que anteriormente se pretendia sobre tudo justificá-las. Como representantes desta nova filosofia pode-se destacar os filósofos Popper (1959), Toulmin (1961), Kuhn (1962), Feyerabend (1970), Lakatos (1970) e Laudan (1977).

\subsubsection{Imre Lakatos}

A competição entre programas de pesquisa, como proposto por Lakatos, juntamente com a história do desenvolvimento da ciência, têm sido utilizadas em pesquisas no ensino de Química (Justi, 1997,1999; Níaz, 1994, 1995 e 2001). Segundo Níaz (2001), essa abordagem provê um instrumento útil para ajudar na reconstrução dos conhecimentos científicos dos estudantes e professores de 
ciência. O autor defende que a reconstrução histórica de progressos científicos, que conduzem inevitavelmente a controvérsias e debates, pode despertar o interesse dos estudantes e facilitar compreensão de conceitos químicos. Em contraste, currículos de química em geral e livros didáticos não só ignoram o contexto no qual a ciência progride, mas também enfatizam roteiros de aprendizagem e estratégias algorítmicas.

A metodologia de Lakatos, segundo Níaz (2001), tem sido alvo de críticas na literatura da filosofia em ciências. Laudan (Justi; 1999) coloca que o foco desta metodologia está na mudança das teorias dentro do programa, dizendo que não há uma teoria racional, ou critérios claros para a escolha da teoria que deve fazer parte do núcleo duro do programa. Outro ponto é que os programas são construídos ao redor da idéia do "núcleo duro" que é visto como sendo muito rígido para que possa acomodar as realidades da mudança da teoria. Contudo, uma crítica avaliativa recente concluiu:

\footnotetext{
"Nós podemos mostrar que a reconstrução racional de Lakatos, ainda que não incorreta nas suas linhas principais de argumentação, pode ser refinada em muitos pontos... Aí não há dúvida, contudo, que o método da reconstrução racional tenha dado uma influência positiva na filosofia da ciência”. (Hettema;1995 em Níaz; 2001, p.245) (tradução nossa)
}

A metodologia dos programas de investigação científica, segundo Lakatos (1998), constitui, como qualquer outra metodologia, um programa de investigação historiográfico, sendo que o historiador que aceita essa orientação procurará na história programas de investigação rivais, alterações progressivas e degenerativas de problemáticas. Cada reconstrução racional produz um padrão característico do desenvolvimento racional do conhecimento científico, mas às vezes, segundo Lakatos (1998), essas reconstruções normativas podem ter necessidade de ser completadas 
por teorias externas empíricas que explicam os fatores residuais não racionais. Mas a reconstrução racional ou história interna é primária, a história externa só tem uma importância secundária. Segundo Lakatos (1998), seja qual for o problema que o historiador da ciência pretende resolver, é necessário, em primeiro lugar, reconstruir a parte concernente ao desenvolvimento do conhecimento científico, ou seja, a história interna.

A caracterização do Programa de Investigação Científica é feita pelos seguintes componentes: o "núcleo duro", o cinturão protetor e uma heurística. Os dois primeiros correspondem ao conjunto de enunciados gerais, são as teorias aceitas na sua época pela comunidade científica. A heurística pode ser negativa ou positiva, conforme representa orientações de pesquisa a evitar ou a prosseguir.

De acordo com Lakatos (1998), esses componentes são assim constituídos:

Núcleo duro: Todos os programas de pesquisa, segundo Lakatos (1998), podem ser caracterizados pelo "núcleo", que reúne os pressupostos básicos e essenciais do programa, ou seja, tudo aquilo que é fundamental para a sua existência. $\mathrm{O}$ abandono desse núcleo duro é o que causa a mudança de programa.

Cinturão protetor: é formado por hipóteses auxiliares que tem como objetivo proteger o núcleo. Segundo Lakatos (1998), é esse cinto de proteção de hipóteses auxiliares que tem que suportar o impacto dos testes e ir se ajustando e reajustando, ou mesmo ser completamente substituído, para defender o núcleo assim fortalecido. Heurística negativa: é uma regra metodológica que não permite o ataque direto ao núcleo do Programa de Investigação, ao contrário ela redireciona o ataque para o cinturão protetor em torno do núcleo. 
A heurística positiva: perante qualquer Programa de Investigação, por mais sólido que seja, deparam-se sempre um conjunto de anomalias, contra-exemplos, que nunca são completamente explicados. A heurística positiva de um programa de Investigação impede que o cientista se confunda no oceano de anomalias. Segundo Lakatos (1999), a heurística positiva apresenta um programa que inclui uma cadeia de modelos, isto é, um conjunto de condições iniciais (que serão substituídas), cada vez mais complicados, que simulam a realidade. O cientista focaliza-se na construção de modelos de acordo com a parte positiva do programa. Ele ignora os contra exemplos reais, os "dados disponíveis". Este desenvolvimento de modelos leva a uma progressão de teorias cada vez mais aperfeiçoadas (Mion e Angotti, 2005).

A competição entre Programas de Investigação científica: Lakatos (1998) propõe que somente existem duas classes de programas científicos de investigação, os progressivos e os degenerativos. A maneira de distinguir entre estas duas classes é, em suas próprias palavras, o seguinte:

"Diz-se que um programa de investigação é progressivo sempre que o seu crescimento teórico antecipe seu crescimento empírico, ou seja, enquanto continue predizendo fatos novos com certo êxito (mudança progressiva do problema); considera-se que um programa está estancado quando seu crescimento teórico está defasado em relação com seu crescimento empírico, ou seja, enquanto somente ofereça explicações post hoc, seja de descobrimentos acidentais ou de fatos previstos por outro programa rival (mudança degenerativa do programa). Quando um programa de investigação explica progressivamente mais que outro rival, o supera, então o rival pode ser eliminado (ou se preferir, armazenado)". (p.33)

É a competição entre diferentes programas contemporâneos que faz desenvolver o quadro teórico da explicação científica. O Programa progressivo é aceito pela comunidade científica, enquanto que o programa degenerativo, segundo 
Lakatos (1998), cairá em desuso, devido à incapacidade demonstrada em explicar novos fatos, em erguer uma teoria coerente.

Lakatos (1998), por exemplo, conceitualiza progresso na ciência com um modelo pluralístico no qual "O choque não é entre teorias e fatos", mas entre duas teorias de alto nível: uma interpretativa, para prover os fatos e outra explanatória para explicá-los, sendo que a teoria interpretativa pode ser igual à teoria explanatória (explicativa) de alto nível. Isto sugere, segundo Niaz (2001), que o progresso na ciência não necessita ser caracterizado como uma dicotomia entre teorias e leis, mas antes como uma "problemática progressiva" de uma tentativa teórica para outra.

Portanto, seguindo essa orientação, procurou-se no desenvolvimento histórico da cinética química identificar quais eram os programas de investigação existentes, e como estes foram sendo substituídos por programas com maior poder explicativo.

\subsection{Estudos focalizando a história e filosofia da ciência no ensino de química}

O propósito deste ítem foi realizar uma revisão bibliográfica de alguns estudos cujo foco foi o emprego da história e filosofia da ciência no ensino de química. Além de auxiliar na elaboração das categorias de análise, servirá de apoio para a análise dos resultados obtidos na presente pesquisa.

Em seu estudo sobre cinética química, Justi $(1997,1999)$ adotou a metodologia de Lakatos dos Programas de Investigação Científica, para avaliar a evolução de modelos históricos, tendo como foco o estudo centrado em modelos. A autora acredita que a análise lakatosiana dos modelos que foram importantes em áreas 
chaves da investigação científica, oferece um caminho para uma importante inclusão da história e filosofia da ciência no currículo de ciência.

O modelo histórico elaborado pela autora, possui um núcleo duro formado por dois elementos: o primeiro é a base teórica do modelo, são as ferramentas analíticas usadas na sua construção; o segundo elemento é formado pelos aspectos fundamentais do fenômeno que o modelo tem para explicar. Este modelo possui um cinturão protetor que é formado por outros aspectos (secundários) do fenômeno que providenciam uma caracterização do modelo.

Os atributos secundários são, em cada caso, as idéias a respeito de:

(i) Energético: idéias relacionadas à influência da energia na velocidade de uma reação química;

(ii) Catálise: idéias que explicam a ação de materiais específicos que mudam a velocidade de uma reação química;

(iii) Caminho da reação: idéias concernentes pelo modo na qual uma reação química é vista ao nível molecular.

A relação entre "problemática progressiva" e "problemática regressiva" associada ao uso de um dado modelo é governada pelo contexto no qual ele é usado. Os principais atributos de cada um dos modelos elaborados por Justi $(1997,1999)$ estão ligados aos significados relacionados à noção de reação química e velocidade de uma reação. Oito modelos consensuais foram identificados pela autora, sendo que o titulo de cada um deles foi derivado de uma base teórica ou dos principais atributos envolvidos. São eles: 1-Modelo Antropomórfico; 2-Modelo da Afinidade Corpuscular; 3- O primeiro Modelo Quantitativo; 4-Modelo do mecanismo; 
5- Modelo Termodinâmico; 6-Modelo Cinético; 7-Modelo do Mecanismo Estatístico, e 8-Modelo do Estado de transição.

Justi (1997), utilizou, como critérios para a análise de um livro didático ${ }^{1}$, os atributos secundários dos oitos modelos acima, onde, segundo a autora, é possível apreciar:

- O entendimento de uma reação química no nível molecular através da analogia com o sistema mecânico;

- A apresentação dos fatores que podem influenciar a velocidade de uma reação;

- A utilização do conceito de energia de ativação para explicar as diferentes velocidades de diferentes reações; e

- A manipulação de variáveis de um modo matemático.

Segundo Justi (1997), os autores do livro didático, no desenvolvimento do texto, não apresentam um único modelo histórico definido, mas sim apresentam diferentes elementos de vários modelos, mas não em uma seqüência, o que não possibilita caracterizar a problemática progressiva e degenerativa de cada um destes modelos.

Justi (1997) observou também que os autores apresentam o conteúdo químico a partir de um ponto de vista empiricista. Isto ocorre, segundo a autora, porque eles tratam o conhecimento científico de forma absoluta: este é apresentado no livro como sendo uma verdade confirmada. Aparecem termos como "Os químicos

\footnotetext{
${ }^{1}$ Tito e Canto. Química 2- Na Abordagem do Cotidiano. São Paulo. Ed. Moderna. 1993.
} 
concluíram", "os químicos representam", que pode significar que "os químicos são autoridades; todos eles dizem a verdade, e nós não podemos questionar isso".

Níaz e Rodriguez (2000), utilizaram critérios baseados na história e filosofia da ciência $^{2}$, para avaliar a apresentação da estrutura atômica em química geral, publicados nos Estados Unidos e no Reino Unido, 23 livros publicados entre 19291967 e 30 livros publicados entre 1970-1992. Os critérios utilizados para a análise foram baseados em três modelos, Thomson $(T)$, Rutherford $(R)$ e Bohr(B). Segundo esses autores, a história da estrutura do átomo desde o final do século 19 e inicio do século 20 mostra a evolução dos modelos de J. J. Thomson, E. Rutherford, e N. Bohr em uma rápida sucessão e com uma competição de modelos, baseada na competição de programas de pesquisas rivais.

A importância do livro didático, na educação em ciências, tem sido reconhecida na transmissão aos estudantes de como uma ciência em particular se desenvolve, e entre outros tópicos nos programas de química em geral, a estrutura atômica, tem sido particularmente satisfatória na introdução de detalhes históricos (Níaz e Rodriguez; 2000). Contudo, os autores apontam que é importante mostrar não somente os resultados experimentais, mas também mostrar como esses resultados foram interpretados pelos cientistas.

Níaz e Rodriguez (2000) apontam que desde 1930 muitos autores enfatizam a importância da história e também reconhecem a falta de estratégias e materiais adequados nessa área, porém os resultados encontrados nessa pesquisa mostram que os livros novos (1970-1992), são ligeiramente um pouco melhores se comparados com os livros antigos (1929-1967), contudo, ambos, os livros novos e

\footnotetext{
${ }^{2}$ Níaz, M (1998). From cathode rays to alpha particles to quantum of action: A rational reconstruction of structure of the atom and its implications for chemistry textbooks. Science Education,82,527-552.
} 
antigos, não somente ignoram a perspectiva da história e da filosofia da ciência, mas também apresentam os resultados experimentais como conclusões finais. Os autores concluíram que tais apresentações nos livros didáticos, não conduzem a um melhor entendimento do progresso científico.

Em seu estudo sobre a importância das leis das proporções definidas e múltiplas, Nìaz (2001), pretendeu alcançar os seguintes objetivos: (1) elaborar um texto baseado na reconstrução racional do desenvolvimento que levou a formulação das leis das proporções definidas e múltiplas; (2) averiguar a visão dos estudantes sobre essas leis; e (3) formular um critério baseado no texto (1) para avaliar os livros didáticos no tratamento dessas leis.

De acordo com Níaz (2001), pesquisas em educação em ciências tem reconhecido não somente a importância da história e filosofia da ciência, mas também as suas implicações nos livros didáticos. Niaz (2001) usa a metodologia de Lakatos porque acredita que ela provê uma estrutura útil para a reconstrução dos entendimentos de estudantes e professores do conteúdo científico, e esta metodologia pode ser aplicada previamente para interpretar pesquisas na educação em ciência.

Muitos livros didáticos, segundo Níaz (2001), apresentam as leis das proporções definidas e múltiplas de uma maneira simples e incontroversa. Apesar de tais apresentações, uma avaliação crítica da história e da filosofia da ciência científica mostra que o desenvolvimento destas duas leis está intimamente relacionado à origem controversa da teoria atômica de Dalton, iniciada desde o inicio do século 19. Neste estudo, Níaz (2001), tenta desenvolver um trabalho que possibilite entender a relação entre os achados experimentais, as leis e teorias. Também, segundo o autor, é muito importante notar que os filósofos da ciência 
diferem consideravelmente em tal questão. Por exemplo, as leis de proporções definidas e múltiplas são interpretadas por alguns cientistas como uma manifestação da lei de Gay-Lussac das combinações de volumes. Por outro lado, uma interpretação alternativa considera as leis como sendo uma manifestação da natureza atômica da matéria. Estas interpretações opostas continuaram quase até a primeira década do século 20 .

Segundo Niaz (2001), estudantes e professores de química geralmente tendem a entender a diferença entre teorias e leis científicas nos seguintes termos: Uma teoria científica não pode ser comprovada na sua totalidade, contudo, uma lei científica não somente pode ser comprovada como também é universal. Ryan e Aikenhead (Niaz; 2001) relataram que muitos estudantes expressam uma relação hierárquica simplista na qual as hipóteses tornan-se teorias e teorias tornan-se leis dependendo da quantidade de "provas por trás da idéia". Lakatos, por exemplo, conceitualiza progresso na ciência com um modelo pluralístico no qual "O choque não é entre teorias e fatos" mas entre duas teorias de alto nível: uma teoria interpretativa, para prover os fatos e uma teoria explanatória para explicá-los, e a teoria interpretativa pode ser igual à teoria explanatória (explicativa) de alto nível.

Segundo Niaz (2001), é importante notar que os livros didáticos geralmente ignoram o fato que quando as leis das proporções definidas e múltiplas foram formuladas, os químicos não sabiam como calcular as fórmulas químicas e as massas atômicas dos elementos. Isto sugere que, nos dias atuais, os nossos livros de química geral, além de usarem as leis das proporções múltiplas e definidas, deveriam também explorar uma abordagem alternativa para ensinar reações químicas. 
Os resultados obtidos nesse estudo mostraram que a maioria dos livros didáticos apresentam as leis de proporções definidas e múltiplas com uma perspectiva indutivista, caracterizada pela seguinte seqüência: resultados experimentais mostrando os elementos químicos combinados em proporções fixas/ múltiplas, seguindo-se pela formulação das leis de proporções definidas e múltiplas, e finalmente a teoria atômica de Dalton foi postulada para explicar essas leis.

Para os autores Praia e Chachapuz (1994), a imagem de ciência que os alunos possuem depende, algumas vezes, do que lhes é proporcionado pelos seus professores de ciência, assim eles acham compreensível o crescente interesse da investigação educacional pelo ensino de ciência dum ponto de vista epistemológico. Segundo os autores, há atualmente evidências claras de que as concepções dos professores acerca da natureza da ciência e do conhecimento científico e do que é o método, influencia a forma de abordar um determinado conteúdo e, portanto a imagem da ciência transmitida ao aluno.

Segundo Praia e Chachapuz (1994), as concepções dos professores de seu país, Portugal, parecem ser majoritariamente dominadas por uma perspectiva empirista acerca do conhecimento científico o qual, de acordo com esse ponto de vista, radicaria fundamentalmente no papel da observação. Os fatos científicos dariam significado à teoria e a observação é tida como a etapa mais importante do método científico.

Praia e Chachapuz (1994) apontam que as correntes contemporâneas da epistemologia (por exemplo, Bachelard, Popper, Kuhn, etc.) defendem uma concepção racionalista do conhecimento científico, segundo o qual, o conhecimento é construído com base em teorias que orientam a observação, em outras palavras, uma observação depende da teoria. Para estes filósofos da ciência, o método 
científico não é entendido como uma sucessão linear de etapas, mas antes um processo conducente à elaboração de idéias sucessivamente mais complexas. No ensino, a perspectiva racionalista defende ser o aluno quem tem a responsabilidade de construir (reconstruir) o seu próprio conhecimento. O professor tem um papel importante como mediador entre o conhecimento científico e o conhecimento do aluno, sendo que a sua grande preocupação deve ser relativa à mudança conceitual e a metodológica e não a simples aquisição de conceitos. Os fatos não podem ser abordados de uma forma descontextualizada, mas antes inseridos numa rede de razões, ou seja, discutidos com os alunos de forma a desenvolver neles o pensamento crítico, a capacidade de fundamentação e de argumentação.

Em seu trabalho sobre as imagens da ciência em livros didáticos de química, os educadores químicos portugueses, Campos e Cachapuz (1997), ressaltam que, existe a necessidade de se articular o ensino de ciências às perspectivas epistemológicas contemporâneas, de sentido racionalista/construtivista, que alguns autores denominam "nova" filosofia da ciência.

Segundo os autores, é freqüente os livros didáticos de química apresentarem uma ciência descontextualizada, separada da sociedade e da vida cotidiana; conceberem o método científico como um conjunto de regras fixas para encontrar "a verdade", começando invariavelmente pela observação dos fenômenos, e apresentarem uma imagem estereotipada do cientista como gênio isolado que descobre teorias, omitindo-se o papel da comunidade científica na construção e validação dessas teorias, assim, seguem predominantemente uma orientação empirista e acumulativa e não marcada por aspectos qualitativos de tipo histórico, tecnológico, sociológico e humanístico. 
A partir da seguinte hipótese "Os livros didáticos de química vinculam, em essência, imagens sobre a natureza da ciência e da construção do conhecimento científico não consonantes com concepções racionalistas, construtivistas, sendo fortemente marcados por perspectivas empirista/indutivas", os autores analisaram a natureza epistemológica das imagens da ciência presentes no capitulo relativo ao tema "ácido-base", de quatro livros didáticos, considerando não só as mensagens explícitas (conteúdo manifesto), mas também inferindo a natureza dessas imagens pelo modo como eram apresentadas aos alunos as leis e teorias de ácido-base e, ainda, o tipo de atividades que eram propostas (conteudo latente). As dimensões e categorias de conteúdo utilizadas na análise foram definidas a priori, a partir de um quadro teórico consonante com os princípios orientadores da "nova" filosofia da ciência, com clara relevância educacional. Foram escolhidas três dimensões de análise: metodologia da ciência (MC), relações ciência/tecnologia/sociedade (CTS) e história da ciência (HC). Para cada dimensão foram definidas diversas categorias. Cada categoria foi operacionalizada segundo duas perspectivas dominantes, uma de sentido empirista / positivista (A) e outra de sentido racionalista(B).

A análise dos livros, através das dimensões consideradas, pareceu confirmar, segundo Campos e Cachapuz (1997), a hipótese de trabalho de que se partiu neste estudo. No que diz respeito à dimensão "metodologia da ciência", todos os livros apresentaram, de uma forma mais ou menos acentuada, uma lógica confirmatória na apresentação das atividades experimentais, isto é, pretendem que os alunos obtenham "dados" a partir de uma dada experiência para confirmar uma lei ou teoria científica. As experiências não são precedidas, na sua maioria, de nenhuma problematização, sendo a avaliação dos resultados feita em função do que se espera confirmar. Os livros didáticos analisados praticamente não apresentaram aos 
alunos atividades que fomentem o pluralismo metodológico e o desenvolvimento de diferentes competências do trabalho científico, como o planejamento de experiências partindo de hipóteses a serem elaboradas pelos alunos ou sugeridas pelos livros, a coleta de materiais, a organização de informação e a pesquisa bibliográfica.

No que diz respeito à dimensão "história da ciência", os livros analisados, embora utilizem a história da ciência no capítulo ácido-base, fazem-no de maneira exclusivamente factual e quase sempre à margem do texto principal. Nenhum dos livros utiliza dados históricos de períodos de controvérsia científica (por exemplo, a "teoria oxigínia" de ácido de Lavoisier ou a teoria da dissociação eletrolítica de Arrhenius) para ilustrar como foram construídas e validadas as teorias ácido-base.

A proposta do estudo de Chiappetta (1991) foi a de examinar o conteúdo de sete livros didáticos de química superior para verificar se estes apresentavam, em seu desenvolvimento teórico, aspectos com ênfase na alfabetização científica. Segundo Chiappetta (1991), os livros didáticos de ciência continuam a ser um componente principal da instrução da ciência no seu país, EUA. Em muitas salas de aula, o livro didático provê um importante suporte instrucional para o professor e por possuir muitas informações científicas, podem influenciar a maneira de os alunos perceberem desenvolvimento da ciência.

Foram elaboradas quatro categorias para análise dos livros didáticos:

1. A ciência como um campo do conhecimento: o objetivo do autor parece ser o de apresentar no texto fatos, conceitos, leis, princípios, teorias, etc. Este tipo de categoria reflete a transmissão do conhecimento científico quando o estudante recebe a informação, pela leitura do texto. 
2. A ciência como um modo de investigação: a intenção do autor parece ser estimular o pensamento dos estudantes pelo questionamento. Apresenta métodos e processos da ciência como observação, medição, classificação, inferência, recolhimento de dados, realizar cálculos, experimentos, etc.

3. A ciência como forma de pensar: o texto ilustra como a ciência em geral, ou um cientista especificamente, "encontra algo".Este aspecto da natureza da ciência representa o pensamento, raciocínio, e reflexão.

4. A interação entre ciência, tecnologia e sociedade: o livro tem a intenção de ilustrar os efeitos ou impactos da ciência na sociedade.

Os resultados revelaram que a maioria dos livros didáticos analisados dá ênfase à ciência como um campo de conhecimento. Seis dos sete livros se limitam a apresentar, fatos, conceitos, princípios e leis associadas à química. Todos os livros analisados pelo autor, não enfatizam a ciência como uma maneira de pensar. Os autores, segundo Chiappetta (1991), não dão importância a como os cientistas elaboram teorias e experimentos, ao desenvolvimento histórico dos conceitos químicos, às relações de causa e efeito, evidências e provas, sendo que esses são, segundo o autor, importantes aspectos do desenvolvimento científico e do desenvolvimento da alfabetização científica, portanto deveriam estar presentes no livro didático. 


\section{CAPÍTULO 2}

\subsection{A Reconstrução Histórica da Cinética Química: Os Programas de Investigação Científica}

Neste trabalho, assim como no estudo realizado por Justi (1997), escolheu-se estudar a cinética química a partir da reconstrução histórica de progressos científicos envolvidos nesta área, de acordo com a metodologia de Imre Lakatos. Portanto, a partir do estudo do desenvolvimento histórico da cinética química, foram elaborados quatro Programas de Investigação Científica que foram caracterizados da seguinte forma:

- Núcleo duro: formado pelo modelo teórico que explica a velocidade de uma reação química, considerando-se o entendimento dos aspectos microscópicos da mesma.

- O cinturão protetor é formado por dois atributos que influenciam a velocidade de uma reação química, sendo que tais influências devem ser explicadas pelas teorias do núcleo do programa de investigação, são eles: a concentração das substâncias reagentes e a temperatura.

Portanto, os cientistas na tentativa de construir modelos teóricos para explicar, em termos microscópicos, a velocidade de uma reação química (núcleo duro), devem ser guiados pelas seguintes questões que formam a Heurística positiva dos Programas de Investigação Científica:

1- De que modo a velocidade de uma reação química depende das concentrações das substâncias reagentes?

2- Como a temperatura pode influenciar a velocidade de uma reação química? 
Pode-se observar no desenvolvimento histórico da cinética química que, em vários momentos com o intuito de resolver algum problema específico, eram propostas pelos cientistas, novas teorias que possuíam um poder explicativo maior que as teorias anteriores, e assim essas novas teorias substituíam as antigas. Portanto, considera-se neste trabalho que um programa de investigação suplanta o anterior, quando apresenta explicações mais amplas sobre as velocidades das reações químicas (núcleo do programa).

Um importante problema atual da cinética química é determinar de que modo as velocidades das reações químicas dependem das concentrações das substâncias reagentes. Isto também é importante para se conhecer de que modo as velocidades são afetadas pelos produtos das reações. Um outro problema é analisar o efeito da temperatura na velocidade das reações. Todos esses problemas estão presentes no capítulo de cinética química da maioria dos livros didáticos dirigidos ao ensino médio. Sendo assim, o interesse deste capítulo aqui apresentado é o de abordar sobre esses aspectos da cinética química.

A reconstrução histórica realizada neste trabalho foi feita a partir de pesquisas de historiadores da ciência, artigos de pesquisadores e artigos originais dos cientistas que estiveram envolvidos no estudo da cinética química. Foram utilizados os estudos dos pesquisadores Laidler (1984, 1987, e 1993) e Justi $(1997,1999)$, que desenvolveram trabalhos tendo como foco o estudo da cinética química.

Através do estudo do desenvolvimento histórico da cinética química, foi possível identificar quatro períodos de tempo que representam os períodos onde foram desenvolvidos os conhecimentos científicos que fazem parte de cada Programa de Investigação Científica. 


\subsubsection{O Período de 1850 a 1867: O reconhecimento da cinética química como campo da Química.}

Na metade do século dezenove (1850 -1867), a cinética química era quase que completamente um assunto empírico, sendo pouco o entendimento sobre como a velocidade da reação poderia ser interpretada em termos de movimentos microscópicos.

Nesse período, muitos estudos experimentais foram realizados, onde se observavam que alguns fatores como a concentração dos reagentes e a temperatura podiam influenciar a velocidade de uma reação, mas foi somente em 1850, quando o químico alemão Ludwig Ferdinand Wilhelmy (1812-1864) estudou a velocidade da inversão da sacarose, é que a cinética química foi reconhecida como um campo de estudo da química (Laidler; 1993).

Nessa reação, a sacarose em presença de um ácido, sofre hidrólise formando frutose e glicose. O curso da reação pôde ser seguido facilmente, e com grande exatidão, pois a sacarose desvia para a direita o plano de polarização da luz, enquanto que a frutose e a glicose são levógiras, isto é, desviam o plano da luz polarizada para a esquerda. Este método de seguir o curso de uma reação química mediante uma medida óptica muito sensível se fundamenta na hipótese de que o giro do plano de polarização é proporcional à concentração do açúcar em solução.

Esse trabalho pioneiro é de grande significância porque foi o primeiro em que foi feita uma abordagem quantitativa da velocidade da reação. Wilhelmy propôs, num primeiro momento, uma equação diferencial expressando que a velocidade era proporcional à concentração do açúcar, integrando-a, mostrou que o resultado da equação foi consistente com os resultados experimentais. No quadro 2.1 apresentase um fragmento da linha de raciocínio proposta por Wilhelmy (1850): 
$d Z$ é o açúcar consumido no intervalo de tempo $d T$, e é assumido que isto é determinado pela fórmula:

$$
-d Z / d T=M Z S
$$

No qual MZ, é o valor médio da quantia infinitamente pequena de unidades de açúcar que são mudadas durante o intervalo de tempo pela ação da quantidade de ácido presente (S) Integrando-se essa equação temos:

$$
\log Z=-\pi \operatorname{Tos} T
$$

ou, desde, que S é constante, e de outro lado $M$ também, é independente de $Z$ e portanto também de $T$, como foi mostrado experimentalmente,

$\log Z=-M S T+C$, para $T=0, Z=Z_{0}$ portanto $\log Z_{0}-\log Z=M S T$, ou $Z=Z_{0} e^{-M S T}$

De acordo com o trabalho procedimental eu, portanto uso a fórmula desenvolvida inicialmente:

$\log Z_{0}-\log Z=M S T$

Quadro 2.1- Extrato do "Poggendorf's Annalen der Physik und chemie", The law by the action of acids on cane sugar occurs. ${ }^{3}$

Seguindo os procedimentos Wilhelmy, ou seja, estudando reações orgânicas onde as medições experimentais eram mais precisas por serem reações mais lentas, em 1865, Augustus George Harcourt (1834-1919), realizou alguns estudos experimentais importantes da cinética de reações químicas.

Harcourt contou com a colaboração do colega escocês William Esson (18381916), um colega da Faculdade de Merton e professor de matemática. Juntos eles desenvolveram equações empíricas que relacionavam a quantidade de produto formado com o tempo. Um dos sistemas investigado por Harcourt e Esson, na Universidade de Oxford no inicio de 1865 , foi o experimento denominado "iodineclock" (relógio de iodo), que envolve a oxidação do íon iodeto e redução de peróxido de hidrogênio em solução ácida (Shorter, 1980):

$$
\mathrm{H}_{2} \mathrm{O}_{2}+2 \mathrm{H}^{+}+2 \mathrm{I}^{-} \rightarrow \mathrm{I}_{2}+2 \mathrm{H}_{2} \mathrm{O}
$$

\footnotetext{
${ }^{3}$ Traduzido por Henry M. Leicester e Hebert S. Klickstein, 1952.
} 
A reação ocorre na presença de amido e de uma pequena quantidade de tiossulfato. O aparecimento de uma cor azul indica a presença do iodo $\left(\mathrm{I}_{2}\right)$ no sistema ${ }^{4}$. O intervalo de tempo entre a mistura dos reagentes e o aparecimento da cor azul é relacionada inversamente à velocidade da reação (a), sob determinadas condições. Através da adição sucessiva de quantidades de solução de tiosulfato, o progresso da reação (a) pode ser seguido. Esson tentando achar uma fórmula matemática que pudesse relacionar aos resultados obtidos experimentalmente, formulou a seguinte hipótese:

“...o total de mudança que acontece em qualquer momento será proporcional à quantidade da substância que então permanece" (Shorter, 1980).(tradução nossa)

Pelo experimento denominado "iodine-clock" a reação pode ser demonstrada cineticamente como sendo de primeira ordem $^{5}$ em relação ao peróxido de hidrogênio, ao iodeto e ao ácido:

$$
-d\left[\mathrm{H}_{2} \mathrm{O}_{2}\right] / d t=k\left[\mathrm{H}_{2} \mathrm{O}_{2}\right]\left[\mathrm{I}^{-}\right]\left[\mathrm{H}^{+}\right]
$$

Nessa mesma época, os noruegueses Guldberg e Waage começaram a deduzir a chamada Lei de ação das massas mediante considerações cinéticas. Em 1864, publicaram um trabalho no qual estudaram a reação entre o acido acético e o álcool etílico. Essa reação, estudada por outros químicos, foi realizada muitas vezes começando com concentrações diferentes. A reação alcançava o equilíbrio e as concentrações dos reagentes e dos produtos eram determinadas.

Dos dados publicados por outros cientistas (como também seus próprios experimentos), Guldberg e Waage foram capazes de determinar um principio geral

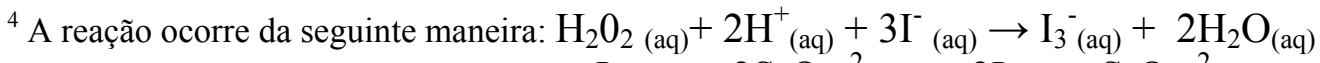$$
\mathrm{I}_{3(\mathrm{aq})}^{-}+2 \mathrm{~S}_{2} \mathrm{O}_{3}{ }_{(\mathrm{aq})}^{-2} \rightarrow 3 \mathrm{I}_{(\mathrm{aq})}^{-}+\mathrm{S}_{4} \mathrm{O}_{6}^{-2}(\mathrm{aq})
$$

A reação com tiosulfato, quando termina, $\mathrm{I}_{3}^{-}$reage com amido dando a cor azul.

${ }^{5} \mathrm{O}$ termo "primeira ordem" como é utilizado atualmente somente surgiu com Ostwald em 1893. (Laidler, 1993)
} 
que é aplicado a todos os equilíbrios químicos. A seguir o que Guldberg e Waage escreveram em 1864:

\begin{abstract}
"If we maintain that for a given chemical process two opposing forces are in effect, one which strives to form new substances and one which strives to restore the original compounds from the new, it is enlightening that, when in the chemical process these forces become equally large, the system is in equilibrium. That the same equilibrium state occurs under the same conditions, whether one goes one way or the other in the process, lies in the nature of the matter. ${ }^{, 6}$

"Se nós aceitamos que para um determinado processo químico duas forças adversárias estão atuando, uma que se esforça para formar substâncias novas e uma que se esforça para restabelecer o composto original, está claro que, quando no processo químico estas forças ficarem igualmente grandes, o sistema está em equilíbrio. $E$ que o mesmo estado de equilíbrio acontece sob as mesmas condições, se acontece de um modo ou de outro no processo, está na natureza da matéria". (tradução nossa)
\end{abstract}

Eles assumiram que o equilíbrio químico é alcançado quando as forças de um sistema são iguais e opostas, e que no equilíbrio a reação tinha então cessado. Contudo, embora a relação de equilíbrio esteja correta, Guldberg e Waage trabalharam em termos de força e não de velocidade. Portanto, seus estudos tinham o foco na idéia de ação de forças químicas (afinidade) e não na idéia do curso de uma reação química como era o caso dos estudos de Harcourt e Esson.

Neste ponto é importante considerar que existem controvérsias entre cientistas e filósofos da ciência em relação à aceitação do trabalho de Guldberg e Waage. Alguns deles consideram que o trabalho deles inaugurou a cinética química, enquanto outros explicitamente negam que eles fizeram alguma contribuição para a

\footnotetext{
${ }^{6}$ Extrato do texto "Studies Concernig Affinty" de P. Waage e C. M. Guldberg (1864), traduzido por Henry M. Leicester e Herbert S. Klickstein (1952).
} 
cinética química. A grande contribuição dos estudos de Guldberg e Waage foi estabelecer uma relação matemática entre as quantidades de substâncias que estão reagindo e a quantidade de produtos formados quando se encontram no equilíbrio.

Nessa época os cientistas envolvidos no estudo da velocidade das reações químicas, sabiam que a temperatura poderia alterar a velocidade de uma reação, pois isso era observado nos seus experimentos, mas ainda não conseguiam elaborar um modelo matemático que explicasse essa influência. Por um período de 60 anos, desde 1850 até 1910, apesar de esforços consideráveis, havia muitas incertezas e controvérsias.

Em suas investigações pioneiras, Wilhelmy, em 1850, sugeriu uma equação empírica relacionando a constante de velocidade, k, com a temperatura (Laidler, 1984). Ele usou a temperatura $\theta$ em Celsius, e esta equação pode ser escrita como:

$$
k=A F^{\theta}(1+G \theta)
$$

onde $A, F$ e $G$ são constantes independentes da temperatura Em termos de temperatura absoluta T, esta equação pode ser escrita como:

$$
k=A^{\prime} F^{T}\left(1+G^{\prime} T\right)
$$

Contudo, esta equação não satisfazia a exigência de que as equações de velocidade, para a reação nas direções direta e inversa, deveriam mostrar uma dependência da temperatura consistente com a constante de equilíbrio. 
Em 1862 Berthelot propôs a equação:

$$
k=A e^{D T}
$$

onde A e D são constantes, a qual satisfazia a condição mencionada acima (Laidler,1987).

Seguindo-se as idéias de Lakatos (1998), pode-se então identificar neste período de tempo o primeiro Programa de investigação Científica que foi denominado como Programa de Investigação Científica de Wilhelmy, Harcourt, Esson e Berthelot (1850-1867) que envolve os estudos destes cientistas, neste período de tempo, e que apresenta a seguinte estrutura:

O núcleo duro: A reação química é entendida como um processo no qual partículas (reagentes) interagem com outras formando novas substâncias (produtos), e a velocidade de uma reação química é proporcional ao número de partículas que estão reagindo num determinado tempo. Portanto, quanto maior a quantidade de substâncias, maior é chance de ocorrer interação entre as elas, o que pode acarretar um aumento de velocidade desta reação.

A Heurística positiva é formada pelas explicações do:

> Efeito da concentração: A velocidade da reação é proporcional ao número de partículas que estão reagindo num dado tempo. Para se calcular a velocidade de uma reação utiliza-se o cálculo diferencial e integral, obtendo-se assim equações que relacionam a velocidade de uma reação química com a concentração dos seus reagentes. 
$>$ Efeito da temperatura: A temperatura pode influir na velocidade de uma reação química, mas não existe um entendimento, em termos microscópicos, de como isto ocorre.

Este programa foi de grande importância na cinética química, pois nele a velocidade de uma reação começou a ser estudada de forma quantitativa com a introdução de equações exponenciais e diferenciais que possibilitavam a determinação da concentração dos reagentes de uma reação química, portanto, esta união da química com a matemática, possibilitou aos cientistas realizarem previsões mais precisas das velocidades das reações. Portanto pode-se dizer que neste programa o enfoque dados aos estudos cinéticos era empírico-matemático.

\subsubsection{Período de 1872 a 1888: O uso do conceito de Energia para explicar a velocidade de uma reação.}

O programa anterior foi suplantado pelo próximo programa (Programa de Investigação Científica de Pfaundler e Van't Hoff;1872-1888), porque apresentava principalmente uma explicação mais ampla, em termos microscópicos, da velocidade de uma reação. Nesta explicação, proposta por Leopold Pfaundler (1839-1918), já começa a ser introduzido o conceito de energia crítica, portanto, somente as partículas que possuem uma certa quantidade de energia conseguem reagir. Ocorreu então, uma modificação da teoria (núcleo duro), que caracterizava o programa de pesquisa anterior.

Pfaundler (Laidler, 1993), baseando-se sua discussão na idéia de equilíbrio dinâmico, o qual foi sugerido em 1850 por Williamson e por Clausius sugeriu que: somente aquelas moléculas que tinham uma quantia maior de energia que a energia 
crítica eram capazes de sofrer reação. Em sua teoria cinética publicada em 1857, Clausius considerou que as moléculas não possuíam apenas movimentos translacionais, mas possuíam também movimentos rotacionais. Ele mostrou que não se podia assumir que a energia translacional seria conservada na colisão, desde que ela poderia ser transformada de um tipo de energia para outro. Ele sugeriu o que poderia ser uma distribuição de velocidades e deu uma explicação para a evaporação de um liquido, resultando no resfriamento:

\section{"Aquelas moléculas com velocidades mais altas que a média, podem ser aquelas que consigam escapar da força atrativa de outras moléculas, e a perda de energia pode ser o resultado da queda da temperatura". (tradução nossa)}

Pode parecer óbvio hoje que moléculas de um gás devem estar se movendo com uma gama de velocidades, mas isso é porque nós já estamos dispostos a acreditar nisso. Este fato não é auto evidente e durante o século dezenove muitos cientistas que tinham dedicado o pensamento a esse assunto, tinham se convencido que a um dado momento haveria uma gama de velocidades e que estas seriam logo igualadas como resultado das colisões entre as moléculas. Segundo Laidler (1993), Clausius não acreditava nisto, mas até mesmo depois de Maxwell ter desenvolvido a sua teoria de distribuição de velocidades ele permaneceu convencido que era satisfatório lidar com a média das velocidades e ignorar a distribuição delas para a maioria dos propósitos.

Em relação ao estudo do efeito da concentração na velocidade de uma reação uma melhor compreensão do curso de uma reação química surgiu em 1884, quando Jacobus Henricus Van't Hoff (1852-1911) publicou seu livro, Études de Dynamique Chimique (fig. 1.1). 


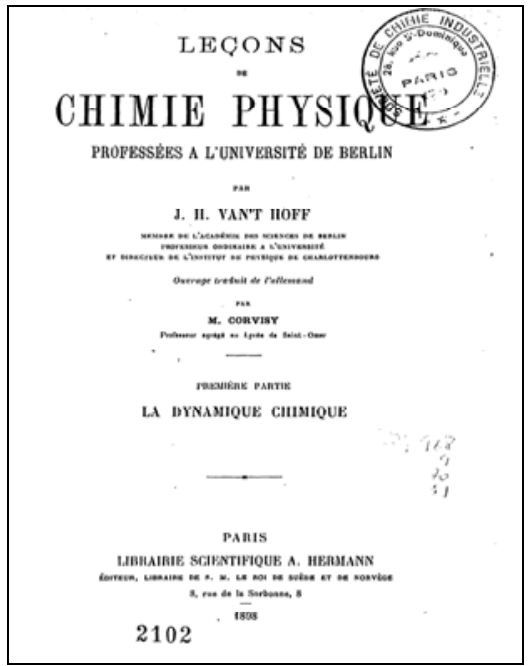

Figura 2.1- Capa do livro Lições de Físico Química, "La Dynamique Chimique", de J. H. Van't Hoff editado em Paris no ano de 1898.

Nele, Van't Hoff estendeu e generalizou a análise matemática do curso de uma reação química, que tinha sido realizada anteriormente por Wilhelmy e por Harcourt e Esson. Uma importante inovação foi que ele reconheceu o significado do que se chama agora por "ordem" (um termo que foi somente introduzido em 1887 por Ostwald) de uma reação.

Van't Hoff, estudando a reação de decomposição do gás $\operatorname{arsina}^{7}$ (reação unimolecular):

$$
2 \mathrm{AsH}_{3(\mathrm{~g})}=2 \mathrm{As}_{(\mathrm{g})}+3 \mathrm{H} 2(\mathrm{~g})
$$

Escreveu uma equação diferencial para esta reação:

$$
-d i=k \mathrm{C}
$$

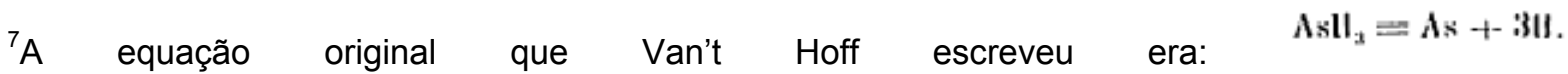
(http://gallica.bnf.fr/ark:/12148/bpt6k91927k/f1.table; pág.189)
} 
onde $c$ é a concentração do reagente no tempo $t$, e $k$ é uma constante, conhecida atualmente como constante de velocidade.

Ele integrou essa equação, obtendo uma expressão para $c$ em função do $t$, e obteve disto o valor da constante $k$. Ele reconheceu assim que, para uma reação de primeira ordem a fração da substância que começa a ser consumida em um dado tempo é independente da quantidade inicial.

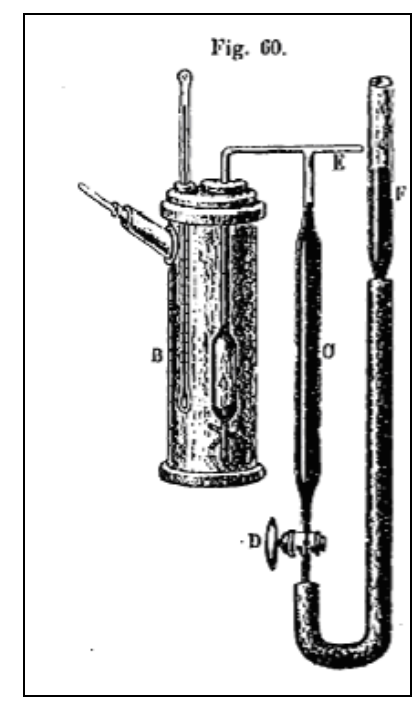

Figura 2.2: Esquema da aparelhagem que Van't Hoff (1898) utilizou para estudar a marcha da reação de decomposição do gás arsênico. O aparelho consiste de um reservatório $A$ no qual após a expulsão do ar, o gás arsênico é introduzido através de um tubo capilar $\mathrm{E}$. Sendo que este é fechado, sem entrada de luz. A determinação da quantidade, decomposta ou não, se faz a partir da medição da pressão por volume a temperatura constante. ${ }^{8}$ (pág.190).

No Études, Van't Hoff introduziu também um método geral, ainda usado hoje, para análise de resultados cinéticos experimentais com o objetivo de determinar a ordem de uma reação química. Este é chamado de método diferencial, que envolve medições de velocidades, $v$, e variações da concentração $c$ do reagente. A relação entre os dois é então:

$$
v=k c^{n}
$$

${ }^{8}$ http://gallica.bnf.fr/ark:/12148/bpttok9192/k/t1.table 
O valor de $\mathrm{n}$ é a inclinação da curva do $\log v$ versus $\log c$

Segundo Laidler e King (1983), outra grande contribuição no estudo da cinética química também foi feita por Van't Hoff em 1884 no que diz respeito à dependência da temperatura na velocidade de reações químicas. Van't Hoff ("La Dynamique Chimique", 1898) apresentou uma equação para a dependência da temperatura considerando-se uma reação em equilíbrio, que em termos modernos pode ser expressa como:

$$
\left(d \ln K_{C} / d T\right)=\Delta U^{0} / R T^{2}
$$

onde $\mathrm{Kc}$ é a constante de equilíbrio de concentração e $\Delta \mathrm{U}^{0}$ é a variação de energia interna. Considerando a reação:

$$
A+B=Y+Z
$$

que é elementar nas duas direções, a velocidade em uma direção é k1[A] [B] e que na reação inversa é $k-1[Y]$ [Z]. No equilíbrio as duas velocidades são iguais:

$$
k 1[A][B]=k_{-1}[Y][Z]
$$

A constante de equilíbrio de concentração $\mathrm{K}_{\mathrm{c}}$ é a relação entre as constantes de velocidade:

$$
[Y][Z] /[A][B]=K c=k_{1} / k_{-1}
$$

Sendo que esta equação pode ser escrita como:

$$
d \ln k_{1} / d T-d \ln k_{-1} / d T=\Delta U^{0} / R T^{2}
$$


Foi discutido por Van't Hoff que as constantes de velocidade k1 e k-1, podem ser influenciadas pelos dois diferentes fatores de energia, E1 e E-1, portanto a equação 8 poderia ser dividida em duas, considerando que $\Delta \mathrm{U}^{0}=\mathrm{E} 1-\mathrm{E}-1$.

$$
d \ln k_{1} / d T=E_{1} / R T^{2}
$$

e

$$
d \ln k_{-1} / d T=E_{-1} / R T^{2}
$$

Van't Hoff, admitindo $E_{1}$ independente da temperatura, integrou a eq. 10 obtendo assim a equação:

$$
k=A \mathrm{e}^{-E / R T}
$$

O fator $\mathrm{A}$ foi muito tempo conhecido como o fator de freqüência, e agora conhecemos como fator pré-exponencial.

Este período é marcado pelos estudos de Van't Hoff, tanto em relação à influência da concentração como a influência da temperatura nas velocidades das reações químicas. Van't Hoff, ao pensar como uma reação química acontece, analisando o processo como um todo, conseguiu formular conceitos teóricos importantes, o que segundo Justi (1997), não era feito pelos químicos, até o tempo dele. Van't Hoff, propôs a existência de fatores que podem exercer influência no curso de uma reação, como a temperatura e o efeito dos solventes. Baseado nessa premissa, ele discutiu muitos aspectos importantes relacionados ao equilíbrio, especialmente a idéia de natureza dinâmica do equilíbrio e o conceito da constante de equilíbrio. 
Portanto, o segundo Programa de Investigação Científica, denominado Programa de Investigação Científica de Pfaundler e Van't Hoff (1872-1888), que representa o conhecimento desenvolvido neste período de tempo pode ser estruturado como possuindo o seguinte núcleo duro: somente as partículas que possuem energia superior à energia crítica podem reagir. A velocidade é, portanto, proporcional ao número de partículas que possuem quantidade de energia superior à energia crítica.

A Heurística positiva deste programa pode ser formada pelas seguintes explicações:

Dfeito da concentração: A análise dos dados experimentais cinéticos e a determinação da ordem de uma reação química passam a ser feita pelo método diferencial. Portanto, nessa época já se tinha o conhecimento de que uma reação poderia ocorrer em mais de uma etapa, embora o conhecimento do mecanismo de reações só pode ser obtido com as modernas técnicas experimentais que surgiram muito tempo depois (década de 60 , século XX). Na equação utilizada por Van't Hoff, para determinar a velocidade de uma reação química entra um novo fator, que é a energia. Portanto, a velocidade da reação depende da concentração das partículas que possuem um valor mínimo de energia para que possam reagir, denominada de energia critica.

Dfeito da temperatura: Um aumento de temperatura causa um aumento do número de partículas com energia suficiente para participarem da reação química.

Contudo, os químicos levando em consideração a concentração e a temperatura, na determinação da lei de velocidade de uma reação, perceberam que 
o valor calculado era muito maior que o valor determinado experimentalmente, portanto, deveriam existir outros fatores que estariam influenciando a velocidade de uma reação química. Esse problema só foi resolvido posteriormente, no próximo programa.

\subsubsection{Período de 1889-1918: As primeiras teorias de colisões entre moléculas.}

Entre 1916-1918, estudando o problema do fator pré-exponencial $A$ da equação ${ }^{9}$ de Van't Hoff, Max Trautz (1879-1960), e o inglês William Cudmore Lewis (1885-1945), com base na teoria das colisões dos gases, propuseram duas abordagens. Por causa da Primeira Guerra Mundial, Trautz e Lewis desconheciam um o trabalho do outro. Seus tratamentos eram muito similares, e foram desenvolvidos a partir da hipótese da radiação, conhecida atualmente ser inaplicável. (Laidler e King, 1983).

Uma importante razão para a popularidade da hipótese de radiação por algum tempo foi que as reações gasosas unimoleculares pareciam ser incapazes de serem explicadas, nos termos de colisões moleculares. A hipótese da radiação parecia oferecer a única explicação, e para alguns investigadores era assumido que se aplicava à reação de todos os tipos. De acordo com a hipótese da radiação formulada por Perrin em 1919, a transferência de energia ocorre por absorção da radiação infravermelha e não por choque entre as moléculas, ou seja, a reação química ocorre pela absorção da radiação infravermelha vinda das paredes do recipiente da reação. Por volta do ano de 1921 a hipótese foi amplamente desacreditada (Laidler e King, 1983).

\footnotetext{
${ }^{9}$ Equação de Van't Hoff: $k=A$ e $\mathrm{e}^{-E / R T}$
} 
Lewis (1918), no seu trabalho "Estudos de Catálise" diz que, inicialmente outros estudos nesta área obtinham expressões com a ajuda da hipótese da radiação para a constante de velocidade e a constante de equilíbrio em função da temperatura. Contudo, nas expressões assim obtidas era necessário ter certo "fator de proporcionalidade" que tinha de ser determinado com a comparação direta com a experiência. Lewis propõe uma tentativa de lidar com este problema de uma maneira mais completa, calculando as constantes de velocidade e de equilíbrio em termos de quantidades, as quais, possuem um significado físico definido e que pode ser determinada teoricamente, sem referências a velocidade real da própria reação química (Lewis, 1918).

Lewis (1918) usou no seu tratamento o conceito de moléculas ativas, onde a velocidade da reação dependia do número de colisões por segundo que aconteciam entre as moléculas ativas das substâncias participantes da reação.

"Active molecules, in unimolecular processes, have therefore no real existence. When, however, we deal with multimolecular reactions, it is conceivable that active molecules exist, the rate of the observed reaction depending on the number of collisions per second which take place between active molecules of the participating substances." (Lewis, p. 471; 1918).

Moléculas ativas, em processos unimoleculares, não têm nenhuma existência real. Porém, quando nós lidarmos com reações multimoleculares, é concebível admitir que moléculas ativas existem, a velocidade da reação observada, depende do número de colisões por segundo que acontece entre moléculas ativas das substâncias participantes. (tradução nossa).

Para Lewis (1918), as moléculas ativas diferem das outras moléculas restantes, no que diz respeito a sua energia interna, a qual é consideravelmente muito maior 
que a energia média que as moléculas de uma substância possuem a uma determinada temperatura.

O tratamento de Lewis, em resumo, pode ser visto a seguir:

No caso de reações bimoleculares, a fração de moléculas que existem no estado ativado pode ser calculada através da equação:

$$
N_{a} / N=e^{-E / R T}
$$

Onde $\mathrm{N}_{\mathrm{a}}$ indica o número de moléculas ativas; $\mathrm{N}$ é o número total de moléculas (onde $\mathrm{N}_{a}$ é muito menor que $\mathrm{N}$ ); $\mathrm{E}$ é o incremento critico considerado em moléculagrama, que é a quantidade de energia que uma molécula-grama de substância pode absorver para se tornar ativa. Sendo esta expressão obtida com base na mecânica estatística para a distribuição de moléculas em um campo de força.

$\mathrm{Na}$ teoria cinética, o número de colisões por c.c. por segundo entre as moléculas ativas é dado pela expressão:

$$
\sqrt{ }{ }^{*} \Pi^{*} \sigma^{2} u^{*} N_{a}^{2}
$$

Onde $N_{a}$ é o número de moléculas ativas por volume,e u significa a velocidade de translação por molécula, e $\sigma^{2}$ a distância na qual as duas moléculas se aproximam uma da outra durante a colisão.

Assim, o número de moléculas que reagem por c.c. por segundo é:

$$
2 * \sqrt{2 *} \Pi^{*} \sigma^{2 *} u^{*} N_{a}^{2}
$$

Conseqüentemente o número de moléculas que reagem por volume de $1 \mathrm{~L}$ por unidade de tempo é:

$$
2000 * \sqrt{ } 2 * \Pi * \sigma^{2}{ }^{*} N_{a}^{2}
$$


Onde $N_{a}$ é o número de moléculas ativas por c.c. Conseqüentemente o número de moléculas ativas por litro é $1000 N_{a}$. Considerando-se $N_{a}=N_{0} C_{a} / 1000$ e que $C_{a}=$ $C e^{-E / R T}$, onde $C$ é a concentração total ou número de moléculas-grama por volume, a velocidade de reação é:

$$
-d c / d t=5,4^{*} 10^{21 *} \sigma^{2 *} u^{*} C^{2} e^{-2 E / R T}
$$

Mas a equação da velocidade é: $-d c / d t=k_{a b s}{ }^{*} C^{2}$, onde $k_{a b s}$ é a constante de velocidade determinada experimentalmente. Portanto, o valor de $k_{a b s}$ é:

$$
5,4^{*} 10^{21 *} \sigma^{2 *} u^{*} e^{-2 E / R T}
$$

Na base puramente cinética, Lewis (1918) observou que a velocidade de uma reação entre as moléculas em uma reação bimolecular por unidade de volume por tempo pode ser dada por:

$$
-d c / d t=5,4 * 10^{21} * \sigma^{2 *} u^{*} C^{2} e^{-2 E / R T}
$$

O fator pré-exponencial nesta expressão é chamado de fator de freqüência de colisão dado pelo símbolo Z. Portanto, a constante de velocidade é expressa como:

$$
k=Z e^{-E / R T}
$$

Fazendo uso do conceito de moléculas ativas, Lewis pode calcular a constante de velocidade para a reação de decomposição do lodeto de hidrogênio, onde houve uma satisfatória concordância entre os valores observados e calculados. 
Contudo, segundo Laidler (1993), foi percebido depois que havia muitas reações, particularmente algumas envolvendo reagentes moleculares de grande complexidade, para as quais eram grandes as discrepâncias entre os valores calculados e observados.

Essas discrepâncias mostraram que a simples teoria das colisões de esferas sólidas não era adequada para as reações químicas. Esta teoria pode ser satisfatória para o tratamento da viscosidade e difusão dos gases, mas para uma teoria de reatividade química era requerida, então uma definição de colisão muito mais precisa. Se duas moléculas estão reagindo elas não tem que meramente colidir com energia mútua suficiente, elas devem vir juntas com uma mútua orientação que é necessária para quebrar e formar ligações. Pela simples teoria cinética, sempre que a colisão for suficientemente energética ocorre uma colisão efetiva, na realidade, as moléculas podem não se aproximar uma da outra do modo correto para que a reação ocorra mesmo elas possuindo energia suficiente para reagir. Uma maneira de remediar esta situação foi à introdução entre 1918-1930 do fator estérico $P$ que supostamente representa a fração do número total de colisões efetivas do ponto de vista da orientação (Laidler, 1987). A constante de velocidade pode ser então escrita como:

$$
k=P Z_{A B} e^{-E / R T}
$$

Foram feitos em anos recentes importantes acréscimos na teoria das colisões original e estes trouxeram significantes contribuições para a teoria das velocidades. Eles são baseados no conceito de seção de choque $\sigma$ para uma reação. 
Estudando o trabalho de Van't Hoff, Ostwald introduziu o termo "ordem de uma reação", em 1893, no estudo de reações sucessivas, nas quais o produto de uma reação sofre uma segunda reação, na qual o produto pode sofrer reações adicionais, ele introduziu seu "método de isolação". Se a velocidade de uma reação depende da concentração de duas substâncias reagentes, a concentração de uma delas pode ser elevada a um valor alto de maneira que não mude apreciadamente durante o processo. A ordem, com respeito ao outro reagente, pode então ser obtida. Em 1888 ele introduziu a idéia de meia vida de um reagente, a qual é o tempo em que metade da quantidade do reagente é consumida.

Ahrrenius (Back, e Laidler, 1967) usou o tratamento de Van't Hoff e notou que a magnitude do efeito da temperatura nas velocidades dos processos químicos é geralmente muito grande para ser explicada em termos de como a temperatura afeta a energia molecular translacional, ou em termos de como a temperatura afeta a viscosidade do meio. Nas suas palavras:

"... the increase in reaction velocity differs in a very important way from the increase with temperature in most physical quantities. Thus the change of these quantities is approximately equal for an increase in temperature of $1^{\circ}$, even for very different values of the temperature (e.g. $0^{\circ}$ and $50^{\circ}$ ). On the other hand the increase (in absolute value) per degree of the reaction velocity is perhaps twice as large at $6^{\circ}$ as at $0^{\circ}$, at $12^{\circ}$ four times as large as at $0^{\circ}$, at $30^{\circ}$ perhaps thirty $\left(2^{5}\right)$ times as large as at $0^{\circ}$, etc. This fact indicates that the increase in reaction velocity with the temperature cannot be explained in terms of the change in physical properties of the reacting substances. "(Arrhenius;1889) ${ }^{10}$

"O aumento da velocidade de reação difere de um modo muito importante do aumento com temperatura na maioria das quantidades físicas. Assim, a mudança destas quantidades é aproximadamente

\footnotetext{
${ }^{10}$ Extrato do texto "On the reaction velocity of the inversion of cane sugar by acids" de Svante Arrhenius (1889), traduzido por Back, M e Laidler, J. K em 1967.
} 
igual para um aumento em temperatura de $1^{\circ}$ (um grau), até mesmo para valores muito diferentes da temperatura (por exemplo, $0^{\circ}$ e $50^{\circ}$ ). Por outro lado, o aumento (em valor absoluto) por grau da velocidade de reação é talvez duas vezes maior a $6^{\circ}$ que a $0^{\circ}$, a $12^{\circ}$ quatro vezes maior que a $0^{\circ}$, a $30^{\circ}$ talvez trinta $\left(2^{5}\right)$ vezes maior que a $0^{\circ}$, etc. Este fato indica que o aumento da velocidade de reação com a temperatura não pode ser explicado em termos da mudança em propriedades físicas das substâncias reagentes." (tradução nossa)

Ele concluiu que um equilíbrio é estabelecido entre moléculas reativas normais e as ativas, as quais são capazes de formar produtos sem a adição de energia mais adiante. O equilíbrio entre moléculas normais e ativas poderá ser deslocado com a temperatura de acordo com a equação de Van't Hoff (eq. 12), de forma que a velocidade poderá variar com a temperatura da mesma maneira. Ele não considerou a energia $E$ dependente da temperatura, adotando assim a equação 13 de Van't Hoff:

$$
k=A \mathrm{e}^{-E a / R T} \quad(22)
$$

Como resultado da interpretação de Arrhenius, esta equação passou a ser chamada de equação de Arrhenius, embora fosse essa elaborada inicialmente por Van't Hoff. Com a sua modéstia característica, Van't Hoff passou a impressão de que foi Arrhenius que tinha obtido primeiro a equação. (Laidler, 1993).

Pode-se interpretar a equação de Arrhenius em termos de barreira de energia da reação; se $E$ é a altura da barreira, a fração de moléculas tendo energia em excesso de $E$ é igual a exp (-E/RT). Hoje, a energia de ativação é usualmente dada pelo símbolo Ea, e esta é considerada uma quantidade experimental definida com base na equação de Arrhenius. Sua definição é:

$$
E_{a}=-R\left(\frac{d \ln k}{d(1 / T)}\right)
$$


Onde $k$ é a constante de velocidade, $T$ é a temperatura absoluta, e $R$ é a constante geral dos gases.

Observa-se, experimentalmente, que em muitas reações o gráfico de In k contra 1/T leva a uma reta (figura 1.3). Este comportamento exprime-se, normalmente, de maneira matemática introduzindo-se dois parâmetros (denominados atualmente de parâmetros de Arrhenius), um representando o coeficiente linear e outro o coeficiente angular da reta, e escrevendo a equação de Arrhenius (eq. 23):

$$
L n k=\ln A-E a / R T
$$

O coeficiente angular é igual a $-E a / R$; portanto, o parâmetro $E a$, energia de ativação, é definido como o coeficiente angular multiplicada por -R. O parâmetro A, que corresponde à interseção da reta com o eixo vertical em $1 / T=0$, é denominado fator pré-exponencial.

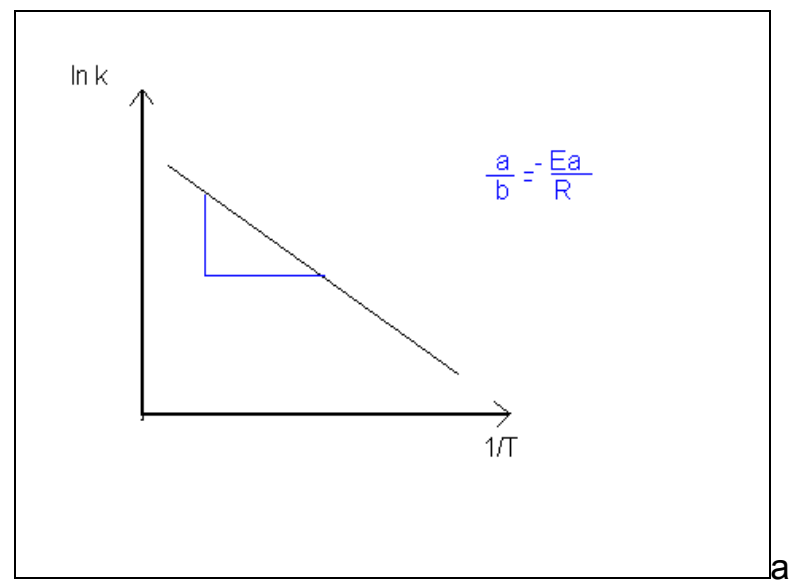

Figura 2.3: $O$ gráfico de Ink versus 1/T é uma reta quando a reação segue o comportamento descrito pela equação de Arrhenius (eq.23).

Somente para uma reação elementar a energia de ativação está necessariamente relacionada para a altura de uma barreira energética; para uma 
reação ocorrendo em mais de uma etapa, a energia de ativação é uma função composta de diferentes energias.

Portanto, nesse período de tempo observa-se que houve um grande acréscimo no entendimento da velocidade de uma reação, principalmente com a Teoria das colisões. Em relação ao efeito da concentração e da temperatura foram dadas novas interpretações a conhecimentos que já tinham sido propostos por outros cientistas. Este novo programa de investigação, que caracteriza o conhecimento científico, desenvolvido neste período de tempo, foi denominado neste trabalho de Programa de Investigação Científica de Trautz -Lewis, Ostwald e Arrhenius (1889-1918), e pode ser caracterizado da seguinte forma:

Núcleo duro: a velocidade de uma reação química depende do número de colisões por segundo que acontecem entre as moléculas ativas das substâncias participantes da reação, mas, se duas moléculas estão reagindo elas não tem que meramente colidir com energia mútua suficiente, elas devem vir juntas com uma mútua orientação que é necessária para quebrar e formar ligações.

\section{Heurística positiva:}

D Efeito da concentração: A concentração influi na velocidade, mas entende-se agora que somente as partículas que possuem uma determinada quantidade de energia, e uma orientação apropriada, conseguem reagir, portanto, a velocidade de uma reação depende agora desses fatores. Outras modificações neste programa foram: a introdução do termo ordem de uma reação, a introdução do método de isolação, e da idéia de meia vida de um reagente. 
> Efeito da temperatura: Um mínimo de energia é necessário para a ocorrência de uma reação está associado com uma "barreira de energia" (Ea, energia de ativação) para aquela reação. Portanto, pode-se entender que um aumento de temperatura aumenta o número de moléculas com energia necessária para transpor essa barreira de energia.

\subsubsection{Período de 1918-1935: A teoria do Estado de Transição.}

Até meados de 1930 importantes trabalhos experimentais em cinética foram realizados com base na interpretação da teoria da colisão, resultando em conclusões de considerável significância, mas estas interpretações, segundo Laidler (1993), foram sendo modificadas através de teorias mais sofisticadas.

Segundo Laidler e King (1983), a aplicação da mecânica estatística na velocidade de uma reação, uma importante característica da teoria do estado de transição, foi desenvolvida bem lentamente e com uma certa irregularidade.

Um desenvolvimento de grande importância para a teoria da velocidade foi à construção da superfície de energia potencial feita por Henry Eyring (1901-1981) e por Michael Polanyi (1891-1976). Com o uso dessas superfícies, tornou-se possível, pela primeira vez, estimar a energia de ativação, embora aproximada, e também responder a muitas questões com respeito ao mecanismo de uma reação.

Em 1932, uma importante contribuição foi feita por H. Pelzer e Eugene Paul Wingner. Nesse trabalho eles consideraram a passagem de um sistema sobre a superfície de energia potencial, e este foi importante por ser o primeiro a ter atenção no foco no "ponto de sela" de uma superfície de energia potencial. Eles perceberam 
que o movimento do sistema pelo ponto de sela controla a velocidade de reação, eles obtiveram então deste modo, uma expressão para a velocidade (Laidler, 1993).

O artigo de Peltzer e Winger contribuiu significativamente para a formulação em 1935 do que veio a ser chamada de teoria do Estado de Transição. Esta teoria, que provê uma valiosa estrutura para o entendimento de todos os tipos de processos químicos e físicos foi desenvolvida independentemente por Henry Eyring e por Michael Polanyi e Meredith Gwynne Evans (1904-1952).

A essência desta teoria é que espécies representadas por pontos próximos ao ponto de sela da superfície de energia potencial, isto é, os complexos ativados, são considerados como estando em um estado de quase-equilíbrio com os reagentes, de forma que suas concentrações podem ser calculadas.

O estado de transição, segundo Evans e Polanyi (1935), pode ser representado pela equação:

$$
\begin{aligned}
& \qquad \mathrm{A}+\mathrm{B}+\mathrm{C} \ldots \rightarrow(\mathrm{ABC} \ldots) \rightarrow \quad \alpha+\beta+\gamma \ldots \\
& \text { Estado inicial Estado de transição } \quad \text { Estado final }
\end{aligned}
$$

onde o termo (ABC...) representa a formação do complexo ativado. A velocidade da reação é então a concentração desses complexos multiplicada pela freqüência com que eles são convertidos em produtos:

Velocidade $=($ concentração do complexo ativado $) \times($ freqüência de decomposição do complexo ativado)

De acordo com esta teoria a freqüência é $k_{B} T / h$, onde $k_{B}$ é a constante de Boltzmann, $h$ a constante de Planck e T a temperatura absoluta. 
Uma compreensão completa do significado da energia de ativação, $E_{a}$, demorou algum tempo para emergir. Havia várias sugestões de que as reações requereriam a formação de espécies intermediarias, mas não havia nenhuma evidência para estas sugestões. Marcelin (1827-1907) foi o primeiro quem avançou nessa compreensão quando ele disse que as moléculas, em média, possuem um valor de energia interna, e que não são capazes de reagirem, elas só se tornaram reativas quando a energia interna delas aumenta acima de um crítico valor.

Em 1918, Tolman (Laidler, 1993) desenvolveu com base na mecânica estatística, relações que davam significado para a energia de ativação, até então somente determinada experimentalmente, através da equação de Arrhenius. De acordo com o seu tratamento, depois melhorado por Fowler e Guggenheim, a energia de ativação por molécula $(E a=E a / L)$ é dada por:

$E a=$ (energia média de todas as moléculas capazes de reagir) - (energia média de todas as moléculas reativas)

Onde L, é a constante de Avogadro, que converte unidade molecular em unidade molar. Esta definição é atualmente conhecida como o Teorema de Tolman.

Com esta nova interpretação da velocidade de uma reação e dos fatores que podem influenciá-la, através da Teoria do Estado de transição, pode-se então dizer que surgiu assim um novo Programa de Investigação Científica. Este novo programa, denominado de Programa de Investigação Científica de Eyring, Polanyi, Evans e Tolman, (1920-1935), apresenta a seguinte estrutura:

Núcleo duro: a velocidade de uma reação química pode ser calculada focalizandose a atenção no complexo ativado. O complexo ativado de uma reação é a configuração onde o ponto de energia potencial é o mais alto, no qual as moléculas 
chegam a um grau de proximidade e distorção tais que qualquer distorção adicional as leva em direção aos produtos (Teoria do Estado de Transição). A velocidade de uma reação é então determinada pela seguinte relação:

Velocidade $=(\text { concentração do complexo ativado })^{*}($ freqüência de decomposição do complexo ativado)

\section{Heurística positiva:}

Efeito da concentração: Uso da superfície de energia potencial para calcular a concentração dos reagentes. O complexo ativado é considerado como estando em um estado de quase-equilíbrio com os reagentes, de forma que suas concentrações podem ser calculadas. A velocidade da reação é proporcional à concentração do complexo ativado

Efeito da temperatura: A energia de ativação adquire um novo significado. Ela agora está relacionada não mais a uma barreira de energia, mas sim a formação do complexo ativado. Quanto menor for a energia de ativação do complexo ativado, maior será a velocidade da reação. 


\section{CAPÍTULO 3}

\section{METODOLOGIA}

\subsection{Critérios adotados na escolha dos livros didáticos.}

Neste trabalho optou-se por analisar exclusivamente os livros didáticos brasileiros (anexo I), pois o foco desse estudo é a realidade do ensino médio brasileiro, não limitando, porém a análise aos livros mais utilizados, mas estendendo-a também àqueles que apresentam propostas curriculares ou metodologias diferenciadas, para que se possa ter uma visão mais ampla das propostas de ensino que estão disponíveis na área da química. Os livros didáticos foram selecionados a partir de diferentes lugares, como sebos, bibliotecas, mas principalmente os mais antigos vieram da biblioteca da Faculdade de Educação, da Universidade de São Paulo, da seção de livros didáticos antigos ${ }^{11}$. Essa coleta de livros didáticos durou aproximadamente seis meses.

Foram analisados livros didáticos pertencentes ao período de tempo que começa em 1929 até o ano de 2004 (tab. 3.1). Escolheu-se trabalhar com um período mais longo para que fosse possível observar as mudanças que poderiam ocorrer na apresentação do conteúdo químico escolhido neste trabalho, observandose assim quais seriam as concepções de ciência que esses livros apresentam.

Os livros didáticos foram divididos em cinco períodos de tempo, que correspondem aos períodos de vigência das reformas educacionais, propostas pelo governo para o ensino médio, pois se imagina que os autores dos livros didáticos

\footnotetext{
${ }^{11}$ Serviço de Biblioteca e documentação da Faculdade de Educação-USP: $\underline{\text { bibfe@edu.usp.br }}$
} 
possam seguir algumas das orientações propostas por essas reformas, quando realizam a transposição didática dos conceitos químicos para o livro didático (tab. 3.2).

\begin{tabular}{|c|c|c|c|}
\hline Período & $\begin{array}{l}\text { Número de } \\
\text { ordem }\end{array}$ & Nome(s) do(s) autor (es) & $\begin{array}{l}\text { Ano de } \\
\text { Edição }\end{array}$ \\
\hline \multirow{3}{*}{ Primeiro (1929 -1941) } & (1) & Dr. Oliveira de Menezes & 1929 \\
\hline & $(2)$ & Miguel Tenório D’Alburqueque & 1931 \\
\hline & (3) & Pe. Ignácio Puig S. J. & 1932 \\
\hline \multirow{5}{*}{ Segundo (1942-1960) } & $(4)$ & Carlos Costa e Carlos Pasquale & 1942 \\
\hline & (5) & Paulo Décourt & 1946 \\
\hline & (6) & $\begin{array}{l}\text { Geraldo Camargo de Carvalho, } \\
\text { Waldemar Saffioti }\end{array}$ & 1954 \\
\hline & (7) & Luciano Francisco Pacheco do Amaral & 1955 \\
\hline & (8) & Luciano Francisco Pacheco do Amaral & 1959 \\
\hline \multirow{3}{*}{ Terceiro (1961-1970) } & (9) & Irmão Firmino Bonato & 1966 \\
\hline & $(10)$ & Chemical Educational Material Study. & 1967 \\
\hline & $(11)$ & Ricardo Feltre, Setsuo Yoshinaga; & 1968 \\
\hline \multirow{5}{*}{ Quarto (1971-1995) } & $(12)$ & Ricardo Feltre & 1976 \\
\hline & (13) & $\begin{array}{l}\text { Yvone Mussa Esperidião, Naídes de } \\
\text { Cerqueira e Silva Alves de Lima }\end{array}$ & 1977 \\
\hline & $(14)$ & Antonio Sardella e Edegar Mateus & 1979 \\
\hline & $(15)$ & Geraldo Camargo de Carvalho & 1980 \\
\hline & $(16)$ & Otávio Aloísio Maldaner, Rui Zambiazi & 1993 \\
\hline \multirow{4}{*}{ Quinto (1996 a 2004) } & $(17)$ & Vera Novais & 1999 \\
\hline & $(18)$ & GEPEQ & 2001 \\
\hline & $(19)$ & $\begin{array}{l}\text { Geraldo Camargo de Carvalho, Celso } \\
\text { Lopes de Souza. }\end{array}$ & 2003 \\
\hline & $(20)$ & Ricardo Feltre & 2004 \\
\hline
\end{tabular}

Tabela 3.1- Livros didáticos estudados por período e ano de edição. 


\begin{tabular}{l|lc}
\hline \multicolumn{1}{c|}{ Período } & \multicolumn{1}{|c}{ Reforma Educacional } & $\begin{array}{c}\text { Número de livros } \\
\text { analisados }\end{array}$ \\
\hline Primeiro (1929 -1941) & Reforma Francisco Campos (1931) & 3 \\
\hline Segundo (1942-1960) & Reforma Gustavo Capanema (1942) & 3 \\
\hline Terceiro (1961-1970) & Lei das Diretrizes e Bases 4024 (1961) \\
\hline Quarto (1971-1995) & Lei das Diretrizes e Bases 5692 (1971) & \multirow{2}{*}{4} \\
\hline Quinto (1996 a 2004) & Lei das Diretrizes e Bases 9394 (1996) \\
\hline
\end{tabular}

Tabela 3.2- Livros didáticos de acordo com a reforma educacional referente a cada período de tempo.

Atualmente o conteúdo da cinética química é apresentado, de maneira geral, nos livros didáticos tradicionais dirigidos ao ensino médio, dividido em quatro partes, às vezes, variando-se somente a ordem de apresentação: estudo da velocidade das reações químicas, condições necessárias para que uma reação química possa ocorrer, fatores que influem na velocidade das reações químicas e catálise. Neste trabalho optou-se por analisar o conteúdo referente ao modelo teórico utilizado para explicar a velocidade das reações químicas e a influência da concentração e da temperatura sobre a velocidade da reação.

Na primeira etapa do trabalho foram identificados no livro didático dentro do tema, Cinética Química, os níveis de explicação teórica atingidos. Para tal fez-se o do uso dos quatro Programas de Investigação Científica, que foram elaborados neste trabalho. Assim, uma primeira tentativa de se explicar à velocidade das reações químicas (interação entre as substâncias que estão reagindo) seria fornecida pelo programa de Investigação Científica de Wilhelmy, Harcourt, Esson e 
Berthelot (1850-1865), a segunda explicação teórica, mais ampla envolvendo o conceito de energia crítica, para explicar a velocidade além dessa interação entre as partículas, já faz parte do Programa de Investigação Científica de Pfaundler e Van't Hoff (1872-1888), uma terceira explicação teórica que inclui, além das condições do segundo modelo para que uma reação ocorra, a necessidade de uma certa freqüência e orientação espacial nas colisões entre as partículas, sendo representada pelo Programa de Investigação Científica de Trautz-Lewis, Ostwald e Arrhenius (1889-1918) e finalmente uma explicação mais atualizada que inclui o conceito de complexo ativado, sendo fornecida pelo Programa de Investigação Científica de Tolman, Eyring, Polanyi, e Evans (1920-1935).

Uma importante observação deve ser feita em relação à escolha do modelo teórico para explicar o efeito da concentração na velocidade de uma reação. Considerou-se neste trabalho que, se o autor do livro didático usar a Lei de Guldberg-Waage para relacionar a velocidade de uma reação química com a concentração das substâncias reagentes, não se pode utilizar os Programas de Investigação Científica para identificar esta explicação. Como já foi dito anteriormente, os estudos de Guldberg e Waage tinham o foco na idéia de ação de forças químicas e não na idéia do curso de uma reação química, como era o caso dos estudos de Harcourt e Esson, que fazem parte do primeiro programa de investigação. Portanto, ao invés de se utilizar à notação de PIC (programa de investigação científica) utiliza-se a notação GW (Guldberg-Waage).

Para efeito de facilitar as analises as principais características destes programas foram resumidas nos quadro I, II e III. A identificação dos programas de investigação nos livros poderá dar uma indicação de como o conhecimento científico (cinética química) foi transposto, através do tempo, para os livros didáticos. 
É importante esclarecer que nesta análise se tem a consciência de que no livro didático, o conhecimento científico muitas vezes é apresentado de forma diferente do que está presente nos quatro programas de investigação científica. Nestes programas, pode-se observar, o desenvolvimento histórico do conhecimento cientifico visto através do olhar dos próprios cientistas e de historiadores da ciência. Mas, esse conhecimento às vezes da maneira que é apresentado, não é adequado para o entendimento dos estudantes do Ensino Médio, fazendo-se então necessária uma adaptação. Por exemplo, o calculo diferencial e integral empregado no cálculo da velocidade de uma reação química nas pesquisas originais, não pertence ao currículo do Ensino Médio em muitas das escolas brasileiras, então, este cálculo é substituído pelo conceito da velocidade média, onde as operações matemáticas são mais simples.

Procurou-se também, analisar nesse tópico de conteúdo, as possíveis visões de ciência que a abordagem revela. Tal análise está detalhada no item 2.2. 


\section{Programas de Investigação Científica}

I- Wilhelmy, Harcourt, Esson e Berthelot (18501865)

\begin{tabular}{ll}
\hline & $\begin{array}{c}\text { Somente as partículas que possuem mais de uma } \\
\text { energia crítica } E \text { (definida na lei de Maxwell como sendo }\end{array}$ \\
II- Pfaundler e Van't Hoff & $\begin{array}{l}\text { igual a exp (-E/RT)), conseguem participar de uma reação } \\
\text { (1872-1888) }\end{array}$ \\
& $\begin{array}{l}\text { química. Portanto, a velocidade de uma reação depende } \\
\text { energia. }\end{array}$ \\
\hline III- Lewis, Ostwald e & Uma reação química pode ser causada por colisões \\
Arrhenius (1889-1918) & $\begin{array}{l}\text { de entre partículas que possuem uma determinada quantidade } \\
\text { barreira de energia desta reação. Portanto, a velocidade de } \\
\text { uma reação depende da freqüencia de colisões entre } \\
\text { partículas que possuem uma certa quantidade de energia. }\end{array}$ \\
\hline Durante a reação química a energia potencial aumenta à \\
medida que os reagentes se aproximam. O complexo ativado \\
IV- Tolman, Eyring, \\
Polanyi, e Evans (1920- \\
1935).
\end{tabular}

\section{Núcleo do programa:}

a) Como se pode explicar, em termos microscópicos, a velocidade de uma reação química?

A reação química é um processo no qual partículas se encontram umas com as outras resultado em novas substâncias, sendo a velocidade de uma reação química proporcional a concentração das substâncias que estão reagindo em um determinado intervalo de tempo.
Somente as partículas que possuem mais de uma 
Programas de Investigação

Científica

- Wilhelmy,

Harcourt, Esson e

Berthelot (1850-

1865)

Heurística Positiva:

b) De que modo às velocidades das reações químicas dependem das concentrações das substâncias reagentes?

A velocidade da reação é proporcional a quantidade de substâncias que estão reagindo num dado tempo. Portanto, quanto maior a quantidade de substâncias, maior é chance de ocorrer interação entre as elas, o que pode acarretar um aumento de velocidade desta reação.

Uso de equações diferenciais como a base para a interpretação de um fenômeno químico.

A velocidade da reação é proporcional ao número de partículas que possuem um valor mínimo de energia, denominada energia crítica.

II - Pfaundler e Van't Hoff (18721888).

Uso do cálculo diferencial e integral para obter equações que relacionam a velocidade de uma reação química com a concentração dos seus reagentes.

$v=k c^{n}$, onde $k=A e^{-E / R T}$, onde a ordem $n$ de uma reação química é determinada experimentalmente.

A velocidade da reação é proporcional ao número de partículas que conseguem transpor a barreira de energia daquela III - Lewis, Ostwald reação.

e Arrhenius (1889-

Introdução do termo ordem de uma reação no lugar da 1918). "molecularidade" de Van't Hoff.

Introdução do método de isolação.

Introdução da idéia de meia vida de um reagente.

A velocidade de uma reação está relacionada a concentração

IV - Tolman, Eyring, Polanyi, e Evans (1920-1935). do complexo ativado:

Velocidade $=($ concentração do complexo ativado $) \times($ freqüência de decomposição do complexo ativado)

Uso da superfície de energia potencial para calcular a concentração dos reagentes (matemática estatística).

Quadro II - Resumo das principais características dos Programas de Investigação Científica. Influência da concentração na velocidade de uma reação química. 
Heurística Positiva:

Programas de

c) Como a temperatura pode influênciar a velocidade de Investigação Científica uma reação química?

I -Wilhelmy, Harcourt, A temperatura pode influir na velocidade de uma reação
$\begin{aligned} & \text { Esson e Berthelot (1850- química, mas não existe um entendimento de como isto } \\ & \text { 1865) } \\ & \text { ocorre. }\end{aligned}$

II -Pfaundler e Van't Hoff

Um aumento de temperatura causa um acréscimo na (1872-1888) freqüência de interação das partículas reativas o que dá origem a um aumento na velocidade da reação química.

Um mínimo de energia é necessário para a ocorrência de uma reação está associado com uma "barreira de energia" III - Lewis, Ostwald e (Ea, energia de ativação) para aquela reação.

Arrhenius (1889-1918)

O equilíbrio entre as partículas normais e ativas poderá ser deslocado com a temperatura de acordo com a equação de Arrhenius $\left(\boldsymbol{k}=\boldsymbol{A} \boldsymbol{e}^{-\mathrm{Ea} / R T}\right)$, de forma que a velocidade poderá variar com a temperatura da mesma forma $\left(\boldsymbol{v}=\boldsymbol{k} \boldsymbol{c}^{\boldsymbol{n}}\right)$.

Para uma reação de uma simples etapa, a energia de IV - Tolman, Eyring, ativação (Ea) é igual à diferença entre a energia do complexo Polanyi, e Evans (1920- ativado e a energia média das substâncias reagentes. 1935).

Quanto menor for a energia de ativação do complexo ativado, maior será a velocidade da reação.

Quadro III - Resumo das principais características dos Programas de Investigação Científica. Influência da temperatura na velocidade da reação química. 


\subsection{As Concepções sobre a Ciência}

Entende-se, neste trabalho, que no ensino de química deve existir a preocupação de mostrar a ciência aos alunos não mais como um conjunto de conhecimentos isolados, mas sim como um construto de um grupo de pessoas que tem por objetivo resolver determinados problemas de sua época. Como os cientistas constroem suas teorias e Leis? De acordo com a filosofia da ciência, não existe um método científico único que possa indicar quais são os passos que os cientistas devem dar em direção a construção de teorias e leis científicas. Vários filósofos abordam o desenvolvimento da ciência de diferentes perspectivas, propondo diferentes caminhos para a construção do conhecimento cientifico (Mellado e Carracedo, 1993).

Escolheu-se analisar a construção do conhecimento cientifico (cinética química) nos livros didáticos em estudo sob o ponto de vista de duas perspectivas filosóficas, a perspectiva empirista/indutivista e a racionalista (quadro IV).

Essas duas perspectivas foram escolhidas porque representam duas linhas bem distintas entre as perspectivas filosóficas ligadas ao entendimento da ciência. Níaz (1994) aponta que a diferença mais importante, entre as metodologias positivista/empirista e a racionalista (por exemplo, a perspectiva de Lakatos), é a idéia de que a ciência não se desenvolve em linha reta, e sim através de muitos pontos de vistas conflituosos. É somente através destes conflitos que se gera a concorrência entre programas rivais, e a ciência aumenta o poder explicativo de suas teorias. 
As características da ciência, que serão identificadas nos livros didáticos, estão relacionadas ao processo de construção das teorias científicas pelos cientistas e ao processo da troca de uma teoria por outra. Essas características, quando presentes no livro didático, podem dar uma idéia de quais tendências sobre a ciência poderão ser transmitida aos leitores. As categorias foram elaboradas a partir dos diversos trabalhos apresentados no primeiro capítulo sobre a História e a Filosofia da ciência no ensino de química. Elas são:

1-Concepção de ciência: Nesta categoria pretende-se verificar como são apresentadas as leis e as teorias científicas no material do livro didático. $\mathrm{Na}$ perspectiva racionalista, o conhecimento científico é visto como um conjunto de hipóteses que são modificáveis e que tendem a fazer uma descrição da realidade. $\mathrm{O}$ livro didático pode então, mostrar o caráter dinâmico da ciência.

Na perspectiva empirista/indutivista o conhecimento é visto como um conjunto de enunciados universais. O livro didático apresenta a ciência como um corpo de conhecimento científico formado por fatos e teorias que são considerados verdadeiros.

Como critério de análise desta categoria, procurar-se-á verificar se o livro didático apresenta a ciência como uma verdade definitiva ou como um conjunto de modelos teóricos que são utilizados até que novos modelos, com maior poder explicativo, sejam elaborados.

2- O desenvolvimento da ciência: Esta categoria está ligada à maneira pela qual os autores dos livros didáticos apresentam o desenvolvimento dos conceitos químicos. Por exemplo, na perspectiva racionalista o conhecimento científico vai aumentando seu poder explicativo, ou seja, vão surgindo modelos com explicações mais amplas, de acordo com o tempo, para um determinado fenômeno em estudo. 
Para a perspectiva empirista/indutivista somente a teoria mais atual é a verdadeira, as explicações anteriores são consideradas como erros que devem ser esquecidos. No livro didático, portanto, somente se encontra a explicação considerada pelos autores como a mais atual, não se encontrando as mudanças ou a evolução das teorias científicas.

Como critério de análise desta categoria, procurar-se-á verificar se o livro didático ilustra alguma evolução conceitual ou se apresenta apenas a explicação considerada pelos autores como a mais atual.

3- A construção do conhecimento científico: Esta categoria está relacionada ao processo de construção do conhecimento científico. Segundo Driver (1996), é o ponto de vista da visão Empirista/ Indutivista:

"O conhecimento científico é o conhecimento provado. Teorias científicas são derivadas, de um modo rigoroso, de fatos adquiridos pela observação e pela experimentação. A ciência é baseada no que nós podemos ver, ouvir, tocar, etc.".

Portanto percebe-se, nesta perspectiva, a importância dada à observação e a experimentação na elaboração do conhecimento. Segundo Lakatos (1998), para um indutivista:

"... somente estas proposições podem ser aceitas no corpo das ciências as quais, ou descrevem fatos sólidos ou são generalizações indutivas infaliveis a partir destes".

Segundo Praia e Chachapuz (1994), as correntes contemporâneas da epistemologia (por exemplo, Bachelard, Popper, Kuhn, etc.), que alguns autores denominam "nova" filosofia da ciência, defendem uma concepção, segundo o qual, o conhecimento é construído com base em teorias que orientam a observação, em outras palavras, uma observação depende da teoria. Para estes filósofos da ciência, o método científico não é entendido como uma sucessão linear de etapas, mas 
antes um processo conducente à elaboração de idéias sucessivamente mais complexas.

Nesta categoria, o livro didático, segundo Campos e Cachapuz (1997), pode apresentar as Leis e teorias utilizando-se de uma seqüência de procedimentos, por exemplo, observação-hipótese-experiência-resultados-conclusões, seguindo assim uma tendência da perspectiva empirista/indutivista, ou seguindo a tendência da perspectiva racionalista que evidencia o pluralismo metodológico na apresentação das leis e teorias científicas.

Como critério de análise desta categoria, procurar-se-á verificar como o livro didático aborda a construção do conhecimento científico, verificando também, como o livro didático descreve como um cientista procede por raciocínio indutivo ou dedutivo no processo de construção do conhecimento científico, mostrando talvez, o desenvolvimento histórico de uma idéia. 


\begin{tabular}{|c|c|c|}
\hline Categorias & empirista/indutivista & racionalista \\
\hline $\begin{array}{l}\text { 1- Concepção de } \\
\text { ciência }\end{array}$ & $\begin{array}{l}\text { Conjunto de enunciados } \\
\text { universais. }\end{array}$ & $\begin{array}{l}\text { Conjunto de hipóteses, } \\
\text { modificáveis, organizadas e que } \\
\text { tendem a fazer uma descrição } \\
\text { da realidade. }\end{array}$ \\
\hline $\begin{array}{l}\text { 2- } 0 \\
\text { Desenvolvimento } \\
\text { da Ciência }\end{array}$ & $\begin{array}{l}\text { O desenvolvimento da ciência é } \\
\text { apresentado de uma forma } \\
\text { continua e acumulativa. }\end{array}$ & $\begin{array}{l}\text { O progresso da ciência é } \\
\text { caracterizado como uma } \\
\text { "problemática progressiva" de } \\
\text { uma tentativa teórica para outra. }\end{array}$ \\
\hline $\begin{array}{l}\text { 3- A construção } \\
\text { do conhecimento } \\
\text { científico }\end{array}$ & $\begin{array}{l}\text { A partir de dados experimentais, } \\
\text { elaboram-se hipóteses e estas se } \\
\text { tornam teorias que depois se } \\
\text { tornam leis dependendo da } \\
\text { quantidade de "provas por trás da } \\
\text { idéia". } \\
\text { A observação é tida como a etapa } \\
\text { mais importante do método } \\
\text { científico. } \\
\text { O papel da experimentação é a } \\
\text { comprovação do conhecimento. } \\
\text { O papel dos cientistas é o de } \\
\text { induzir e estabelecer } \\
\text { comprovações empíricas de leis e } \\
\text { princípios. }\end{array}$ & $\begin{array}{l}\text { O conhecimento é construído } \\
\text { com base em teorias que } \\
\text { orientam a observação, em } \\
\text { outras palavras, uma observação } \\
\text { depende da teoria. } \\
\text { O método científico não é } \\
\text { entendido como uma sucessão } \\
\text { linear de etapas, mas antes um } \\
\text { processo conducente à } \\
\text { elaboração de idéias } \\
\text { sucessivamente mais } \\
\text { complexas. } \\
\text { O papel dos cientistas é o } \\
\text { estabelecer hipóteses e elaborar } \\
\text { explicações Racionais } \\
\text { (dedutivas). }\end{array}$ \\
\hline
\end{tabular}

Quadro IV - Categorias para a identificação da perspectiva filosófica adotada pelos livros didáticos. 


\subsection{Validação}

Foi realizada nesse estudo, uma validação do instrumento de análise do livro didático com o objetivo de testar a aplicabilidade das categorias elaboradas neste trabalho. Ela foi feita por três pesquisadoras, da área de ensino de química, que analisaram de maneira independente um dos livros didáticos escolhidos por esse estudo (livro 5/1946), utilizando-se primeiramente os programas de investigação científica para identificar os níveis de explicação teóricos atingidos (quadros I, II e III) e em seguida identificando quais tendências sobre a ciência que este livro pode apresentar, utilizando-se as três categorias elaboradas neste estudo (quadro IV).

Na primeira fase da análise, houve divergência em relação à explicação que o livro possuía para a influência da concentração na velocidade de uma reação. Duas, das três educadoras, concordaram que o autor do livro didático usou a lei de Guldberg-Waage a terceira escolheu a explicação do segundo programa, pois, segundo ela, o autor usa os termos ordem e molecularidade durante sua explicação.

Após discussão com as analisadoras, chegou-se a conclusão de que embora o autor use os termos ordem e molecularidade, ele não aponta no texto do livro, uma definição clara destes termos, dizendo até que em certas ocasiões é comum considerá-los como sendo iguais, e também não explica que a ordem só pode ser determinada experimentalmente, portanto, como ele mesmo coloca:

\footnotetext{
"A influência da concentração na velocidade das reações, se encontra claramente expressa na lei da ação das massas ou lei de Guldberg e Waage (1864)...." ( Livro 5, 194; 6p.372)
}

Portanto, a explicação para a influência da concentração na velocidade de uma reação química, pode ser indicada como sendo feita pela lei de Guldberg-Waage e não pelos programas de investigação científica. 
Quanto à verificação da imagem da ciência, não houve divergência entre três análises, todas apontaram que a visão de ciência que o livro apresenta está próxima da visão fornecida pela perspectiva empirista/indutivista. Seguindo-se essas orientações a análise final do livro número cinco feita pela autora deste trabalho pode ser visualizada no capítulo 4.

\section{Programas de Investigação Científica}

\begin{tabular}{clcc}
\hline & $\begin{array}{l}\text { Explicação, em } \\
\text { termos } \\
\text { microscópicos, da } \\
\text { velocidade de uma } \\
\text { reação química. }\end{array}$ & $\begin{array}{l}\text { Explicação de como a } \\
\text { velocidade de uma } \\
\text { reação química } \\
\text { depende das } \\
\text { concentrações das } \\
\text { substâncias reagentes. }\end{array}$ & $\begin{array}{l}\text { Explicação da } \\
\text { influência da } \\
\text { temperatura na } \\
\text { velocidade de uma } \\
\text { reação química. }\end{array}$ \\
\hline $\mathbf{1}$ & PIC-I & PIC-II & PIC-II \\
\hline $\mathbf{2}$ & PIC-I & GW & PIC-II \\
\hline PIC-I & GW & PIC-II \\
\hline
\end{tabular}

Tabela 3.3- Caracterização do livro didático de 1946. Nota: PIC-II: Programa de Investigação Científica de Pfaundler e Van't Hoff (1872-1888); PIC-III: Programa de Investigação Científica de Lewis, Ostwald e Arrhenius (1889-1918).

Categorias: Imagem da Ciência

\begin{tabular}{ccccc}
\hline & $\begin{array}{l}\text { 1- Concepção } \\
\text { de ciência }\end{array}$ & $\begin{array}{l}\text { 2- O Desenvolvimento } \\
\text { da Ciência }\end{array}$ & $\begin{array}{l}\text { 3- A construção do } \\
\text { conhecimento } \\
\text { científico }\end{array}$ \\
\hline $\mathbf{1}$ & $\mathrm{E} / \mathrm{l}$ & $\mathrm{E} / \mathrm{l}$ & $\mathrm{E} / \mathrm{I}$ \\
\hline $\mathbf{2}$ & $\mathrm{E} / \mathrm{l}$ & $\mathrm{E} / \mathrm{l}$ & $\mathrm{E} / \mathrm{l}$
\end{tabular}

Tabela 3.4- Concepções da ciência apresentadas pelo livro didático de 1946. Nota:

E/I=Empirista/Indutivista, $R=$ Racionalista, $N=$ Não identificado. 


\section{CAPÍTULO 4}

\section{ANÁLISE DOS LIVROS DIDÁTICOS}

\subsection{Primeiro Período (1929 à 1941)}

No final da Primeira República, em matéria educacional, poucos avanços haviam ocorrido em relação ao final do Império (Piletti e Piletti, 2002). Não havia um sistema educacional de educação, o Governo Federal nada fazia em relação ao ensino primário, que ficava ao encargo dos recursos reduzidos dos estados, e o ensino secundário continuava sendo irregular, não seriado, tendo como principal objetivo preparar os alunos para o ensino superior.

Com a revolução de 1930, alguns dos reformadores educacionais da década anterior passaram a ocupar cargos importantes na administração do ensino, procurando por em prática as idéias que defendiam. (Manifesto dos Pioneiros da Educação Nova).

Segundo Piletti e Piletti (2002), a primeira iniciativa da Revolução de 1930, no campo da educação, foi à criação do Ministério da Educação e das secretarias de educação dos estados. Para Ministro da Educação foi escolhido Francisco Campos, e para ele o ensino secundário tinha dupla finalidade: a formação geral e a preparação para o ensino superior. Assim se manifesta Francisco Campos, em sua Exposição de Motivos da Reforma (Decreto no. 19890/31):

\footnotetext{
"A finalidade exclusiva não há de ser a matrícula nos cursos superiores; o seu fim, pelo contrário, deve ser a formação do homem para todos os grandes setores da atividade nacional, construindo seu espírito todo um sistema de hábitos, atitudes e comportamentos que o
} 
habilitem a viver por si mesmo e a tomar em qualquer situação as decisões mais convenientes e mais seguras".

Em 1931, a estrutura do ensino secundário foi proposta em dois graus, com duração total de sete anos. O curso fundamental tinha duração de cinco anos, seguido de um curso complementar ou pré-universitário de dois anos. O curso complementar pretendia adaptar os candidatos aos cursos superiores e, por isso mesmo, era dividido em três ramos: para os que se destinassem aos estudos jurídicos, dava-se ênfase as matérias de humanidades; para os que pretendiam cursar medicina, farmácia e odontologia, a predominância ficava para as ciências naturais e biológicas e para os que objetivavam os cursos de engenharia e arquitetura, o estudo de matemática era fundamental.

Esta reforma de 1931, segundo Sicca (1990), prescreveu para o ensino de Química o seguinte objetivo:

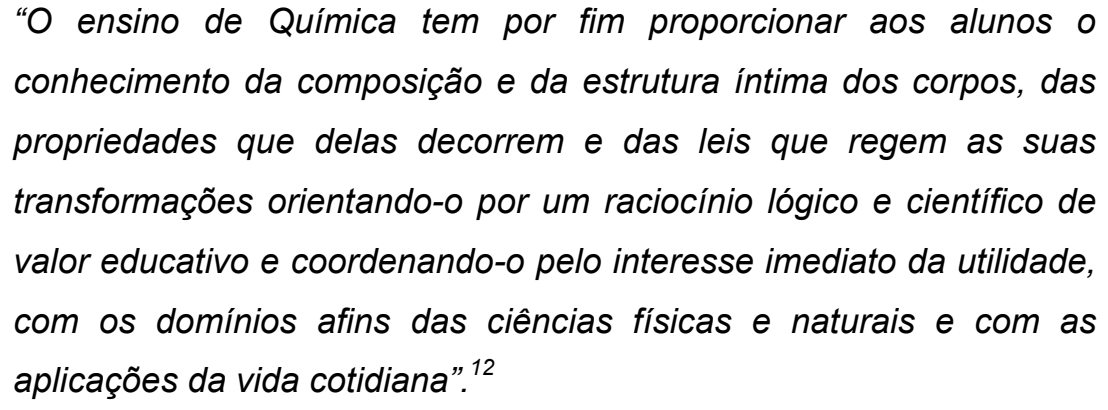

Segundo Sicca (1990), existia nessa época a recomendação de que no ensino de química, a observação de fenômenos junto com a experimentação, deveriam fazer parte do desenvolvimento dos conteúdos químicos.

\footnotetext{
${ }^{12}$ Art.10 do Decreto 19.890, de 18 de abril de 1931.
} 


\subsubsection{A análise dos livros}

Neste período de tempo serão analisados três livros didáticos, respectivamente dos anos de 1929, 1931 e 1932. Estes livros não possuem um capítulo próprio de cinética química. Neles, a velocidade de reação química encontra-se dentro do tópico relativo ao estudo das reações químicas.

Estes livros possuem um caráter enciclopédico, ou seja, apresentam as leis e teorias e os cientistas que as estabeleceram, mas não possuem atividades para os alunos realizarem como experimentos e exercícios.

\section{Livro 1- 1929.}

O conteúdo do livro é dividido em três partes. A primeira parte é destinada ao estudo das reações químicas e nele se encontra o item: "Estudo das velocidades das reações químicas e da Lei das massas ativas de Guldberg e Waage e sua demonstração analítica". Segundo o autor este livro é "destinado aos que desejam ensinar e aprender".

\section{I- Nível de explicação teórica atingido:}

\section{a- Modelo teórico que explica a velocidade de uma reação química:}

O autor explica que nas misturas gasosas, existe uma atração "recíproca" entre as moléculas, e quando elas se chocam elas podem vir a reagir quimicamente. Portanto, segundo o autor:

\footnotetext{
“... é necessário que as moléculas, se encontrem, se choquem, e a reação se processará com tanto mais velocidade quanto maior for o número total de choques úteis".(p.125)
} 
Esta explicação é coerente com a explicação dada pelo primeiro programa de investigação (quadro I), pois a velocidade seria dependente da interação (choques) entre as partículas. $\mathrm{O}$ autor, ainda apresenta que:

"Sendo as reações gasosas o resultado de choques intermoleculares, percebe-se que em virtude desta agitação e da lei do grande número de choques, ora em certo número de moléculas do sistema inicial pelo contato produzem associações moleculares correspondentes ao sistema final, ora, inversamente, se chocam se destroem para de novo formar compostos iniciais. Mas as velocidades destes sistemas não são iguais, de sorte que no fim de algum tempo, há predominância de um sistema sobre outro. Se as velocidades fossem iguais, haveria equilibrio".(p.125)

Está presente no livro didático a idéia de que as velocidades de formação de produtos e do consumo dos reagentes são iguais somente quando o sistema encontra-se em equilíbrio. Para o autor:

"Essas são noções gerais novas, desconhecidas da química clássica e que permitem tirar duas lições: A primeira é que: "num sistema químico há simultaneamente formação e destruição dos produtos da reação,e a segunda é que prova-se que a velocidade de uma reação, isto é, o quociente da quantidade transformada pelo tempo gasto para efetuar esta transformação, não é uma constante. Esta velocidade é análoga a velocidade média que se considera em mecânica." (p.125)

O autor menciona ainda que:

"Essas noções não fornecem conhecimentos precisos sobre o
movimento nas reações, e sobre a evolução química de um sistema,
podendo-se dizer apenas que a velocidade é maior no inicio do que
no final de uma reação. Para se ter uma indicação completa é
necessário raciocinar, como em mecânica, sobre a velocidade
instantânea".(p.126)

$\mathrm{O}$ autor procura fazer um paralelo com o conceito de velocidade dado pela Física, embora se trate de conversões/transformações e não de espaço por umidade de tempo. Deve ser notado que o autor ressalta a "novidade" do assunto. Talvez a 
idéia de "evolução química" tenha aproximação com a idéia de mecanismo ou curso de uma reação.

\section{b- A Influência da concentração sobre a velocidade:}

A influência da concentração na velocidade de uma reação é explicada pelo autor através da lei de Guldberg e Waage. A Lei da ação das massas é apresentada da seguinte forma para se poder calcular a velocidade instantânea de uma reação:

\footnotetext{
"A velocidade de evolução de um sistema de corpos é proporcional ao produto das massas ativas dos componentes do sistema...... No equilíbrio as velocidades de transformação dos dois sistemas são iguais."
}

O conceito de massa ativa se refere à quantidade de moléculas que se chocam durante a reação. Não há referência a constante de velocidade, ficando a velocidade somente dependente das massas ativas das substâncias que reagem.

Não se encontram neste livro, explicações sobre a influência da temperatura na velocidade de uma reação química.

\section{II- Características da ciência. Categorias:}

1-Concepção de ciência: O autor apresenta no livro que: "uma lei fundamental domina a cinética química que é a lei da ação das massas ou lei de Guldberg e Waage". Não são mencionadas no texto limitações ou exceções ao uso desta lei ficando a imagem de que ela pode ser aplicada a qualquer reação química, sendo, portanto apresentada como uma lei universal. O trecho do parágrafo onde o autor diz que: "Essas são noções gerais novas, desconhecidas da química clássica..." enfatiza a idéia uma teoria geral válida para o entendimento de todas reações químicas, o que pode revelar uma imagem da ciência coerente com a fornecida pela perspectiva empirista/indutivista. 
2- O desenvolvimento da ciência: A lei de Guldberg e Waage é apresentada no livro didático como um novo conhecimento da química clássica. $\mathrm{O}$ autor do livro não indica no texto qual era o conhecimento anterior que se tinha a respeito do estudo da velocidade de uma reação química. Essa idéia de que somente o conhecimento mais atual seja verdadeiro pode ser coerente com as idéias da perspectiva filosófica empirista/indutivista.

3- A construção do conhecimento científico: A Lei da ação das massas, segundo o livro didático, foi obtida através da observação de determinadas reações químicas. Portanto a lei foi obtida pela análise dos dados obtidos pela experimentação. Essa importância dada à observação, no processo de construção de uma lei, pode demonstrar uma tendência emprirista/indutivista do livro didático na forma de se apresentar à construção do conhecimento científico.

O conhecimento cientifico apresentado no livro didático é coerente com os estudos cinéticos iniciais, ou seja, os primeiros estudos empíricos onde se tinha a preocupação de estudar quantitativamente a influência da concentração na velocidade de uma reação química.

Pode-se observar, pela análise das categorias da ciência, que este livro didático parece apresentar uma tendência voltada à perspectiva empirista/indutivista, mas, faz-se necessário lembrar, que esta perspectiva filosófica é a que era aceita neste período de tempo. 


\section{Livro 2- 1931.}

Este livro é destinado ao ensino secundário, e segundo as palavras do autor:

"Estes apontamentos de Chimica Geral representam as lições dadas a nossos alunos do magistério particular".

O livro não é estruturado na forma de capítulos, mas sim, como diz o nome, na forma de apontamentos. $\mathrm{O}$ apontamento que se refere ao estudo das velocidades de uma reação química é o de número 684 .

\section{I-Nível de explicação teórica atingido:}

Não se encontra neste livro, uma teoria que explique a velocidade de uma reação química em termos microscópicos. A preocupação do autor está em demonstrar a influência de determinados fatores na velocidade de uma reação, mas sem a preocupação de explicar essa influência em ternos microscópicos.

\section{b- A Influência da concentração sobre a velocidade:}

O autor explica a velocidade de uma reação química através do estudo de Lemoine, de 1877. Segundo o autor do livro, Lemoine em 1877, estudando rigorosamente formação de $\mathrm{HI}$ concluiu que: "A velocidade da reação é devida à mudança de concentração de um dos reagentes ou componentes do sistema na unidade de tempo". Concluindo ainda que:

\footnotetext{
"A velocidade das reações é igual ao produto das concentrações pelo coeficiente de velocidade." E que "o estudo deste coeficiente de velocidade está ligado diretamente ao estudo das equações reversiveis." (p.264).
}

Pode-se supor que esta relação entre velocidade e concentração, proposta pelo autor, seja coerente com a explicação do primeiro programa de investigação (Wilhelmy, Harcourt, Esson e Berthelot,1850-1865), onde a velocidade da reação é proporcional a quantidade de partículas que estão reagindo num dado tempo. 


\section{c- A influência da temperatura:}

Segundo o autor, Lemoine, observou que para cada temperatura a quantidade de produtos da reação é função do tempo. Portanto, o aumento ou a diminuição da temperatura de uma reação química pode alterar a velocidade desta:

"Lemoine, observou que ......o aumento ou a diminuição da temperatura de uma reação química pode alterar a velocidade desta." (p265.)

Portanto, observa-se que embora o autor do livro coloque que a variação da temperatura altera o valor da velocidade de uma reação química, não é proposto um modelo teórico, que explique essa relação entre a temperatura e a velocidade. Podese então dizer que esta ausência de explicação é coerente com o primeiro programa de investigação científica (Wilhelmy, Harcourt, Esson e Berthelot;1850-1865), onde não se tinha ainda um conhecimento de como era a influência da temperatura na velocidade de uma reação química.

O autor para discutir o efeito da temperatura na velocidade de uma reação se baseia em um artigo de 1877, época onde os estudos com a temperatura não estavam estabelecidos, sendo que no ano da edição desse livro (1929), já eram conhecidos os estudos de Arrhenius (1889).

\section{II- Características da ciência. Categorias:}

1-Concepção de ciência e 2- O desenvolvimento da ciência: Estas categorias não foram identificadas no livro didático. O livro não apresenta leis e teorias ligadas ao estudo da velocidade de uma reação química.

3-A construção do conhecimento científico: pode-se observar como o cientista chega ao conhecimento científico: 
"Lemoine em 1877 estudou rigorosamente a formação de HI.... concluiu: para cada temperatura a quantidade de produtos da reação é função do tempo" (p 265.)

Portanto, tem-se a idéia de que através do estudo rigoroso de um experimento, pode se chegar a uma conclusão caracterizando assim uma visão empirista/indutivista da construção do conhecimento científico.

O fato de o autor trabalhar com o conteúdo químico na forma de apontamentos parece que não permitiu ao autor explorar o desenvolvimento da ciência.

\section{Livro 3- 1932.}

Segundo o autor, esse livro segue a divisão da química que é: $1^{\mathrm{a}}$. Química Geral; 2a . Química dos metalóides; $3^{\mathrm{a}}$. Química dos metais, e $4^{\mathrm{a}}$. Química Orgânica. Encontrou-se, neste trabalho, a terceira edição deste livro, do ano de 1939, mas o conteúdo relativo ao estudo das velocidades das reações químicas continuava sendo o mesmo do livro do ano de 1932.

Segundo o autor este livro é destinado:

$$
\begin{aligned}
& \text { "Aos alunos de preparatórios das carreiras de ciências nas } \\
& \text { universidades como para aqueles que começam a estudar a química } \\
& \text { no ginásio, seminários, escolas normais, etc". }
\end{aligned}
$$

\section{I- Nível de explicação teórica atingido:}

Neste livro o conteúdo sobre cinética química aparece inserido no capítulo "Estudo sobre a reação química".

a- Modelo teórico que explica a velocidade de uma reação química: 
O autor aponta que a afinidade pode influir na velocidade de uma reação química e esta é definida como sendo a força seletiva de união que há entre os elementos. A afinidade está relacionada à força de atração que uma partícula exerce sobre a outra. Não há indicação que haja a necessidade de interação, ou choque entre as partículas reagentes e que a velocidade dependa desta interação.

A idéia de afinidade já não era mais utilizada pelos químicos nessa época (1932).

\section{b- A Influência da concentração sobre a velocidade:}

No livro aparece a seguinte definição para a velocidade de uma reação:

"Chama-se velocidade das reações a relação entre a quantidade de substância que se produz na reação e o tempo gasto para produzi-la. Esta relação costuma-se representar pela expressão matemática: $V=m / t$ na qual, $m$ representa a massa transformada e to tempo empregado na transformação." (p.12)

Pode-se dizer então, que esta relação é coerente com a conclusão que Wilhelmy (PIC-I), chegou em sua pesquisa, porque não há referencia a constante de velocidade, sendo a velocidade dependente somente da massa da substancia reagente.

Não se encontram neste livro explicações sobre a influência da temperatura.

\section{II- Características da ciência. Categorias:}

1-Concepção de ciência: A definição da velocidade é representada por uma expressão matemática, como uma regra geral, novamente, como no livro de 1929, sem exceções ao seu uso, isso pode levar o leitor a construir uma concepção de ciência com tendências empiristas/indutivistas. 
2- O desenvolvimento da ciência: Não se identificou esta categoria no livro didático.

3- A construção do conhecimento científico: $O$ autor descreve no livro que os fatores que podem modificar as reações podem ser observados através de exemplos de determinadas reações químicas. É dada como exemplo a reação do gás cloro com o gás hidrogênio, a qual a luz pode favorecer a reação. Nota-se no livro didático uma grande valorização do trabalho experimental, como se fosse o único modo possível de se obter o conhecimento científico, apresentando assim tendências empiristas/indutivistas. 


\section{Discussão}

Pode-se observar que os livros didáticos deste primeiro período não apresentam uma explicação em termos energéticos da velocidade de uma reação química, e quando eles propõem uma explicação, esta é condizente com a apresentada pelo primeiro programa (Programa de Investigação Científica de Wilhelmy, Harcourt, Esson e Berthelot, 1850-1865), ou seja, que a velocidade depende da quantidade de partículas que estão participando de uma reação química. A identificação dos programas de investigação científica nos livros didáticos, deste período, pode ser visualizada na tabela 4.1..

Não há nenhuma referência à teoria da colisão, embora ela tenha sido desenvolvida entre 1916 e 1918, portanto aproximadamente 15 anos antes da publicação dos livros analisados desse período, o que se pode considerar que é um intervalo muito pequeno de tempo para que houvesse uma adaptação deste conhecimento científico para estes livros que eram destinados ao ensino médio.

Para explicar a interação entre partículas se encontra no livro de 1932 a idéia de afinidade química. Esta idéia de força seletiva de união (afinidade) surgiu no século dezessete, quando R. Boyle e I. Newton, entre outros, propuseram a idéia de que a matéria era constituída de pequenas partículas invisíveis (Laidler, 1993). A reação química era então entendida como um processo no qual partículas elementares interagem com outras como resultado de suas afinidades químicas. Esta foi a primeira vez, segundo Justi e Gilbert (1999) que a origem de uma "força" que provoca uma reação química foi vista para ser relacionada com as características das partículas, ou originadas delas. No começo do século dezenove a idéia de afinidade foi sendo substituída pela idéia de interação, portanto uma reação química ocorreria devido à interação das partículas que estão reagindo. 
Em relação à explicação da influência da temperatura na velocidade de uma reação química, não há ainda, em nenhum dos livros analisados, um modelo teórico que possa explicar essa influência, embora já apareça a idéia de que ela pode influenciar na velocidade (livro 2 de 1931).

Nota-se nos livros didáticos desse período de tempo, que na transposição didática não foi levado muito em consideração o conhecimento químico que já estava consolidado e aceito pela comunidade científica. $\mathrm{Na}$ tabela 4.1 pode-se observar a quase total ausência de modelos explicativos tanto para a velocidade de uma reação como para a influência da temperatura na velocidade. Esses livros didáticos não possuem um capitulo de cinética química o que pode refletir a pouca importância desse conhecimento na época da edição desses livros.

Analisando-se os livros através das categorias referentes às concepções da ciência, pode-se observar que os livros didáticos deste período apresentam uma imagem predominantemente empirista/indutivista da ciência (tab.4.2), principalmente no que se refere à construção do conhecimento científico (metodologia) e ao desenvolvimento da ciência, o que era esperado, pois esse era o paradigma que predominava nesse período de tempo. O conteúdo químico no livro didático é apresentado através da exemplificação dos trabalhos dos cientistas, onde se percebe uma grande valorização no papel da observação e da experimentação na construção do conhecimento científico:

\footnotetext{
"Lemoine em 1877 estudou rigorosamente a formação de HI.... concluiu: para cada temperatura a quantidade de produtos da reação é função do tempo" ('1931,p 265.)
}

Outra característica dos livros didáticos deste período é que eles parecem ser destinados para uso como fonte de consulta, onde o conhecimento científico é apresentando na forma de relatos como se fossem a descrição dos trabalhos dos 
próprios cientistas, não possuindo exercícios e experimentos dirigidos ao aluno. Portanto, pode-se dizer que estes livros enfatizam uma imagem da química que Schenetzler (1980), chama de "ciência de receita".

O livro 2 parece seguir a proposta da Reforma Francisco Campos (1931), que estipula que o ensino médio tem o objetivo de preparar os alunos para uma carreira no ensino superior:

$$
\begin{aligned}
& \text { "Aos alunos de preparatórios das carreiras de ciências nas } \\
& \text { universidades como para aqueles que começam a estudar a química } \\
& \text { no ginásio, seminários, escolas normais, etc". }
\end{aligned}
$$

Sendo que os livros de 1929 e de 1931, que foram publicados antes e no ano da reforma Francisco Campos de 1931, são destinados aos alunos que querem seguir a carreira do magistério:

\footnotetext{
“Este livro é destinado aos que desejam ensinar e aprender".(1929)

"Estes apontamentos de Chimica Geral representam as lições dadas a nossos alunos do magistério particular".(1931)
}

Percebe-se então que os objetivos destes três livros são o de auxiliar na formação profissional do aluno e/ou prepará-lo para o ensino superior, o que estaria em acordo com os objetivos para o ensino médio propostos pela reforma Francisco Campos (1931). 


\begin{tabular}{l|lll}
\hline \multirow{2}{*}{\begin{tabular}{l} 
Livros \\
Didáticos/ \\
\cline { 2 - 4 } Ano
\end{tabular}} & $\begin{array}{l}\text { Explicação, em } \\
\text { termos } \\
\text { microscópicos, } \\
\text { da velocidade de } \\
\text { uma reação } \\
\text { química. }\end{array}$ & $\begin{array}{l}\text { Explicação de como a } \\
\text { velocidade de uma reação } \\
\text { química depende das } \\
\text { concentrações das } \\
\text { substâncias reagentes. }\end{array}$ & $\begin{array}{l}\text { Explicação da } \\
\text { influência da } \\
\text { temperatura na } \\
\text { velocidade de uma } \\
\text { reação química. }\end{array}$ \\
\hline \multirow{2}{*}{$2 / 1931$} & PIC-I & GW & A \\
\cline { 2 - 4 } $3 / 1932$ & PIC-I & PIC-I & PIC-I \\
\cline { 2 - 4 } & PIC-I & A \\
\hline
\end{tabular}

Tabela 4.1- Caracterização dos livros didáticos do primeiro período(1929-1932). Nota: PIC-I: Programa de Investigação Científica de Wilhelmy, Harcourt, Esson e Berthelot (1850-1865); PIC-II: Programa de Investigação Científica de Pfaundler e Van't Hoff (1872-1888); GW: indica o uso da Lei de Guldberg-Waage; A= indica a ausência da explicação teórica no livro didático.

\begin{tabular}{c|ccc}
\hline & \multicolumn{4}{|c}{ Categorias } \\
\hline $\begin{array}{c}\text { Livros } \\
\text { Didáticos/Ano }\end{array}$ & $\begin{array}{c}\text { 1- Concepção } \\
\text { de ciência }\end{array}$ & $\begin{array}{c}\text { 2- O Desenvolvimento } \\
\text { da Ciência }\end{array}$ & $\begin{array}{c}\text { 3- A construção do } \\
\text { conhecimento científico }\end{array}$ \\
\hline \multirow{2}{*}{$2 / 1929$} & $\mathrm{E} / \mathrm{l}$ & $\mathrm{E} / \mathrm{l}$ & $\mathrm{N}$ \\
\cline { 2 - 4 } $2 / 1931$ & $\mathrm{~N}$ & $\mathrm{~N}$ & $\mathrm{E} / \mathrm{l}$ \\
\cline { 2 - 4 } $3 / 1932$ & $\mathrm{E} / \mathrm{l}$ & $\mathrm{N}$ & $\mathrm{E} / \mathrm{l}$ \\
\hline
\end{tabular}

Tabela 4.2- Concepções da ciência apresentadas pelos livros didáticos do primeiro período

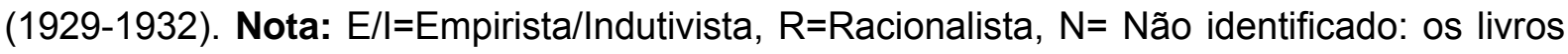
didáticos não fazem menção explicita a qualquer uma das duas interpretações. 


\subsection{Segundo período (1942 à 1960)}

Esse período se refere à vigência da reforma educacional Gustavo Capanema, então Ministro da Educação e Saúde do governo de Getúlio Vargas, que implantou a Lei Orgânica do ensino secundário, número 4.244 de nove de abril de 1942.

Segundo Piletti e Piletti (2002), a lei de 1942, em seu $1^{\circ}$. Artigo estabeleceu os seguintes objetivos para o ensino secundário: "Formar... a personalidade integral dos adolescentes; acentuar e elevar... a consciência patriótica e a consciência humanística; dar preparação intelectual geral que possa servir de base a estudos mais elevados de formação especial".

A estrutura do ensino secundário em 1942 continuou sendo, como no período anterior, dividida em dois graus, mas com a duração modificada: um curso ginasial de quatro anos sucedia um curso colegial de três anos, que perdeu o seu caráter quase exclusivo de preparatório para o curso superior e passou a preocupar-se mais com a formação geral. O curso colegial dividia-se em dois ramos, o colegial clássico e o colegial científico. (Piletti e Piletti, 2002).

Segundo Villani (et al, 2005), durante a década de 1950, a escola secundária no Brasil era considerada "um instrumento de ascensão social: o exame de admissão funcionava como um rito de passagem, praticamente como é o nosso atual vestibular", portanto, isso pode justificar o grande aumento na procura pelo ensino secundário, em especial ao colegial científico.

Em relação ao ensino de química, o pensamento oficial, era que: "O ensino deveria cumprir sua "finalidade educativa de particular interesse, a formação do espírito científico", além de propiciar a aquisição dos conhecimentos que constituem esta ciência e suas aplicações na vida corrente( Sicca, p.58;1990)". 
A realização desses objetivos tinha como condição essencial, segundo Sicca (1990):

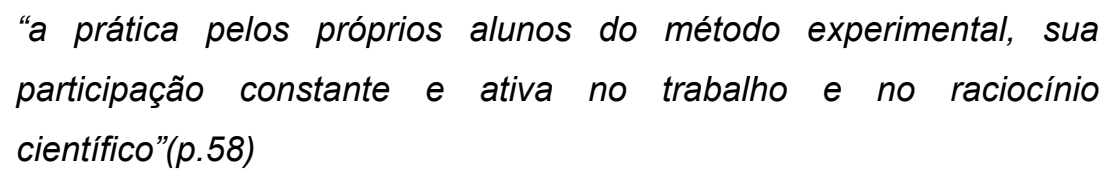

Portanto, pode-se perceber que a experimentação no ensino de química passa a ter uma função educativa.

\subsubsection{A análise dos livros}

A este período pertencem cinco livros didáticos (1942, 1946, 1954, 1955 e 1959). Esses livros didáticos, diferentemente daqueles livros do primeiro período, já começam a apresentar na sua estrutura um capítulo dirigido ao estudo da velocidade das reações químicas, mas somente dois livros (1955 e 1959), que são do mesmo autor, Luciano Francisco Pacheco do Amaral, possuem alguns exercícios dirigidos aos alunos, no final do capítulo de cinética química.

\section{Livro 4- 1942.}

Esse livro não possui uma apresentação nem carta ao leitor, portanto não foi possível identificar qual é a proposta didática do autor.

Esse livro possui um capitulo voltado para a o estudo da velocidade de reações químicas denominado "Velocidade das reações. Fatores que modificam a velocidade das reações".

Segundo o autor a cinética química é à parte da química que estuda a velocidade das reações. Onde a velocidade é: 


$$
\begin{gathered}
V_{m}=x / T \\
V=\lim v_{m}=d x / d t
\end{gathered}
$$

Onde $T$ é o tempo (p. 89). Observa-se o uso de uma equação diferencial no cálculo da velocidade, ao invés de se utilizar à idéia de velocidade média.

\section{I- Nível de explicação teórica atingido:}

\section{a- Modelo teórico que explica a velocidade de uma reação química:}

O autor para explicar em termos microscópicos a velocidade de uma reação coloca que:

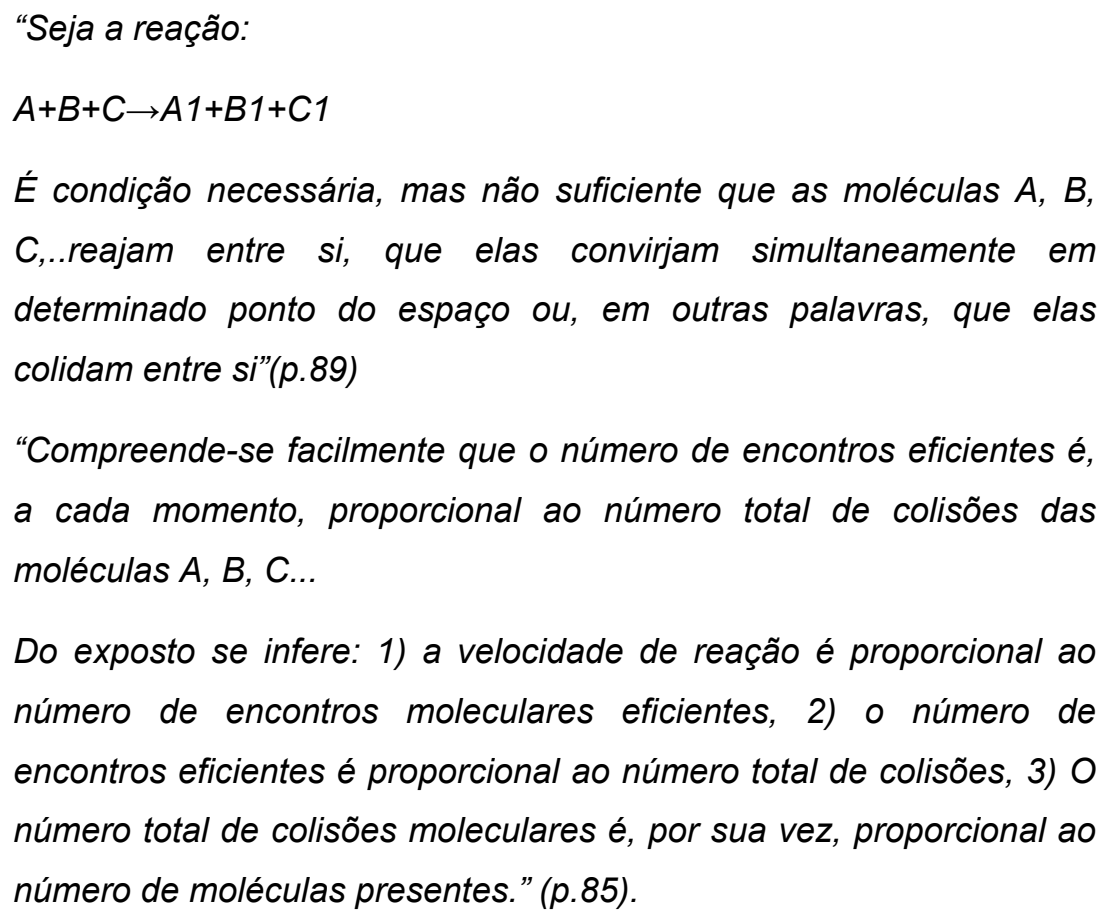

Essa explicação é coerente com a explicação do primeiro programa (Wilhelmy, Harcourt, Esson e Berthelot;1850-1865), onde a velocidade de uma reação química depende do número de encontros moleculares. O autor não indica a necessidade das moléculas possuírem um mínimo de energia para que elas possam colidir entre si, o que já era levado em consideração na teoria das colisões proposta por Lewis. 
Percebe-se aqui que o autor já avança um pouco mais no modelo explicativo, pois tenta dar uma explicação para o fato de ocorrerem colisões, instiga a pensar mais sobre fatores que podem interferir, além de se preocupar com a afinidade das partículas, avançando no nível microscópico, apresentando, portanto um pensamento mais abstrato.

\section{b- A Influência da concentração sobre a velocidade:}

A lei de Guldberg e Waage é usada, pelo autor, para explicar o efeito da concentração na velocidade de uma reação:

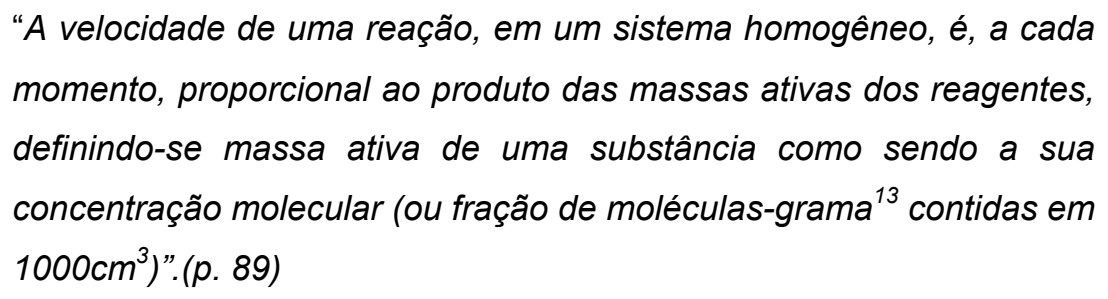

Segundo o autor, esta lei, estabelecida em 1867, por Guldberg e Waage, denominada lei da ação das massas, pode ser enunciada do seguinte modo:

\footnotetext{
"A velocidade de uma reação é, a cada instante proporcional a uma constante, própria da reação em determinadas condições experimentais, e ao produto das concentrações dos reagentes, cada uma delas elevada à potência correspondente ao número de moléculas com que o respectivo reagente figura na equação." ( $p .89)$

"Sendo então a reação: $m A+n B \rightarrow p C$

em que $m, n$ e $p$ são os coeficientes moleculares da reação. $A$ velocidade dessa equação é, em um dado instante:$$
V=k c(A)^{m} \cdot c(B)^{n}
$$

onde $k$ é denominado coeficiente de velocidade, que depende principalmente da própria reação, isto é, da natureza das substâncias reagentes." (p.89).
}

Para o autor os coeficientes $m$ e $n$, da equação da velocidade correspondem ao número de moléculas que participam da reação (molecularidade), não os

\footnotetext{
${ }^{13}$ Molécula-grama ou massa molar é a massa, em gramas, de $6,02 \times 10^{23}$ moléculas de substância.
} 
relacionando com a ordem de uma reação química, que seria determinada experimentalmente.

\section{c- A influência da temperatura:}

O autor afirma que a experiência mostra que a variação de temperatura exerce grande influência sobre a velocidade da reação:

"Van't Hoff afirma que um aumento de $10^{\circ} \mathrm{C}$ na temperatura de um sistema químico, duplica, e às vezes triplica a velocidade da reação." (p.90).

Não há no trabalho de Van't Hoff nenhuma citação referente a essa regra que relaciona a temperatura com a velocidade da reação (Justi ,1997). Portanto, pode-se dizer que se tentou resumir a investigação experimental de Van’t Hoff, sobre o efeito da temperatura na velocidade de uma reação química, a uma regra simples que pode ser aplicada a qualquer reação química.

Para explicar o efeito da temperatura na velocidade, o autor escreve:

"A principio, procurou-se atribuir a influência da temperatura sobre a velocidade das reações ao aumento do número de encontros moleculares que, de acordo com a teoria cinética, toda elevação de temperatura provoca. Contudo, a comparação dos dados da teoria cinética, com os resultados obtidos no estudo da velocidade das reações, mostra-nos que esta explicação é insuficiente. Deve-se antes admitir que a elevação da temperatura aumenta, não somente o número de encontros moleculares, como a própria proporção de encontros moleculares eficientes. Em outras palavras, a elevação da temperatura ativa às moléculas, isto é, aumenta as suas possibilidades de reação". (p.90).

"A elevação da temperatura afrouxa, até romper, a união que mantêm os átomos na estrutura da molécula, facilitando, conseqüentemente, a formação de novas moléculas". (p.90).

Portanto, esta explicação é coerente com a explicação dada pelo segundo programa de investigação científica (Pfaundler e Van't Hoff;1872-1888) no qual 
assume-se que um aumento de temperatura causa um acréscimo na freqüência de colisões de moléculas reativas, o que dá origem a um aumento na velocidade da reação química.

Neste livro, aparece a idéia de que existe uma "união" que mantêm os átomos na estrutura da molécula, sendo que este termo união, já se aproxima um pouco mais da idéia de ligação química, do que o termo "associação molecular", utilizado pelo livro 1 (1929):

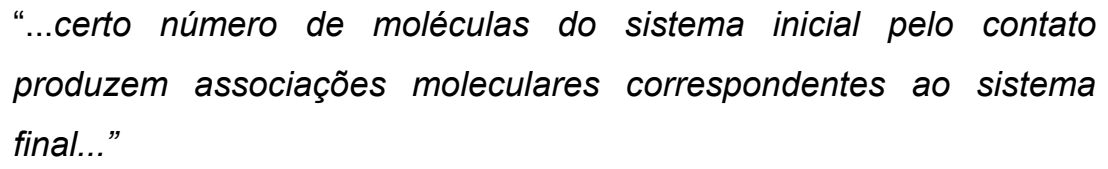

\section{II- Características da ciência. Categorias:}

1-Concepção de ciência: apresentada no livro é coerente com a perspectiva empirista/indutivista, A lei de Guldbeg-Waage, e a regra de Vant Hoff, são apresentadas como sendo enunciados universais, não se apresentando os limite de seus usos, não havendo indicações que são modelos teóricos elaborados para descrever uma determinada realidade que pode ser modificada com o tempo.

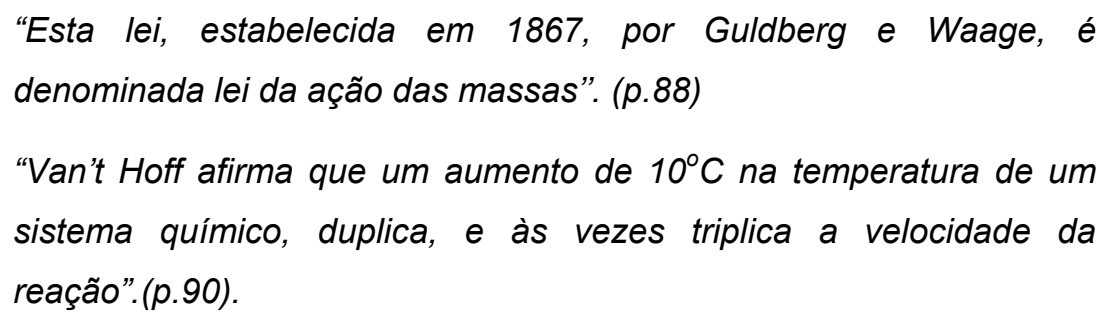

2- O desenvolvimento da ciência: No livro didático, somente se encontra a explicação considerada pelos autores como a mais atual (lei de Guldberg-Waage), não se encontrando as mudanças ou a evolução das teorias científicas, indicando assim tendências empiristas/indutivistas no desenvolvimento da ciência. 
3- A construção do conhecimento científico: Para explicar o efeito da temperatura o autor usa a regra de Van't Hoff, que foi obtida através da observação de dados experimentais. Portanto, o papel do cientista parece ser o de partir de dados experimentais e propor regras e teorias, indicando uma concepção empirista/indutivista da construção do conhecimento científico.

\section{Livro 5- 1946.}

Este livro é destinado à terceira série do curso do colegial científico. Este livro não possui uma apresentação nem carta ao leitor, portanto não foi possível identificar qual é a proposta didática do autor. A única nota colocada pelo autor é: “Uso autorizado pelo Ministério da Educação e Saúde, registro no. 1653”.

Segundo o autor do livro "a cinética química é a parte da química que trata da velocidade das reações" (p. 367).

\section{I- Nível de explicação teórica atingido:}

\section{a- Modelo teórico que explica a velocidade de uma reação química:}

O autor coloca que o equilíbrio esta "intimamente ligado à velocidade das reações" e por isso o estudo do equilíbrio químico encontra-se no capítulo referente à cinética química. A velocidade de uma reação é definida como:

“...o número de mols de uma substância que desaparece ou se forma numa reação, durante a unidade de tempo; é pois, o resultado que se obtém dividindo a diminuição da concentração dos reagentes, durante um certo tempo, por esse tempo." (p.367).

Portanto, oberva-se que a velocidade é definida através de uma relação matemática. Embora o autor não utilize modelos explicativos para explicar a 
velocidade em termos microscópicos, ele indica que a velocidade depende da concentração dos reagentes, portanto esta explicação é coerente a com a do primeiro programa de investigação científica (Wilhelmy, Harcourt, Esson e Berthelot;1850-1865).

\section{b- A Influência da concentração sobre a velocidade de uma reação:}

Segundo o autor:

"A influência da concentração na velocidade das reações, se encontra claramente expressa na lei da ação das massas ou lei de Guldberg e Waage (1864), que pode ser enunciada da seguinte maneira: a velocidade de uma reação é proporcional a concentração molecular de cada um dos reagentes." (p.372)

No texto do livro, a velocidade de uma reação é expressa da seguinte forma:

"V= ka em que a representa a concentração molecular dos reagentes e $k$ uma grandeza constante chamada constante de reação ou constante de velocidade."

"Generalizando, suponhamos a reação:

$n A+n_{1} A_{1}+n_{2} A_{2}+\ldots \ldots \ldots \rightarrow m B+m_{1} B_{1}+m_{2} B_{2}+\ldots$

em que reagem na $=n 1 a n, n 2 a 2 \ldots$. mols de $A$ de $A_{1}$, de $A_{2}$, etc,

De acordo com a Lei da ação das massas

$V=k a^{n} \cdot a_{1}^{n 1} \cdot a_{2}^{n 2} \cdots$

Portanto, de acordo com a lei de ação das massas, a velocidade de uma reação química é proporcional ao produto das concentrações moleculares dos reagentes, cada concentração sendo elevada à potência numericamente igual ao coeficiente dessa substância na equação que representa a reação." (p.372).

O autor apresenta que existe uma distinção entre o termo ordem e molecularidade de uma reação:

"A molecularidade de uma reação informa qual o número de moléculas que tomam parte em cada ato que conduz a reação, enquanto que a ordem de uma reação mostra qual o número de moléculas cujas concentrações determinam a velocidade da reação.” 
“......Portanto, da equação estequiométrica de uma reação nem sempre se pode concluir qual sua verdadeira ordem e molecularidade; só a experiência permite certificar-se a respeito. Todavia, é usual se proceder considerando molecularidade e ordem como idênticas, mas quando necessário, apontando a diferença e se possivel, explicando-a." (p.374)

$\mathrm{Na}$ época que esse livro foi publicado, já se sabia que a ordem e a molecularidade de uma reação eram conceitos distintos e que a ordem de uma reação só poderia ser determinada experimentalmente, mesmo assim o autor escreve que "é usual se proceder considerando molecularidade e ordem como idênticas...".

Aparece neste livro, uma explicação das etapas de uma reação relacionadas com a ordem dessa reação:

\begin{abstract}
"Numa reação que se processa por etapas a velocidade da reação que se dá com maior lentidão é a que determina a ordem daquela reação e como etapas lentas são praticamente sempre as reações das 3 primeiras ordens, são pouco freqüentes reações de ordem superior". (p.375)
\end{abstract}

Embora o autor indique que uma reação química pode ocorrer em mais de uma etapa, ele explica a influência da concentração na velocidade de uma reação usando a lei da ação das massas (Guldeberg-Waage).

\title{
c- A influência da temperatura:
}

O autor escreve que:

"A velocidade das reações, em quase todas, aumenta com a temperatura, fato que pode ser observado nas reações não reversíveis, onde a velocidade de uma reação inversa não intervém para complicar o fenômeno".

Para o autor, o efeito da temperatura só é evidente nas reações irreversíveis. 
"Os fatos mostram que nas reações químicas ordinárias, um aumento de $10^{\circ} \mathrm{C}$ faz com que a velocidade da reação seja multiplicada por um coeficiente compreendido entre 2 e 4 (coeficiente de temperatura)." (p.369.)

A regra acima é conhecida como a regra de Van`t Hoff. Novamente, como no livro anterior (1942), aparece esta tentativa de relacionar, através de uma regra, a temperatura com a velocidade.

Como a temperatura influi na velocidade? Segundo o autor do livro didático:

"Pensou-se que o efeito da temperatura sobre a velocidade das
reações poderia ser devido a um incremento na energia cinética das
moléculas e conseqüentemente maior número de colisões, mas esse
incremento... é incomparavelmente menor do que a variação
observada na velocidade da reação".
"Goldschimidt e Arrhenius formularam a hipótese de que num
sistema químico devem ser distinguidas as moléculas ordinárias ou
inativas e as moléculas ativas, as únicas que tomam parte no
fenômeno e cujo número cresce com a temperatura".(p.370).

Portanto, as moléculas ativas seriam as que possuíam um incremento de energia necessário para que conseguissem reagir. Essa explicação é coerente com a do segundo programa (Pfaundler e Van't Hoff,1872-1888), onde se assume que um aumento de temperatura causa um acréscimo na freqüência de colisões de moléculas reativas, o que dá origem a um aumento na velocidade da reação química.

\section{II- Características da ciência. Categorias:}

1-Concepção de ciência: $O$ autor apresenta o conhecimento cientifico no livro como um conjunto de leis e enunciados universais:

\footnotetext{
"A influência da concentração na velocidade das reações, se encontra claramente expressa na lei da ação das massas ou lei de Guldberg e Waage (1864)".
} 
Essa forma de representar a ciência é coerente com a perspectiva empirista/indutivista

2- O desenvolvimento da ciência: Embora o autor descreva as tentativas anteriores de se explicar o efeito da temperatura, na velocidade de uma reação, no texto em geral a perspectiva filosófica que ele apresenta é a empirista/ indutivista.

3- A construção do conhecimento científico: Quando o autor se refere aos fatores que intervem na velocidade da reação, é possível perceber que as teorias são derivadas de fatos experimentais. Assim, a partir da observação de fatos experimentais, elaborou-se uma regra que relaciona a temperatura com a velocidade de uma reação. Portanto, pode-se dizer que a perspectiva filosófica que é coerente com esse tipo de abordagem, na construção do conhecimento cientifico, é a perspectiva empirista/indutivista.

\footnotetext{
"Os fatos mostram que nas reações químicas ordinárias, um aumento de $10^{\circ} \mathrm{C}$ faz com que a velocidade da reação seja multiplicada por um coeficiente compreendido entre 2 e 4 (coeficiente de temperatura)".(p.369).
}

Nota-se que esse autor, avança em relacionar a velocidade com a idéia de equilíbrio, o que demonstra uma preocupação maior com o pensar do aluno, ou seja, ele extrapola a idéia e começa a relacionar os conceitos, mesmo que impregnado de idéias empiristas. Mas, também se observou que ele apresenta muitos conceitos sem se reportar ao desenvolvimento desses, dando a impressão que tais conceitos foram apresentados aos alunos como regras gerais.

\section{Livro 6-1954.}


Este livro não possui uma apresentação nem carta ao leitor, portanto não foi possível identificar qual é a proposta didática do livro. Mas o autor coloca que o livro esta de acordo com os novos programas, conforme portaria No. 966 de 2/10/51 1 1045 e 14/12/51.

O capitulo de cinética química está, segundo os autores, incluído no programa oficial do terceiro ano científico, e é denominado "Cinética das Reações; conceito de velocidade de reação,fatores que a influenciam. Catálise". Segundo os autores, a cinética Química: "é a parte da química que estuda a velocidade das reações e os fatores que nela influem."(p.363).

\section{I- Nível de explicação teórica atingido:}

\section{a- Modelo teórico que explica a velocidade de uma reação química:}

No livro não há uma explicação teórica, em termos microscópicos, para a velocidade de uma reação. A velocidade é definida como:

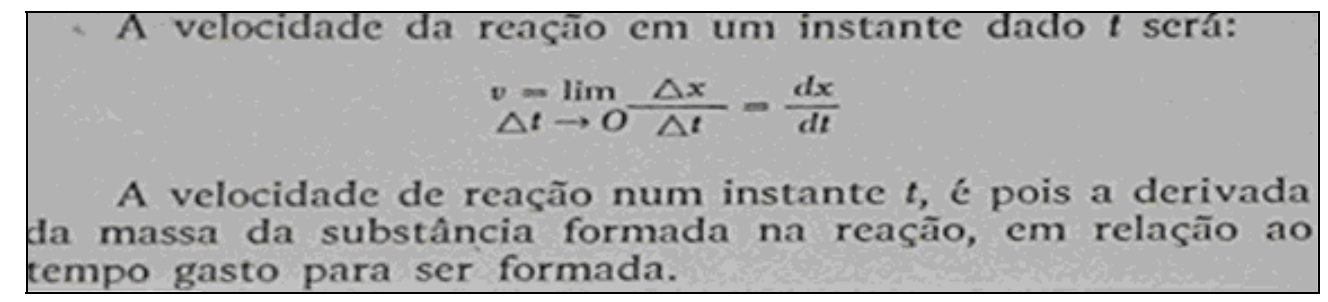

Figura 4.1- Definição da velocidade de uma reação (p.364)

Assim como o livro 4 de 1942, os autores deste livro usam o cálculo diferencial para calcular a velocidade. Outro ponto é que é usada massa e não a concentração no cálculo da velocidade.

\section{b- A Influência da concentração sobre a velocidade de uma reação:}


Para explicar a influência da concentração na velocidade de uma reação os autores usam inicialmente o estudo de Wilhelmy, sobre o estudo da hidrólise da sacarose (fig. 3.5).

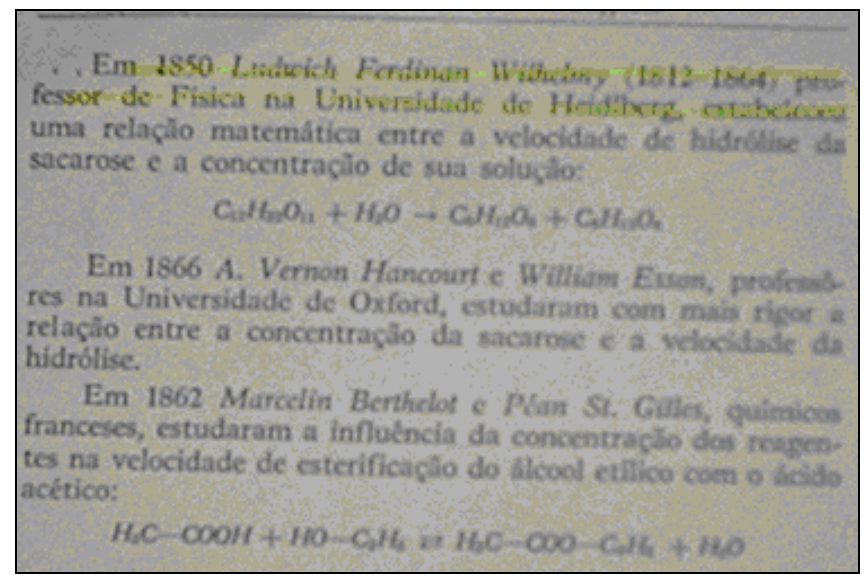

Figura 4.2- Apresentação em ordem cronológica, dos estudos realizados sobre o efeito da concentração na velocidade de uma reação. (p.366).

Finalmente, a influência da concentração dos reagentes na velocidade de uma reação química é explicada através da lei da ação das massas:

“...dois cientistas noruegueses: Cato Maximilian Guldberg (18361902) e seu cunhado Peter Waage (1833-1900), enunciaram a seguinte lei, denominada lei da ação das massas."

\section{A velocidade de uma reaç̃o química é a cada temperatura, proporcional ao produto das massas ativas dos reagentes."}

Figura 4.3- Enunciado da lei da ação das massas. (p.371)

Os autores apresentam que existe um enunciado ainda mais rigoroso que o anteriormente apresentado da lei da ação das massas que é:

\footnotetext{
"A velocidade de uma reação química é, a cada temperatura, diretamente proporcional ao produto das concentrações molares dos reagentes, quando as concentrações são elevadas a potências iguais aos coeficientes dos reagentes na equação da reação." (p.368).
} 
No livro, a explicação da influência da concentração na velocidade é feita utilizando-se a lei da ação das massas, mas não se coloca nenhuma restrição ao seu uso.

No texto do livro aparece a definição de ordem e de molecularidade das reações, mas não há explicações sobre o mecanismo.

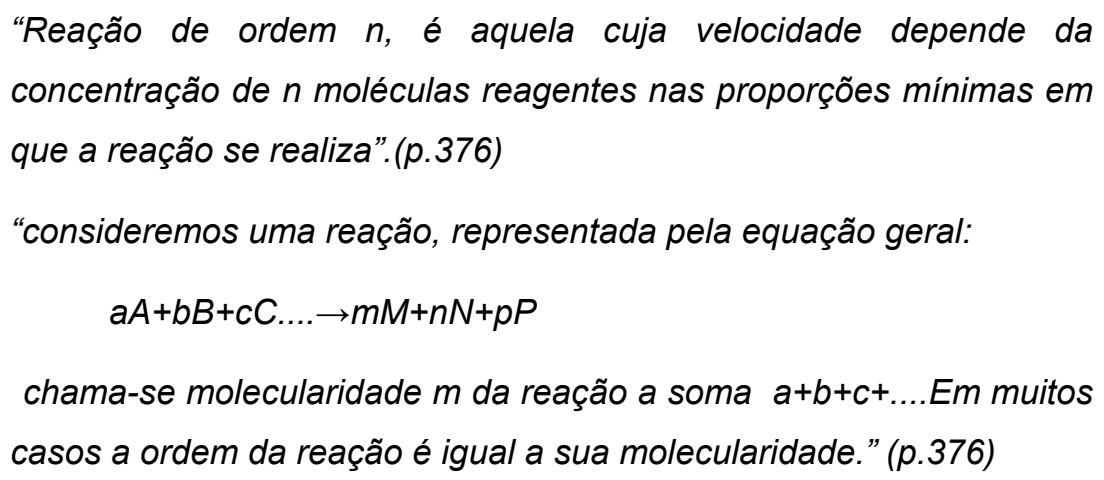

A ordem é relacionada, no livro, ao coeficiente estequiométrico da equação química, não se coloca que a ordem só pode ser determinada experimentalmente. Ainda, os autores apontam, que em muitos casos a ordem pode ser considerada igual a molecularidade, o que pode deixar o leitor confuso.

\section{c- A influência da temperatura:}

Para explicar a influência da temperatura na velocidade os autores do livro didático apresenta a regra de Van't Hoff:

"Uma elevação de $10^{\circ} \mathrm{C}$ na temperatura de uma reação duplica ou triplica a sua velocidade".(p.372).

Apontando que essa regra é apenas aproximada e muitos são os desvios observados.

Embora os autores se refiram a Van't Hoff para explicar a influência da temperatura, não apresentam qual é o efeito da elevação da temperatura nas moléculas participantes da reação química, portanto, a explicação do livro fica então 
coerente com o primeiro programa (Wilhelmy, Harcourt, Esson e Berthelot,18501865), onde não se tem ainda um conhecimento teórico sobre a influência da temperatura na velocidade de uma reação.

\section{B - Características da ciência. Categorias:}

1-Concepção de ciência: Apresenta os conceitos relacionados à cinética química na forma de leis e enunciados universais, indicando, portanto uma concepção de ciência coerente com a apresentada pela perspectiva empirista/indutivista.

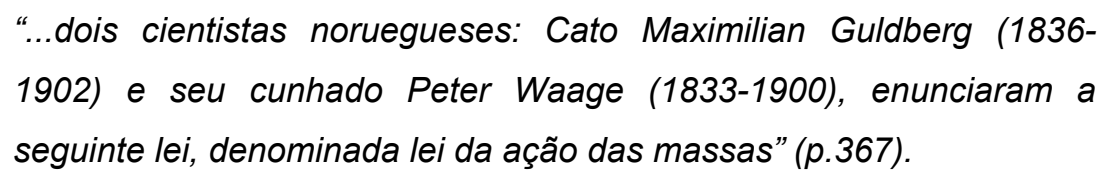

Não ha indicação de limites ao uso desta lei, como se ela fosse aplicável a qualquer reação química.

2-O desenvolvimento da ciência: O desenvolvimento da ciência é apresentado de uma forma contínua e acumulativa como é ilustrado na figura 3 , em que há uma apresentação em ordem cronológica, dos estudos realizados sobre o efeito da concentração na velocidade de uma reação, indicando assim uma perspectiva empirista/indutivista do desenvolvimento da ciência.

3- A construção do conhecimento científico: Observa-se que estes autores apresentam os conceitos de forma arbitrária, relacionando-os aos dados experimentais. Assim o aluno pode ficar com a impressão que a experimentação é a parte mais importante do método cientifico, portanto poderá adquirir uma concepção de ciência predominantemente empirista/indutivista. 


\section{Livro 7- 1955}

Este livro faz parte de uma coleção denominada "Didática do Brasil", que é formada por três livros didáticos. Esses livros não possuem uma apresentação nem carta ao leitor, portanto não foi possível identificar qual é a proposta sua proposta de ensino. O autor aponta que este livro está de acordo com a portaria No.1045 de 14 de dezembro de 1951, e assim como o livro 6 de 1954, apresenta o programa oficial da terceira serie do curso científico, do qual o capitulo de cinética faz parte .

O estudo das velocidades das reações faz parte do capítulo de reações químicas. No final do capítulo há cinco questões abertas relacionadas à velocidade das reações. Por exemplo, 1- Definir velocidade média da reação; 3- quais os fatores que influenciam a velocidade das reações, entre outras.

\section{I- Nível de explicação teórica atingido:}

\section{a- Modelo teórico que explica a velocidade de uma reação química:}

O autor aponta que as

\footnotetext{
"Reações químicas são transformações pelas quais uma substância pura se transforma em outra, pela ação de uma segunda substância ou sob a influência de diversas modalidades de energia".(p.195)
}

Mas, não menciona quais são essas diversas modalidades de energia. O autor aponta que é necessário o emprego de certos fatores para que se possa acelerar a velocidade e assim aumentar o rendimento das reações, entre estes fatores estão a concentração e a temperatura. Mas não explica, em termos microscópicos, como se dá a influência destes fatores. Portanto, a explicação é coerente com a do primeiro programa de investigação (Wilhelmy, Harcourt, Esson e Berthelot,1850-1865). 
Outro ponto é que na definição de reação química, parece que apenas uma substância se transforma, dando a idéia de transmutação e de que há um reagente principal.

\section{b- A Influência da concentração sobre a velocidade de uma reação:}

O autor apresenta que:

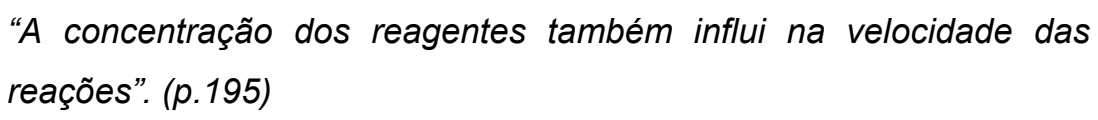

Como exemplo o autor coloca a reação do ácido clorídrico (concentrado e depois diluído) com o alumínio, chegando a conclusão que a reação é mais rápida com o ácido mais concentrado. Pode-se então dizer que a explicação é coerente com a do primeiro programa (Wilhelmy, Harcourt, Esson e Berthelot,1850-1865), onde o aumento de concentração causa um aumento na velocidade de uma reação química.

\section{c- A influência da temperatura:}

O autor menciona que as variações de temperatura exercem grandes influências sobre a velocidade das reações químicas:

\footnotetext{
“Jacobus Henricus Van't Hoff (1852-1911) estabeleceu a seguinte regra: para cada $10^{\circ}$.C e elevação de temperatura, a velocidade de uma reação duplica ou triplica". (p.198).
}

O autor se refere a Van't Hoff para explicar a influência da temperatura, mas não apresenta qual é o efeito da elevação da temperatura nas moléculas participantes da reação química, portanto, a explicação do livro fica então coerente com o primeiro programa (Wilhelmy, Harcourt, Esson e Berthelot,1850-1865), onde não se tem ainda um conhecimento teórico sobre a influência da temperatura na velocidade de uma reação. 


\section{II- Características da ciência. Categorias:}

1-Concepção de ciência: As regras e teorias não são apresentadas como modelos teóricos que podem vir a ser substituídos no futuro. Portanto, fica uma imagem de ciência pronta e acabada que é coerente com a imagem de ciência fornecida pela perspectiva empirista/indutivista.

2- $O$ desenvolvimento da ciência: $O$ livro não mostra $O$ desenvolvimento das teorias e modelos explicativos, embora a época em que foi escrito tais conhecimentos já estavam disseminados, indicando assim uma concepção de desenvolvimento da ciência coerente com a perspectiva empirista/indutivista.

3- A construção do conhecimento científico: o cientista elabora regras através do estudo de dados experimentais:

“Jacobus Henricus Van't Hoff (1852-1911) estabeleceu a seguinte regra: para cada $10^{\circ}$.C e elevação de temperatura, a velocidade de uma reação duplica ou triplica". (p.198).

O autor então pode estar enfatizando uma concepção da construção do conhecimento científico coerente com a perspectiva empirista/indutivista.

Novamente, como nos livros anteriores, a concepção de ciência que predomina é a fornecida pela perspectiva empirista/ indutivista, onde o conhecimento científico é apresentado de uma forma que pode levar o leitor a ter uma idéia de que este é verdadeiro e definitivo.

\section{Livro 8- 1959}

Este livro é do mesmo autor que o livro anterior (7/1955), e já possui uma estrutura bem diferente, começando por apresentar um capítulo de cinética química e também por propor, no final do capítulo, exercícios dirigidos aos alunos. Mas 
também como o livro de 1955, não possui uma apresentação, não sendo possível identificar a proposta do autor.

\section{I- Nível de explicação teórica atingido:}

Segundo o autor, a cinética química é a parte da química que estuda a velocidade e reação e os fatores que a influenciam.

"A velocidade de uma reação química é medida pela quantidade de substancia transformada, ou formada, na unidade de tempo"(p.257)

a velocidade média de uma reação é:

$$
\mathrm{v}_{\mathrm{m}}=\Delta \mathrm{x} / \Delta \mathrm{t}
$$

Sendo que a velocidade, num instante t, será:

$$
v_{\Delta t \rightarrow 0}=\lim \Delta x / \Delta t=d x / d t
$$

\section{a- Modelo teórico que explica a velocidade de uma reação química:}

Não se encontram no livro explicações, em termos microscópicos, para a velocidade de uma reação química.

\section{b- A Influência da concentração sobre a velocidade de uma reação:}

Segundo o autor:

"A influência da concentração dos reagentes na velocidade de reação foi rigorosamente estudada por dois cientistas noruegueses, Cato Maximilian Guldberg (1836-1902) e Peter Waage (1833-1900) :

$a A+b B+c C+\ldots \rightarrow m M+n N+p P$

A expressão matemática da lei da ação das massas é:

$v=k[A]^{a} \times[B]^{b} \times[C]^{c} \times \ldots$

$N a$ equação acima, $V$ é a velocidade da reação; $k$ é a constante de proporcionalidade, denominada constante de velocidade....."(p.266) 
"Lei de Guldberg-Waage: A velocidade de uma reação química, a cada temperatura, é diretamente proporcional ao produto das massas ativas dos reagentes" (p.266).

O autor aponta que a lei de ação das massas (lei de Guldberg-Waage) pode ser enunciada mais rigorosamente:

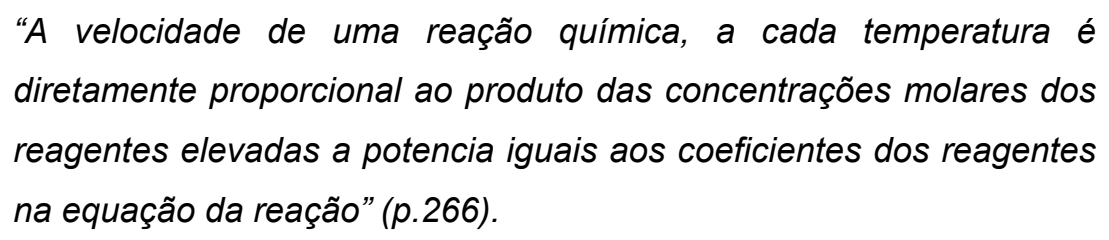
diretamente proporcional ao produto das concentrações molares dos reagentes elevadas a potencia iguais aos coeficientes dos reagentes na equação da reação" (p.266).

Aparece no livro os conceitos de molecularidade e de ordem de uma reação:

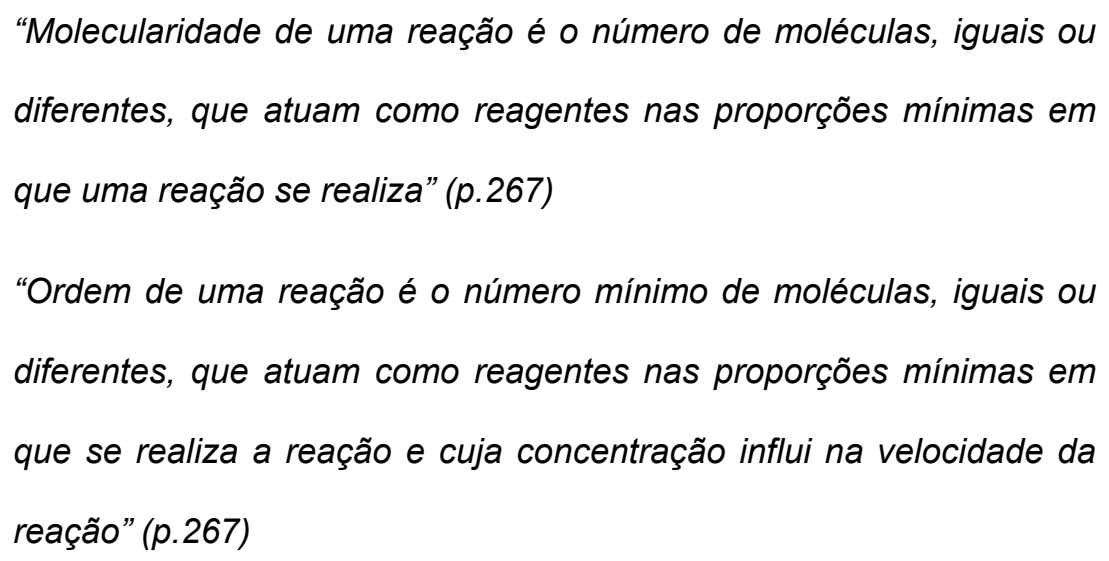

Portanto, o autor apresenta uma diferença entre ordem e molecularidade de uma reação, mas ele não menciona que a ordem de uma reação só é possível de ser determinada experimentalmente, ou seja, a ordem de uma reação é uma quantidade empírica.

Portanto, para explicar a influencia da concentração na velocidade de uma reação o autor não utiliza nenhuma explicação em termos microscópicos, não faz uso de algumas das explicações encontradas nos quatro programas de investigação científicas elaborados neste trabalho, mas usa a Lei de Guldberg-Waage

\section{c- $A$ influência da temperatura:}

O autor escreve que: 
"As variações de temperatura exercem grande influência sobre a velocidade das reações químicas. Geralmente as reações são favorecidas pelo aquecimento" (p.260).

O autor utiliza a regra de Van't Hoff para explicar a influência da temperatura, mas não explica essa influência em termos microscópicos, portanto a explicação está mais coerente com a dada pelo primeiro programa de investigação (Wilhelmy, Harcourt, Esson e Berthelot,1850-1865), onde não se tinha um conhecimento de como a temperatura influenciava, em termos microscópicos, a velocidade de uma reação química.

\section{II- Características da ciência. Categorias:}

1-Concepção de ciência: As leis e teorias encontradas no texto do livro são apresentadas como leis gerais:

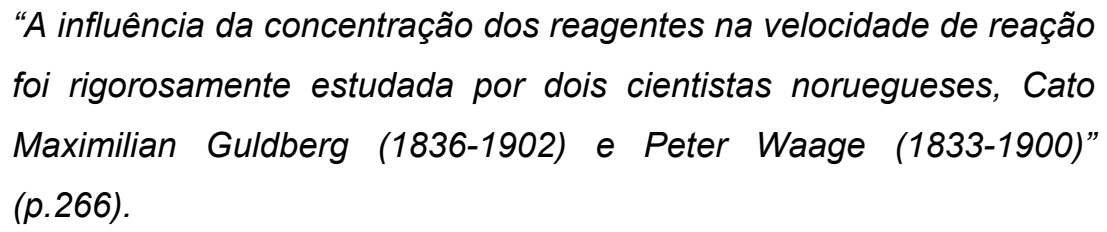

Portanto, essa maneira de apresentar a ciência pode ser coerente com a perspectiva empirista/indutivista.

2- O desenvolvimento da ciência: no livro não se encontra o desenvolvimento de teorias.

3- A construção do conhecimento científico: A autor enfatiza o uso da experimentação na elaboração da explicação da influência da temperatura na velocidade de uma reação:

\footnotetext{
"Van't Hoff estabeleceu a seguinte regra: para cada $10^{\circ} . \mathrm{C}$ de elevação de temperatura, a velocidade de uma reação duplica ou triplica" (p.260).
} 


\section{Discussão}

Pode-se observar neste período que nenhum dos livros analisados apresenta uma explicação em termos microscópicos da velocidade de uma reação química.

Em relação à influência da temperatura na velocidade de uma reação, já aparece em dois livros $(1942,1946)$ um modelo teórico que explica a influência da temperatura, que é de que um aumento de temperatura causa um acréscimo na freqüência de colisões das moléculas reativas. O livro de 1946 cita a explicação de Arrhenius sobre o conceito de moléculas ativas, mas não está presente no texto a definição de energia de ativação, por isso a explicação é mais coerente com a do segundo programa de investigação.

Quanto à influência da concentração na velocidade de uma reação química, somente o livro de 1955 não usa a lei de Guldberg-Waage para explicá-la. Observase que nos livros de 1946, 1954 e de 1959 os conceitos de molecularidade e ordem de uma reação já estão presentes, mas somente no livro de 1946 encontra-se um entendimento de mecanismo de uma reação. Estes conceitos não foram apresentados pelos livros anteriores.

Comparando-se a época em que esses livros foram editados, com o conhecimento científico que já estava disponível nesse período de tempo, pode-se notar uma grande defasagem de tempo.

A identificação dos programas de investigação científica nos livros didáticos pode ser visualizada na tabela 4.3 .

Pela análise das características da ciência pode-se concluir que os livros didáticos deste período, assim como os do período anterior, apresentam ainda uma 
imagem predominantemente empirista/indutivista da ciência (tab. 4.4). O que é coerente, pois essa é a visão de ciência que predominava nesta época.

Todos os livros analisados apresentam uma perspectiva empirista/indutivista em relação a concepção de ciência, primeira categoria, ou seja, todos os livros deste período apresentam as leis e teorias científicas como um conjunto de enunciados universais:

\section{"A influência da concentração na velocidade das reações, se encontra claramente expressa na lei da ação das massas ou lei de Guldberg e Waage (1864)" (p.372,1946).}

Quanto á segunda categoria, o desenvolvimento da ciência, a perspectiva filosófica apresentada pelos livros continua sendo predominantemente empirista/indutivista, pois o desenvolvimento dos conteúdos químicos relativos a cinética química é apresentado de uma forma continua e acumulativa.

Em relação à terceira categoria da analise, a construção do conhecimento científico, todos os livros analisados apresentam a perspectiva filosófica empirista/indutivista, onde a observação na experimentação é tida como etapa mais importante, porque daí se obtém as teorias e leis:

\footnotetext{
"Os fatos mostram que nas reações químicas ordinárias, um aumento de $10^{\circ} \mathrm{C}$ faz com que a velocidade da reação seja multiplicada por um coeficiente compreendido entre 2 e 4 (coeficiente de temperatura)".(p.369, 1946).
}

Um ponto importante observado nos livros didáticos deste período de tempo, como também nos livros do primeiro período (1929-1941), é a indicação dos autores das teorias e leis e exemplos de experimentos realizados pelos cientistas. Embora a imagem de ciência seja predominantemente empirista/indutivista, o conhecimento científico não é apresentado, no livro, como um saber sem produtor, sem origem. 
Embora os livros analisados não apresentem uma introdução ou carta ao leitor, onde geralmente indicam quais são os objetivos do ensino de química, observou-se que dois livros possuem uma nota dizendo que seguem a determinação do Ministério da Educação. Isso ocorre, porque a reforma Capanema (1942) impôs a uniformidade curricular, e os livros passaram a ser rigorosamente controlados por inspetores federais (Schnetzler;1980).

Quanto à orientação educacional de incluir a experimentação no ensino de química, em relação aos livros analisados, essa orientação parece não ter sido cumprida, pois esses livros não possuem experimentos dirigidos aos alunos. 


\section{Programas de Investigação Científica}

\begin{tabular}{cccc}
\hline $\begin{array}{l}\text { Livros } \\
\text { DidáticosI } \\
\text { Ano }\end{array}$ & $\begin{array}{l}\text { Explicação, em } \\
\text { termos } \\
\text { microscópicos, da } \\
\text { velocidade de uma } \\
\text { reação química. }\end{array}$ & $\begin{array}{l}\text { Explicação de como a } \\
\text { velocidade de uma reação } \\
\text { química, depende das } \\
\text { concentrações das } \\
\text { substâncias reagentes. }\end{array}$ & $\begin{array}{l}\text { Explicação da } \\
\text { influência da } \\
\text { temperatura na } \\
\text { velocidade de uma } \\
\text { reação química. }\end{array}$ \\
\hline $4 / 1942$ & PIC-I & GW & PIC-II \\
\hline $5 / 1946$ & PIC-I & GW & PIC-II \\
\hline $6 / 1954$ & A & GW & PIC-I \\
\hline $7 / 1955$ & PIC-I & PCI-I & PCI-I \\
\hline $8 / 1959$ & A & GW & PCI-I \\
\hline
\end{tabular}

Tabela 4.3- Caracterização dos livros didáticos do segundo período (1942 a 1960). Nota: PIC-I:Programa de Investigação Científica de Wilhelmy, Harcourt, Esson e Berthelot (18501865); PIC-II: Programa de Investigação Científica de Pfaundler e Van’t Hoff (1872-1888); GW: indica o uso da Lei de Guldberg-Waage; A= indica a ausência da explicação teórica no livro didático.

\begin{tabular}{cccc}
\hline $\begin{array}{l}\text { Livros } \\
\text { Didáticos/Ano }\end{array}$ & $\begin{array}{c}\text { 1- Concepção de } \\
\text { ciência }\end{array}$ & $\begin{array}{c}\text { 2- O Desenvolvimento da } \\
\text { Ciência }\end{array}$ & $\begin{array}{c}\text { 3- A construção do } \\
\text { conhecimento } \\
\text { científico }\end{array}$ \\
\hline $4 / 1942$ & $E / l$ & $E / l$ & $E / l$ \\
\hline $5 / 1946$ & $E / l$ & $E / l$ & $E / l$ \\
\hline $6 / 1954$ & $E / l$ & $E / l$ & $E / l$ \\
\hline $7 / 1955$ & $E / l$ & $E / l$ & $E / l$ \\
\hline $8 / 1959$ & $E / l$ & $E / l$ & $E / l$ \\
\hline
\end{tabular}

Tabela 4.4- Concepções de ciência apresentadas pelos livros didáticos segundo período (1942 a 1960). Nota: E/I=Empirista/Indutivista, R=Racionalista, N: Não identificado: os livros didáticos não fazem menção explicita a qualquer uma das duas interpretações. 


\subsection{Terceiro período (1961 à 1970)}

Esse período se refere à vigência da lei das Diretrizes e Bases da Educação Nacional No. 4024 que foi promulgada no ano de 1961. Esta foi a primeira lei brasileira a estabelecer diretrizes e bases da educação em todos os níveis, do préprimário ao superior. Alguns dos objetivos da educação estabelecidos pela lei de número 4024/61 eram: desenvolver integralmente a personalidade humana e a sua participação na obra do bem comum, o preparo do indivíduo e da sociedade para o domínio dos recursos científicos e tecnológicos que lhes permitem utilizar as possibilidades e vencer as dificuldades do meio, entre outros.

A estrutura do ensino médio era dividida em dois ciclos (ginasial, de quatro anos, e colegial, de três anos). O ensino colegial abrangia o curso secundário, o curso técnico (industrial, agrícola, comercial e outros que fossem regulamentados) e o curso de formação de professores para o primário e o pré-primário (ensino normal). (Piletti e Piletti;2002)

Os currículos, com a lei no. 4024/61 deixaram de ser rigidamente padronizados, admitindo-se uma certa variedade, quanto às disciplinas. $\mathrm{O}$ currículo da $3^{\mathrm{a}}$ série colegial passou a ser diversificado, visando o "preparo dos alunos para os cursos superiores”. (Piletti e Pilett, 2002).

Diferentemente do período anterior, a escola tinha maior liberdade para elaborar os seu próprios programas, tendo também ocorrido em algumas escolas a introdução dos projetos americanos elaborados no começo da década de 60 (Villani et al, 2005). Um exemplo de um projeto americano, na área da química, que foi aplicado no ensino médio é o "Chemical Educational Material Study", que ficou conhecido como Chem Study (1 ${ }^{a}$. Publicação em 1960) que foi publicado no Brasil, em uma versão traduzida, em 1967, o qual será analisado neste trabalho. 


\subsubsection{A análise dos livros}

A este período pertencem três livros didáticos $(1966,1967$ e 1968). Com exceção do livro de 1966, os demais possuem exercícios e experimentos no capítulo referente a cinética química. Portanto, pode-se dizer que o livro didático deixa de ser apenas um material para consulta, apresentando uma nova função que é a de ensinar conceitos científicos aos alunos, aí entram então os exercícios e os experimentos.

\section{Livro 9- 1966.}

Este livro não propõe exercícios ou experimentos para os alunos. O autor aponta que a Cinética Química também abrange o estudo do equilíbrio químico.

No prefácio deste livro pode-se ter uma idéia a quem este era dirigido:

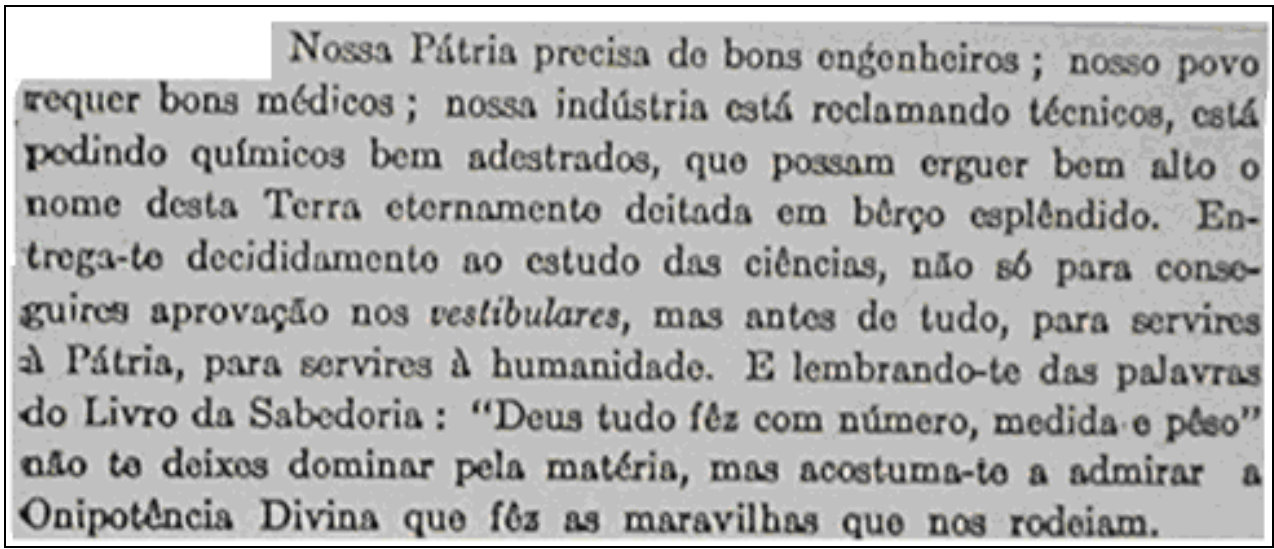

Figura 4.4- Trecho do prefácio do livro. (p.7)

Observa-se assim no texto, um grande sentimento nacionalista onde a ênfase do ensino está no preparo para o vestibular, pois o país e a indústria, segundo o autor, necessitam de bons engenheiros e bons médicos e químicos bem adestrados. 
Nesse livro, o capitulo de cinética química, encontra-se no programa de química para a terceira série do científico. O titulo do capitulo é: "Cinética das reações; conceito de velocidade de reação, fatores que a influenciam; catálise".

\title{
I- Nível de explicação teórica atingido:
}

\section{a- Modelo teórico que explica a velocidade de uma reação química:}

A Cinética Química, segundo o autor:

\begin{abstract}
"Estuda propriamente a velocidade das reações, isto é, as quantidades de substâncias transformadas durante a unidade de tempo. Reação total: a velocidade anula-se depois de certo tempo; Reação reversível: as velocidades de sentidos contrários chegam a igualar-se".(p.208).
\end{abstract}

O autor propõe a seguinte explicação, para ocorrência de uma reação química:

$$
\begin{aligned}
& \text { "Com efeito, são os encontros ou choques entre as moléculas } \\
& \text { reagentes que ocasionam as rupturas ou combinações; e como estes } \\
& \text { choques são tanto mais freqüentes quanto maior o número de } \\
& \text { moléculas por unidade de volume compreende-se que o número de } \\
& \text { rupturas ou combinações seja proporcional à concentração molecular } \\
& \text { dos reagentes".(p.301). }
\end{aligned}
$$

Esta explicação é coerente com a explicação do Programa de Investigação Científica de Wilhelmy, Harcourt, Esson e Berthelot (1850-1865), onde a velocidade depende da interação (choques) entre as partículas, pois não há menção a energia das moléculas.

O livro utiliza o termo combinação para indicar a formação de produtos, este termo começou a ser usado no século XIII para indicar a ocorrência de uma reação química. O filósofo Alberto Magnus (1193-1280), explicava as "combinações 
químicas" admitindo que elas só ocorriam quando as substâncias apresentavam alguma relação de semelhança entre $\mathrm{si}^{14}$.

\section{b- A Influência da concentração sobre a velocidade de uma reação:}

"A velocidade de transformação é, a cada instante, proporcional à quantidade de substâncias que resta a transformar". (p.302).

O autor menciona que antes se explicava a ocorrência de uma reação química em termos de afinidade entre os reagentes, e essa explicação perdeu o seu valor quando se observou que as reações poderiam ser reversíveis. De acordo com o texto do livro:

“....há relação entre o sentido e a velocidade de uma reação e o grau de concentração das massas que o constituem, daí a lei de ação da massa..." (p.301).

A lei de Guldberg e Waage (1867) é enunciada como:

"A velocidade de uma reação é, a cada instante, proporcional ao produto das concentrações dos reagentes". (p.301).

O autor faz a distinção entre ordem e molecularidade de uma reação da seguinte forma:

"Molecularidade é o número de moléculas, diferentes ou idênticas, que entram em jogo no $1^{\circ}$. membro da equação:

a) Uma reação da forma $A=B+C+\ldots$ é monomolecular;

b) $A+B \rightarrow C+D+\ldots$. ou $2 A \rightarrow C+D$... são bimoleculares;

c) $A+B+C \rightarrow D=\ldots \quad$ ou $\quad A+2 B \rightarrow C+\ldots$ ou $\quad 3 A \rightarrow B \ldots$ são trimoleculares."(p.303)

"Ordem de uma reação: é o número de moléculas do $1^{\circ}$. membro que se deve considerar como tendo influência sobre a velocidade da reação; neste sentido, nem sempre o número de ordem da reação coincide com a sua molecularidade". (p.303).

\footnotetext{
${ }^{14}$ Texto da internet. http://allchemy.iq.usp.br/pub/metabolizando/bb57007l.doc
} 
O autor, não indica quais são as condições para que a ordem e a molecularidade sejam iguais, ficando assim incompleta a explicação.

O autor, em seguida, apresenta exemplos de reações de primeira e segunda e terceira ordem, salientando que:

\begin{abstract}
“.....as reações de terceira ordem são raras, sendo mais raras ainda reações de ordem superior, porque tais reações se processam geralmente por etapas intermediarias, sendo a mais lenta a que determina a ordem da reação em estudo". (p.303).
\end{abstract}

Embora no livro apareçam os termos molecularidade e ordem de uma reação, para explicar a influência da concentração na velocidade, o autor usa a lei da ação das massas, em vez da teoria (heurística positiva) do primeiro programa de investigação científica (Wilhelmy, Harcourt, Esson e Berthelot; 1850-1865). Não aparece no texto o conceito de mecanismo de uma reação.

\title{
c- A influência da temperatura:
}

O autor explica a influência da temperatura na velocidade da reação da seguinte forma:

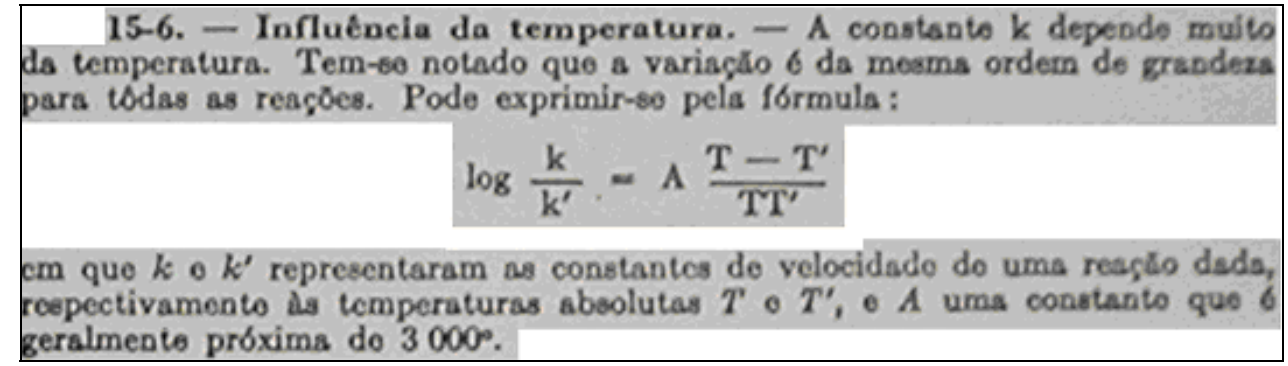

Figura 4.5- Expressão matemática que relaciona a temperatura com a velocidade de uma reação. (p.302)

O autor diz que através desta fórmula pode-se prever que uma reação considerada atualmente impossível se torna realizável, desde que se possa efetuar a temperatura suficientemente elevada. Inversamente, uma temperatura 
suficientemente baixa impede qualquer reação, mencionando que essa conseqüência é verificada experimentalmente.

Embora o autor use a equação matemática formulada por Arrhenius, não há no texto do livro referências ao conceito de energia de ativação e nem à relação encontrada em alguns livros, entre a temperatura e o aumento da freqüência de colisões. Portanto, a explicação encontrada no livro é coerente com o primeiro programa de investigação científica (Wilhelmy, Harcourt, Esson e Berthelot;18501865), porque o autor apenas aponta que a constante de velocidade de uma reação, $k$, depende muito da temperatura, mas não explica como se dá essa influência. $O$ autor não avança no nível de explicações, na apresentação de modelos microscópicos que justifiquem o comportamento matemático apresentado.

\section{II- Características da ciência. Categorias:}

1-Concepção de ciência: as teorias são apresentadas no livro como leis universais onde não há limitações a sua aplicação: "a Lei de ação de massa, enunciada por Guldberg e Waage, em 1867...." (p. 301), indicando portanto uma perspectiva empirista/indutivista.

2- O desenvolvimento da ciência: $O$ livro ilustra o desenvolvimento de teorias quando discute a mudança de explicação das reações químicas, onde aponta que a explicação anterior não possui mais valor, indicando assim a perspectiva empirista/indutivista onde somente a teoria mais atual é a verdadeira, as explicações anteriores são consideradas como erros que devem ser esquecidos:

“....Esta explicação, que se generalizou a caso semelhantes, perde todo o seu valor diante do fato que a reação acima pode seguir marcha inversa, isto é, ser reversível"(p.300) 
3- A construção do conhecimento científico: Esta categoria não foi identificada no livro didático.

\section{Livro 10- 1967.}

Este material foi desenvolvido por um grupo de trabalho composto por professores de escolas de ensino médio e de Universidades norte americanas. A proposta de ensino do livro pode ser representada por um trecho da sua introdução:

“Confiou-se muito no trabalho de laboratório para que os princípios da
química pudessem ser obtidos diretamente das experiências
realizadas pelos estudantes.....A química vai sendo desdobrada
gradual e logicamente, em vez de apresentada como uma coleção de
fatos, enunciados e dogmas. Esperamos transmitir uma consciência
do significado e das possibilidades das atividades científicas que
ajudará o futuro cidadão a receber calma e sabiamente o crescente
impacto dos avanços tecnológicos sobre o seu meio social." (p.IV).

São propostos para os alunos exercícios, tanto durante o desenvolvimento da teoria, como também no final do capítulo. Acompanhando o livro texto, vem o livro de laboratório que contêm experimentos específicos para cada capítulo do livro teórico.

O capítulo inicia-se com vários exemplos de reações químicas que ocorrem em diferentes velocidades (reações com oxigênio do ar: vela, gás, ferro), os autores mencionam que a preocupação do capítulo é a velocidade das reações e os fatores que a determinam para que se possa controlá-las.

\section{I- Nível de explicação teórica atingido:}

\section{a- Modelo teórico que explica a velocidade de uma reação química:}

Para os autores o estudo das velocidades das reações é chamado Cinética Química.

"As reações se processam com diferentes velocidades. Nós nos preocupamos com a velocidade das reações e procuramos saber que 
fatores a determinam para podermos controlá-las. Dada a reação:

$\mathrm{CO}_{(g)}+\mathrm{NO}_{2(g)} \rightarrow \mathrm{CO}_{2(g)}+\mathrm{NO}_{(g)}$

A velocidade da reação é dada pelo quociente entre o número de moles que reagiram e o intervalo de tempo."(p.129)

\title{
Velocidade $=\underline{\text { quantidade de }} \mathrm{NO}_{2}$ consumido intervalo de tempo$$
=\text { quantidade de } \mathrm{NO}_{2} \text { consumido }
$$ por unidade de tempo
}

Figura 4.6- O quociente entre o número de moles que reagiram e o intervalo de tempo é chamado de velocidade da reação. (p.130)

Para explicar a velocidade de uma reação química o livro didático apresenta um modelo teórico chamado de Teoria das Colisões:

\begin{abstract}
"Na concepção molecular da matéria, é natural supor que duas moléculas devem se aproximar uma da outra para poderem reagir. Portanto, postulamos que as reações químicas dependem das colisões entre as partículas reagentes - átomos, moléculas, ou íons. Este modelo para a velocidade de reação é chamado teoria das colisões e fornece uma base conveniente para entender o efeito da concentração. A maior freqüência de colisões resulta em maior velocidade de reação." p.131.
\end{abstract}

O livro didático, na sua explicação sobre a velocidade de uma reação química, usa a teoria das colisões, mas não faz referência á orientação espacial adequada que as moléculas devem possuir para que o choque seja efetivo. Mas adiante se encontra a explicação de que além de colidirem, as moléculas devem possuir um valor de energia mínimo, portanto a velocidade de uma reação seria dependente também do número de moléculas que possuíssem esse valor mínimo de energia:

\footnotetext{
"Os químicos verificaram que as reações químicas ocorrem quando ocorrem colisões, mas apenas quando as colisões envolvem mais do que uma certa quantidade de energia" (p. 136).
} 
Através da leitura do texto do livro didático observa-se que a explicação dada para a velocidade de uma reação química é coerente com a do segundo programa. $A$ próxima explicação dos autores sobre a velocidade das reações em termos microscópicos, envolve a explicação da formação do complexo ativado:

\footnotetext{
"Quando as moléculas colidem e a reação se processa, os átomos têm de formar momentaneamente, ligações menos estáveis do que as ligações existentes nos reagente ou nos produtos da reação. Esses rearranjos moleculares de alta energia se assemelham a passagem nas montanhas - eles colocam uma barreira de energia entre os reagentes e os produtos. A reação só se dá se as moléculas que colidem tem energia suficiente para superar a barreira imposta pelos arranjos instáveis." (p.138).
}

A explicação, mais avançada, da velocidade, em termos microscópicos, é a que se pode encontrar no quarto programa (programa de Investigação Científica de Tolman, Eyring, Polanyi, e Evans;1920-1935), pois envolve a teoria do estado de transição.

\section{b- A Influência da concentração sobre a velocidade de uma reação:}

A explicação sobre a influência da concentração na velocidade de uma reação também é a fornecida pela teoria das Colisões. Assim, um aumento na concentração dos reagentes poderia acarretar em um aumento na freqüência dos choques, e isso acarretaria um aumento na velocidade da reação (fig. 4.7). 


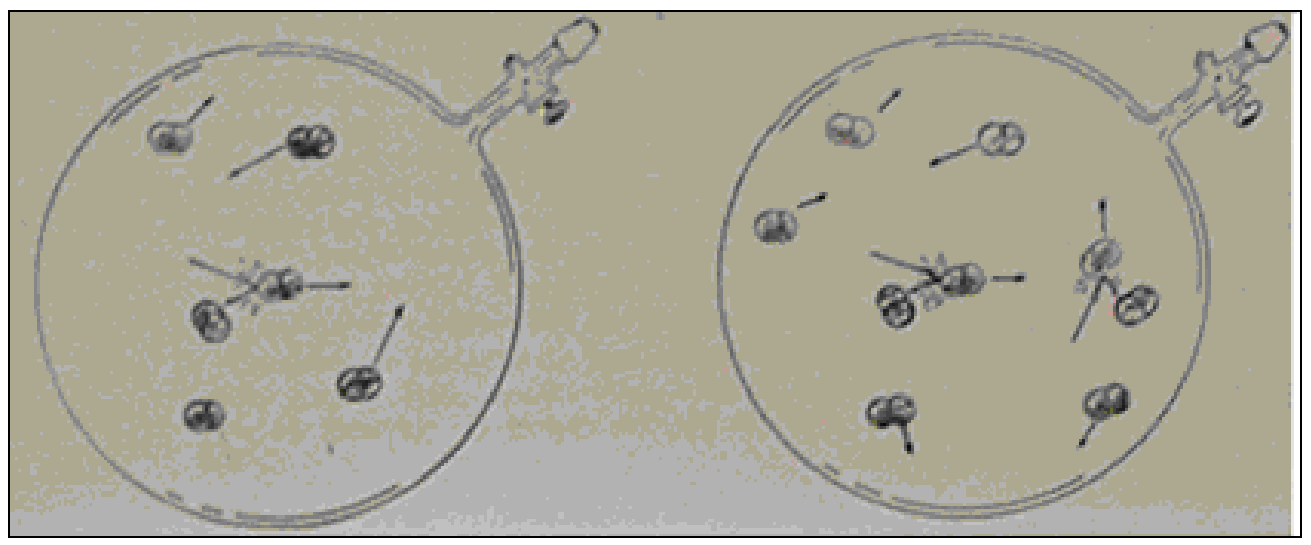

Figura 4.7- O aumento de colisões por segundo depende da concentração (p.132).

Segundo os autores:

“.... em algumas reações as concentrações de alguns dos reagentes não afetam a velocidade. A explicação para isso é encontrada nos detalhes do mecanismo da reação. A reação mais lenta no mecanismo de uma reação é chamada à etapa determinadora da velocidade".

“...... Em geral, o mecanismo da reação não pode ser deduzido da equação que exprime a reação completa. As várias etapas segundo as quais os átomos são rearranjados e recombinados devem ser determinadas pela experiência." (p.131)

De acordo com o texto do livro, aumentando-se a freqüência das colisões, aumenta-se a velocidade de uma reação, mas este aumento da velocidade está ligado ao mecanismo da reação química. Segundo os autores, o mecanismo de uma reação só pode ser determinado experimentalmente. Não foi utilizada a Lei de Guldberg-Waage para explicar o efeito da concentração na velocidade de uma reação. A explicação dada é a que se pode encontrar no terceiro programa (Programa de Investigação Científica de Lewis, Ostwald e Arrhenius,1889-1918). Portanto, verifica-se que é necessário entender o mecanismo de uma reação para entender-se a influência da concentração na velocidade da reação química.

\section{c-A influência da temperatura:}


De acordo com os autores, os químicos verificaram que as reações químicas acontecem quando ocorrem colisões, mas apenas quando as colisões envolvem mais de que uma certa quantidade de energia.

No texto está mencionado que para que ocorra uma reação química é necessário que as moléculas possuam certa quantidade de energia, portanto havendo mais do que essa energia mínima, ou "energia limiar", a reação pode ocorrer; havendo menos, ela não pode se dar. A elevação da temperatura aumenta a velocidade porque aumenta a freqüência de colisões, entretanto, dizem os autores que, este é um efeito muito pequeno em comparação com o efeito resultante do aumento do número de moléculas que têm energia suficiente para produzir a reação. $\mathrm{Na}$ figura 4.8 pode-se observar a explicação dada pelo livro da relação da temperatura com a energia:

\begin{abstract}
"A temperatura $T_{1}$, a área sombreada abaixo da curva correspondente a essa temperatura é proporcional ao número de moléculas que possuem esta energia, ou energia maior. Como são poucas as moléculas que preenchem essa condição, poucas colisões contribuem para a reação, e esta é lenta. Mas, se elevarmos a temperatura para $T_{2}$, o número de moléculas que possuem energia $E$, ou mais, será aumentado na mesma proporção que a área sombreada." (p.137).
\end{abstract}

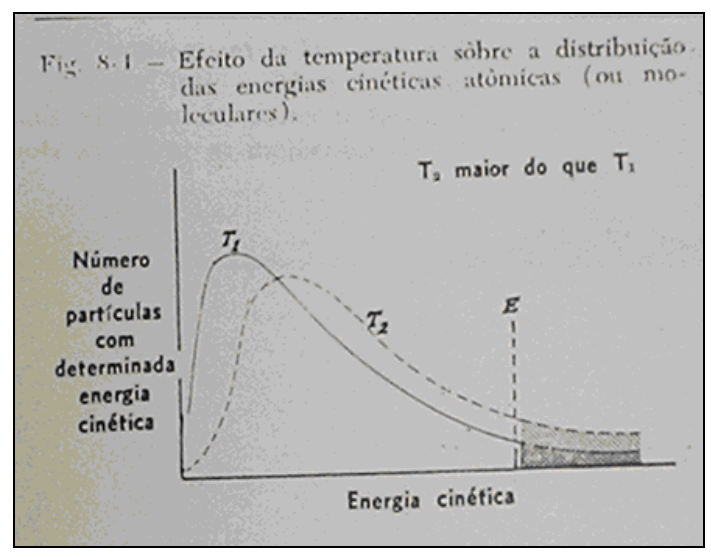

Figura 4.8- Efeito da temperatura sobre a distribuição das energias cinéticas atômicas. (p. 137) 
A definição de energia de ativação, segundos os autores é:

"Chamamos de energia de ativação à diferença entre a elevada energia potencial do complexo ativado e a baixa energia dos reagentes. A energia de ativação é a energia necessária para transformar os reagentes no complexo ativado. Para isso, pode ser necessário enfraquecer ou romper ligações, forçando os reagentes a se aproximarem apesar das forças repulsivas, ou armazenando energia numa molécula em vibração, de maneira que ela reaja quando ocorre uma colisão." (p. 140).

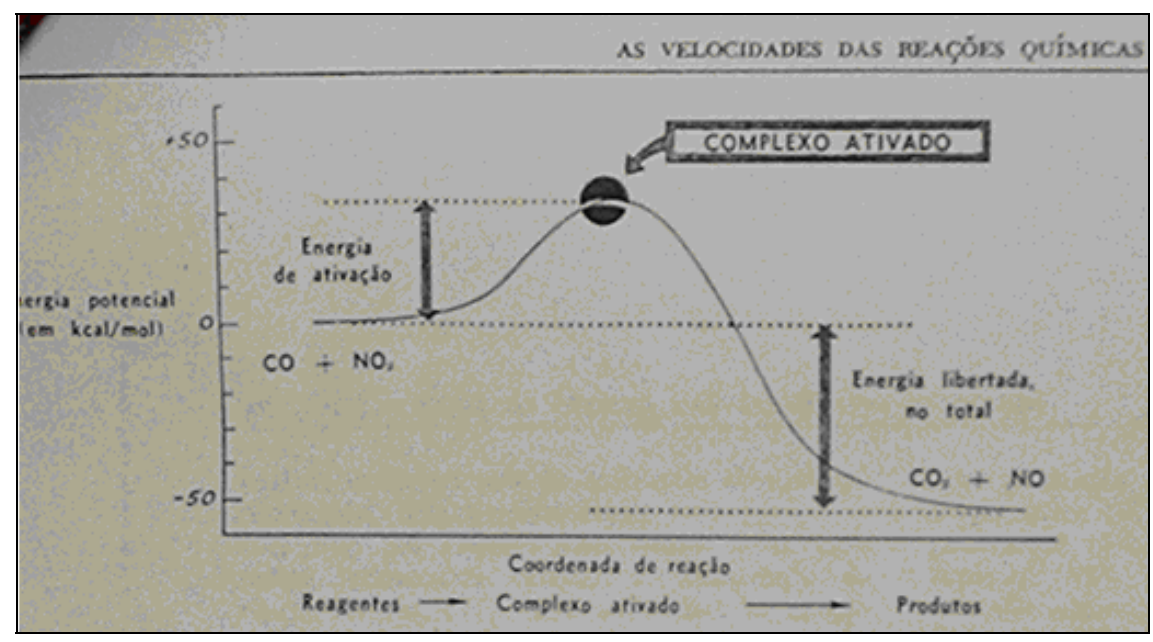

Figura 4.9- Diagrama da energia potencial para a reação entre $\mathrm{CO}_{(\mathrm{g})}$ e $\mathrm{NO}_{2(\mathrm{~g})}$. $(\mathrm{p} .140)$.

A explicação dada é a que se pode encontrar no quarto programa (Tolman, Eyring, Polanyi, e Evans,1920-1935) pois já se encontra a relação entre energia de ativação e o complexo ativado.

Pode-se observar, neste livro, a utilização de diagramas para a representação dos processos. Isso não ocorreu nos livros que foram analisados anteriormente.

\section{II- Características da ciência. Categorias:}

1-Concepção de ciência: são enfatizados os modelos teóricos e hipóteses, sugerindo uma perspectiva racionalista da ciência:

"Na concepção molecular da matéria, é natural supor que duas moléculas devem se aproximar uma da outra para poderem reagir. Portanto, postulamos que a reações químicas dependem das colisões 
entre as partículas reagentes - átomos, moléculas, ou íons. Este modelo para a velocidade de reação é chamado teoria das colisões e fornece uma base conveniente para entender o efeito da concentração."p.131

2- O desenvolvimento da ciência: No texto percebe-se o aumento do poder explicativo das teorias durante o desenvolvimento do capítulo. Portanto, essa forma de apresentação de conteúdo pode levar o leitor a ter uma imagem de ciência coerente com a perspectiva racionalista, onde o progresso da ciência é caracterizado por uma problemática progressiva, de uma tentativa teórica para outra.

3- A construção do conhecimento científico: $O$ texto do livro sugere uma perspectiva empirista/indutivista da construção do conhecimento científico, onde a ênfase está na observação: “....Procurou-se apresentar e usar repetidamente um quadro válido dos passos pelos quais um cientista avança. Observações e medidas levam ao desenvolvimento de princípios unificadores e, a seguir, esses princípios são usados para inter-relacionar diversos fenômenos.

\section{Livro 11- 1968.}

Embora esse livro não possua introdução ou carta ao leitor, percebe-se que um dos objetivos propostos pelos autores é o preparo para o vestibular, pois antes do índice existe uma relação de abreviações adotadas pelos autores, para os nomes das escolas superiores, permitindo que se identifiquem as fontes dos exercícios propostos no final do capitulo de cinética química, todos extraídos de vestibulares.

Há no livro um capítulo referente à cinética química denominado Cinética e Equilíbrios Químicos, portanto, como no livro 9 (1966), a cinética e o equilíbrio químico aparecem ainda no mesmo capítulo. 


\section{I- Nível de explicação teórica atingido:}

\section{a- Modelo teórico que explica a velocidade de uma reação química:}

Segundo o livro, cinética química é a parte da química em que se estuda a velocidade das reações. A velocidade é definida como:

"velocidade média é o quociente entre a variação do número de mols da substância considerada $(\Delta n)$ e a variação do tempo em que isso se verificou $(\Delta t): v$ média $=(\Delta n) /(\Delta t)$. velocidade instantânea é a derivada da velocidade media, em relação ao tempo:v= $d n / d t "(p .307)$

No livro não há uma explicação teórica, em termos microscópicos, para a velocidade de uma reação.

\section{b- A Influência da concentração sobre a velocidade de uma reação:}

A influência da concentração do reagente na velocidade das reações químicas é explicada pelo autor através da lei da ação das massas ou Lei de Guldberg e Waage:

$$
\begin{aligned}
& \text { "A velocidade de uma reação, em certo instante, é diretamente } \\
& \text { proporcional ao produto das concentrações molares dos reagentes } \\
& \text { nesse instante, ficando a concentração molar elevada a uma potência } \\
& \text { igual ao coeficiente que o reagente considerado apresentar na } \\
& \text { equação química correspondente. Exemplo: } \\
& a A+b B+c C=x X+y Y+z Z \text {, } \\
& v=k[A\}^{a} .[B]^{b} \cdot[C]^{c} \text { ". (p.308) }
\end{aligned}
$$

O autor do texto menciona que existem restrições ao uso desta lei, mas ele não explica quais são essas restrições:

"Infelizmente a lei de Guldberg-Waage falha muitas vezes, de modo que a expressão matemática da velocidade deve ser, quase sempre estabelecida a partir de dados experimentais obtidos no laboratório, 
este é um dos motivos pelos quais a cinética química é uma das partes mais complicadas de toda a química". (p.309)

Pela afirmação acima do autor, pode-se ficar com a impressão de que, por depender de dados experimentais, a cinética pode tornar-se mais complicada que outras áreas da química, ou do ponto de vista pedagógico, a cinética química é difícil, complicada (não queira você, reles aluno, tentar entender!), ou ainda essa afirmação tenha a ver, com a insegurança dos autores com relação a esse conteúdo.

\section{c- A influência da temperatura:}

Os autores não explicam como a temperatura pode interferir na velocidade de uma reação química. O único fator explicado é a ação da concentração, que segundo o autor é o mais importante.

\section{II- Características da ciência. Categorias:}

1-Concepção de ciência: as teorias são apresentadas no livro como leis universais, como a lei de ação de massa, ou lei de Guldberg e Waage indicando assim a perspectiva empirista/indutivista.

\section{2- O desenvolvimento da ciência; 3- A construção do conhecimento científico:}

Estas categorias não foram identificadas no livro didático. Os autores do livro didático não colocam no texto, o desenvolvimento e a construção dos conhecimentos científicos envolvidos na cinética química. 


\section{Discussão}

O livro didático de 1967 (Chem-study) é o que apresenta uma explicação em termos microscópicos da velocidade das reações químicas coerente com o programa de investigação científica mais atual (Tolman, Eyring, Polanyi, e Evans; 1920-1935).

No livro de 1968 (tab.4.5), pode-se notar a preocupação do autor em enfatizar as fórmulas matemáticas necessárias para o cálculo da velocidade de uma reação. Por exemplo, nas definições da velocidade instantânea e média, e também na utilização da lei de ação das massas, mas não existem explicações em termos microscópicos a respeito da velocidade de uma reação e do efeito da concentração e da temperatura na velocidade da reação.

Como nos períodos anteriores, a lei de Guldberg-Waage continua a ser utilizada para explicar o efeito da concentração na velocidade de uma reação nos livros de 1966 e de 1968. Já o livro de 1967 (Chem-study) explica esse efeito através da teoria da colisão e pelo entendimento do mecanismo de uma reação química.

Uma explicação da influência da temperatura na velocidade de uma reação também só é apresentada pelo livro de 1967 (Chem-study), a explicação dada já relaciona a energia de ativação com a formação do complexo ativado (PIC-IV: Tolman, Eyring, Polanyi, e Evans;1920-1935). Este livro, além de possuir uma estrutura teórica bem atualizada, propõe durante o desenvolvimento do capítulo, experimentos e exercícios para facilitar a aprendizagem dos conceitos químicos, apresentando também uma imagem de ciência que é predominantemente racionalista. Por exemplo, a perspectiva filosófica que representa a concepção de 
ciência nesse livro, é a perspectiva racionalista, pois nele a ciência é apresentada como um conjunto de hipóteses e modelos:

"Na concepção molecular da matéria, é natural supor que duas moléculas devem se aproximar uma da outra para poderem reagir. Portanto, postulamos que a reações químicas dependem das colisões entre as partículas reagentes - átomos, moléculas, ou íons. Este modelo para a velocidade de reação é chamado teoria das colisões e fornece uma base conveniente para entender o efeito da concentração." $(1967, p .131)$

Observou-se nos livros didáticos deste período que a concepção de ciência que predomina é ainda, como nos períodos anteriores, empirista/indutivista, no que diz respeito à concepção de ciência e a construção do conhecimento científico (tab.4.6).

O Chem-study, segundo Lopes (1990), advogava uma concepção empíricopositivista para a construção do conhecimento científico, e visa desenvolver essa concepção no ensino. Segundo a autora:

"A ciência era concebida com base na observação, da qual se desprendiam as regularidades a serem explicadas por raciocínios lógicos comprovados pela experimentação. A experimentação garante também a descoberta de novos fatos, de forma que o ciclo se fecha: volta-se à observação, depois ao raciocínio, depois à experimentação".

Os livros deste período têm como objetivos a formação técnica e o preparo para o vestibular, portanto pode-se inferir que eles seguem as orientações propostas pela LDB 4024/1961.

O Chem-study apresenta o tratamento dos conteúdos químicos de maneira coerente com a sua proposta inicial, que é a de introduzir os alunos nas atividades científicas. Portanto, como o livro foi elaborado para atender uma demanda sóciopolítica da época, que era a de atender a necessidade de se formar mais cientistas, isso acaba sendo refletido no livro, na escolha e na maneira de tratar os conteúdos. 
Outro ponto que chama a atenção nos livros analisados desse período, é a maior ênfase que é dada aos exercícios, talvez na tentativa de mecanização de certos procedimentos ou no treinamento para o vestibular. 


\begin{tabular}{|c|c|c|c|}
\hline & \multicolumn{3}{|c|}{ Programas de Investigação Científica } \\
\hline $\begin{array}{l}\text { Livros } \\
\text { Didáticos/Ano }\end{array}$ & $\begin{array}{l}\text { Explicação, em } \\
\text { termos } \\
\text { microscópicos, da } \\
\text { velocidade de uma } \\
\text { reação química. }\end{array}$ & $\begin{array}{l}\text { Explicação de como a } \\
\text { velocidade de uma } \\
\text { reação química depende } \\
\text { das concentrações das } \\
\text { substâncias reagentes. }\end{array}$ & $\begin{array}{l}\text { Explicação da } \\
\text { influência da } \\
\text { temperatura na } \\
\text { velocidade de uma } \\
\text { reação química. }\end{array}$ \\
\hline 9/1966 & PIC-I & GW & PIC-I \\
\hline $10 / 1967$ & PIC- IV & PIC- III & PIC- IV \\
\hline $11 / 1968$ & A & GW & A \\
\hline
\end{tabular}

Tabela 4.5- Caracterização dos livros didáticos do terceiro período (1961-1970). Nota: PICI:Programa de Investigação Científica de Wilhelmy, Harcourt, Esson e Berthelot (18501865); PIC-III:Programa de Investigação Científica de Lewis, Ostwald e Arrhenius (18891918);PIC-IV:Programa de Investigação Científica de Tolman, Eyring, Polanyi, e Evans (1920-1935);GW: indica o uso da Lei de Guldberg-Waage; A= indica a ausência da explicação teórica no livro didático.

\begin{tabular}{c|ccc}
\hline & \multicolumn{4}{|c}{ Categorias } \\
\hline \begin{tabular}{c|c} 
Livros \\
Didáticos/Ano
\end{tabular} & $\begin{array}{l}\text { 1- Concepção de } \\
\text { ciência }\end{array}$ & $\begin{array}{l}\text { 2- O Desenvolvimento } \\
\text { da Ciência }\end{array}$ & $\begin{array}{l}\text { 3- A construção do } \\
\text { conhecimento } \\
\text { científico }\end{array}$ \\
\hline $9 / 1966$ & $\mathrm{E} / \mathrm{l}$ & $\mathrm{E} / \mathrm{N}$ & $\mathrm{N}$ \\
\hline $10 / 1967$ & $\mathrm{R}$ & $\mathrm{R}$ & $\mathrm{N}$ \\
\hline $11 / 1968$ & $\mathrm{E} / \mathrm{N}$ & $\mathrm{N}$ & $\mathrm{N}$ \\
\hline
\end{tabular}

Tabela 4.6- Concepções de ciência apresentadas pelos livros didáticos do terceiro período (1961-1970). Nota: E/l=Empirista/Indutivista, R=Racionalista, N= Não identificado: os livros didáticos não fazem menção explicita a qualquer uma das duas interpretações. 


\subsection{Quarto período (1971 à 1995)}

Esse período refere-se à vigência da Lei das Diretrizes e Bases No. 5692 de 11 de agosto de 1971. Com essa lei, o governo reformou o primeiro e segundo graus quase sem discussão e sem a participação de estudantes, professores e outros setores sociais interessados. Esta é a época do regime militar no governo brasileiro.

Os objetivos gerais da educação eram os mesmos estabelecidos pela anterior, Lei no. 4024/61. Quanto ao ensino de $1^{\circ}$. e $2^{\circ}$. graus, o artigo $1^{\circ}$. da Lei $5692 / 71$ estabelece o seguinte objetivo:

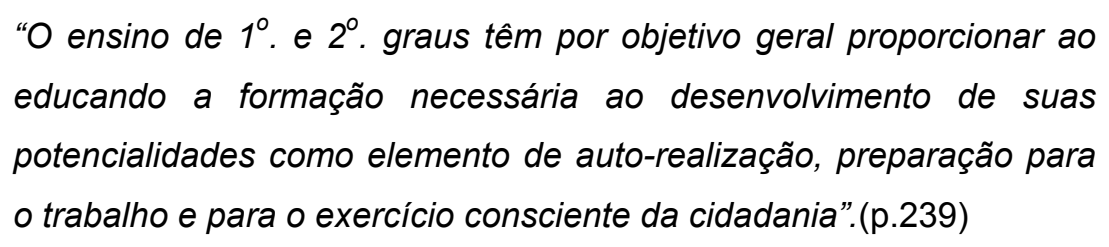

A reforma de 1971 modificou a estrutura anterior do ensino. O antigo curso primário (de quatro a seis anos) e o antigo ginásio foram unificados num único curso de $1^{\circ}$. grau, com duração de oito anos. Os ramos profissionais existentes no antigo ginásio - industrial, comercial, agrícola e normal - desapareceram. Portanto, segundo Piletti e Piletti (2002), o ensino de primeiro grau não oferecia mais formação profissional, mas destinava-se somente à educação geral. O ensino do $2^{\circ}$.Grau pela reforma de 1971, tornou-se todo ele profissionalizante.

A partir de 1983, por força de lei de número 7044, de 18 de outubro de 1982, os estabelecimentos ficaram livres para oferecer ou não a habilitação profissional.

Quanto ao currículo, a reforma de 1971 aumentou o número de matérias obrigatórias em todo o território nacional. O núcleo comum obrigatório passou a abranger dez conteúdos específicos: um de comunicação e expressão (Língua Portuguesa); três de estudos sociais (Geografia, Historia e Organização Social e Política do Brasil); dois de ciências (matemática e ciências físicas e biológicas) e 
quatro práticas educativas (Educação Física, Educação Artística, Educação Moral e Cívica e Programas de saúde). A química fazia parte das ciências físicas e biológicas.

Os objetivos para o ensino das ciências, segundo Sicca (1990) eram:

"Nas ciências, o desenvolvimento do pensamento lógico e a vivência do método cientifico, sem deixar de por em relevo as tecnologias que resultam de suas aplicações". (p.85)

Os grandes projetos institucionais que existiam no Brasil na década de 70 eram caracterizados por uma visão empirista do conhecimento científico, mas segundo Villani (et al, 2005), devido ao movimento que ocorria, fora do país, na filosofia da ciência esta visão começou a ser questionada, sendo então introduzida uma nova forma de se olhar à ciência através da nova filosofia da ciência, de cunho racionalista, que teria efeitos no ensino de ciências.

\subsubsection{A análise dos livros}

Como esse período de tempo abrange três décadas, nesse trabalho foram analisados cinco livros didáticos (1976, 1977, 1979, 1980 e 1993). Destes livros, dois possuem propostas diferenciadas de ensino de química que serão apresentadas a seguir, são os livros de 1977 e o de 1993.

\section{Livro 12-1976}

No prefácio deste livro o autor menciona que os conteúdos químicos estão divididos em pequenos itens, seguidos de resumos, exercícios e testes, citando que "o aluno só aprende trabalhando", e que segundo o autor, "no parecer de muitos professores, este é um dos pontos altos da didática dessa obra". 
Os exercícios e testes, segundo o autor, foram selecionados "criteriosamente e dispostos em ordem coerente e crescente de dificuldade". O quarto capítulo é o de cinética química e catálise, onde o autor aponta que "serão apresentadas de um modo completo e moderno". Esse capítulo ainda inclui o estudo do Equilíbrio Químico.

\title{
I-Nível de explicação teórica atingido:
}

\section{a-Modelo teórico que explica a velocidade de uma reação química:}

O autor explica que:

\begin{abstract}
"De acordo com a teoria da colisão, pode-se dizer que a velocidade irá depender: da freqüência de choques; da energia (violência) dos choques e de uma orientação apropriada das moléculas no instante do choque".(p.187)
\end{abstract}

Aponta ainda que o último fator representa a "probabilidade" das moléculas reagentes se chocarem de modo tal a produzirem a reação desejada. Este fator, segundo o autor, depende então da geometria (formato) das moléculas reagentes e do "tipo de reação que está sendo executada". Conseqüentemente, é mencionado que, os fatores que mais influem na velocidade de uma dada reação são a freqüência e a energia dos choques.

Segundo o autor, a maiorias das reações tem, contudo, um mecanismo mais complexo, de tal modo que a reação ocorre em várias etapas sucessivas ou reações elementares sucessivas, sendo então necessária, para explicar a velocidade de uma reação, de uma teoria mais moderna, a teoria do Complexo Ativado. No livro é mencionado que tal teoria admite que,no instante do choque, ocorre um progressivo enfraquecimento das ligações entre as moléculas iniciais e fortalecimento das ligações entre as moléculas finais, mas não é estabelecida uma relação entre essa teoria com a velocidade de uma reação. Mesmo assim, pode-se dizer que a 
explicação dada pelo autor é coerente com a do quarto programa (Tolman, Eyring, Polanyi, e Evans, 1920-1935).

\section{b-A Influência da concentração sobre a velocidade de uma reação:}

Segundo o autor:

"Aumentando-se a concentração dos reagentes (número de moléculas por unidade de volume) nós iremos aumentar a freqüência dos choques ${ }^{15}$ entre as moléculas reagentes e, conseqüentemente, aumentar a velocidade da reação".(p.193)

O autor representa a lei de velocidade de uma reação através da lei da ação das massas ou Lei de Guldberg-Waage.

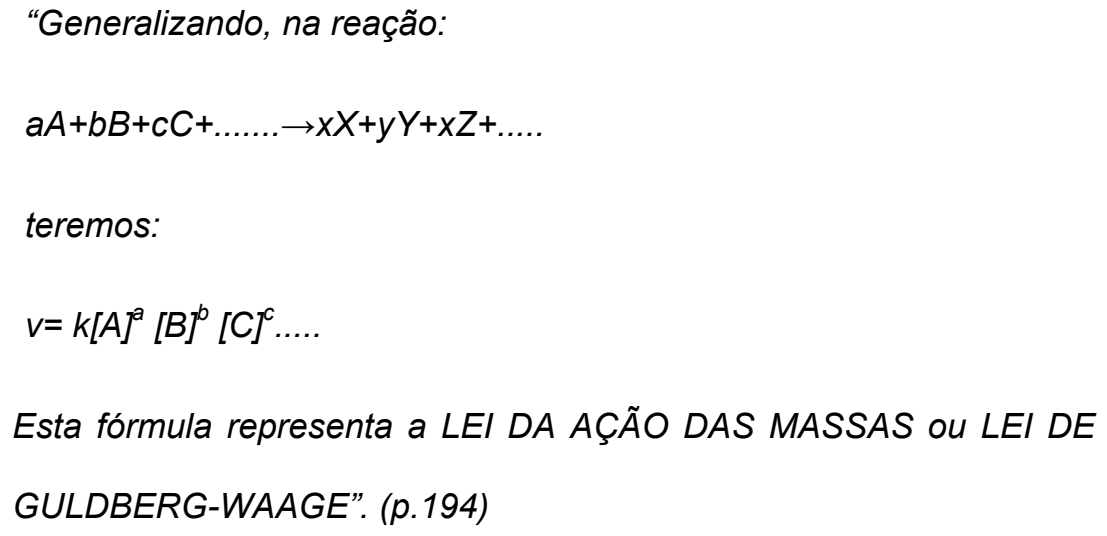

Onde $k$ é chamada de constante cinética ou constante de velocidade específica da reação, e que depende de todos os outros fatores que influem na velocidade de uma reação, especialmente da temperatura.

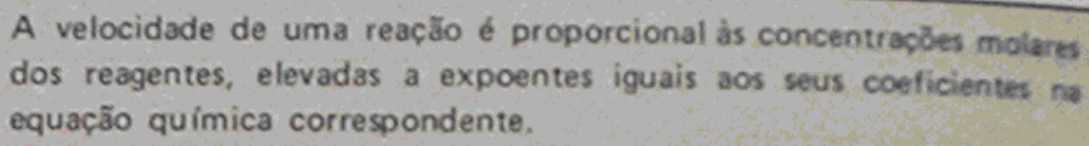

Figura 4.10- Enunciado da Lei de Guldberg-Waage (p.194)

\footnotetext{
${ }^{15}$ Negrito do autor do livro didático.
} 
O autor menciona que a Lei de Guldberg-Waage, "só tem valor quando determinada experimentalmente para cada reação em particular", e que a velocidade depende fundamentalmente do andamento, ou seja, do mecanismo da reação: "a etapa mais lenta de uma reação é a etapa determinante da velocidade da reação" (p.196).

Parece haver uma contradição entre o estabelecimento de uma lei que tem um caráter geral e sua dependência de cada reação. Não fica claro que a velocidade de uma reação é determinada experimentalmente e que a lei de Guldberg-Waage é uma tentativa de generalização, restrita a reações que apresentam um dado caminho.

Segundo o texto do livro, na cinética química é importante se ter os conceitos de ordem e molecularidade de uma reação:

"ORDEM: é a soma dos expoentes aos quais estão elevadas as concentrações na fórmula experimental da velocidade”.(p.196)

"MOLECULARIDADE: é o número de moléculas que se chocam (ou que formam o complexo ativado) em cada etapa da reação".(p.196)

O autor apresenta um algoritmo e não um conceito de ordem de reação. Quanto ao mecanismo o autor menciona que:

"A velocidade depende fundamentalmente do andamento, ou seja, do mecanismo da reação. "( $p$. 196)

Mas não explica como se da esta dependência, e não relaciona o mecanismo com o conceito de ordem.

Considerou-se então que, embora no livro apareçam os termos molecularidade e ordem de uma reação, para explicar a influência da concentração na velocidade, o autor usa a lei da ação das massas (Guldberg-Waage). 


\section{c-A influência da temperatura:}

O autor começa a explicação sobre a influência da temperatura apresentando a regra de Van't Hoff:

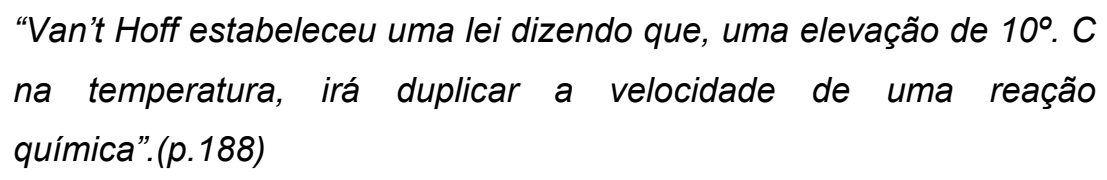

Mas aponta, em seguida, que existem muitas exceções a essa lei.

De acordo com o texto do livro, a temperatura é um dos fatores que mais influem na velocidade de uma reação:

"um aumento de temperatura ira aumentar não só a freqüência dos choques entre as moléculas reagentes, como também a energia com que as moléculas se chocam". (p.188) ${ }^{16}$

O autor diz que, em quase todas as reações é necessário dar um empurrão (aquecimento) inicial para levar os reagentes a um "estado ativado", onde se forma o chamado complexo ativado.

"Para atingir a elevação correspondente ao estado ativado, as
moléculas reagentes devem ter uma energia igual ou maior que é a
chamada de ENERGIA DE ATIVAÇAO, só depois disto, é que a
reação se completa”.(p.189)

O autor menciona que a curva de Maxwell-Boltzmann mostra que a maior parte das moléculas tem uma "energia média", mas, no entanto, diz que somente as moléculas com energia igual ou superior a "energia de ativação", $E_{a t}$ (área hachurada da fig 4.11), conseguirão reagir, pois:

\footnotetext{
"Somente essas moléculas poderão vencer a elevação existente no gráfico de "variação de energia/andamento da reação'”'(p.191)
}

\footnotetext{
${ }^{16}$ Negritos do autor do livro didático.
} 


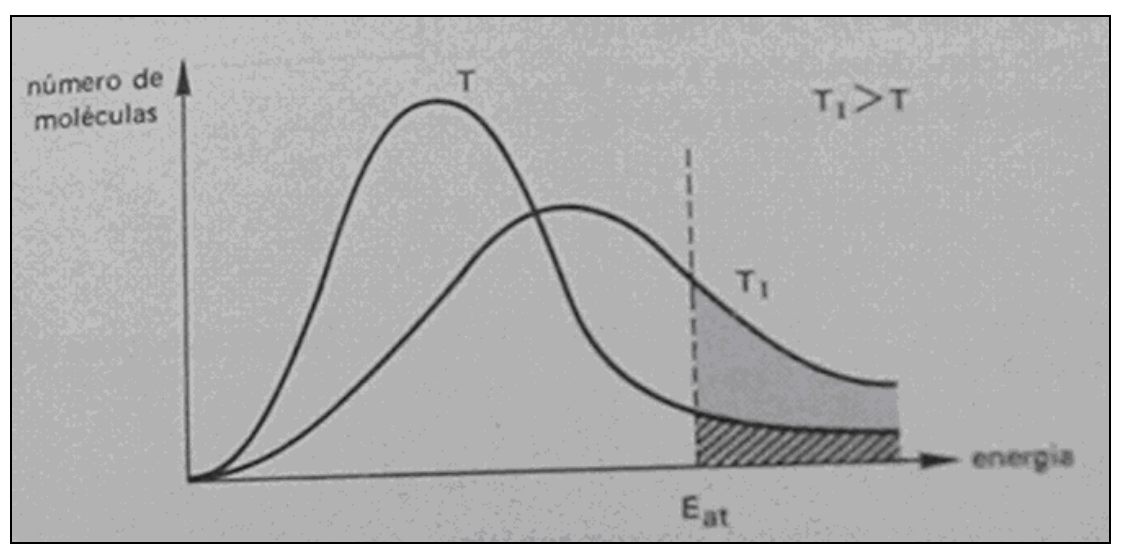

Figura 4.11- Curva de Maxwell-Boltzmann (p. 191).

Segundo o autor:

"O aumento da área pontilhada em relação à área hachurada é, em geral, muito grande com o aumento da temperatura. Isso nos faz entender porque a temperatura influi enormemente na velocidade das reações".(p.191)

"Entre duas reações químicas semelhantes, será mais rápida aquela que apresentar menor energia de ativação". (p.191)

A explicação dada pelo autor para a influência da temperatura é coerente com a do quarto programa (Tolman, Eyring, Polanyi, e Evans, 1920-1935), pois relaciona a energia de ativação com a formação do complexo ativado.

Deve ser notado que no livro anterior, que é do mesmo autor (1968, Ricardo Feltre em parceria com Setsuo Yoshinaga), o efeito da temperatura não é tratado.

\section{II- Características da ciência. Categorias:}

1-Concepção de ciência: As teorias são apresentadas nos livros didáticos como leis gerais, enunciados universais:

“Van't Hoff estabeleceu uma lei dizendo que, uma elevação de $10^{\circ}$. C na temperatura, irá duplicar a velocidade de uma reação química”.(p.188)

"De acordo com a teoria da colisão, pode-se dizer que a velocidade irá depender: da freqüência de choques; da energia (violência) dos 
choques e de uma orientação apropriada das moléculas no instante do choque".(p.187)

Portanto, a ciência não é apresentada como um conjunto de hipóteses que vão sendo modificadas através do tempo. A ciência, no livro analisado, é apresentada como um conjunto de fatos e teorias considerados verdadeiros, e que podem ser considerados universais, indicando assim uma visão de ciência coerente com a perspectiva empirista/indutivista.

2-O desenvolvimento da ciência: No texto percebe-se o aumento do poder explicativo das teorias durante o desenvolvimento do capítulo. Portanto, essa forma de apresentação de conteúdo pode levar o leitor a ter uma imagem de ciência coerente com a perspectiva racionalista.

3-A construção do conhecimento científico: Esta categoria não foi identificada no livro didático.

\section{Livro 13- 1977}

A característica básica desse processo de aprendizagem proposta pelas autoras é o ensino indutivo. A proposta deste livro é a que através da experimentação se desenvolva o aprendizado de conceitos químicos. Durante o estudo, o aluno é:

“....convidado a observar sistemas químicos em interação, sendo que, para tanto, vai recebendo, à medida do necessário, o instrumental adequado e as explicações de como utiliza-lo. De suas observações e conclusões se obtêm modelos para a realidade, sendo a coroação desse processo o modelo denominado teoria da estrutura atômica." (p. VII).

Portanto, a proposta de ensino deste livro pode ser resumida na seguinte seqüência: 
$1^{\circ}$. Realização de experimentos;

$2^{\circ}$.Construção de modelos para explicar os fatos observados durante a experimentação e;

$3^{\circ}$. Confronto entre os modelos criados pelos alunos e os modelos científicos.

O objetivo da unidade referente a cinética química, segundo as autoras é: "fazer um estudo experimental quantitativo da velocidade das reações e dos fatores que as afetam, propondo teorias, que, desenvolvidas, vão permitir o esclarecimento de fatos observados".(p.61).

Na introdução desta unidade é apresentada a importância do estudo da cinética química na área tecnológica, dando exemplos de aplicações do estudo da velocidade de reações nas áreas de tecnologia espacial, bioquímica e petroquímica.

No final da unidade são propostos exercícios para a fixação dos conceitos desenvolvidos.

\section{I-Nível de explicação teórica atingido:}

\section{a- Modelo teórico que explica a velocidade de uma reação química:}

No livro didático a explicação em termos microscópicos da velocidade de uma reação é desenvolvida na seguinte seqüência: primeiro é necessário que haja colisões entre as moléculas reagentes, e para que as moléculas colidam estas necessitam possuir uma certa energia mínima, e em seguida está presente a seguinte explicação:

\footnotetext{
"As moléculas devem colidir com uma certa energia cinética para que o choque seja aproveitável. Logo após a colisão, forma-se uma associação mais complexa que as duas moléculas iniciais que armazena por algum tempo, geralmente muito curto, a energia cinética. Este arranjo instável se
} 
decompõe, dando origem aos produtos. O diagrama da figura $6.1^{17}$ mostra claramente a situação descrita".(p. 64)

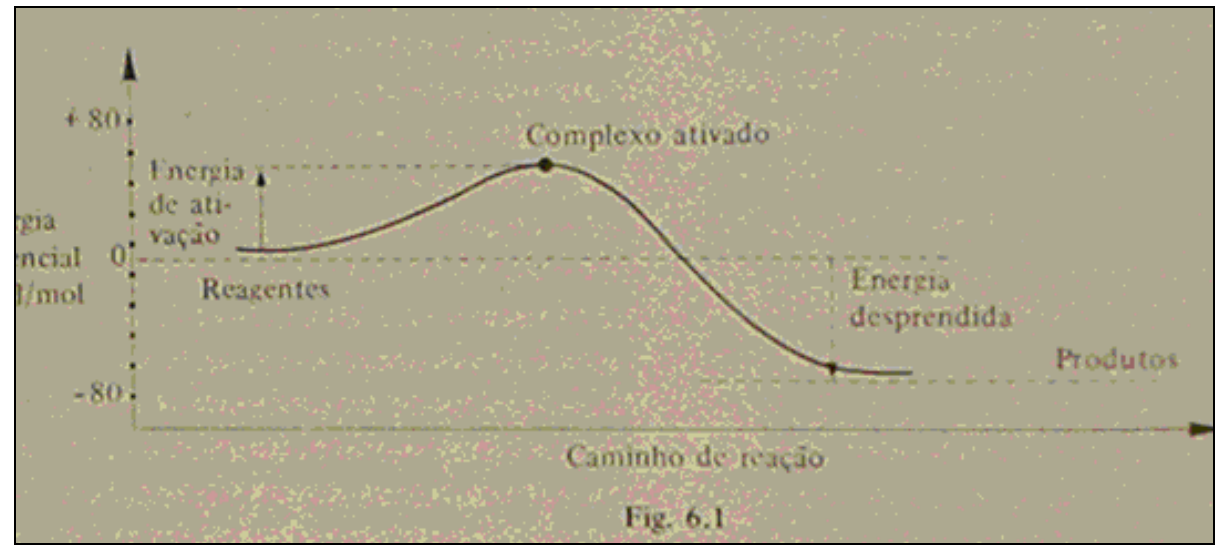

Figura 4.12- Formação do complexo ativado.(p.64)

A velocidade da reação depende então da energia requerida pelo complexo ativado:

"Se o complexo ativado requer pouca energia para a sua formação, a reação deverá ser rápida, mesmo em temperaturas médias, pois no conjunto das moléculas presentes muitas terão energia suficiente para formar o complexo ativado e iniciar o processo".(p.64)

A explicação acima é então coerente com o quarto programa (Tolman, Eyring, Polanyi, e Evans; 1920-1935), pois explica a reação química e a velocidade através da teoria do estado de transição.

\section{b- A Influência da concentração sobre a velocidade de uma reação:}

\section{Segundo as autoras:}

"A equação que relaciona a velocidade com a concentração dos reagentes é chamada "equação da velocidade"' ( $p .73)$

"As reações também se processam em etapas nas quais nem sempre participam todas as moléculas reagentes indicadas na equação total da reação".(p.73)

\footnotetext{
${ }^{17}$ fig. 4.12
} 
"Somente o estudo experimental da reação poderá indicar quais os reagentes que participam da etapa mais lenta, pois deles vai depender a velocidade global da reação".(p.73)

Segundo as autoras, a velocidade de uma reação pode ser formalizada na seguinte expressão:

\section{$\mathrm{V}=\mathrm{K}[\text { Reagentes }]^{\mathrm{n}}$}

Significando, segundo o texto do livro, que:

"a velocidade da reação é proporcional, sendo $k$ uma constante de proporcionalidade, à concentração dos reagentes afetados de um expoente $\boldsymbol{n}$ que será descoberto no estudo experimental da reação. Os reagentes aqui mencionados são aqueles que participam da etapa determinadora da velocidade da reação, e não todos os reagentes que aparecem na equação." (p.73).

"A ordem de uma reação é dada pela soma dos expoentes que aparecem na expressão da sua lei da velocidade".(p.73).

A explicação fornecida pelo livro é coerente com o terceiro programa de investigação (Lewis, Ostwald e Arrhenius; 1889-1918), pois se encontra a definição de ordem de uma reação, e indica-se que a lei da velocidade para uma reação química só pode ser determinada experimentalmente.

\section{c-A influência da temperatura:}

O efeito da temperatura é explicado no livro através da figura 4.13 , onde se encontra o gráfico onde:

\footnotetext{
"E representa a energia de ativação de uma reação qualquer. O pico do gráfico mostra que é maior o número de moléculas com energia intermediária em cada temperatura $t_{1}$ ou $t_{2}$ do que o número de moléculas aceleradas ou retardadas."(p.65).
} 


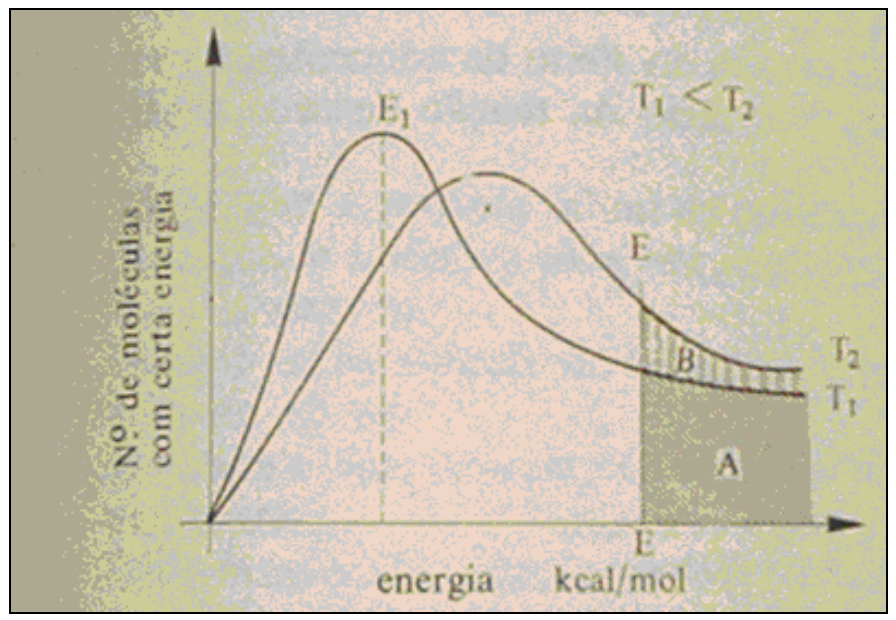

Figura 4.13- Efeito da temperatura sobre a distribuição da energia cinética. (p.65)

A definição de energia de ativação encontrada no livro é a de energia necessária para formar o complexo ativado. Sendo que:

"A energia de ativação é um valor característico para as moléculas que formam o complexo ativado Isto significa que o valor da energia não pode ser alterado; mas é possível acelerar uma reação de dois modos:

(a) Ativando com alguma forma de energia as moléculas reagentes para que um maior número delas tenha a energia suficiente para formar o complexo ativado,

(b) Mudando o "caminho da reação", de modo a formar outro complexo ativado que requeira menor quantidade de energia." (p.65).

Portanto, explicação dada pelos autores relaciona a energia de ativação com a formação do complexo ativado, sendo esta a explicação do quarto programa (Tolman, Eyring, Polanyi, e Evans; 1920-1935).

\section{II- Características da ciência. Categorias:}

1-Concepção de ciência: Segundo as autoras: "Cada ciência é um ponto de vista que se assume num determinado momento para estudar os sistemas materiais que formam o mundo que nos cerca”. O texto indica que a ciência é modificável e visa explicar uma determinada realidade, portanto é coerente com a perspectiva 
Racionalista. Essa visão de ciência, segundo a perspectiva racionalista, também é observada no desenvolvimento do capitulo da cinética química. O conhecimento cientifico é apresentado como um conjunto de hipóteses, que vão sendo modificadas através do tempo.

2-O desenvolvimento da ciência: As explicações tornam-se mais completas durante o desenvolvimento do conteúdo no livro didático. Portanto, essa forma de apresentação de conteúdo pode levar o leitor a ter uma imagem de ciência coerente com a perspectiva Racionalista.

3-A construção do conhecimento científico: A proposta do livro é a de um ensino indutivo, portanto a observação de dados experimentais é colocada como a uma etapa importante do método científico, sendo coerente com a perspectiva empirista/indutivista.

\section{Livro 14- 1979}

A proposta do livro, segundo os autores, é apresentar aos alunos do $2^{\circ}$. Grau (ensino médio):

"Uma visão global da Química, oferecendo-Ihes os alicerces para estudos posteriores mais aprofundados". (carta dos autores). ${ }^{18}$

De acordo com os autores, os alunos já ouviram falar em energia cinética, que é a energia de movimento, transferindo-se essa idéia para uma reação química, os autores mencionam que:

"A cinética química é o estudo dos movimentos das partículas reagentes, numa reação".(p.98) ${ }^{19}$

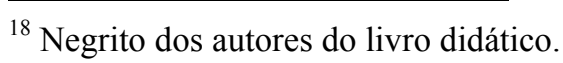


"Que é cinética química?

É a parte da química que estuda a velocidade de uma reação, bem como os fatores que a influenciam"(p.98)

\title{
I- Nível de explicação teórica atingido:
}

\section{a- Modelo teórico que explica a velocidade de uma reação química:}

Os autores apontam que para ocorrer uma reação é necessário que haja colisão entre as moléculas para que se formem novas substâncias. Mas, apontam também que, além de colidirem, as moléculas devem possuir uma "orientação certa" com uma "quantidade suficiente de energia":

\begin{abstract}
"As moléculas das substancias reagentes estão em constante e desordenado movimento, e com isso, elas sofrem colisões. Entretanto, para que a reação ocorra, as moléculas não deverão somente colidir, mas colidir com uma orientação certa e com quantidade suficiente de energia". $(p .100)^{20}$
\end{abstract}

Esta explicação é, portanto, coerente com a do terceiro programa (Lewis, Ostwald e Arrhenius;1889-1918).

\section{b- A Influência da concentração sobre a velocidade de uma reação:}

Para explicar o efeito da concentração os autores apresentam:

$$
\begin{aligned}
& \text { "Os cientistas Guldberg-Waage, estudando a influência da } \\
& \text { concentração dos reagentes na velocidade de uma reação, chegaram } \\
& \text { a seguinte conclusão: } \\
& \text { Numa determinada temperatura, a velocidade de uma reação é } \\
& \text { diretamente proporcional ao produto das concentrações molares dos } \\
& \text { reagentes." (p.101-102) } \\
& \text { "A velocidade da reação é proporcional ao produto das concentrações } \\
& \text { molares dos reagentes, elevadas a expoentes iguais aos respectivos } \\
& \text { coeficientes na equação química balanceada" (p.102). }
\end{aligned}
$$

Segundo a lei da ação das massas, a equação para o cálculo da velocidade é:

\footnotetext{
${ }^{19}$ Negrito dos autores do livro didático.

${ }^{20}$ Negrito dos autores do livro didático.
} 


$$
v=k x \text { (produto das concentrações molares dos reagentes) }
$$

Não foram encontrados no livro os conceitos de ordem, molecularidade e de mecanismo de uma reação química.

\section{c- A influência da temperatura:}

A influência da temperatura é explicada pelos autores através da relação abaixo:

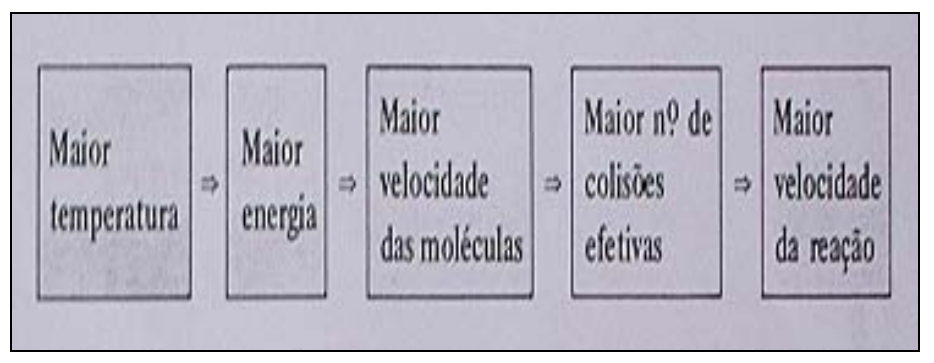

Figura 4.14- Relação entre a temperatura e a velocidade de uma reação (p.101).

Mencionam ainda, que se baseando em dados experimentais Van't Hoff estabeleceu a seguinte regra:

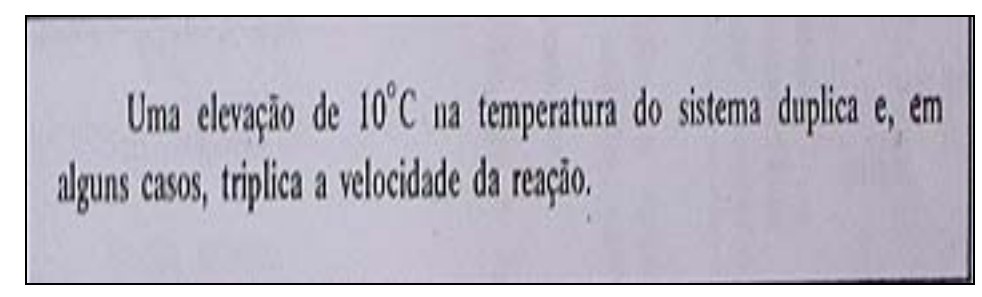

Figura 4.15- Regra de Van' Hoff (p.101)

A explicação dada se aproxima as idéias apresentadas no segundo programa (Pfaunder e Van't Hoff;1872-1888), pois relaciona o aumento da temperatura com o acréscimo na freqüência de colisões.

\section{II- Características da ciência. Categorias:}

1-Concepção de ciência: As teorias são apresentadas nos livros didáticos, como enunciados gerais (ex: regra de Van't Hoff e Lei de Guldberg-Waage), os autores 
não mostram no texto, o caráter dinâmico da ciência, sendo então esta forma de abordagem coerente com a visão de ciência que a perspectiva empirista/indutivista apresenta.

2-O desenvolvimento da ciência: no livro didático não se encontra um texto, que mostre a evolução conceitual das explicações teóricas utilizadas no capítulo da cinética química, indicando assim uma perspectiva empirista/indutivista do desenvolvimento da ciência.

3-A construção do conhecimento científico: $O$ papel da experimentação é o de fornecer dados aos cientistas, para que esses possam elaborar regras e teorias (perspectiva empirista/indutivista):

"Os cientistas Guldberg-Waage, estudando a influência da concentração dos reagentes na velocidade de uma reação, chegaram a seguinte conclusão.."(p.101)

“Baseando-se em dados experimentais, Van't Hoff estabeleceu.... essa regra ficou conhecida como regra de Van't Hoff". (p.101).

Observa-se que o nome dos cientistas aparecem juntos, Guldberg-Waage, eles parecem ter perdido um pouco suas identidades e se transformaram em um único nome.

\section{Livro 15 - 1980}

Não há nesse livro carta ao leitor ou qualquer observação do autor em relação à proposta pedagógica do livro. Para o autor, o capitulo cinética química é a parte da química que estuda a velocidade das reações. Não há exemplos de aplicação dos estudos cinéticos na ciência, na indústria, ou em qualquer outra área de atividade.

\section{I-Nível de explicação teórica atingido:}




\section{a- Modelo teórico que explica a velocidade de uma reação química:}

No texto do livro encontra-se a seguinte explicação para a velocidade de uma reação em termos microscópicos:

"Aumentando-se a concentração dos reagentes, aumenta tam'bem o numero de partículas reagentes (moléculas ou íons) por unidade de volume; com isto as partículas reagentes ficarão mais próximas uma das outras e aumentará o número de colisões entre elas no mesmo tempo. Com o aumento do número de colisões por unidade de tempo entre as partículas reagentes, aumentará a velocidade da reação (TEORIA DA COLISÃO)".(p.156).

O autor relaciona o aumento da freqüência das colisões entre as partículas reagentes com o aumento da velocidade, portanto a explicação fornecida pelo livro didático é coerente com a do terceiro programa (Lewis, Ostwald e Arrhenius;18891918).

b-A Influência da concentração sobre a velocidade de uma reação:

A influência da concentração na velocidade é explicada através da colisão entre as partículas. Portanto, aumentando-se a concentração dos reagentes, aumenta-se o número de colisões, pois segundo o autor, as partículas reagentes estarão mais próximas uma das outras.

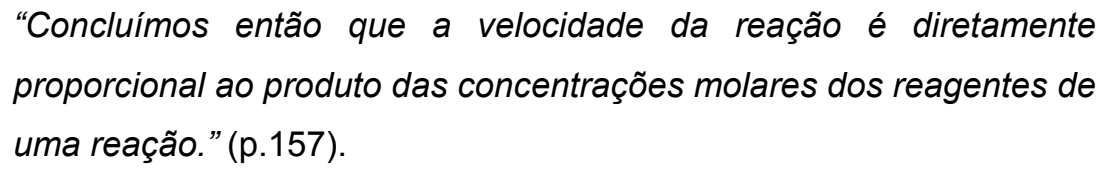
proporcional ao produto das concentrações molares dos reagentes de uma reação." (p.157).

O autor menciona então, que para uma reação qualquer a velocidade pode ser calculada através do uso da lei da Ação das Massas (lei de Guldberg-Waage-1864): 


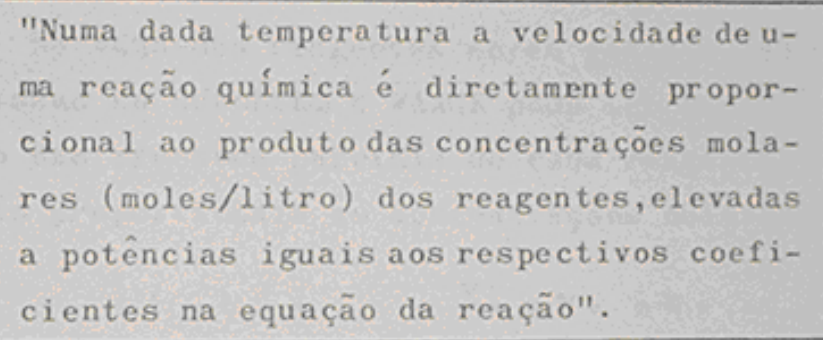

Figura 4.16- Enunciado da Lei de Guldberg-Waage. (p.161).

Segundo o autor, outros pesquisadores como Bertholet estudaram o efeito da concentração dos reagentes na velocidade de uma reação, mas aponta que:

"Quem enunciou a lei definitiva relacionando matematicamente a velocidade da reação com a concentração dos reagentes, foi a dupla Guldberg-Waage". (p.162).

Não há no texto referência às limitações ao uso da lei de Guldberg-Waage.

O termo molecularidade das reações aparece no texto definido como sendo "o número mínimo de moléculas dos reagentes, necessário para que a reação considerada possa se realizar".

A ordem de uma reação é determinada, segundo o autor, em função da equação de velocidade da reação:

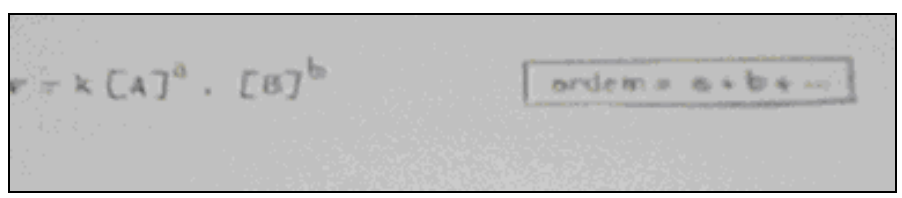

Figura 4.17- Cálculo da ordem de uma reação. (p.178).

Não se encontra no livro o conceito de mecanismo de uma reação química. Portanto, para explicar a influência da concentração na velocidade o autor utiliza a Lei de Guldberg-Waage.

\section{b-A influência da temperatura:}


Segundo o autor, a elevação da temperatura produz um aumento na energia cinética das moléculas dos reagentes e, portanto, um aumento de sua velocidade. Com isso, "as colisões serão mais violentas, e haverá aumento de velocidade da reação".(p.152).

O autor usa um gráfico para explicar o efeito da temperatura na velocidade de uma reação (fig.4.21), onde relaciona a energia de ativação com a velocidade de uma reação química:

$$
\begin{aligned}
& \text { "Pode-se verificar pelo gráfico, que o número de moléculas com } \\
& \text { energia cinética mais elevada que a energia de ativação }\left(E_{a}\right) \text { na } \\
& \text { temperatura } T_{1} \text { é muito pequeno; nestas condições a velocidade da } \\
& \text { reação na temperatura } T_{1} \text { é muito pequena; pode-se verificar pelo } \\
& \text { gráfico que na temperatura } T_{2} \text { o número de moléculas com energia } \\
& \text { cinética maior que a energia de ativação }\left(E_{a}\right) \text { é grande suficiente para } \\
& \text { que a reação se realize com velocidade satisfatória". (p154). }
\end{aligned}
$$

Portanto, a explicação encontrada no texto pode ser considerada coerente com a do terceiro programa (Lewis, Ostwald e Arrhenius;1889-1918).

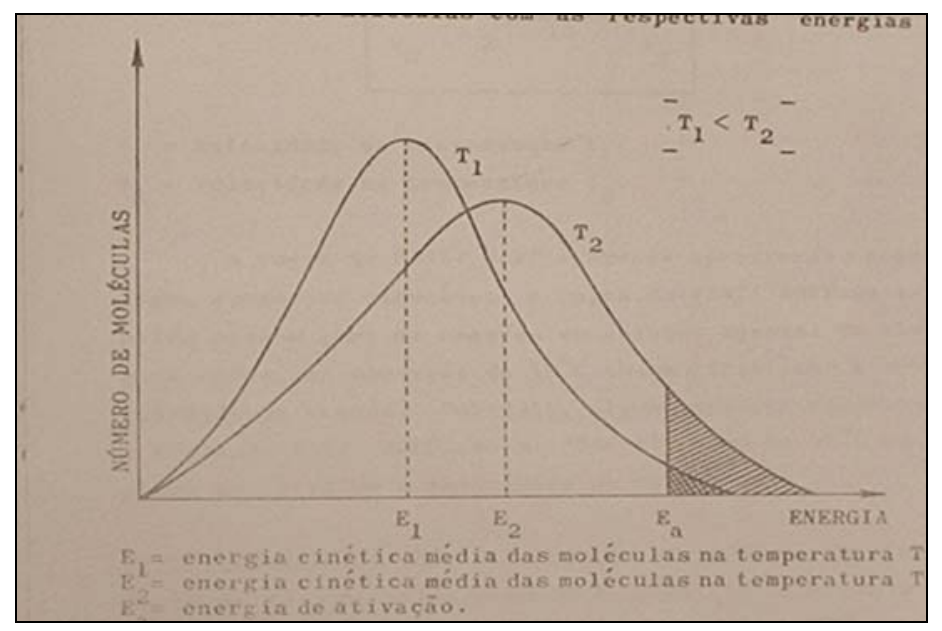

Figura 4.18- Curvas de distribuição das energias cinéticas das moléculas reagentes em duas temperaturas $T_{1}$ e $T_{2} \cdot(p .153)$.

Porém, o autor indica a seguinte relação entre a temperatura e a velocidade de uma reação: 
"Van't Hoff, estudando a influência da temperatura na velocidade das reações, estabeleceu uma regra: Uma elevação de $10^{\circ} \mathrm{C}$ na temperatura duplica a velocidade da reação (Regra de VAN'T HOFF)".(p.154)

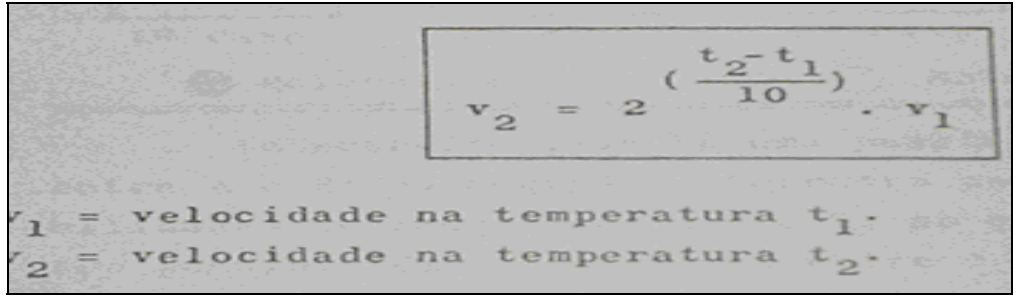

Figura 4.19- Cálculo da velocidade usando-se a regra de Van't Hoff (p. 155).

O autor menciona que a regra de Van't Hoff é apenas aproximada e como regra apresenta exceções.

O autor, nesse livro já apresenta uma explicação em termos microscópicos para a velocidade de uma reação química, utilizando a teoria das colisões e o conceito de energia de ativação, conceitos que não estavam presentes no seu livro que foi anteriormente analisado ( Geraldo Camargo de Carvalho em parceria com Waldemar Saffioti, livro 6,1954), porém ele ainda utiliza a lei de Guldberg-Waage e a regra de Van't hoff, na explicação da concentração e da temperatura respectivamente. Pode-se observar então, uma necessidade do autor em representar matematicamente essas influências, para que ele possa cobrar esses cálculos nos exercícios que ele propõe no capítulo de cinética química.

\section{II- Características da ciência. Categorias:}

1-Concepção de ciência: esta categoria no livro didático pode ser caracterizada pela perspectiva Empirista/indutivista. As leis e teorias são apresentadas no livro como enunciados universais:

"Quem enunciou a lei definitiva relacionando matematicamente a velocidade da reação com a concentração dos reagentes, foi a dupla Guldberg-Waage”. (p.162). 
2- O desenvolvimento da ciência: No livro, para explicar o efeito da concentração na velocidade de uma reação, aparece um pequeno desenvolvimento histórico, mas esse é feito de maneira contínua e acumulativa, não há indicação que uma teoria suplantou outra por aumentar seu poder explicativo:

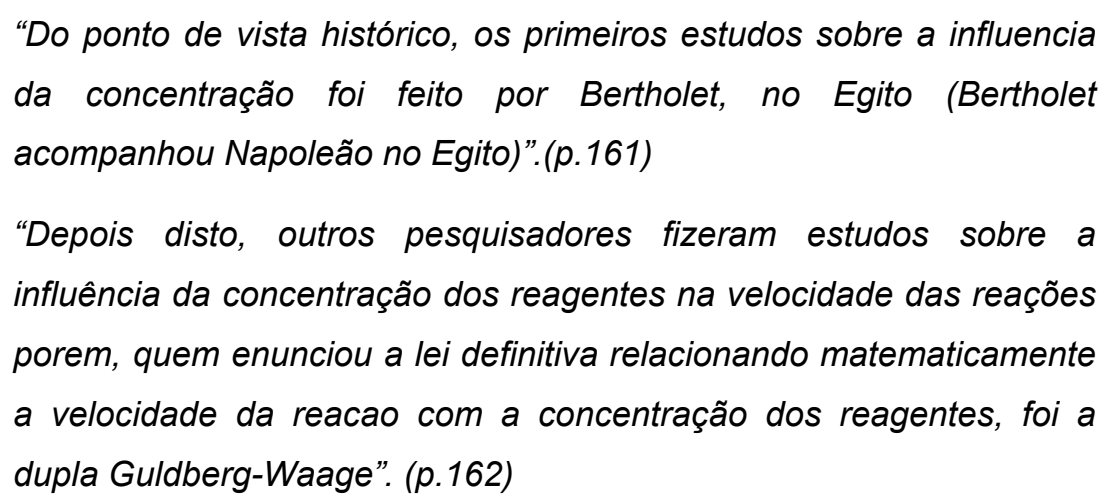

Essa maneira de abordar o desenvolvimento da ciência pode ser considerada coerente com a perspectiva empirista/indutivista.

3- A construção do conhecimento científico: é abordada de acordo com as idéias da perspectiva empirista/indutivista, onde o conhecimento é obtido através do estudo de dados experimentais:

\footnotetext{
"Van't Hoff, estudando a influência da temperatura na velocidade das reações, estabeleceu uma regra.." (p.154).
}

\section{Livro 16- 1993}

Este livro dá prosseguimento ao livro "Química -1", da mesma coleção. Os autores fazem parte atualmente do grupo de pesquisadores da área de ensino de química denominado Gipec (Grupo Interdepartamental de Pesquisa sobre Educação em Ciências -UNIJUÍ).

$\mathrm{Na}$ carta ao leitor os autores colocam que o conhecimento químico, historicamente construído permitiu ao homem a ação de criar e recriar a natureza, 
mudando assim essa relação entre o homem e a natureza, continuando o texto coloca que:

\begin{abstract}
"Cabe também a Educação Química, coordenada por Educadores engajados na luta coletiva do entendimento dos processos produtivos, debater e socializar estes conhecimentos e, assim possibilitar a formação de cidadãos mais conscientes e ativos nos processos desencadeados".(capa, livro Química 2).
\end{abstract}

Segundo os autores do livro, o ensino é estruturado:

“.....em seqüências de atividades sobre as quais se desenvolvem o debate e a discussão entre professores e alunos com vistas ao entendimento da transformação de substâncias, especificamente nos processos de solução, do envolvimento da energia nas reações químicas, da velocidade em que se dão tais reações, da reversibilidade delas nas posições de equilíbrio, da interconversão entre energia química, elétrica e térmica." (capa, livro Química 1).

O capítulo de cinética química inicia-se com um experimento proposto para perceber que as reações químicas ocorrem em velocidades diferentes.

\title{
I- Nível de explicação teórica atingido:
}

\section{a- Modelo teórico que explica a velocidade de uma reação química:}

Como principal requisito para a ocorrência de uma reação química os autores apontam que é necessário que:

“...ocorram colisões entre as moléculas dos reagentes, resultando em um arranjo de átomos que seja diferente do inicial. Com isto verificase que não basta apenas ocorrer uma colisão entre os átomos, mas deve haver uma orientação favorável a formação dos produtosColisões Efetivas." (p. 84).

Mas adiante no texto tem-se a explicação da formação do complexo ativado:

"No decorrer da reação até a formação dos produtos,
intermediariamente são formados outros compostos instáveis,
constituindo-se de um aglomerado de átomos que atuam como uma
estrutura de transição entre reagentes e produtos, denominado de


complexo ativado. No complexo ativado, as ligações entre as moléculas reagentes encontram-se parcialmente rompidas, $e$ as novas ligações estão parcialmente formadas”.(p. 85).

Continuando, encontra-se no texto a explicação de que para que algumas reações químicas aconteçam é necessário que as moléculas reagentes absorvam uma certa quantidade de energia: "Essa energia absorvida fica armazenada nas ligações do complexo ativado, e é denominada de Energia de Ativação (Ea)".

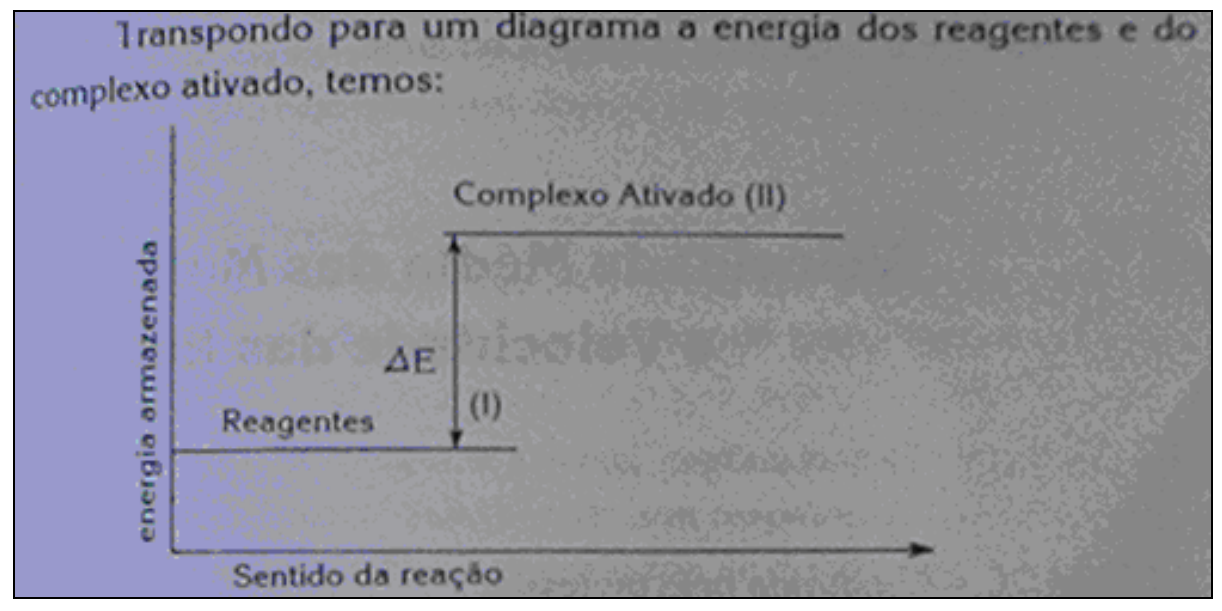

Figura 4.20- Variação de energia durante uma reação química, onde $\Delta \mathrm{E}$ (variação de energia) corresponde a energia absorvida durante a reação (Ea). (p.85).

A explicação acima descrita é coerente com o quarto programa (Tolman, Eyring, Polanyi, e Evans; 1918-1935), pois utiliza a teoria do estado de transição para explicar a velocidade de uma reação.

b- A Influência da concentração sobre a velocidade de uma reação:

No livro encontra-se a afirmação de que a velocidade de uma reação está relacionada à variação da concentração dos reagentes e produtos. E que esta relação pode ser expressa pela lei de Guldberg-Waage: 
de uma reação está relacionada com a variaçăo da concentraçáo dos reagentes e produtos. Cientistas Noruegueses estudaram as rela. çōes existentes entre as concentraçòes das substáncias que participam de uma reação química com a velocidade desta reaçáo e concluíram que a velocidade de uma reação, a uma temperatura constante, é proporcional ao produto das concentraçôes molares dos reagentes elevadas a potências iguais aos respectivos coeficientes na equação química balanceada: $v=k[R]-$ Lei de GulbergWaage ou Lei da Ação das Massas. Esta Lei vale apenas para reaçós elementares ou que se realizam em etapa única. Nos demais casos a expressăo da Lei de velocidade é determinada experimentalmente.

Figura 4.21- Explicação para a influência da concentração na velocidade da reação. (p.84)

Não ha no texto do livro referências aos conceitos de ordem e molecularidade de uma reação química.

Em relação ao curso de uma reação no texto encontra-se a seguinte explicação:

"..normalmente em uma reação química, até a obtenção das espécies finais, ocorre a formação de outros compostos, que são formados e consumidos durante o decorrer da reação, denominados de compostos intermediários....A velocidade da reação química está diretamente relacionada à facilidade ou dificuldade (rapidez) de formação dos compostos nos passos intermediários." (p.96)

Portanto, considerou-se que a influência da concentração na velocidade, não faz parte de nenhum dos quatro programas de investigação.

\section{c- A influência da temperatura:}

Para entender o efeito da temperatura os autores propõem uma atividade prática que consiste em dissolver comprimidos efervescentes em água a temperatura ambiente e em água gelada, propondo em seguida as seguintes questões:

"A velocidade da reação foi influenciada pela temperatura da água? Comentar, e Qual a influência do aumento da temperatura sobre a 
velocidade da reação? Discutir as possíveis causas da alteração da velocidade" (p.89).

Não se encontrou no livro as respostas a essas questões, portanto cabe ao professor discutir essas questões com os alunos. Não há no texto do livro uma explicação sobre relação da temperatura com a energia de ativação.

Somente analisando a proposta do experimento pode-se chegar à idéia de que a temperatura pode influir na velocidade da reação. Esta explicação se aproxima do primeiro programa (Wilhelmy, Harcourt, Esson e Berthelot;1850-1865).

\section{II- Características da ciência. Categorias:}

1-Concepção de ciência: é caracterizada pela perspectiva empirista/indutivista. No desenvolvimento do conteúdo entende-se que a ciência é formada por um conjunto de leis e não de hipóteses que são modificáveis.

2- O desenvolvimento da ciência: Esta categoria não foi identificada no livro didático.

3- A construção do conhecimento científico: o livro didático utiliza a experimentação como parte do desenvolvimento do conteúdo do capitulo de cinética química, onde o seu papel seria o de comprovar as teorias e as leis que se desejam que os alunos aprendam. Esse tipo de abordagem pode levar os alunos a desenvolverem, uma idéia da construção do conhecimento científico, que é coerente com a perspectiva empirista/indutivista, onde é dada uma grande importância ao papel da observação na experimentação, e não na formulação de hipóteses e modelos explicativos. 


\section{Discussão}

A explicação encontrada, em termos microscópicos, para a velocidade de uma reação, em três dos cinco livros é a do quarto programa de investigação (Tolman, Eyring, Polanyi, e Evans; 1918-1935), portanto usam a teoria do complexo ativado. Os outros dois livros utilizam a teoria da colisão, portanto nesse período verifica-se que já existe por parte dos autores uma necessidade de explicar a velocidade de uma reação química em termos microscópicos.

Quanto à influência da concentração na velocidade a maioria dos livros didáticos ainda utiliza a Lei de Guldberg-Waage (tab. 4.7), sendo que o livro de 1980 não coloca limitações ao uso desta lei. A única exceção é o livro de 1977, o qual explica a influência da concentração através da teoria do terceiro programa de investigação (Lewis, Ostwald e Arrhenius; 1889-1918).

A influência da temperatura é explicada na maioria dos livros com exceção do livro de 1993. Nesses quatro livros $(1976,1977,1779,1980)$ já aparece o conceito de energia de ativação relacionada à velocidade de uma reação.

Na proposta de ensino dos livros de 1977 e de 1993 a experimentação tem grande importância no desenvolvimento do conteúdo. Nesses livros, os experimentos são elaborados com o objetivo de se verificar quais são os fatores que afetam a velocidade de uma reação e também de provocar discussões, através de questões, entre alunos e professores.

Parece que o Chem-study (1967), dá um certo direcionamento ao tratamento desse assunto (cinética química) nos livro didáticos brasileiros desse período. Dois 
deles parecem adotar uma certa abordagem metodológica proposta no Chem-study (a experimentação), e a maioria enfoca modelo explicativos com mais profundidade do que vinha sendo feito até então.

É interessante notar que embora os autores dos livros recorram a explicações mais complexas em termos de modelos, também apresentam conhecimentos práticos, como a regra de Van't Hoff, a ordem como sendo a soma dos expoentes de uma reação química. É interessante também a persistência do emprego da "lei de Guldberg-Waage” para se apresentar uma equação matemática para a velocidade de reação, exceção feita a um dos livros (n.13,1977), mesmo sem as devidas considerações de seus limites.

Talvez esse tipo de transposição didática justifique uma certa praticidade pedagógica de poder tratar operacionalmente um conceito. A introdução de noções de mecanismo ou de reações em etapas (lentas e rápidas), não contribuiu, em vários desses livros, para relativizar ou restringir aquela lei.

O intervalo de tempo para que esses livros didáticos, na sua maioria, começassem a utilizar teorias mais complexas para explicar a velocidade de uma reação foi bastante longo. Demorou aproximadamente 40 anos para que as idéias vinculadas ao último programa de investigação científica (Tolman, Eyring, Polanyi, e Evans; 1920-1935) começassem aparecer nos livros didáticos brasileiros.

A química já tinha se firmado como um campo de estudo no Brasil, já estavam consolidados cursos superiores e de licenciatura em Química.

Embora nesta época estivessem ocorrendo grandes mudanças no ensino e sendo estas influenciadas pela nova filosofia da ciência, os livros didáticos analisados ainda apresentam, concepções de ciência mais coerentes com a 
perspectiva empirista/indutivista, sendo que apenas o livro de 1977 começa a apresentar algumas características da ciência coerentes com a perspectiva racionalista (tab. 4.8). Essas características se referem à concepção de ciência e ao seu desenvolvimento. Portanto, apresenta a ciência como um conjunto de hipóteses que são modificáveis, onde o seu progresso é caracterizado por estas mudanças teóricas, revelando assim o caráter dinâmico da ciência.

Em relação à construção do conhecimento científico, os livros analisados dão grande ênfase à experimentação e à observação no desenvolvimento do conteúdo, o que segundo Campos e Cachapuz (1997), pode levar os alunos a ver o método cientifico como um conjunto de regras fixas para encontrar "a verdade", começando invariavelmente pela observação dos fenômenos, seguindo assim, uma orientação predominantemente empirista.

Segundo Sicca (1990), a pedagogia oficial nos anos setenta enfatizava no ensino de ciências, e em particular no ensino de química, a vivência do método científico, através do uso da experimentação, mas obervou-se que apenas dois livros didáticos (1977 e 1993), utilizam a experimentação no desenvolvimento do conteúdo. 


\begin{tabular}{clcc}
\hline & \multicolumn{3}{c}{ Programas de Investigação Científica } \\
\hline & $\begin{array}{l}\text { Explicação, em } \\
\text { termos } \\
\text { microscópicos da } \\
\text { Livros }\end{array}$ & $\begin{array}{l}\text { Explicação de como a } \\
\text { velocidade de uma } \\
\text { reação química } \\
\text { depende das } \\
\text { colocidacicos/Ano } \\
\text { velontrações das } \\
\text { reação química. }\end{array}$ & $\begin{array}{l}\text { Explicação da } \\
\text { influência da } \\
\text { temperatura na } \\
\text { velocidade de uma } \\
\text { reação química }\end{array}$ \\
\hline $12 / 1976$ & PIC-IV & GW & PIC- IV \\
\hline $13 / 1977$ & PIC-IV & PIC-III & PIC-IV \\
\hline $15 / 1980$ & PIC-III & GW & PIC-II \\
\hline $16 / 1993$ & PIC-III & GW & PIC-III \\
\hline
\end{tabular}

Tabela 4.7- Caracterização dos livros didáticos do quarto período (1971-1995). Nota: PICI:Programa de Investigação Científica de Wilhelmy, Harcourt, Esson e Berthelot (18501865); PIC-II: Programa de Investigação Científica de Pfaundler e Van't Hoff (18721888);PIC-III:Programa de Investigação Científica de Lewis, Ostwald e Arrhenius (18891918); PIC-IV: Programa de Investigação Científica de Tolman, Eyring, Polanyi, e Evans (1920-1935); GW: Indica o uso da Lei de Guldberg-Waage.

\begin{tabular}{|c|c|c|c|}
\hline & & Categorias & \\
\hline $\begin{array}{l}\text { Livros } \\
\text { Didáticos/Ano }\end{array}$ & $\begin{array}{l}\text { 1- Concepção de } \\
\text { ciência }\end{array}$ & $\begin{array}{l}\text { 2- O Desenvolvimento } \\
\text { da Ciência }\end{array}$ & $\begin{array}{l}\text { 3- A construção do } \\
\text { conhecimento científico }\end{array}$ \\
\hline $12 / 1976$ & $E / I$ & $\mathrm{R}$ & $\mathrm{N}$ \\
\hline $13 / 1977$ & $\mathrm{R}$ & $\mathrm{R}$ & $E / I$ \\
\hline $14 / 1979$ & $E / I$ & $E / I$ & $E / I$ \\
\hline 15/1980 & $E / I$ & $E / I$ & $E / I$ \\
\hline $16 / 1993$ & $E / I$ & $\mathrm{~N}$ & $E / I$ \\
\hline
\end{tabular}

Tabela 4.8- Concepções de ciência apresentadas pelos livros didáticos do quarto período (1971 -1995). Nota: E/l=Empirista/indutivista, R=Racionalista, N= Não identificado: os livros didáticos não fazem menção explicita a qualquer uma das duas interpretações. 


\subsection{Quinto período (1996 a 2004)}

Segundo a Lei número de 9394, de 20 de dezembro de 1996, a educação deve abranger os processos formativos que se desenvolvem na vida familiar, na convivência humana, no trabalho, nas instituições de ensino e pesquisa, nos movimentos sociais e organizações da sociedade civil e nas manifestações culturais, também coloca que a educação deverá vincular-se ao mundo do trabalho e à prática social.

O ensino médio, com duração mínima de três anos, segundo a lei de número 9394/96, tem como algumas finalidades, a consolidação e o aprofundamento dos conhecimentos adquiridos no ensino fundamental, possibilitando o prosseguimento de estudos; a preparação básica para o trabalho e a cidadania do educando, para continuar aprendendo, de modo a ser capaz de se adaptar com flexibilidade a novas condições de ocupação ou aperfeiçoamento posteriores; o aprimoramento do educando como pessoa humana, incluindo a formação ética e o desenvolvimento da autonomia intelectual e do pensamento crítico, entre outras.

Quanto ao currículo, o ensino médio deverá seguir as seguintes diretrizes:

\footnotetext{
“I - destacará a educação tecnológica básica, a compreensão do significado da ciência, das letras e das artes; o processo histórico de transformação da sociedade e da cultura; a língua portuguesa como instrumento de comunicação, acesso ao conhecimento e exercício da cidadania;

II - adotará metodologias de ensino e de avaliação que estimulem a iniciativa dos estudantes;

III - será incluída uma língua estrangeira moderna, como disciplina obrigatória, escolhida pela comunidade escolar, e uma segunda, em caráter optativo, dentro das disponibilidades da instituição."
} 
No ano de 2000, o Ministério da Educação lançou os Parâmetros Curriculares Nacionais como um complemento da LDB 9394/96, onde estão definidos os objetivos do ensino médio:

\begin{abstract}
"Os objetivos do Ensino Médio em cada área do conhecimento devem envolver, de forma combinada, o desenvolvimento de conhecimentos práticos, contextualizados, que respondam às necessidades da vida contemporânea, e o desenvolvimento de conhecimentos mais amplos e abstratos, que correspondam a uma cultura geral e a uma visão de mundo. Para a área das Ciências da Natureza, Matemática e Tecnologias, isto é particularmente verdadeiro, pois a crescente valorização do conhecimento e da capacidade de inovar demanda cidadãos capazes de aprender continuamente, para o que é essencial uma formação geral e não apenas um treinamento específico" (p.6).
\end{abstract}

Observa-se, então, que o objetivo do ensino não é somente proporcionar ao aluno do ensino médio uma formação específica, técnica, mas sim proporcionar uma formação geral, contextualizada, de forma a permitir que estes alunos exerçam de forma consciente as suas escolhas na comunidade em que vivem. No ensino de química, em especial no que diz respeito à cinética química, nos PCNs (2000) é proposta a seguinte abordagem:

"O tratamento das relações entre tempo e transformação química deve ser iniciado pela exploração dos aspectos qualitativos, que permitem reconhecer, no dia-a-dia, reações rápidas, como combustão e explosão, e lentas, como o enferrujamento e o amadurecimento de um fruto, estabelecendo critérios de reconhecimento. Controlar e modificar a rapidez com que uma transformação ocorre são conhecimentos importantes sob os pontos de vista econômico, social e ambiental. É desejável, portanto, que o aluno desenvolva competências e habilidades de identificar e controlar as variáveis que podem modificar a rapidez das transformações, como temperatura, estado de agregação, concentração e catalisador, reconhecendo a aplicação desses conhecimentos ao sistema produtivo e a outras situações de interesse social. Estabelecidas essas relações e ampliando-as, é preciso que se percebam as relações quantitativas que expressam a rapidez de uma transformação química, 
reconhecendo, selecionando ou propondo procedimentos experimentais que permitem o estabelecimento das relações matemáticas existentes, como a "lei da velocidade".(p.33).

Portanto, há uma orientação mais específica relativa aos conteúdos de cinética de química que devem ser abordados no ensino médio. De acordo com tais orientações, deve-se iniciar o ensino de cinética a partir da observação de fenômenos que o aluno encontra no seu cotidiano, para que ele entenda a dependência da temperatura e da concentração na velocidade e assim ele possa, em um segundo momento estabelecer relações matemáticas para determinar a velocidade de uma reação química. Pode-se esperar, então, que os livros didáticos que foram publicados após os Parâmetros Curriculares Nacionais possam ser influenciados por algumas de suas diretrizes em ralação ao ensino de química.

\subsubsection{A análise dos livros}

Foram analisados cinco livros didáticos neste período de tempo. Todos os livros possuem exercícios e experimentos dirigidos aos alunos, mas apenas dois livros, 2001 e 2003, utilizam a experimentação para o desenvolvimento dos conceitos, e não como uma atividade complementar, optativa, como, por exemplo, os exercícios e testes.

\section{Livro 17- 1999.}

Na apresentação do volume 1 (um) da coleção do qual faz parte este livro, a autora explica como o livro é estruturado. 
A autora utiliza no inicio de cada capitulo, perguntas-chave, "cujas respostas são obtidas por meio da compreensão dos conceitos que nele estão desenvolvidos", e os conceitos são introduzidos, "sempre que possível, a partir de conhecimentos que você já tenha (seção: você pode refletir)".

Quanto aos experimentos, a autora aponta que são sugestões de experimentos simples que podem ser executados na escola, mesmo que ela não disponha de laboratório. Contudo ela utiliza esses experimentos apenas como ilustração, o aluno não é solicitado a realizar o experimento, durante o desenvolvimento do capitulo.

Todas as seções do livro, segundo a autora, têm como objetivo cumprir várias funções, como por exemplo:

" - Relacionar a química com outras áreas do conhecimento ou com temas do cotidiano, como saúde, ambiente, literatura, agricultura,etc; - analisar aspectos históricos da evolução da Química e da vida de alguns cientistas." (carta de apresentação, Vol.1)

O capítulo de cinética química, no livro inicia-se com a pergunta-chave: Por que estudar velocidade de reação? Segundo a autora: "as reações químicas têm permitido a humanidade resolver muitas das questões que a desafiam".

Para iniciar o estudo dos fatores que afetam uma reação, a autora sugere um experimento ("Você pode experimentar") onde os fatores temperatura, concentração e o estado de divisão de um sólido (superfície de contato), podem ser verificados. Percebe-se uma preocupação com a construção do conceito, tanto que há uma tentativa de abordar os conceitos a partir do experimento, no entanto ela explica os fatos, o aluno não é solicitado a elaborar uma explicação para os fatos que aparecem no experimento, portanto não há problematização. 
O livro didático possui vários exercícios, tanto em forma de questões abertas como também na forma de testes, sendo que muitos deles são de vestibulares passados.

A definição para a velocidade usada pela autora é a de velocidade média:

"v= variação da quantidade de uma substância/intervalo de tempo considerado".(p.134)

Onde existe a seguinte observação:

"Estamos discutindo o conceito de VELOCIDADE MÉDIA de uma reação, num dado intervalo de tempo, $\Delta$ t. $O$ conceito de velocidade instantânea (quando $\Delta t$ tende a zero) foge ao nível de nosso curso."(p.134)

\section{I-Nível de explicação teórica atingido:}

\section{a- Modelo teórico que explica a velocidade de uma reação química:}

Para explicar, em termos microscópicos, a velocidade de uma reação a autora inicialmente utiliza a teoria das colisões:

\section{"Segundo a teoria das colisões, o que determina a velocidade da reação é a natureza e a quantidade de choques moleculares." (p.139).}

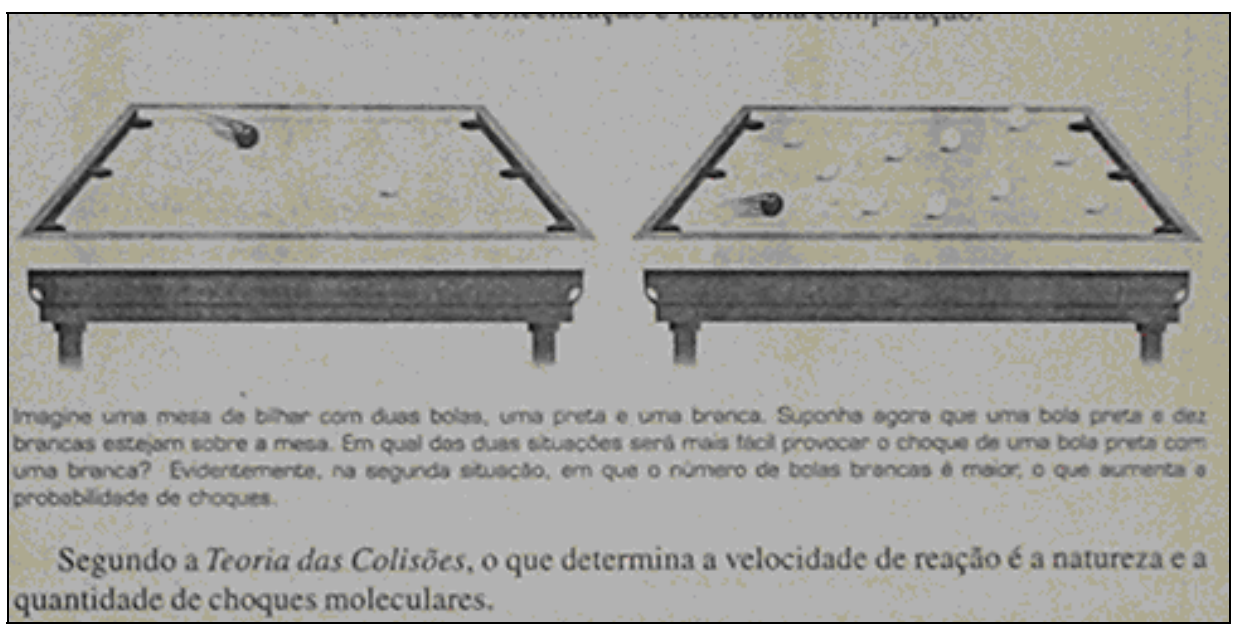

Figura 4.22- reapresentação dos choques microscópicos (p.139). 
No entanto, segundo a autora, nem todos os choques moleculares tem como conseqüência à formação de novas substâncias:

"Para haver transformação, devemos ter quebra de ligações químicas e formações de novas ligações, o que requer colisões eficazes ou efetivas, nas quais são indispensáveis duas condições:

- orientação favorável das moléculas em choque;

- colisão suficientemente energética". (p.140).

A fig.4.23 reproduz a ilustração da reação entre o ácido clorídrico e a água utilizada pela autora para indicar a necessidade da orientação adequada da molécula no momento da colisão.

A colisão ser suficientemente energética significa para autora que: "é essencial que a energia cinética das moléculas seja suficiente para enfraquecer as ligações que mantêm unidos os átomos na molécula reagente" (p.140). A energia mínima necessária para que os reagentes possam se transformar em produtos é denominada pela autora de energia de ativação.

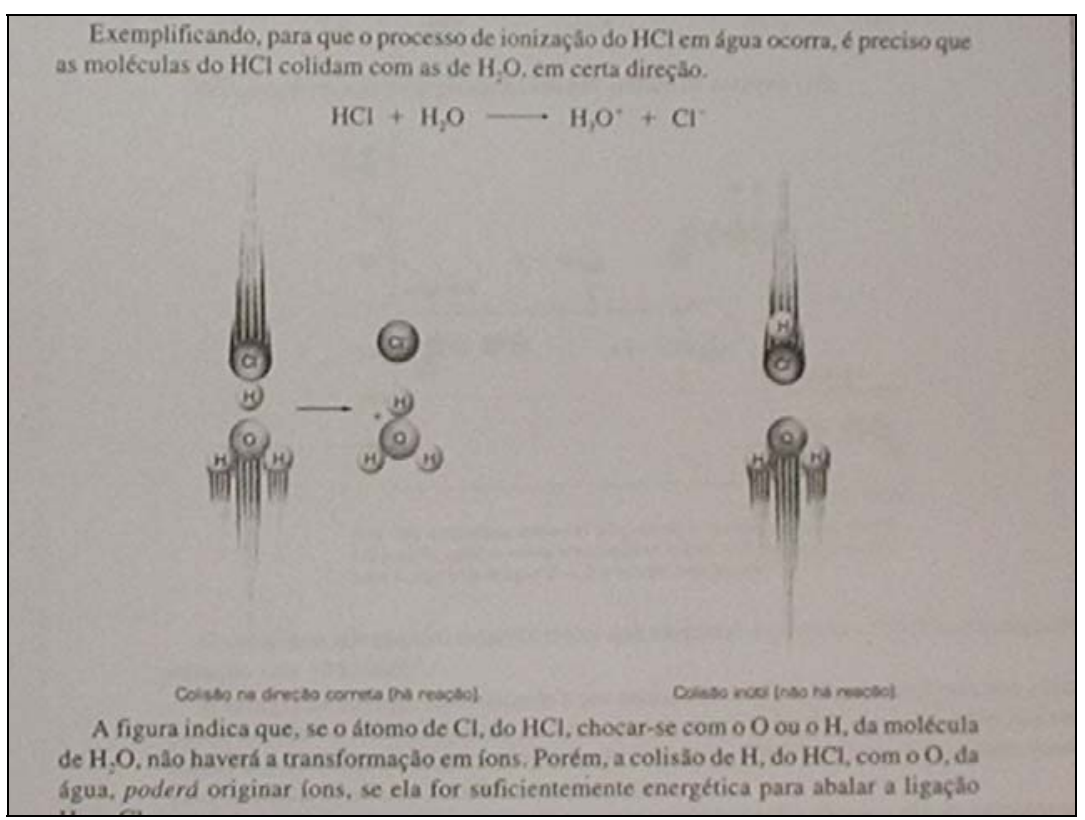

Figura 4.23- A ocorrência de uma reação depende da orientação espacial apropriada (demonstrado no lado esquerdo da figura).(p.140). 
Chama a atenção à idéia de "enfraquecer as ligações" que também é encontrada no livro 10 de 1967 (Chem-study), e que não é utilizada em outros livros onde se encontra com mais freqüência a idéia de "romper ligações".

A autora explica que, ao atingir a energia de ativação os reagentes se transformam em um produto intermediário chamado complexo ativado. A influência da energia de ativação na velocidade de uma reação, segundo a autora é:

"Quanto maior a energia de ativação de uma reação espontânea,
menor a velocidade da reação, já que haverá menos moléculas com
energia acima desse valor mínimo. O inverso também é
verdadeiro".(p.141)

A explicação desenvolvida pela autora é coerente com a do quarto programa (Tolman, Eyring, Polanyi, e Evans; 1918-1935), pois em sua explicação ela relaciona a velocidade de uma reação à formação do complexo ativado.

\section{b- A Influência da concentração sobre a velocidade de uma reação:}

Segundo a autora, o modelo teórico utilizado inicialmente para explicar o efeito da concentração na velocidade é o da Teoria das Colisões.

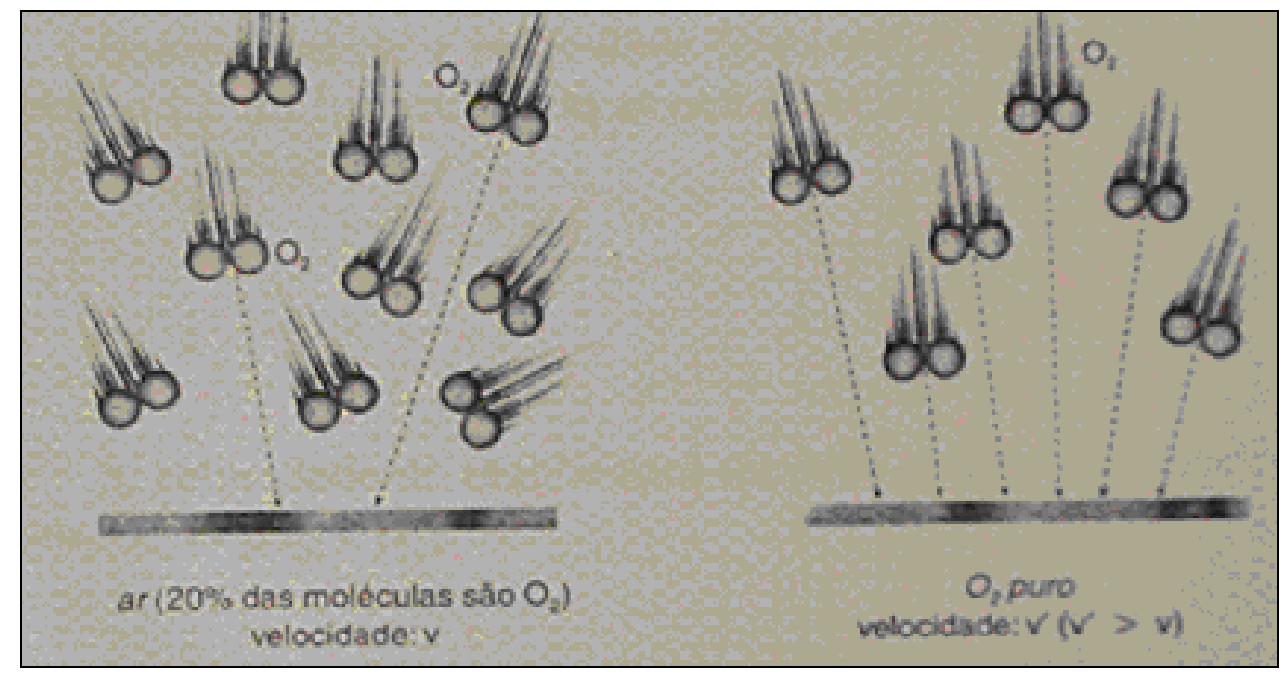

Figura 4.24- Relação entre a concentração e a velocidade, sob a análise da Teoria das colisões (p.148). 
A autora aponta que a velocidade de reação é proporcional ao produto das concentrações:

$$
\mathrm{v}_{1}=\mathrm{k}_{1}[\mathrm{c}]
$$

e que se pode calcular a velocidade em função da concentração dos reagentes utilizando-se a lei da ação das massas:

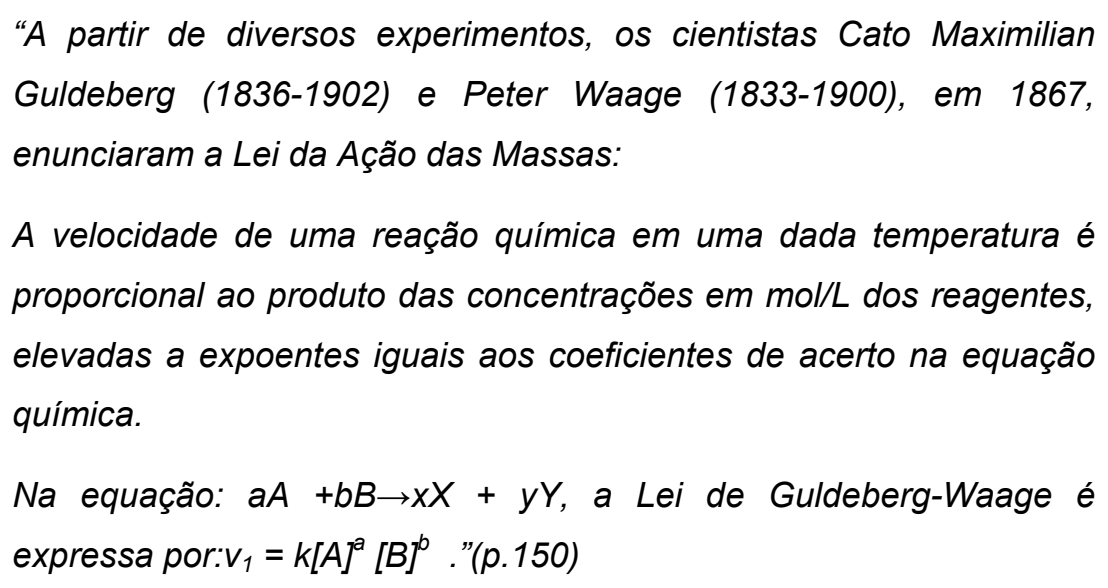
mas em seguida ela diz que:

"Com a realização de novos experimentos da velocidade da reação, os cientistas perceberam que nem sempre seria possivel usar a expressão da Lei de Guldberg-Waage sem qualquer alteração, porque na verdade, a lei que relaciona velocidade instantânea é determinada experimentalmente".(p.150)

Para determinar esta lei, a autora diz que é necessário estudar o mecanismo da reação, na qual a velocidade de uma reação é determinada por sua etapa mais lenta:

"Na realidade, qualquer reação química complexa que ocorra a uma velocidade razoável é a soma de uma serie de processos mais simples chamados etapas de reação" (p.151)

"Chamamos mecanismo de reação o conjunto de etapas segundo as quais os reagentes interagem para originar produtos".(p.151)

"A velocidade de uma reação é determinada por sua etapa mais lenta"(p.152) 
Portanto, pela análise do desenvolvimento teórico acima descrito pode-se concluir que a explicação encontrada é coerente com a do terceiro programa (Lewis, Ostwald e Arrhenius;1889-1918), isto é a concentração influi na velocidade, mas somente as partículas que possuem uma determinada quantidade de energia, e uma orientação apropriada, conseguem reagir, e também a um entendimento do que significa a ordem de uma reação:

"Como o mecanismo é deduzido de medidas experimentais, podemos dizer, mais precisamente, que:"

$$
v_{1}=k[A]^{x}[B]^{y} \quad \begin{array}{ll}
\text { - } & \text { e y são determinados experimentalmente. }
\end{array}
$$

Figura 4.25- lei da velocidade de uma reação (p.152)

\section{c- A influência da temperatura:}

A autora aponta que através do experimento proposto inicialmente chega-se à seguinte relação:

\section{Aumentar a temperatura de um sistema implica aumentar a velocidade de reaçjo} maior temperatura maior velocidade de reaço

Figura 4.26- Relação entre a temperatura e a velocidade válida tanto para sistemas homogêneos quanto para os heterogêneos. (p.145).

Menciona também que no século $\mathrm{XX}$, tentando estabelecer uma relação matemática entre temperatura e velocidade da reação, Van't Hoff propôs que: 
Figura 4.27- Regra de Van't Hoff. (p.145).

Segundo Justi (1997), não há no trabalho de Van't Hoff nenhuma citação referente a essa regra que relaciona a temperatura com a velocidade da reação.

A autora menciona que, segundo a teoria das colisões, para que ocorra uma reação química entre duas moléculas, deve-se ter colisão orientada e suficientemente energética (igual ou maior que a energia de ativação). Portanto, um aumento de temperatura faz com que a velocidade de uma dada molécula aumente, e conseqüentemente a energia cinética desta molécula também aumentará, o que significa uma maior probabilidade de que, ao se chocar com outra, haja uma colisão suficientemente energética.

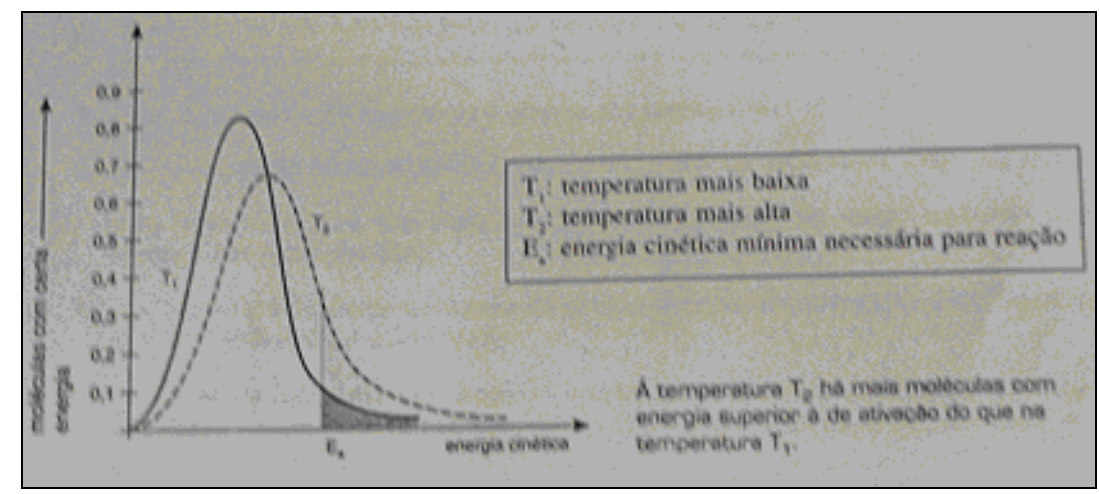

Figura 4.28- Distribuição de energia cinética das moléculas (p.146)

Segundo a autora (fig 4.28):

"Quando a temperatura aumenta, há mais moléculas com energia cinética maior. Com isso a curva de distribuição se desloca para a direita. Assim quanto maior a temperatura (T1>T2), maior número de moléculas com energia cinética superior a energia de ativação" (p.147).

Portanto: 
"Quanto maior a energia de ativação de uma reação, mais ela será afetada pelo aumento da temperatura".(p.147)

e que genericamente pode-se estabelecer a seguinte relação:

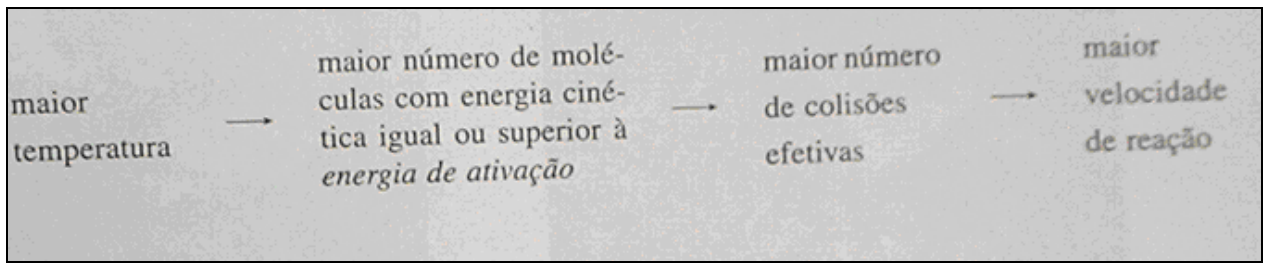

Figura 4.29- Relação entre a temperatura e a velocidade de uma reação. (p.147).

A explicação encontrada no texto do livro é coerente com a fornecida pelo terceiro programa (Lewis, Ostwald e Arrhenius;1889-1918), porque a autora utiliza a teoria das colisões e o conceito de energia de ativação, para explicar a influencia da concentração na velocidade de uma reação.

\section{II- Características da ciência. Categorias:}

1-Concepção de ciência: As teorias científicas são modelos teóricos criados pelos cientistas para tentar descrever uma determinada realidade, sendo, portanto coerente com a perspectiva racionalista:

A autora aponta que a lei de Guldberg-Waage, não conseguia explicar reações que eram mais complexas, pois experimentalmente o valor encontrado para a velocidade era muito diferente daquele calculado pela ação das massas (GuldbergWaage). A autora lança então a seguinte questão:

"A que modelos os cientistas recorreram para explicar esse fato?".(p.151)

2- O desenvolvimento da ciência: As teorias vão aumentando seu poder explicativo, durante o desenvolvimento do capítulo. Portanto, essa forma de apresentação de conteúdo pode levar o leitor a ter uma imagem de ciência coerente com a perspectiva racionalista. 
3- A construção do conhecimento científico: A autora coloca que a lei de Guldberg-Waage foi elaborada a partir da observação de dados experimentais, indicando portanto uma visão de construção do conhecimento cientifico coerente com a perspectiva empirista/indutivista:

\footnotetext{
"A partir de diversos experimentos, os cientistas noruegueses Cato Maximilian Guldberg (1836-19002) e Peter Waage ((1833-1900), enunciaram a Lei da ação das massas..."(p.150)

"Com a realização de novos experimentos da velocidade da reação, os cientistas perceberam que nem sempre seria possível usar a expressão da Lei de Guldberg-Waage sem qualquer alteração, porque na verdade, a lei que relaciona velocidade instantânea é determinada experimentalmente".(p.150)
}

\section{Livro 18- 2001}

Este livro faz parte da série "Interações e transformações", elaborada pelo GEPEQ - Grupo de Pesquisa em Educação Química - do Instituto de Química da Universidade de São Paulo, que é formado por professores de química, tanto do ensino médio como do ensino superior, e por pesquisadores da área de ensino de ciências.

A proposta dessa série de livros, destinada ao Ensino Médio, é a de estudar a química através de temas extraídos do cotidiano do aluno, com o objetivo de fazer o aluno compreender a importância de se conhecer e entender o mundo em que ele vive, sob a ótica da química.

\footnotetext{
"A partir do conhecimento que você já tem, de suas experiências vividas e adquiridas no dia-a-dia, este livro trabalhará visando construir, ou reconstruir, idéias sobre o mundo físico e as transformações que nele ocorrem, levando-o a perceber como os conceitos são elaborados". (apresentação, modulo I)
}

A cinética química é tratada no volume 2 juntamente com o equilíbrio químico. 
O desenvolvimento dos conceitos, nesse modulo, é feito dentro das visões termodinâmica e cinética. Dentro da perspectiva cinética: “...a rapidez da transformação é analisada segundo os mecanismos explicativos possíveis. Também aqui, se parte de aspectos macroscópicos, terminando com a interpretação microscópica da transformação." (pág.9, guia do professor).

A abordagem dos aspectos cinéticos de uma transformação química é feita, pelos autores, partindo-se do estudo do nitrogênio, da amônia e da síntese da amônia na indústria. Assim, o aluno percebe a importância do nitrogênio no organismo humano, na atmosfera e finalmente na síntese da amônia, que é a matéria prima para fabricação de fertilizantes. Os aspectos cinéticos de uma transformação química começam a aparecer no livro, na discussão da necessidade de se controlar a produção da amônia, onde se verificam que certos fatores como a concentração, a temperatura e a pressão, principalmente, têm grande influência na velocidade da síntese de amônia.

\section{I- Nível de explicação teórica atingida:}

\section{a- Modelo teórico que explica a velocidade de uma reação química:}

Partindo-se de idéias sobre transformações químicas, anteriormente construídas, os autores apresentam uma relação de fatos que podem ser explicados parcialmente pelo modelo de partículas que o aluno já possui:

\footnotetext{
"as transformações químicas se dão através da interação entre as partículas das substâncias reagentes, ou seja, através dos encontros (colisões) entre as partículas";

"a transformação é um rearranjo de átomos, que envolve o rompimento de ligações entre os átomos nas partículas reagentes e formação de outras ligações nos produtos, com liberação ou absorção de diferentes formas de energia"(p.63)
} 
Em vista disso os autores dizem que: "é necessária uma análise mais detalhada dos fatores que afetam a rapidez das transformações químicas para se chegar às idéias atualmente aceitas (modelo)".(p.64)

No livro, o estudo da velocidade de uma reação é feito através da análise dos fatores que podem influenciá-la, como a temperatura e a concentração, assim durante esse estudo são apresentados modelos explicativos que incluem a teoria das colisões e da teoria do estado de estado de transição.

Portanto pode-se inferir que o modelo apresentado, no texto como mais atual para explicar em termos microscópicos, a velocidade de uma reação é o que pertence ao quarto programa de investigação científica (Tolman, Eyring, Polanyi, e Evans; 1918-1935).

\section{b-A Influência da concentração sobre a velocidade de uma reação:}

Pode-se observar que o livro não utiliza a lei de Guldberg-Waage para explicar a relação entre a concentração e a velocidade de uma reação química. A explicação não é feita através de uma relação matemática, como foi feito nos livros anteriores, mas sim a partir de dados experimentais (experimento de Zartmann, p.66-67).

Segundo os autores, o aumento da concentração aumenta o número de colisões capazes de formar os complexos ativados, mas apontam que somente essa teoria não consegue explicar o efeito da concentração na velocidade de uma reação.

Para entender este efeito, os autores colocam que é necessário conhecer o mecanismo de uma reação:

"As transformações químicas se desenvolvem segundo o caminho que abrange uma seqüência de etapas......... mecanismo só pode 
ser deduzido através do estudo experimental da transformação" (p.76).

A etapa que determina a velocidade de uma reação é a etapa mais lenta, pois, de acordo com o livro, a rapidez das demais depende da quantidade de produtos formada na etapa lenta.

A explicação para o efeito da concentração é então coerente com a do quarto programa (Tolman, Eyring, Polanyi, e Evans; 1918-1935), pois relaciona a velocidade com a formação do complexo ativado.

\section{c- A influência da temperatura:}

O efeito da temperatura é discutido inicialmente através de exemplos como a fermentação do leite e a queima de materiais combustíveis, onde se observa que: "a variação de temperatura afeta de modo significativo a rapidez das transformações químicas”. (p.65).

Considerando-se a idéia de que a matéria é formada por partículas, que estão em constante movimento:

"A elevação da temperatura acelera a movimentação das partículas,
aumentando sua energia cinética e, desta forma, aumentando o
número de colisões possíveis. Conseqüentemente, aumenta a
possibilidade de ocorrer transformação (choques efetivos). Em vista
disso as transformações tornam-se mais rápidas". (p.65).

Portanto, segundo os autores, a temperatura aumenta a freqüência de colisões, o que explica, em parte, o efeito da temperatura na rapidez da transformação. Mas, dizem que é necessário considerar, na eficiência da colisão, não somente o número de partículas, mas também a "energia da colisão". Para explicar essa energia é discutido no livro, o experimento de Zartmann (p. 66-69).

Da análise do experimento conclui-se que: 
"Considerando-se que a temperatura está associada à energia cinética média das partículas, seria razoável admitir que a uma dada temperatura só ocorrerão colisões que podem resultar em transformação química, quando as partículas atingirem certo valor mínimo de energia chamada energia limiar. Esta é condição necessária,mas não suficiente para a ocorrência da transformação". (p.68).

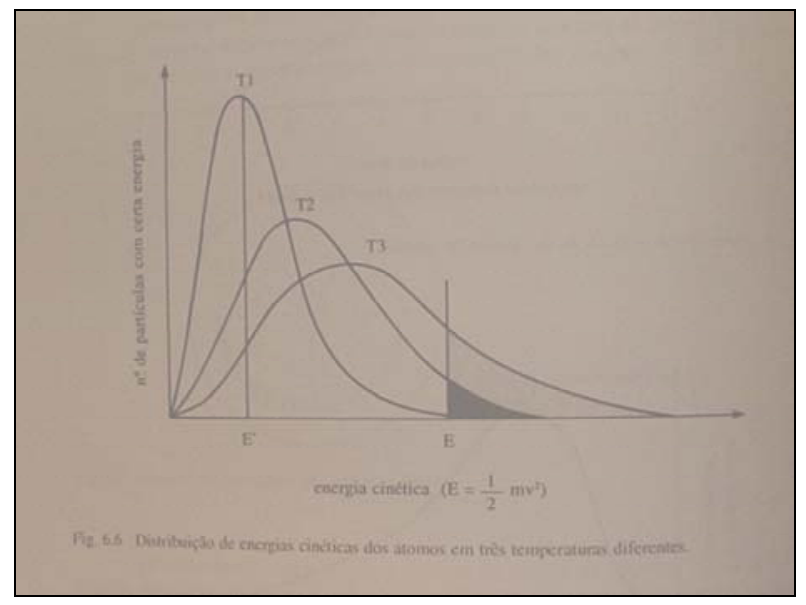

Figura 4.30- Distribuição de energias cinéticas dos átomos em função da temperatura ( $p$. 70).

Pela análise do gráfico da distribuição de energia cinética (fig.4.33), os autores concluem que:

\begin{abstract}
"A elevação da temperatura modifica a distribuição da energia cinética, aumentando o número de partículas com energia igual ou superior a limiar. Conseqüentemente, aumenta o número de choques efetivos, ou seja, aqueles capazes de causar o rompimento e a formação de ligações. Desta forma as transformações químicas tornam-se mais rápidas". (p.71)
\end{abstract}

Essa energia mínima necessária para que uma transformação química ocorra, é denominada pelos autores de "energia de ativação", que está relacionada a uma barreira energética. Portanto, para que as partículas superem essa barreira elas devem possuir uma energia cinética mínima, ou seja, uma energia igual ou superior à energia de ativação: 
"Quanto maior a energia de ativação de uma transformação, mais lenta esta tenderá a ser, pois menos partículas reagentes terão condições energéticas suficientes para atingi-la”.(p.72)

Entretanto, citam os autores que, para haver colisão efetiva, além da necessidade de as partículas possuírem energia cinética mínima, outra condição que deverá estar presente: os choques deverão correr entre regiões privilegiadas dessas partículas (fig.4.34).

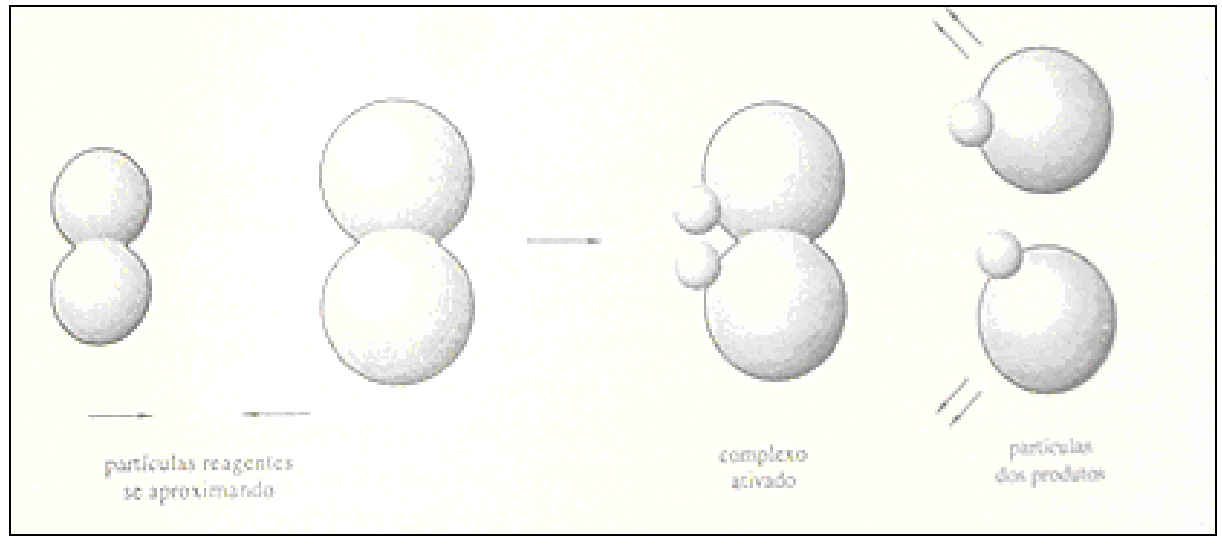

Figura 4.31- Representação de uma colisão efetiva (p.73).

Ocorrendo esses choques, nestas condições, os autores apontam que as partículas reagentes se associam formando aglomerado de curta existência com energia suficiente para o rompimento e formação das ligações, denominado complexo ativado (fig. 4.35), sendo que esta etapa da transformação é denominada de estado de transição.

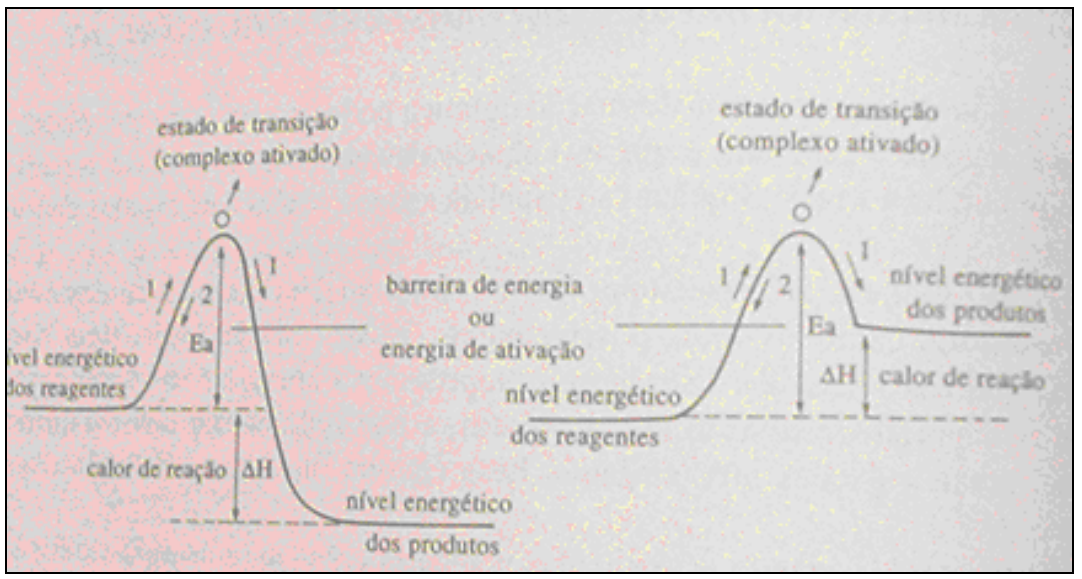

Figura 4.32-Possíveis percursos de uma transformação química (p. 72), 
A explicação, encontrada no livro, para a influência da temperatura na velocidade de uma reação, é a fornecida pela teoria do estado de transição, portanto a teoria do quarto programa de investigação científica(Tolman, Eyring, Polanyi, e Evans; 1918-1935).

Percebe-se, que os autores transitam de um período a outro, o que denota a preocupação com a evolução histórica, percebe-se a preocupação com o desenvolvimento do conceito no decorrer tempo;

\section{II-Características da ciência. Categorias:}

1-Concepção de ciência: As teorias científicas são apresentadas como modelos explicativos que vão sendo modificados através do tempo, indicando a visão da perspectiva racionalista:

\footnotetext{
"O modelo explicativo atualmente aceito para explicar a rapidez das transformações químicas” (p.65).
}

2-O desenvolvimento da ciência: As teorias vão aumentando seu poder explicativo. Portanto, essa forma de apresentação de conteúdo pode levar o leitor a ter uma imagem de ciência coerente com a perspectiva racionalista, ou seja, que o progresso da ciência é caracterizado como uma problemática progressiva de uma tentativa teórica para outra.

\section{3-A construção do conhecimento científico:}

Os autores utilizam a experimentação no desenvolvimento do conteúdo, mas propõem que os alunos construam modelos explicativos para explicar os fatos que irão ser observados, sendo essa abordagem coerente então com a perspectiva racionalista: 


\begin{abstract}
"Nessa atividade, fatos já conhecidos serão apresentados e idéias anteriormente construídas serão retomadas. A partir daí, deverão ser propostas explicações para esses fatos" (p.63)

"Assim, considerando que:......proponha novas idéias sobre o comportamento das partículas que sejam capazes de explicar as constatações apresentadas a seguir:...."( $p .63)$
\end{abstract}

Embora se encontrem no livro os modelos explicativos que estão relacionados com o estudo da cinética química, não foi fornecida pelos autores deste livro, os nomes dos cientistas que estiveram envolvidos no desenvolvimento destes modelos.

\title{
Livro 19- 2003
}

$\mathrm{Na}$ apresentação do livro didático ao aluno os autores apontam que:

"Acreditamos existir em você o desejo do conhecimento. Acreditamos, também, que este livro é capaz de fazer despertar sua curiosidade. Você perceberá que a ciência não está apenas nos laboratórios, mas em tudo ao nosso redor. Procuramos indicar, ao longo dos capítulos, profissões que empregam o conhecimento abordado em cada um deles. Esperamos, com isso, contribuir para a importante escolha da sua carreira”'.(p.3)

Quanto à didática do livro os autores apontam que:

$$
\begin{aligned}
& \text { "Finalmente elaboramos uma obra que possibilitará o } \\
& \text { desenvolvimento de um curso em que não caberá a você apenas o } \\
& \text { papel de repetidor do conhecimento, mas o de engenheiro de novas } \\
& \text { idéias }{ }^{21 " ~(p .3) ~}
\end{aligned}
$$

Pode-se notar a influência da LBD 9394/96 na apresentação desse livro. No livro 15 (1980), o autor Geraldo Camargo de Carvalho (um dos autores do livro de 2003), não indica a proposta pedagógica do livro.

No capitulo de cinética química, os autores iniciam o estudo da velocidade, com exemplos de reações químicas que ocorrem no organismo, na indústria, onde a

\footnotetext{
${ }^{21}$ Negrito do autor.
} 
cinética química é definida como a parte da química que estuda a velocidade das reações e os fatores que a influenciam.

No livro, não há experimentos dirigidos aos alunos, os autores utilizam a experimentação apenas para demonstrar algum conteúdo, sem que haja algum tipo de solicitação da participação do aluno. O capitulo de cinética química possui vários exercícios, tanto em forma de questões abertas como também na forma de testes, que são divididos pelos autores em exercícios de fixação, colocados logo após as definições teóricas e os exercícios de revisão, colocados no final do capítulo de cinética química, sendo que esses exercícios de revisão são na sua maioria, de vestibulares.

\section{I- Nível de explicação teórica atingida:}

\section{a- Modelo teórico que explica a velocidade de uma reação química:}

Para uma reação ocorrer, segundo os autores, é necessário haver colisão entre as moléculas dos reagentes, mas essa condição, entretanto não é suficiente. Durante uma reação química há a formação de uma estrutura de transição chamada de complexo ativado:

Para haver a formação do complexo ativado, segundo o texto do livro, são necessárias duas condições:

“I. As moléculas devem colidir numa posição geométrica favorável; II. A colisão entre as moléculas deve ocorre com um mínimo de energia de ativação." (p.231)

“...forma-se uma estrutura de transição com ligações intermediárias entre as moléculas dos reagentes e as dos produtos. Essa estrutura é chamada de complexo ativado." (p.230) 
A explicação acima descrita é coerente com o quarto programa (Tolman, Eyring, Polanyi, e Evans;1918-1935), pois utiliza a teoria do estado de transição (formação do complexo ativado), para explicar a ocorrência de uma reação química.

\section{b- A Influência da concentração sobre a velocidade de uma reação:}

A influência da concentração é explicada pela teoria das colisões. A equação matemática que relaciona a velocidade da reação com as concentrações é, segundo os autores, determinada experimentalmente. Não se encontra no texto o uso da lei de Guldberg-Waage.

Segundo os autores, por meio da equação da velocidade, determinada experimentalmente, é proposto um mecanismo para a reação, isto é, são sugeridas as possíveis etapas de seu mecanismo:

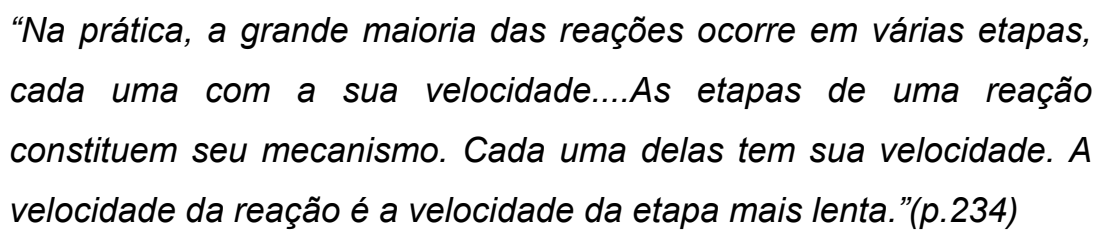

Os autores também apontam que a ordem de uma reação é determinada experimentalmente:

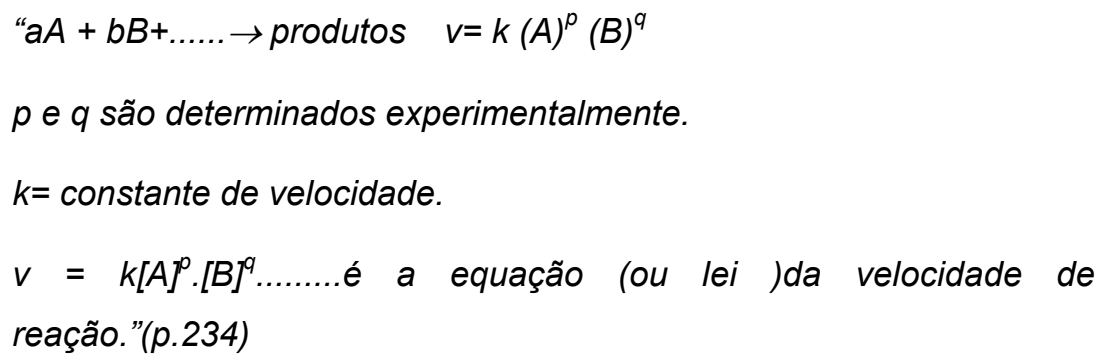

Portanto, a explicação encontrada no texto do livro é coerente com a fornecida pelo terceiro programa (Lewis, Ostwald e Arrhenius;1889-1918), onde a velocidade de uma reação está relacionada ao seu mecanismo, sendo que a equação da velocidade da reação é determinada experimentalmente. 


\section{c- A influência da temperatura:}

Segundo os autores:

$$
\begin{aligned}
& \text { "O aumento de temperatura produz um aumento da agitação (energia } \\
& \text { cinética)".(p.232). }
\end{aligned}
$$

A energia de ativação é representada no livro como uma "barreira" no caminho dos reagentes:

$$
\begin{aligned}
& \text { “Como a energia representa uma "barreira" no caminho dos } \\
& \text { reagentes } \rightarrow \text { produtos, quanto maior for a energia de ativação de uma } \\
& \text { reação, maior será essa "barreira"e, conseqüentemente, mais difícil } \\
& \text { será transpô-la, mais difícil será a reação"(p.232). } \\
& \text { "Consideradas as condições de uma reação, quanto maior for sua } \\
& \text { energia de ativação, menor será sua velocidade e vice-versa".(p.232). }
\end{aligned}
$$

No livro é apresentada a relação entre energia de ativação e a temperatura:

$$
\begin{aligned}
& \text { "Aumento da temperatura } \rightarrow \text { aumento da energia cinética média das } \\
& \text { moléculas } \rightarrow \text { aumento do número de moléculas com energia maior que } \\
& \text { a energia de ativação } \rightarrow \text { aumento do número de colisões } \\
& \text { efetivas } \rightarrow \text { aumento da velocidade de reação."(p.232) }
\end{aligned}
$$

Portanto, a explicação dada é coerente com a do terceiro programa (Lewis, Ostwald e Arrhenius;1889-1918), pois relaciona a temperatura à velocidade de uma reação, através a teoria das colisões e a idéia de energia de ativação, sendo que esta tem o significado ligado a uma barreira de energia que no caminho dos reagentes em direção a formação dos produtos, significado dado por Arrhenius.

\section{II- Características da ciência. Categorias:}

1-Concepção de ciência: Os conceitos químicos são entendidos pelos autores como sendo um conjunto de enunciados universais não aparecem no texto à idéia de que estes conceitos são hipóteses, modelos explicativos, propostos pelos cientistas que podem ser no futuro modificadas. Essa idéia de ciência pode ser coerente com a perspectiva empirista/indutivista. 
2-O desenvolvimento da ciência: No livro didático somente se encontra a explicação considerada pelo autor como a mais atual. Os autores não mostram no texto a evolução das explicações, demonstrando então ser coerente com a perspectiva empirista/indutivista.

3- A construção do conhecimento científico: Não se identificou esta categoria no livro didático.

\section{Livro 20- 2004.}

$\mathrm{Na}$ introdução deste livro o autor, além de enfatizar as relações da química com o cotidiano e com outras disciplinas, diz que também procura mostrar:

“.... a maneira pela qual a humanidade tem buscado o conhecimento a observação dos fenômenos da natureza, as tentativas de explicar os fatos observados e os resultados práticos da aplicação desse saber no dia-a-dia. Pretendemos, com essas alterações mostrar ao aluno que a ciência não construiu uma realidade distante, acessível apenas aos próprios cientistas. Pelo contrario, ele é parte integrante de nossa vida, pois foram justamente as necessidades mais básicas que lançaram a humanidade neste caminho".(p.4)

Portanto, nota-se uma preocupação em transmitir ao aluno a Idéia de que a ciência e, portanto, o conhecimento construído pelos cientistas, está presente no seu dia-a-dia.

$\mathrm{Na}$ relação de exercícios presentes no livro didático encontram-se várias questões dos últimos vestibulares e do Exame Nacional do Ensino Médio (Enem).

\section{I- Nível de explicação teórica atingida:}

$\mathrm{Na}$ introdução do capítulo, o autor dá exemplos de reações rápidas e lentas encontradas no dia-a-dia, como a ferrugem, a queima de uma vela e a explosão de 
dinamite. Diz que é possível acelerar e retardar uma reação química. Um dos objetivos da cinética química é, segundo o autor, controlar a velocidade das reações químicas. Mas adiante coloca que o objetivo da cinética química é o estudo da velocidade das reações químicas e dos fatores que influem nessa velocidade.

\section{a- Modelo teórico que explica a velocidade de uma reação química:}

Para explicar a velocidade, o autor usa a teoria das colisões:

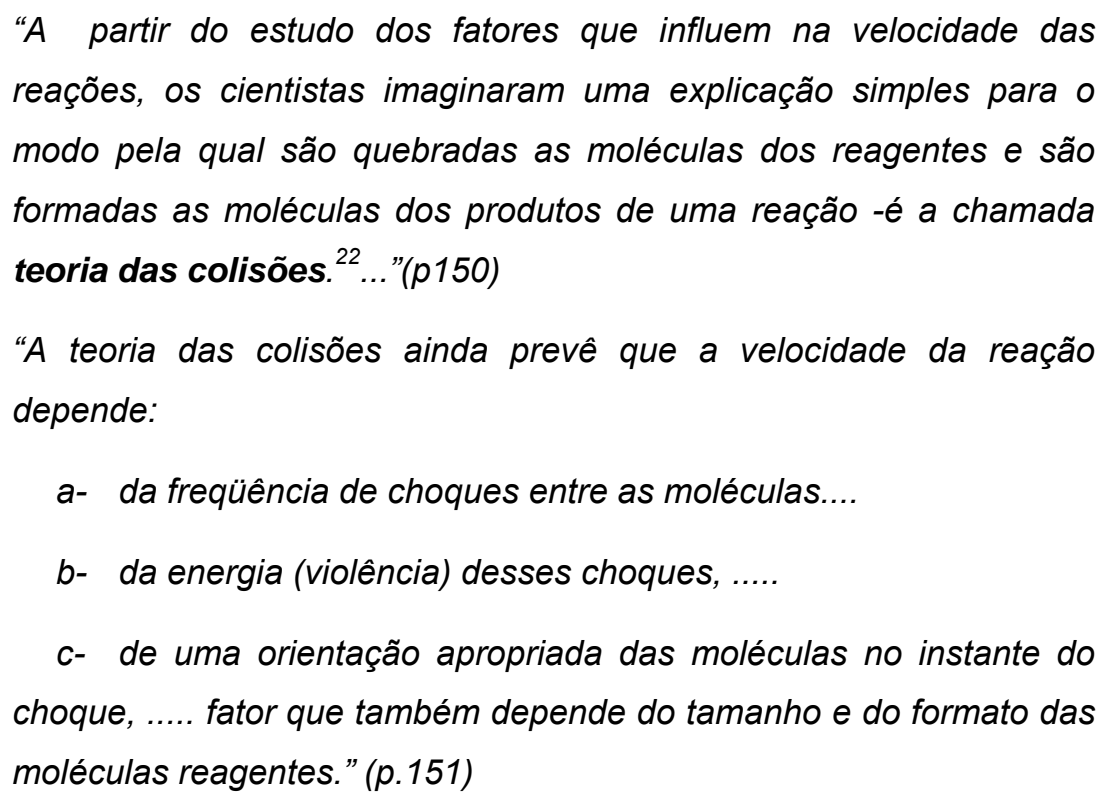

Portanto, pode-se concluir que a explicação dada acima para a velocidade é coerente com a do terceiro programa (Lewis, Ostwald e Arrhenius;1889-1918), que utiliza a teoria das colisões para explicar a velocidade de uma reação química.

\section{b-A Influência da concentração sobre a velocidade de uma reação:}

Para explicar a dependência da concentração na velocidade de uma reação, o autor não utiliza a lei de ação das massas (Guldberg-Waage), mas sim usa a teoria das colisões:

\footnotetext{
"Aumentando-se a concentração dos reagentes (número de moléculas por unidade de volume), aumentamos a freqüência dos
}

\footnotetext{
${ }^{22}$ Negrito do autor do livro didático.
} 
choques entre as moléculas reagentes e, como conseqüência da teoria das colisões, aumenta a velocidade da reação."(p.160)

O autor introduz a lei cinética da velocidade, através da descrição de um experimento, o estudo cinético da seguinte reação:

$$
\mathrm{H}_{2}(\mathrm{~g})+\mathrm{I}_{2}(\mathrm{~g}) \rightarrow 2 \mathrm{HI}(\mathrm{g})
$$

Onde os dados obtidos podem ser traduzidos pela seguinte relação matemática:

$$
\mathrm{v}=\mathrm{k}\left[\mathrm{H}_{2}\right]\left[\mathrm{I}_{2}\right]
$$

A partir do experimento o autor aponta que:

"A velocidade de uma reação é proporcional às concentrações molares dos reagentes, elevadas a expoentes que são determinados experimentalmente:

$$
\begin{gathered}
a A+b B \rightarrow x X+y Y \\
v=k[A]^{m}[B]^{n}
\end{gathered}
$$

Onde os expoentes $m$ e $n$ são determinados experimentalmente." (p.162)

Quanto ao mecanismo de uma reação, o autor aponta que este é:

"o conjunto de reações elementares pelas quais passa uma reação
global"(p.163)

Portanto, a explicação dada pelo autor é coerente com a do terceiro programa de investigação científica (Lewis, Ostwald e Arrhenius;1889-1918), pois o autor, explica o efeito da concentração na velocidade de uma reação, através da teoria das colisões e também aponta que a lei da velocidade de uma reação só pode ser obtida experimentalmente.

\section{c- A influência da temperatura:}


Segundo o autor, a temperatura é um dos fatores que mais influem na velocidade:

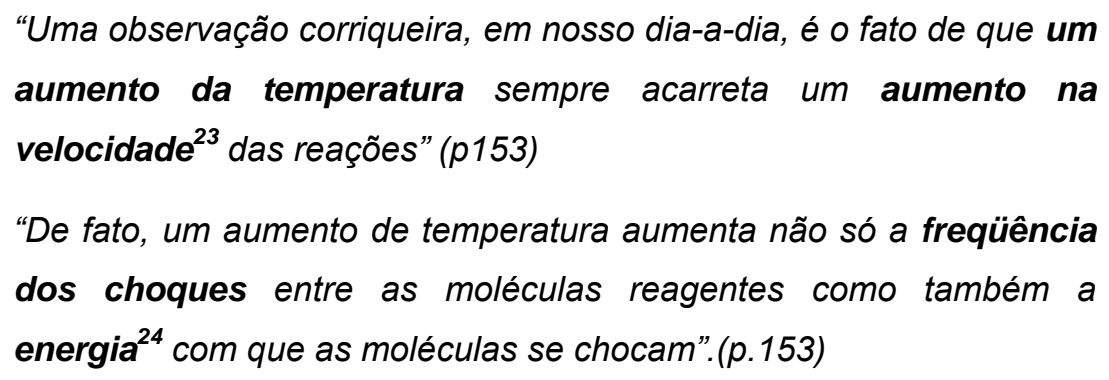

O autor aponta que em decorrência das várias observações que eram feitas sobre o efeito da temperatura nas reações químicas, Van't Hoff estabeleceu uma lei:

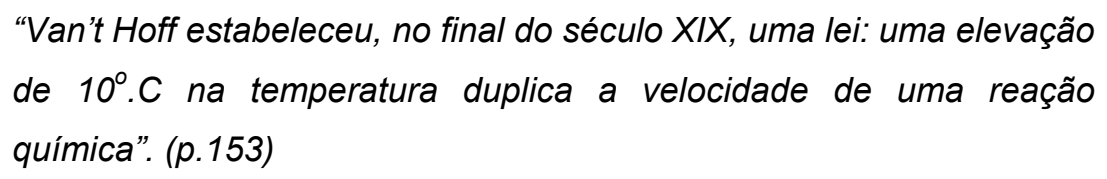

Observa-se que nos livros dos períodos anteriores, essa relação estabelecida por Van't Hoff era denominada "regra de Van't Hoff", mas o autor deste livro passa a chamar de "Lei de Van't Hoff", aumentando assim o status dessa relação entre a temperatura e a velocidade, sendo que, não há no trabalho de Van't Hoff nenhuma citação referente a essa regra que relaciona a temperatura com a velocidade da reação (Justi;1997).

Diz também que é necessário um "empurrão inicial" para que algumas reações aconteçam:

\footnotetext{
"O empurrão inicial é necessário para levar os reagentes a um estado ativado, em que se forma o complexo ativado. Pela teoria do complexo ativado (na realidade, um aprimoramento da teoria das colisões), admite-se que, no instante do choque, ocorre um progressivo enfraquecimento das ligações entre as moléculas iniciais e um fortalecimento das ligações entre as moléculas finais". (p.154)
}

\footnotetext{
${ }^{23}$ Negritos do autor do livro didático.

${ }^{24}$ Negritos do autor do livro didático.
} 
"Note que, para atingir a elevação correspondente ao estado ativado, as moléculas reagentes devem ter uma energia igual (ou maior) que uma energia mínima chamada de energia de ativação $\left(E_{a t}\right) "(p .154)$

"Energia de ativação ${ }^{25}\left(E_{a t}\right)$ : é a energia mínima que as moléculas devem possuir para reagir, ao se chocarem (Isto é, para termos uma colisão efetiva)". (p.154)

Portanto, a explicação dada pelo autor relaciona a energia de ativação com a formação do complexo ativado (teoria do estado de transição), sendo esta a explicação do quarto programa (Tolman, Eyring, Polanyi, e Evans; 1920-1935).

\section{II- Características da ciência. Categorias:}

1-Concepção de ciência: As teorias são apresentadas como Leis universais, e não como um conjunto de hipóteses, modificáveis, caracterizando assim a visão da perspectiva empirista/indutivista:

\footnotetext{
"Lei cinética da velocidade das reações: $A$ velocidade de uma reação é proporcional às concentrações molares dos reagentes, elevadas a expoentes que são determinados experimentalmente"(p.162).

"Van't Hoff estabeleceu, no final do século XIX, uma lei: uma elevação de $10^{\circ}$.C na temperatura duplica a velocidade de uma reação química". (p.153)
}

2-O desenvolvimento da ciência: Não é discutido no livro o desenvolvimento das teorias ficando a idéia de que somente as teorias atuais são verdadeiras, portanto não há necessidade do livro conter as teorias anteriores. O autor não mostra o dinamismo da ciência, portanto a visão apresentada é coerente com a visão da perspectiva empirista/indutivista.

\footnotetext{
${ }^{25}$ Negritos do autor do livro didáico.
} 
3- A construção do conhecimento científico: O papel dos cientistas é o de induzir e estabelecer comprovações empíricas de Leis e princípios, indicando assim uma visão da construção do conhecimento científico coerente com a perspectiva empirista/indutivista.:

"A partir do estudo dos fatores que influem na velocidade das reações, os cientistas imaginaram uma explicação simples......"(p.150). 


\section{Discussão}

A explicação encontrada em três livros analisados (1999, 2001 e 2003) para a velocidade de uma reação química, em termos microscópicos, está de acordo coma a explicação utilizada atualmente (PIC-IV), ou seja, estes utilizam a teoria do estado de transição (complexo ativado) para explicar a velocidade. (tab. 4.9).

Somente um dos quatro livros (1999) deste período utiliza a lei de GuldbergWaage para explicar a influência da concentração na velocidade de uma reação.

Quanto à influência da temperatura na velocidade, já se tem a compreensão de que é necessária uma quantidade mínima de energia (energia de ativação), sendo que os livros 18 e 20 relacionam a energia de ativação com a formação do complexo ativado.

O livro 19 segue a linha dos livros tradicionais onde não são propostos experimentos, mas apenas exercícios, que se encontram no final do capítulo para que o aluno responda com base na teoria anteriormente vista no livro. Os livros de 1999 e 2001 propõem experimentos para serem realizados durante o desenvolvimento do conteúdo, embora neles o papel da experimentação não seja o mesmo. No livro de 2001 , os experimentos fazem parte do desenvolvimento do conteúdo, por exemplo, no estudo da influência da temperatura na velocidade a partir do experimento é que o aluno constrói uma explicação para justificar essa influência. Já no livro de 1999, o experimento é apenas uma sugestão, pois logo em seguida a autora cita que pode ser observado nestes experimentos, já explicando a ocorrência desses fatos utilizando-se de um conhecimento científico.

O livro de 1999 apresentou uma imagem de ciência que pode ser considerada contraditória, pois no desenvolvimento teórico a imagem de ciência é coerente com a 
perspectiva racionalista, mas nos trechos em que a autora utiliza exemplos da história da química, a imagem de ciência que predomina é a fornecida pela perspectiva empirista/indutivista. Contudo, a perspectiva filosófica deste período continua sendo como nos períodos anteriores predominantemente empirista/indutivista (tab. 4.10).

É importante notar nesse período o emprego reduzido da lei de GuldbergWage, já que nos períodos anteriores, ela era ainda muito utilizada para relacionar a concentração dos reagentes com a velocidade de uma reação química. Isso pode ser reflexo da influência do grande número de pesquisas que estavam ocorrendo, nessa época, na área de ensino de ciências ou da influência da legislação educacional ou também dos PCN's, portanto, os autores dos livros didáticos começaram a dar uma maior atenção à transposição didática dos conhecimentos científicos para o livro didático. Nota-se, por exemplo, o uso de uma idéia mais atual como a do estado de transição. 
Programas de Investigação Científica

\begin{tabular}{|c|c|c|c|}
\hline $\begin{array}{l}\text { Livros } \\
\text { Didáticosl } \\
\text { Ano }\end{array}$ & $\begin{array}{l}\text { Explicação, em } \\
\text { termos } \\
\text { microscópicos, da } \\
\text { velocidade de uma } \\
\text { reação química. }\end{array}$ & $\begin{array}{l}\text { Explicação de como a } \\
\text { velocidade de uma } \\
\text { reação química depende } \\
\text { das concentrações das } \\
\text { substâncias reagentes. }\end{array}$ & $\begin{array}{l}\text { Explicação da } \\
\text { influência da } \\
\text { temperatura na } \\
\text { velocidade de uma } \\
\text { reação química. }\end{array}$ \\
\hline $17 / 1999$ & PIC-IV & PIC-III & PIC-III \\
\hline $18 / 2001$ & PIC-IV & PIC-IV & PIC-IV \\
\hline $19 / 2003$ & PIC-IV & PIC-III & PIC-III \\
\hline $20 / 2004$ & PIC-III & PIC-III & PIC-IV \\
\hline \multicolumn{4}{|c|}{$\begin{array}{l}\text { Tabela 4.9- Caracterização dos livros didáticos do quinto período (1996-2004). Nota:PI } \\
\text { III:Programa de Investigação Científica de Lewis, Ostwald e Arrhenius (1889-1918); PI } \\
\text { IV:Programa de Investigação Científica de Tolman, Eyring, Polanyi, e Evans (1920-1935). }\end{array}$} \\
\hline \multicolumn{4}{|c|}{ Categorias } \\
\hline $\begin{array}{l}\text { Livros } \\
\text { Didáticos/Ano }\end{array}$ & $\begin{array}{l}\text { 1- Concepção de } \\
\text { o ciência }\end{array}$ & $\begin{array}{l}\text { 2- O Desenvolvimento } \\
\text { da Ciência }\end{array}$ & $\begin{array}{l}\text { A construção do } \\
\text { onhecimento } \\
\text { entífico }\end{array}$ \\
\hline $17 / 1999$ & $\mathrm{R}$ & $\mathrm{R}$ & $E / l$ \\
\hline $18 / 2001$ & $\mathrm{R}$ & $\mathrm{R}$ & $\mathrm{R}$ \\
\hline $19 / 2003$ & $E / I$ & $E / l$ & $\mathrm{~N}$ \\
\hline $20 / 2004$ & $E / I$ & $E / I$ & $E / I$ \\
\hline
\end{tabular}

Tabela 4.10- Imagens da ciência apresentadas pelos livros didáticos do quinto período

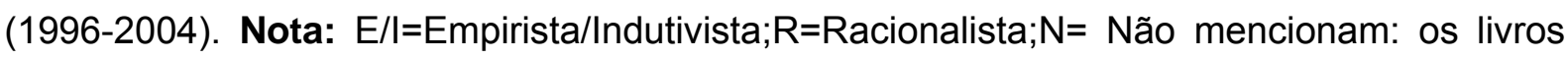
didáticos não fazem menção explicita a qualquer uma das duas interpretações. 


\section{CAPÍTULO 5}

\section{CONCLUSÕES E CONSIDERAÇÕES}

Segundo Vincent e Stengers (1992), “a cinética é uma hipótese realista, implica que as moléculas dos químicos sejam efetivamente reconhecidas como entidades discretas, susceptíveis de movimento, de colisão, ou seja, de comportamento individual". E isso pode ser observado desde o início dos estudos das velocidades das reações químicas onde se pode constatar a preocupação dos cientistas em propor uma explicação microscópica do processo, isto é, os cientistas sempre buscaram entender a velocidade de uma reação química em termos atômicomoleculares, utilizando para isso a construção de modelos teóricos.

No entanto, nos livros didáticos analisados, percebe-se a dificuldade de os autores fazerem propostas que permitam uma aprendizagem por parte dos alunos dentro da visão microscópica, os alunos dificilmente são motivados a construí-la, mas são intensamente informados destas idéias científicas de forma pronta e acabada. O que se nota na maioria dos livros didáticos é a ênfase dada ao aspecto empírico e matemático no tratamento dos conceitos envolvidos no tema cinética química.

Segundo Justi (1997), as possíveis justificativas para esse tipo de abordagem seriam: a familiaridade dos estudantes com as leis da mecânica, o que poderia facilitar o entendimento destas idéias, ou a grande ênfase que é dada à abordagem matemática no ensino de química em geral.

Nos livros didáticos analisados a teoria das colisões proposta por Lewis em 1918, que foi a primeira teoria que explicou, em termos microscópicos, a velocidade 
de uma reação, começou a aparecer a partir do ano de 1967, 49 anos depois de ser formulada. A transposição didática dessa teoria para o livro didático demorou um período de tempo relativamente grande.

Já a teoria do Estado de Transição (1935) começou a ser utilizada pelos autores dos livros didáticos para explicar a velocidade de reação, em termos microscópicos, a partir de 1967 (livro 10, Chem-study), portanto, 32 anos após a sua aceitação pela comunidade científica. Provavelmente, esse menor período de tempo se deve à influência do projeto norte-americano que visava a formação de um maior número de cientistas, portanto, o livro didático deveria possuir conhecimentos científicos mais atualizados. Em tal projeto, segundo seus autores, é "dada ênfase aos princípios químicos em detrimento da Química descritiva para retratar convenientemente a evolução da Química nas duas últimas décadas" (os autores se referem às décadas de 40 e 50).

Esta nova forma de se olhar para a velocidade de uma reação química, utilizando-se o modelo explicativo denominado teoria do Estado de Transição, é bastante diferente daquela iniciada por Wilhelmy em 1850, onde os estudos cinéticos eram praticamente empíricos e não se possuía um entendimento, em termos de microscópicos, da velocidade de uma reação. Portanto, através da substituição de um programa de investigação por outro, pode-se perceber quanto o entendimento envolvido na cinética química mudou e que provavelmente continuará mudando nos próximos anos. Esta visão dinâmica da ciência se estiver presente no livro didático, segundo Níaz (2001), talvez ajude os alunos a entender melhor o processo de construção do conhecimento científico.

A Lei de Guldberg-Waage é utilizada pelos autores de 11 livros didáticos, até o ano de 1993 (tab. 5.1) para explicar a influência da concentração na velocidade de 
uma reação, nos demais livros essa influência é explicada a partir da lei de velocidade de Van't Hoff. Uma diferença importante entre as duas equações é que na de Van't Hoff a ordem é determinada experimentalmente, enquanto que a ordem na Lei de Guldberg-Waage é determinada pela soma dos coeficientes estequiométricos de uma reação. Portanto, a lei de Guldberg-Waage somente seria correta, segundo Pereira (2004), quando a reação química ocorresse conforme está escrita, o que corresponde a se afirmar que se trata de uma etapa elementar do mecanismo. Mas, mesmo colocando-se limitações ao uso da Lei de GuldbergWaage, o aluno pode ficar com a idéia de que esta é uma lei geral que pode ser aplicada a todas reações químicas.

Dos livros do quinto período (1999-2004), somente um, o de 1999, utiliza a lei da ação das massas de Guldberg-Waage, embora a autora mencione que esta lei, por suas limitações, não seja mais utilizada para se determinar a lei da velocidade de uma reação química. É interessante notar que nas orientações curriculares para o ensino de Química propostas nos PCN's (2000), há recomendação especifica em relação ao tratamento da "lei da velocidade":

\footnotetext{
“.... é preciso que se percebam as relações quantitativas que expressam a rapidez de uma transformação química, reconhecendo, selecionando ou propondo procedimentos experimentais ${ }^{26}$ que permitem o estabelecimento das relações matemáticas existentes, como a "lei da velocidade".(p.33).
}

Os livros didáticos mais recentes analisados enfatizam a forma experimental da determinação de uma lei cinética, e conseqüentemente da ordem de uma reação. Portanto, pode-se dizer que os livros atualizaram o seu conteúdo teórico, não seguindo somente as mudanças que ocorrem na ciência, mas sim seguindo as

\footnotetext{
${ }^{26}$ Negrito da autora deste trabalho.
} 
orientações curriculares propostas pelos PCN's. Assim, conforme Bittencourt (1999), este processo de transposição didática parece que não dependeu apenas da ciência de referência, mas também sofreu influências de outros fatores, como o das reformas educacionais.

No inicio do período de tempo estudado neste trabalho, 1929, até o ano de 1966, não havia a preocupação por parte dos autores de explicar a influência, em termos microscópicos, da temperatura na velocidade de uma reação, com exceção dos livros de 1942 e 1946, cuja explicação é coerente com a do terceiro programa de investigação científica (Lewis, Ostwald e Arrhenius;1889-1918). A teoria do estado de transição começou a ser utilizada para explicar a influência da temperatura na velocidade de uma reação química a partir do ano 1967 (Chemstudy). E mesmo assim, alguns livros mais atuais, ainda não a utilizam para explicar o efeito da temperatura na velocidade.

O Chem-study (1967), foi o primeiro livro editado no Brasil a abordar teorias mais atuais, como já foi mencionado anteriormente, esse material foi elaborado visando a introdução de um conteúdo científico mais atualizado, dentro de uma visão considerada mais moderna de ensino:

"O vertiginoso desenvolvimento da Ciência e tecnologia
contemporânea tornou imperioso que se cuidasse, não só da
atualização, mas ate da reformulação do ensino de Química na
escola secundaria". (p. V-Introdução).

Essa forma de abordar o conhecimento científico também está presente no livro das autoras Yvone e Naídes (1977), que elaboraram seu material tendo como referência o Chem-study (1967).

É interessante notar, que alguns dos livros analisados utilizam mais de um programa de investigação para explicar a velocidade de uma reação e os fatores 
que a influenciam. Alguns livros, durante a explicação teórica, transitam de um programa para outro, seguindo uma ordem de um programa de menor poder explicativo para outro de maior, com o objetivo de mostrar a evolução teórica, outros utilizam programas diferentes para explicar a velocidade de uma reação química e os fatores que a influenciam, mostrando assim uma certa incoerência teórica.

Foram analisados três livros de épocas diferentes, do mesmo autor, Geraldo Camargo de Carvalho. Pode-se observar, a partir da tabela 5.1, que houve uma evolução conceitual, sendo que foi mais acentuada na explicação em termos microscópicos da velocidade de uma reação, que era ausente no primeiro livro e passou para a explicação dada pelo PIC-IV e na explicação da influência da concentração, que era feita pela Lei de Guldberg-Waage e passou a ser feita pelo PIC-III. Quanto à imagem de ciência que esses livros podem transmitir, ela é totalmente marcada pela perspectiva empirista/indutivista, portanto pode-se entender que o autor não teve a preocupação de atualizar as concepções de ciência que ele poderá transmitir aos alunos.

Do autor Ricardo Feltre também foram analisados três livros (1968,1976 e 2004) e percebeu-se que ocorreu uma mudança em relação ao conteúdo teórico do livro de 1968 para os livros de 1976 e 2004 (tab. 5.1), em termos de explicação da velocidade de uma reação, contudo isso não ocorreu em relação às concepções de ciência, pois essas, quando identificadas nos livros (tab. 5.2), continuaram ser coerentes com a perspectiva filosófica empirista/indutivista.

Observou-se neste trabalho pela análise dos livros didáticos que a perspectiva filosófica que aparece predominantemente nos livros didáticos é a perspectiva empirista/indutivista (tab. 5.2), o que é coerente com a hipótese admitida neste trabalho. 
Quanto à concepção de ciência, primeira categoria, em 15 livros a ciência é vista como um conjunto de enunciados universais, e não como modelos explicativos modificáveis que são elaborados pelos cientistas.

“.....Portanto, de acordo com a lei de ação das massas, a velocidade de uma reação química é proporcional ao produto das concentrações moleculares dos reagentes....(p.372,1942).

Exceções são os livros de 1967, 1977, 1999 e 2001:

"Este modelo para a velocidade de reação é chamado teoria das colisões e fornece uma base conveniente para entender o efeito da concentração..."(p.131;1967).

"...a que modelos os cientistas recorreram para explicar esse fato".(p.151; 1999).

Analisando a segunda categoria, o desenvolvimento da ciência, percebeu-se que até a metade da década de sessenta a perspectiva filosófica apresentada pelos livros analisados foi a empirista/indutivista, portanto o seu progresso é apresentado de forma continua e acumulativa, não são demonstrados os conflitos e problemas que ocorreram durante o desenvolvimento do conhecimento cientifico. Mas, entendese que estes livros foram influenciados por essa perspectiva filosófica por que essa era a visão de ciência que prevalecia nessa época.

Os livros que apresentam concepções mais coerentes com a perspectiva racionalista são os de 1967, 1977,1999 e 2001, no que se refere à concepção de ciência e ao seu desenvolvimento. Observa-se a influência das idéias da nova filosofia da ciência (racionalismo). Nestes livros, mesmo sendo de décadas diferentes, percebe-se que seus autores estão comprometidos em oferecer aos seus leitores, neste caso os alunos de ensino médio, um material coerente com a visão moderna da ciência. 
Um dos pontos observados neste trabalho é que os autores dos livros didáticos utilizaram a experimentação de diferentes formas em cada período de tempo, para a demonstrar a construção do conhecimento cientifico (terceira categoria). Nos dois primeiros períodos, ela aparece na descrição dos trabalhos dos cientistas, portanto o autor utiliza esta descrição para desenvolver o conteúdo químico.

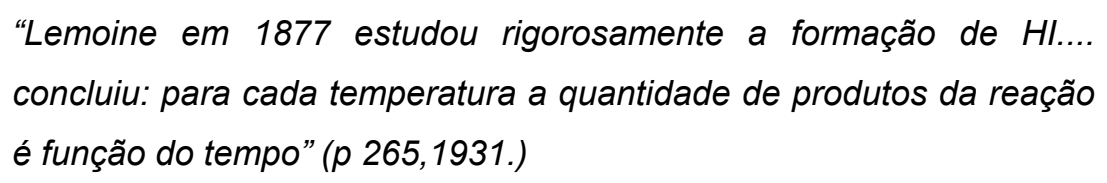

A experimentação aparece como forma de comprovar a teoria, ou seja, através dos resultados obtidos pela experimentação os cientistas elaboram as suas teorias e leis.

"Os fatos mostram que nas reações químicas ordinárias, um aumento
de $10^{\circ} \mathrm{C}$ faz com que a velocidade da reação seja multiplicada por um
coeficiente compreendido entre $2 \begin{array}{lllllll}\text { (coeficiente de } \\ \text { temperatura)".(p.369,1946) }\end{array}$

No terceiro (1966-1968) e quarto (1977- 1993) períodos a experimentação aparece como uma atividade dirigida ao aluno, portanto voltada para a aprendizagem dos conceitos:

\footnotetext{
"Confiou-se muito no trabalho de laboratório para que os princípios da química pudessem ser obtidos diretamente das experiências realizadas pelos estudantes".(Introdução, 1967).

"O aluno é convidado a observar sistemas químicos em interação, sendo que, para tanto, vai recebendo, à medida do necessário, o instrumental adequado e as explicações de como utilizá-lo. De suas observações e conclusões se obtêm modelos para a realidade, sendo a coroação desse processo o modelo denominado teoria da estrutura atômica".(p. VII; 1977).
}

Mas em todos esse livros o papel da experimentação é o de comprovar teorias e leis, portanto eles possuem uma visão empirista/indutivista da construção do conhecimento científico. A única exceção encontrada foi o livro de 2001 do quinto 
período (1999-2004), nele o conhecimento cientifico é construído com base no conhecimento que os alunos já possuem sendo que estes é que orientam a observação, durante o experimento.

"A partir do conhecimento que você já tem, de suas experiências vividas e adquiridas no dia-a-dia, este livro trabalhará visando construir, ou reconstruir, idéias sobre o mundo físico e as transformações que nele ocorrem, levando-o a perceber como os conceitos são elaborados".(apresentação, modulo l;2001)

Os livros analisados apresentaram no mínimo uma das três categorias relativas às concepções de ciência tanto da perspectiva empirista/indutivista como da perspectiva racionalista. Deve-se considerar que os livro didáticos podem ter influência na visão que os alunos estão desenvolvendo sobre a ciência no ensino médio. Finalizando, não é intenção deste trabalho indicar como deve ser planejado o ensino de cinética química, no Ensino Médio, mas em vista dos resultados obtidos, pode-se apresentar alguns pontos para se levar em consideração no planejamento do ensino desse tópico que teriam por objetivo facilitar a aprendizagem:

Planejar o ensino de cinética química, utilizando-se os programas de investigação científica, para que o aluno entenda a evolução histórica dos modelos explicativos, entenda, portanto, como esses modelos vão sendo substituídos por outros com maior poder explicativo, evitando assim um ensino estanque e fragmentado.

Fazer um paralelo entre o conhecimento que o aluno possui e o conhecimento científico de cada programa de investigação científica. Assim, o professor poderá identificar qual é grau de conhecimento que o aluno possui dentro do tópico cinética química, sendo esse o primeiro passo para superar as dificuldades na aprendizagem deste tópico. 
Caracterizar a ciência como uma construção humana que visa aumentar o conhecimento do homem sobre o mundo natural, ajuda-lo a resolver determinados problemas e também melhorar as suas condições de vida. 


\begin{tabular}{|c|c|c|c|c|}
\hline \multirow[b]{2}{*}{ Períodos } & \multirow[b]{2}{*}{$\begin{array}{l}\text { Livro } \\
\text { Didáticol } \\
\text { Ano }\end{array}$} & \multicolumn{3}{|c|}{ Programas de Investigação Científica } \\
\hline & & $\begin{array}{l}\text { Explicação, em } \\
\text { termos microscópicos } \\
\text { da velocidade de uma } \\
\text { reação química. }\end{array}$ & $\begin{array}{l}\text { Explicação de como a } \\
\text { velocidade de uma } \\
\text { reação química } \\
\text { depende das } \\
\text { concentrações das } \\
\text { substâncias reagentes. }\end{array}$ & $\begin{array}{l}\text { Explicação da } \\
\text { influência da } \\
\text { temperatura na } \\
\text { velocidade de uma } \\
\text { reação química. }\end{array}$ \\
\hline \multirow{3}{*}{1929 - 1941} & 1/1929 & PIC-I & GW & A \\
\hline & $2 / 1931$ & $\mathrm{~A}$ & PIC-I & PIC-I \\
\hline & $3 / 1932$ & PIC-I & PIC-I & A \\
\hline \multirow{5}{*}{$1942-1960$} & $4 / 1942$ & PIC-I & GW & PIC-II \\
\hline & $5 / 1946$ & PIC-I & GW & PIC-II \\
\hline & $6 / 1954$ & A & GW & PIC-I \\
\hline & $7 / 1955$ & PIC-I & $\mathrm{PCl}-\mathrm{I}$ & PCl-I \\
\hline & $8 / 1959$ & $A$ & GW & PCl-I \\
\hline \multirow{3}{*}{ 1961-1970 } & 9/1966 & PIC-I & GW & PIC-I \\
\hline & $10 / 1967$ & PIC- IV & PIC-III & PIC- IV \\
\hline & $11 / 1968$ & $A$ & GW & $A$ \\
\hline \multirow{5}{*}{ 1971-1995 } & $12 / 1976$ & PIC-IV & GW & PIC- IV \\
\hline & $13 / 1977$ & PIC-IV & PIC-III & PIC-IV \\
\hline & $14 / 1979$ & PIC-III & GW & PIC-II \\
\hline & $15 / 1980$ & PIC-III & GW & PIC-III \\
\hline & $16 / 1993$ & PIC-IV & GW & $\mathrm{PCl}-\mathrm{I}$ \\
\hline \multirow{4}{*}{ 1996-2004 } & $17 / 1999$ & PIC-IV & PIC-III & PIC-III \\
\hline & $18 / 2001$ & PIC-IV & PIC-IV & PIC-IV \\
\hline & $29 / 2003$ & PIC-IV & PIC-III & PIC-III \\
\hline & $20 / 2004$ & PIC-III & PIC-III & PIC-IV \\
\hline \multirow{6}{*}{\multicolumn{2}{|c|}{ Total $=\mathbf{2 0}$}} & $A=4$ & $A=0$ & $A=3$ \\
\hline & & PIC-I = 6 & PIC-I = 3 & PIC-I = 6 \\
\hline & & PIC-II = 0 & PIC-II = 0 & PIC-II = 3 \\
\hline & & PIC-III = 3 & PIC-III = 5 & PIC-III =3 \\
\hline & & \multirow[b]{2}{*}{ PIC-IV = 7} & PIC-IV = 1 & \multirow[b]{2}{*}{ PIC-IV =5 } \\
\hline & & & $G W=11$ & \\
\hline
\end{tabular}

Tabela 5.1- Caracterização dos livros didáticos (1929-2004). Nota: PIC-l: Programa de Investigação Científica de Wilhelmy, Harcourt, Esson e Berthelot (1850-1865); PIC-II: Programa de Investigação Científica de Pfaundler e Van't Hoff (1872-1888); PICIII:Programa de Investigação Científica de Lewis, Ostwald e Arrhenius (1889-1918); PICIV:Programa de Investigação Científica de Tolman, Eyring, Polanyi, e Evans (19201935);GW: Guldberg-Waage;A:indica a ausência da explicação teórica no livro didático. 


\begin{tabular}{|c|c|c|c|c|}
\hline \multirow[b]{2}{*}{ Períodos } & \multicolumn{4}{|c|}{ Categorias } \\
\hline & Livrolano & $\begin{array}{l}\text { 1- Concepção } \\
\text { de ciência }\end{array}$ & $\begin{array}{l}2-0 \\
\text { Desenvolvimento da } \\
\text { Ciência }\end{array}$ & $\begin{array}{l}\text { 3- A construção do } \\
\text { conhecimento } \\
\text { científico }\end{array}$ \\
\hline \multirow{3}{*}{ 1929-1941 } & 1/1929 & $\mathrm{E} / \mathrm{l}$ & $E / I$ & $\mathrm{~N}$ \\
\hline & 2/1931 & $\mathrm{N}$ & $\mathrm{N}$ & $\mathrm{E} / \mathrm{l}$ \\
\hline & $3 / 1932$ & $\mathrm{E} / \mathrm{l}$ & $\mathrm{N}$ & $E / I$ \\
\hline \multirow{5}{*}{$1942-1960$} & 4/1942 & $E / l$ & $E / I$ & $E / I$ \\
\hline & $5 / 1946$ & $E / I$ & $E / I$ & $E / I$ \\
\hline & 6/1954 & $E / l$ & $E / I$ & $E / I$ \\
\hline & 7/1955 & $\mathrm{E} / \mathrm{I}$ & $E / I$ & $E / I$ \\
\hline & $8 / 1959$ & $\mathrm{E} / \mathrm{l}$ & $\mathrm{E} / \mathrm{l}$ & $\mathrm{E} / \mathrm{I}$ \\
\hline \multirow{3}{*}{ 1961-1970 } & 9/1966 & $\mathrm{E} / \mathrm{l}$ & $E / I$ & $\mathrm{~N}$ \\
\hline & $10 / 1967$ & $\mathrm{R}$ & $\mathrm{R}$ & $E / I$ \\
\hline & 11/1968 & $\mathrm{E} / \mathrm{I}$ & $\mathrm{N}$ & $\mathrm{N}$ \\
\hline \multirow{5}{*}{ 1971-1995 } & $12 / 1976$ & $E / l$ & $\mathrm{R}$ & $\mathrm{N}$ \\
\hline & $13 / 1977$ & $\mathrm{R}$ & $\mathrm{R}$ & $E / I$ \\
\hline & $14 / 1979$ & $\mathrm{E} / \mathrm{I}$ & $E / I$ & $E / I$ \\
\hline & $15 / 1980$ & $\mathrm{E} / \mathrm{l}$ & $E / I$ & $\mathrm{E} / \mathrm{I}$ \\
\hline & $16 / 1993$ & $E / l$ & $\mathrm{~N}$ & $E / I$ \\
\hline \multirow{4}{*}{ 1996-2004 } & $17 / 1999$ & $\mathrm{R}$ & $\mathrm{R}$ & $E / l$ \\
\hline & $18 / 2001$ & $\mathrm{R}$ & $\mathrm{R}$ & $\mathrm{R}$ \\
\hline & $19 / 2003$ & $\mathrm{E} / \mathrm{I}$ & $E / I$ & $\mathrm{~N}$ \\
\hline & $20 / 2004$ & $\mathrm{E} / \mathrm{l}$ & $E / I$ & $\mathrm{~N}$ \\
\hline \multirow{3}{*}{\multicolumn{2}{|c|}{ Total $=20$}} & $E / I=15$ & $E / I=11$ & $E / I=13$ \\
\hline & & $R=4$ & $R=5$ & $R=1$ \\
\hline & & $N=1$ & $N=4$ & $N=6$ \\
\hline
\end{tabular}

Tabela 5.2- Concepções de ciência apresentadas pelos livros didáticos (1929-2004). Nota: $\mathrm{E} / \mathrm{l}=$ Empirista/Indutivista; $\mathrm{R}=$ Racionalista; $\mathrm{N}=$ Não mencionam: os livros didáticos não fazem menção explicita a qualquer uma das duas interpretações. 


\section{REFERÊNCIAS BIBLIOGRÁFICAS}

ABIMBOLA, I. O.;The Relevance of the "New" Philosophy of Science for the Science Curriculum. School Science and Mathematics. Volume 83 (3), March, p.181-193; 1983.

ARAUJO, W. N.; Relações históricas de precedência como orientações para o ensino médio de química: a noção clássica de Valencia e o livro didático de Química. Dissertação de mestrado. Universidade Federal Fluminense. 2003.

BITTENCOURT, C. M. F. Ensino de História: fundamentos e métodos. Série: Docência em formação em Ensino Fundamental. Editora Cortez.p. 31-52;2005.

BITTENCOURT, C. M. F. As humanidades no ensino. Educação e Pesquisa. Vol.25 no. 2 . Faculdade de Educação. USP-São Paulo July/Dec. 1999.

CACHAPUZ, A; C., C; Imagens de ciência em manuais de química portugueses. Química Nova na Escola. No.6, p.23-29;1997.

CAMPANARIO, J. M. e Otero, J. C.;Mas allá de las ideas previas como dificultades de aprendizaje: Las pautas de pensamiento, las concepciones epistemológicas y las estrategias metacognitivas de los alumnos de ciências. Enseñanza de las ciências, 18 (2), p.155-169; 2000.

CHIAPPETTA, E. L.; Sethena, H.G.;Fillman, D.A.; A Quantitative Analysis of High School Chemistry Textbooks for Scientific Literacy Themes and Expository Learning Aids. Journal of Research in Science Teaching. Vol.28; No.10; pp.939-951. 1991.

DRIVER, R.; Leach,J. ;Millar, R.; Scott,P. ;Young People's Images of Science. p.144. Open university Press.1996. 
EYRING, H.; The Activated Complex and the Absolute Rate of Chemical Reactions. Chemical Reviews,17;p. 65-77;1935.

EVANS, M.G.; Polanyi, M. Some Applications of the Transition State Method to the Calculation of Reaction Velocities, Especially in Solution. Transactions of the Faraday Society. Vol.XXXI, p.875-894;1935.

GILBERT ,J. K.; Onno de Jong; Justi, R.; Treagust, D. F. e Van Driel, J. H. Chemical Education: Towards Research-based Practice; p.293-315. Science \& Technology Education Library ; 2002.

HOUSE, J. E.; Principles of Chemical Kinetics.p.89-109. Wn C. Brown Publishers. 1997.

JUSTI, R.; Gilbert, J. K.;History and Philosophy of Science Through Models: The Case of Chemical Kinetics. Science and Education,8;287-307; 1999.

JUSTI, R.; Models in the Teaching of Chemical Kinetics. Tese de Doutorado. University of Reading;1997.

LAKATOS, I.; História da ciência e suas reconstruções racionais. Biblioteca de filosofia contemporânea. Edições 70; 1998.

LAKATOS, I.; Falsificação e metodologia dos programas de investigação científica. p.54-64. Biblioteca de filosofia contemporânea. Edições 70; 1999.

LAIDLER, K. J. ;The World of Physical Chemistry.p.233-283. Oxford Univ. Press; 1993.

LAIDLER, K. J. ;The development of the Arrhenius equation. Journal of Chemical Education. Vol 61 (6) ;pp.494-498;1984. 
LAIDLER, K. J. ; King, M. C. The development of Transition-State Theory. Journal Phys. Chemical. 87 ;pp.2657-2664;1983.

LISO, R. J. ;Torres, E.M. ;López, F. S. Los processos ácido-base en los textos actuales y antiguos (1868-1955). Educación Química 13 (2) ;p.90 -100;2002.

LEWIS, W. C. M. Studies in Catalysis. Part IX. The Calculation in Absolute Measure of Velocity Constants and Equilibrium Constants in Gaseous Systems. Journal of the Chemical Society, 113 p.471-491;1918.

LOPES, R. C. A.; Livros Didáticos: Obstáculos ao aprendizado da ciência química. Química Nova, 15 (3) p.254-261; 1992.

LOPES, R. C. A.; Livros Didáticos: Obstáculos ao aprendizado da ciência química. Dissertação. p.109 -110; 1990.

LOPES, A. R. C.; Conhecimento escolar: ciência e cotidiano. Cap. VII-Processo de mediação (ou transposição) didática. p.201-220. Ed. UERJ. 1999.

MELO, M. R.; Estrutura Atômica e Ligações Químicas-Uma Abordagem para o Ensino Médio. p.2-4. Dissertação de Mestrado. UNICAMP.2002.

MELLADO, V.; Carracedo, D.; Contribuciones de la Filosofía de la Ciencia a la Didática de las Ciencias. Historia y Epistemología de las Ciencias. Enseñanza de las Ciencias, 11(3), p.331-339,1993.

MION, R. A; Angotti, J.A. P.; Em busca de um perfil epistemológico para a prática educacional em educação em ciências. Ciência \& Educação. V.11, no.2, p.165$180 ; 2005$. 
MORENO, M.; Sastre, G.;Bovet,M.;Leal, L.; Conhecimento e Mudança. Os Modelos Organizadores na construção do conhecimento. Editora da UNICAMP. Editora Moderna. p.327-334.2000.

NÍAZ, M.; Más allá del Positivismo: Una Interpretación Lakatosiana de la Enseñanza de las Ciências. Enseñanza de las Ciências,12 (1),p.97-100,1994.

NÍAZ, M.; How Important are the Laws of Definite and Multiple Proportions in Chemistry and Teaching Chemistry?-A History and Philosophy of Science Perspective. Science \& Education (10);p.243-266. 2001.

NÍAZ, M.; Teaching Chemistry as Rhetoric of Conclusions or Heuristic Principles - A History and Philosophy of Science Perspective. Chemistry Education: Researche and Practice in Europe (1);p.315-322. 2000.

PEREIRA, N. J. C.; Reflexões sobre conceitos da cinética química e equilíbrio químico. Ed. do autor. p.1-40. 2004.

PESSANHA, E. C.; Daniel, Ma. E. B. Menegazzo, Ma. A. Da história das disciplinas escolares à história da cultura escolar: uma trajetória de pesquisa. Revista Brasileira de Educação. No. 27; p.57-69, RJ; 2004.

PILETTI, C; Piletti, N; Filosofia e História da Educação. Série Educação. Editora Ática. p. 206-256. 2002.

PITOMBO, L.R; Cinética Química. Nuevos temas de química em la enseñanza secundaria.UNESCO. p.31-78. 1974.

SCHNETZLER, R. P.; Tese de Mestrado. O tratamento do conhecimento químico em livros didáticos brasileiros para o ensino secundário de química de 1875 a 1978 . UNICAMP -Faculdade de Educação, 1980. 
SHORTER, J. A. G.; Vernon Harcourt. A founder of chemical kinetics and a friend of “Lewis Carrol”. Journal of Chemical Education. Vol 57 (6) ;pp.411-416;1980.

SICCA, N.A. L.;A Experimentação no Ensino de Química-2 ${ }^{\circ}$ Grau. Dissertação de mestrado. UNICAMP-Faculdade de Educação;p.23-95. 1990.

VINCENT, B. B.; Stengers, I.; História da Química. Instituto Piaget. p.309-345.1992.

\section{REFERÊNCIAS BIBLIOGRÁFICAS NA INTERNET:}

http://gallica.bnf.fr/ark:/12148/bpt6k91927k/f1.table. Acessado em 22 de Agosto de 2006. VAN'T Hoff, J. H; Études de Dynamique Chimique. Paris. 1898.

http://chimie.scola.acparis.fr/sitedechimie/hist chi/text origin/guldberg waage/Conce rning-Affinity.html. Acessado em 29 de Agosto de 2005. Waage and C.M. Guldberg. Studies Concerning Affinity. 1864. Henry I. Abrash, Tanslator. California State University, Northridge, CA.91330.

http://web.lemoyne.edu/ giunta/wilhelmy.html. Acessado em 16 de Novembro de 2005. Wilhelmy, Ludwig Ferdinand. The Law By Which the Action of Acids on Cane Sugar Occurs. Excerpt from Poggendorf's Annalen der Physik und Chemie 81, 413433, 499-526 (1850) [from Henry M. Leicester and Herbert S. Klickstein, eds., A Source Book in Chemistry, 1400-1900 (Cambridge, MA: Harvard, 1952).

http://web.lemoyne.edu/ giunta/arrlaw.html. Acessado em 16 de Novembro de 2005. Svante Arrhenius (1859-1927).excerpt from: On the Reaction Velocity of the Inversion of Cane Sugar by Acids. Zeitschrift für Physikalische Chemie 4, 226- (1889) [as translated and published in Margaret H. Back \& Keith J. Laidler, eds., Selected Readings in Chemical Kinetics (Oxford: Pergamon, 1967)] 
http://dbhs.wvusd.k12.ca.us/webdocs/Equilibrium/Equilibrium-Constant.html.

Acessado em 4 de Julho de 2005. The Equilibrium Constant. Guldberg and Waage,1864.

http://www.sbf1.sbfisica.org.br/eventos/epef/viii/PDFs/CO21 3.pdf

Acessado em outubro/2006. VILLANI, A.; Pacca, J. L. de A.; Freitas D.; Formação do Professor de Ciências no Brasil: Tarefa Impossível? Departamento Metodologia de Ensino-UFSCar-São Carlos. p.1-20. 2005. 


\section{ANEXO I}

\section{Livros Didáticos do Primeiro Período (1929 - 1941):}

1. Noções Succintas de Chimica Philosophica. Dr. Oliveira de Menezes. $4^{\mathrm{a}}$. Edição. Jacinto Ribeiro dos Santos -Editor. Rio de Janeiro;p.125-130; 1929.

2. Apontamentos de Chimica Geral. Miguel Tenório D’Alburqueque. Jacinto Ribeiro dos Santos -Editor. Rio de Janeiro; p.264-265; 1931.

3. Curso Geral de Química. Pe. Ignácio Puig S. J. Edição da Livraria do Globo-Porto Alegre; Capítulo II: Estudo sobre Reação Química; p.12-18; 1932.

\section{Livros Didáticos do Segundo Período (1942-1960):}

4. Química. $3^{\circ}$. Volume. Carlos Costa e Carlos Pasquale; Capítulo: Velocidade das reações e fatores que modificam a velocidade das reações; p.85-90; 1942.

5. Química - $3^{\circ}$ Livro -Ciclo Colegial. Paulo Décourt. Edições Melhoramentos -São Paulo; Unidade XII-Cinética Química; p.366-375. A velocidade de reação e seus fatores. Estudo dos equilíbrios químicos. Catálise; 1946.

6. Química para o terceiro ano colegial (curso científico), 2a . Edição. Geraldo Camargo de Carvalho, Waldemar Saffioti. Companhia Editorial Nacional - São Paulo; Unidade XVI: Cinética das reações: conceito de velocidade de reação, fatores que a influenciam. Catálise; p.363-377; 1954.

7. Química. Primeira Série. Curso Colegial. Coleção Didática do Brasil, Série colegial, Vol.9. Luciano Francisco Pacheco do Amaral. Editora do Brasil S/A- Porto Alegre; Capítulo XI-Reações Químicas. p.195-199;1955. 
8. Química. Terceira Série. Luciano Francisco Pacheco do Amaral. Editora do Brasil S/A- Porto Alegre; Capítulo XI- Cinética química; p.257-269; 1959.

\section{Livros Didáticos do Terceiro Período (1961-1970):}

9. Química. Terceira Série.Curso Colegial. 9ª . Edição.Irmão Firmino Bonato. Editora

F. T. D. S/A- São Paulo; Capítulo XV-Cinética das reações. Catálise. p.208$310 ; 1966$.

10. Química. Uma ciência experimental. Volume 1. Texto organizado pelo Chemical Educational Material Study. EDART- São Paulo- Livraria Editora LTDA. Capítulo 8. “As Velocidades das Reações químicas"; p.129-146; 1967.

11. Físico - química. Volume 3. Ricardo Feltre, Setsuo Yoshinaga; Capítulo 6Cinética e equilíbrio químico, p.307- 310; 1968.

\section{Livros Didáticos do Quarto Período (1971-1995):}

12. Química. Segundo grau. Volume dois. Ricardo Feltre. Editora Moderna- São Paulo; Capítulo 4- cinética química e catálise, p.182-286; 1976.

13. Química dos experimentos as teorias. Volume 2. Yvone Mussa Esperidião, Naídes de Cerqueira e Silva Alves de Lima. Companhia Editora Nacional -São Paulo; Unidade 6- Velocidade das reações químicas; p.61-76; 1977.

14. Química Fundamental. Volume 2. Antonio Sardella e Edegar Mateus. Capítulo de Cinética química, p.98-110; 1979.

15. Química Moderna. Terceiro Volume. Geraldo Camargo de Carvalho. Livraria Nobel - São Paulo. Capítulo 20 - Cinética Química; p.149-182; 1980. 
16. Química 2. Consolidação de conceitos fundamentais. Otávio Aloísio Maldaner, Rui Zambiazi. Editora UNIJUI-RS;Capítulo 4- Cinética Química - Princípios. p.83-96; 1993.

\section{Livros Didáticos do Quinto Período (1996-2004):}

17. Química 2. Vera Novais. Atual Editora -São Paulo. Capítulo 6 - Velocidade das Reações-A Cinética Química; p.130-168; 1999.

18. Química - Ensino Médio. Interações e Transformações II. Reelaborando Conceitos sobre Transformações Químicas (Cinética e Equilíbrio). GEPEQ. Edusp São Paulo; 2001.

19. Química. Volume Único para o Ensino Médio. Geraldo Camargo de Carvalho, Celso Lopes de Souza. Editora Scipione - São Paulo. Capítulo 18- Cinética Química. p.226-240;2003.

20. Química. Físico-Química. Ricardo Feltre. Editora Moderna - São Paulo. Capítulo 4. Cinética química. p.143-179, 2004. 